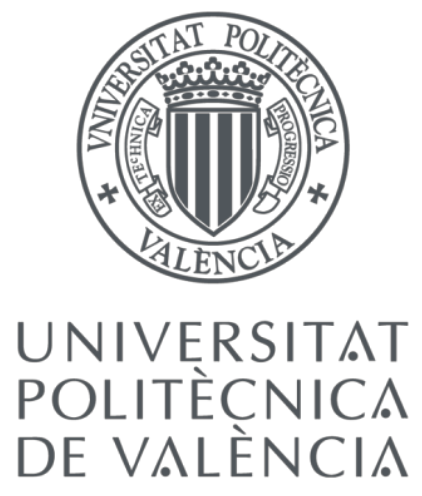

Departamento de Proyectos de Ingeniería

\title{
EMPRENDIMIENTO Y UNIVERSIDAD EMPRENDEDORA: CONCEPTUALIZACIÓN, PROPUESTA METODOLÓGICA Y CARACTERIZACIÓN DE LA UNIVERSIDAD POLITÉCNICA DE VALENCIA
}

\section{TESIS DOCTORAL}

Autora:

Mónica Arroyo Vázquez

Director:

Dr. Fernando Jiménez Sáez

Valencia, Enero de 2016 

$\mathcal{A}$ Celia y Fernando 
"No podemos resolver problemas de la misma manera que cuando los creamos", Albert Einstein

"Si no hay sentido de confianza en la organización, si las personas viven preocupadas por cubrirse las espaldas... la creatividad será una de las primeras víctimas", Napoleón

"Nunca he perfeccionado un invento en el que no pensara en términos de su utilidad para los demás. Averiguo qué necesita el mundo, luego procedo a inventar", Thomas Edison 


\section{Agradecimientos}

Después de más de diez años de andadura como doctoranda, son muchas las personas que me vienen a la cabeza en esta última fase. De antemano quiero pedir disculpas si me dejo a alguien en el tintero, pero la memoria y los nervios pueden jugarnos a veces una mala pasada.

Quiero dirigir mis primeras palabras de agradecimiento al profesor Ignacio Fernández de Lucio, porque aunque él no lo sepa, fueron él, su entusiasmo y su calidad como docente e investigador quienes me animaron a continuar por la senda del doctorado. Durante todos estos años siempre ha estado ahí cuando lo he necesitado, sobre todo en las múltiples idas y venidas con el tema de la tesis. Pero no sólo con la tesis, sino con el resto de mi carrera profesional como gestora y mi aún corta experiencia como investigadora.

Continuando con los profesores del Departamento de Proyectos de Ingeniería de la UPV, que me dieron clase durante los cursos de doctorado, quiero hacer una mención especial al Profesor Eliseo Gómez-Senent, quien lamentablemente nos dejó el pasado año y de quien guardo un entrañable recuerdo, no sólo como docente e investigador, sino como persona. Al resto de profesores, $\mathrm{M}^{\mathrm{a}}$ Carmen González, Mónica García, Pablo Aragonés, Félix Lozano y Ernesto de los Reyes, quiero agradecer su apoyo y aliento durante todos estos años ya que todos han querido seguir mi trayectoria y me han animado y alentado a continuar con este proyecto.

Cuando comencé con el doctorado, desarrollaba mi labor en el Instituto IDEAS de la UPV. Gran parte de lo aquí expuesto y del trabajo realizado tiene su origen en mi experiencia dentro de este servicio, por lo que no puedo más que agradecer a sus diferentes directores, José Luis Alonso, Juan Ignacio Dalmau y José Millet por todo lo que aprendí y por todo lo que me han enseñado. Por supuesto, no quiero olvidarme de todos y cada uno de los compañeros que tuve durante los 12 años en que estuve trabajando 
en IDEAS. A todos muchas gracias, porque también habéis contribuido a que esta tesis sea posible.

Me gustaría hacer una mención muy especial al Profesor Peter van der Sijde, de la Universidad de Twente, que durante mis 6 meses de estancia, fue mi mentor y, bajo su supervisión y gracias a sus consejos y apoyo, conseguí comenzar en serio esta tesis. Desde luego, este trabajo probablemente no se habría realizado sin el impulso y el apoyo del que hoy es mi colega y amigo Peter. Thank you very much, Peter!

Durante los últimos años (y los más productivos) de esta tesis, también he tenido la suerte de pertenecer al Departamento de Dirección de Empresas "Juan José Renau Piqueras" de la Universitat de València. Quiero expresar mi agradecimiento a todos los compañeros, pero en especial a los dos directores que conocí, Rafael Fernández y Justo Herrera y al Profesor Joaquín Alegre, quienes siempre me animaron y apoyaron a terminar la tesis.

Quiero también desde aquí expresar mi más sincero agradecimiento a todos y cada uno de los compañeros y amigos del Instituto de Gestión de la Innovación y del Conocimiento (INGENIO, CSIC-UPV), donde estoy desarrollando actualmente mi labor de investigación y la presente tesis. Especialmente quiero agradecer su apoyo, tanto moral como profesional y académico, a su actual director, Antonio Gutiérrez, a Isabel Piqueras, nuestra gerente, y a Elena Castro y Adela García, porque siempre me han animado y me han escuchado cuando lo he necesitado. A ellos y al resto de investigadores y compañeros de INGENIO (también al personal de administración sin el que no podríamos funcionar), muchísimas gracias. 
Por último, pero no menos importante quiero dar las gracias a mi familia, a mis padres y a mi abuela, que podrán ver el resultado de este trabajo, pero también a los que ya no podrán verlo, mis suegros y mi abuelo materno y mis abuelos paternos. Por supuesto a Fernando, mi esposo, que además ha tenido que sufrir el rol de director de esta tesis. Sin él, su paciencia y sus consejos, esta tesis no habría sido posible.

A todos, muchas gracias. 


\section{Resumen}

La presente tesis se centra en la caracterización de las universidades emprendedoras como agentes clave para el desarrollo socioeconómico de sus territorios, partiendo del debate sobre la conceptualización del término emprendimiento y sus implicaciones para la aplicación y análisis empírico. Los objetivos específicos de la tesis están relacionados con (1) la divergencia entre la conceptualización de emprendimiento y su aplicación práctica; (2) la transformación y consideración de las universidades en emprendedoras y su reestructuración para atender a las nuevas necesidades; (3) la caracterización de la Universidad Politécnica de Valencia como emprendedora. La tesis se estructura en seis capítulos. El primero de ellos es una introducción en la que se exponen los objetivos, la justificación y la metodología. El segundo de los capítulos se centra en el marco teórico, donde se aborda la conceptualización del término emprendimiento y su relación con el desarrollo económico así como su estudio desde diferentes perspectivas (evolucionismo, institucionalismo y sistemas de innovación). El capítulo 3 está destinado al marco empírico donde se abordan las políticas de emprendimiento, las organizaciones y universidades emprendedoras y los programas de apoyo al emprendimiento como servicios innovadores en universidades emprendedoras. En el siguiente capítulo, desarrollamos nuestra propuesta conceptual y modelo teórico de Fomento del Emprendimiento y Apoyo al Desarrollo de Empresas. En este tratamos el tema de la divergencia entre la conceptualización del término emprendimiento y su aplicación práctica y proponemos una conceptualización del término emprendimiento. Así mismo, analizamos el fomento del emprendimiento en la universidad española y exponemos nuestro modelo de FEyADE así como la propuesta metodológica para su implantación. El capítulo 5, se centra en el caso práctico de la UPV, analizando cada una de sus tres misiones así como su gestión y caracterizando a esta universidad como emprendedora. Así mismo, nos centramos en la caracterización del Instituto IDEAS como servicio innovador y emprendedor dentro de la UPV. Para finalizar este capítulo, aplicamos el modelo de FEyADE al caso de la UPV. El último de los capítulos de la tesis se expone las conclusiones generales de la misma, y las líneas de investigación futuras a partir de este trabajo. 


\section{Resum}

La present tesi es centra en la caracterització de les universitats emprenedores com a agents clau pel desenvolupament socioeconòmic dels seus territoris, partint del debat sobre la conceptualització del terme emprendidoria i les seues implicacions per a l'aplicació i l' anàlisi empírica. Els objectius específics de la tesi estan relacionats amb (1) la divergència entre la conceptualització d'emprendidoria i la seua aplicació pràctica; (2) la transformació i consideració de les universitats en emprenedores i la seua reestructuració per a atendre les noves necessitats; (3) la caracterització de la Universitat Politècnica de València com emprenedora.

La tesi s'estructura en sis capítols. El primer d'ells és una introducció en què s'exposen els objectius, la justificació i la metodologia. El segon dels capítols es centra en el marc teòric, on s'aborda la conceptualització del terme emprendidoria i la seua relació amb el desenvolupament econòmic així com el seu estudi des de diferents perspectives (evolucionisme, institucionalisme i sistemes d'innovació). El capítol 3 està destinat al marc empíric on s'aborden les polítiques d'emprendidoria, les organitzacions i universitats emprenedores i els programes de suport a l' emprendidoria com a serveis innovadors en universitats emprenedores. En el següent capítol, desenvolupem la nostra proposta conceptual i model teòric de Foment de l'Emprendidoria i Suport al Desenvolupament d'Empreses. En este tractem el tema de la divergència entre la conceptualització del terme emprendidoria i la seua aplicació pràctica i proposem una conceptualització del terme emprendidoria. Així mateix, analitzem el foment de l'emprendidoria en la universitat espanyola, exposem el nostre model de FEyADE i la proposta metodològica per a la seua implantació. El capítol 5, es centra en el cas pràctic de la UPV, analitzant cada una de les seues tres missions així com la seua gestió i caracteritzant a esta universitat com emprenedora. Així mateix, ens centrem en la caracterització de I'Institut IDEAS com a servei innovador i emprenedor dins de la UPV. Per a finalitzar este capítol, apliquem el model de FEyADE al cas de la UPV. En l' últim dels capítols de la tesi s'exposen les conclusions generals de la mateix, i les línies d'investigació futures a partir d'este treball. 


\section{Abstract}

This thesis analyses the characterization of the entrepreneurial universities as key agents for the economic development of their territories. We set out from the debate on the definition of the term Entrepreneurship and its implications for the implementation and empirical analysis. The specific objectives of the thesis are related to (1) the divergence between the conceptualization of entrepreneurship and practical application; (2) the consideration of universities as entrepreneurial ones and their modifications to meet new needs and roles; (3) the characterization of the Polytechnic University of Valencia as an entrepreneurial institution. The thesis is divided into six chapters. The first one is an introduction that outlines the objectives, rationale and methodology. The second chapter focuses on the theoretical framework, where the definition of the term entrepreneurship and its relation to economic development and study from different perspectives (evolution, institutionalism and innovation systems) is addressed.

Chapter 3 is addressed to set the empirical framework where entrepreneurship policies are studied and analysed, organizations and entrepreneurial universities and programs to support entrepreneurship as well as entrepreneurial universities' innovative services.

In the next chapter, we develop our conceptual and theoretical proposal for the Promotion of Entrepreneurship and Business Development Support (FEyADE) services. In this chapter we address the divergence issue between the conceptualization of the term entrepreneurship and its actual application and propose an alternative definition of entrepreneurship. In addition, we analyze the promotion of entrepreneurship in the Spanish university and depict out FEyADE model and the methodology for its implementation.

Chapter 5 focuses on the actual case of the UPV, analyzing each of its three missions as well as its management process and characterize this university as an entrepreneur. Also, we focus on the characterization of IDEAS as an innovative and enterprising service within the Polytechnic University of Valencia. To finish this chapter, we apply the model to the case of FEyADE UPV.

Last chapter of the thesis is devoted to draw conclusions of the study, and to set future research lines from the results. 


\section{Índice de Contenidos}

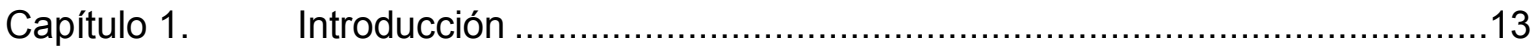

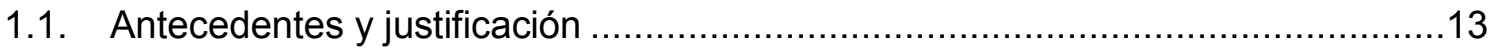

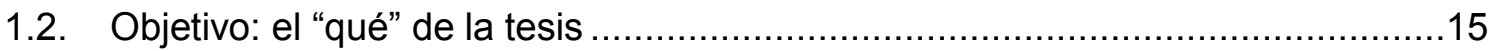

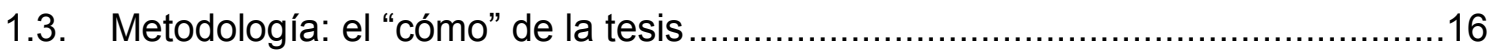

1.4. Motivación y aportaciones: el "por qué" de la tesis ..........................................18

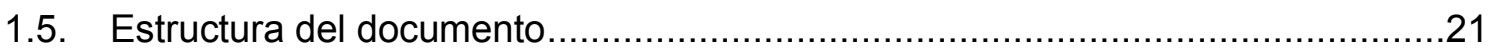

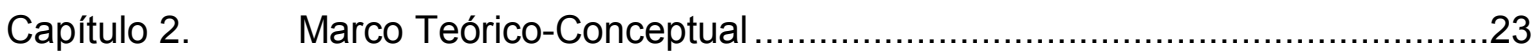

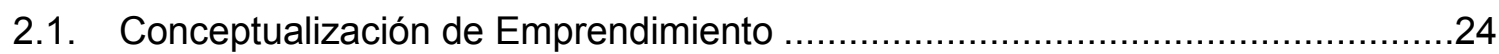

2.2. Emprendimiento y Desarrollo Económico …...................................................

2.3. Teorías económicas sobre las que basar nuestro estudio del emprendimiento ..38

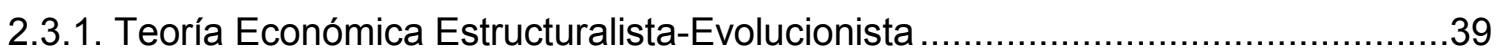

2.3.1.1. Antecedentes de la teoría económica evolucionista.............................42

2.3.1.2. Temáticas en las que ha influido el evolucionismo...............................49

2.3.1.3. El emprendimiento desde la perspectiva evolucionista ........................52

2.3.2. Evolucionismo e Institucionalismo: coexistencia y convergencia en economía...54

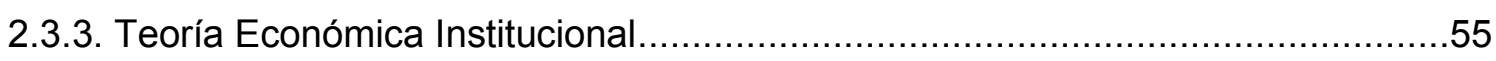

2.3.3.1. Evolución de la teoría económica institucional ..................................56

2.3.3.2. Aplicación de la Economía Institucional al estudio del Emprendimiento58

2.4. El Emprendimiento en los Sistemas de Innovación .........................................63

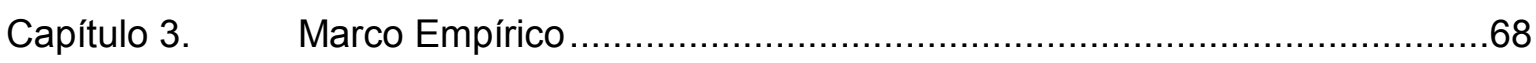

3.1. El emprendimiento en las políticas Europeas .............................................. 70

3.1.1. Políticas de Emprendimiento en España .................................................... 74

3.1.2. Políticas de Emprendimiento en la región de Twente ......................................80

3.2. Organizaciones y Universidades Emprendedoras …................................... 83

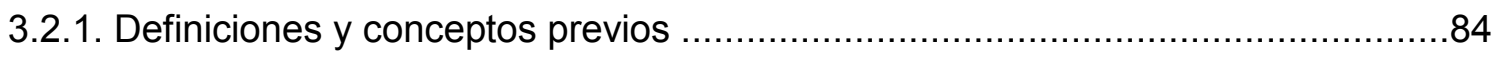

3.2.2. La Universidad como organización emprendedora .......................................87

3.2.3. Transferencia de Tecnología y Universidades Emprendedoras ........................93

3.3. Servicios Innovadores en Universidades Emprendedoras: los Programas de

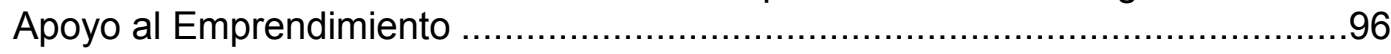

3.4. Reflexiones sobre el emprendimiento en el marco empírico propuesto ...............99 
Capítulo 4. Propuesta Conceptual y Modelo Teórico …......................................... 102

4.1. Divergencia entre conceptualización y análisis empírico en los estudios sobre

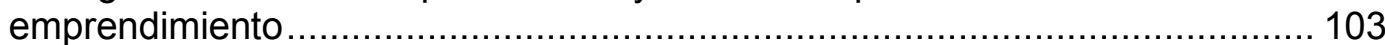

4.1.1. Implicaciones para los resultados, conclusiones y recomendaciones .............. 109

4.1.2. Una propuesta de conceptualización sobre emprendimiento .......................... 112

4.2. El Fomento del emprendimiento en la universidad española ........................... 114

4.2.1. Formación emprendedora y en emprendimiento............................................. 118

4.2.2. Innovación y Emprendimiento en la Educación Superior ................................ 122

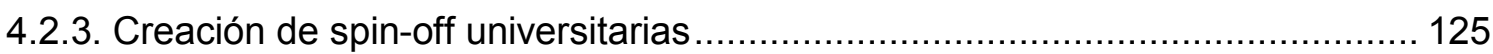

4.3. Hacia un modelo integral de Fomento del Emprendimiento Universitario ......... 135

4.3.1. Fomento del Emprendimiento .......................................................... 140

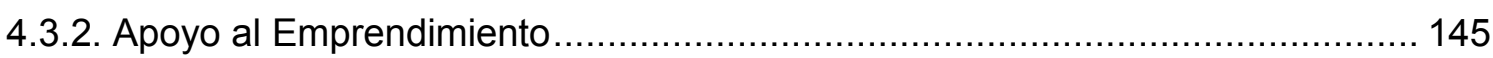

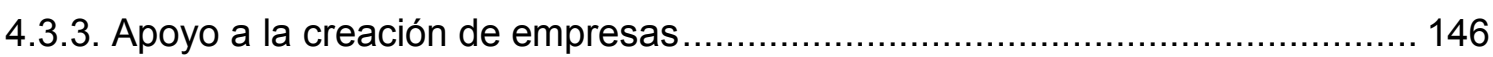

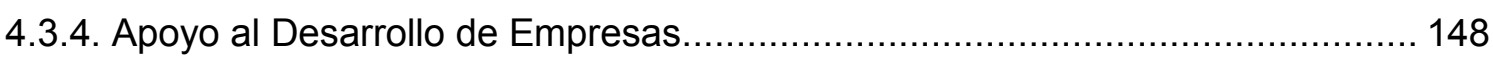

4.4. Propuesta metodológica para la implantación del modelo de FEyADE ............. 150

Capítulo 5. Análisis: el caso de la Universidad Politécnica de Valencia (UPV) ..... 155

5.1. Análisis de la UPV como universidad emprendedora.................................. 156

5.1.1. Evolución histórica del fomento del emprendimiento en la UPV ..................... 160

5.1.2. Formación innovadora y emprendedora en la UPV ..................................... 166

5.1.3. Investigación y Relaciones Universidad-Empresa en la UPV .......................... 175

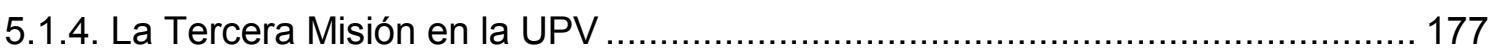

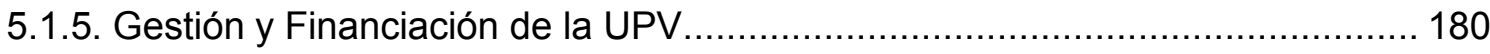

5.1.6. Caracterización de la UPV como universidad emprendedora .......................... 185

5.1.7. El Instituto IDEAS de la UPV como servicio innovador y emprendedor............ 189

5.2. Aplicación del modelo de FEyADE al caso de la UPV .................................. 197

5.2.1. El entorno de la UPV: identificación de los agentes involucrados ................... 197

5.2.2. Contribución de los agentes: cobertura de necesidades ............................... 200

Capítulo 6. Conclusiones y Líneas Futuras ......................................................... 205

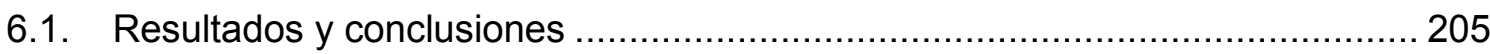

6.2. Líneas de Investigación Futuras .................................................................... 213

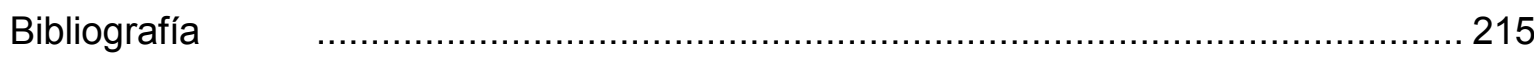




\section{Índice de Figuras}

Figura 1: Modelo de Sistema de Innovación ...................................6 67

Figura 2: Divergencia entre base teórica y análisis empírico del emprendimiento.

Figura 3: Emprendedores vs Empresarios ................................. 113

Figura 4: Representación del modelo de FEyADE ............................ 139

Figura 5: Fomento del Emprendimiento en el modelo de FEyADE ........ 141

Figura 6: Funcionamiento del modelo de FEyADE........................... 144

Figura 7: Apoyo al Emprendimiento. ......................................... 145

Figura 8: Apoyo a la Creación de Empresas.................................... 147

Figura 9: Apoyo al Desarrollo de empresas .................................. 149

Figura 10: Cambios orgánicos en IDEAS y su motivación según cambios a nivel estatal y UPV. 165

Figura 11: Distribución de la financiación de la UPV para el año 2015. . 184

Figura 12: Cobertura de los Diferentes Capitales por los Agentes Implicados 


\section{Índice de Tablas}

Tabla 1: Conceptualización de emprendimiento según principales autores106

Tabla 2: Actividades de FEyADE en Universidades Públicas Españolas .. 116

Tabla 3: Capitales, alcance y recursos necesarios ............................... 151

Tabla 4:Posibles agentes a considerar en el proceso de FEyADE ........... 152

Tabla 5: Contribución de los agentes al proceso de FEyADE.................. 153

Tabla 6: Cooperación entre agentes y contribución a las actividades del proceso de FEyADE ...................................................... 154

Tabla 7: Asignaturas sobre innovación y emprendimiento en titulaciones de grado oficiales de la UPV (Grado).

Tabla 8:Asignaturas sobre innovación y emprendimiento en Titulaciones oficiales UPV (Posgrado) ....................................................... 168

Tabla 9: Valoración de las competencias de los titulados UPV al incorporarse a la organización.

Tabla 10: Fortalezas y Debilidades de la UPV como universidad emprendedora.

Tabla 11: Evolución de las actividades de IDEAS por años (1997-2011). . 191

Tabla 12: Implementación de las características de servicios innovadores en el Instituto IDEAS 196

Tabla 13: Agentes involucrados en el proceso de FEyADE en la UPV...... 198

Tabla 14: Contribución de los agentes de la UPV al proceso de FEyADE. 201

Tabla 15:Cooperación entre agentes y contribución a las actividades de FEyADE en la UPV.. 


\title{
Listado de Acrónimos
}

\author{
AUTM Association of University Tecnology Managers \\ BEST Business Environment Simplification Task Force \\ CFP Centro de Formación Permanente \\ CPI Ciudad Politécnica de la Innovación \\ CTT Centro de Apoyo la Innovación, la investigación y la Transferencia \\ de Tecnología \\ DPI Derechos de Propiedad Intelectual \\ DUI Doing-Using-Interacting model \\ EBT Empresa de Base Tecnológica \\ FEyADE Fomento del Emprendimiento y Apoyo al Desarrollo de Empresas \\ FPE $\quad$ Formación Profesional Específica \\ GEM Global Entrepreneurship Monitor \\ I+D Investigación y Desarrollo \\ I+D+i Investigación, Desarrollo e Innovación \\ ICE Instituto de Ciencias de la Educación \\ IDEAS Iniciativas para el Desarrollo de Empresas Nuevas \\ LOCE Ley Orgánica de Calidad de la Educación \\ LOE Ley Orgánica de Educación \\ LOMCE Ley Orgánica para la Mejora de la Calidad Educativa \\ LOMLOU Ley Orgánica de Modificación de la Ley Orgánica de \\ Universidades \\ LOU Ley Orgánica de Universidades \\ MICYT Ministerio de Industria, Comercio y Turismo \\ MOOC Massive Open Online Course \\ NIKOS Dutch institute for knowledge intensive entrepreneurship | \\ University of Twente
}




\begin{tabular}{|c|c|}
\hline OCDE & Organización para la Cooperación y el Desarrollo \\
\hline OTA & Office of Technology Assessment \\
\hline OTRI & Oficina de Transferencia de Resultados de Investigación \\
\hline PAE & Programa de Apoyo al Emprendimiento \\
\hline PEGASUS & $\begin{array}{l}\text { Programa de Mejora en la Gestión de la Administración y los } \\
\text { Servicios Universitarios }\end{array}$ \\
\hline PFE & Plan de Fomento Empresarial \\
\hline PIB & Producto Interior Bruto \\
\hline PYME & Pequeña y Mediana Empresa \\
\hline SBA & Small Business Act \\
\hline SI & Sistema de Innovación \\
\hline SIE & Servicio Integrado de Empleo \\
\hline SIN & Sistema Nacional de Innovación \\
\hline STI & Science-Technology-Innovation model \\
\hline TIC & Tecnología de la Información y las Comunicaciones \\
\hline UNESCO & $\begin{array}{l}\text { Organización de las Naciones Unidas para la Educación, la } \\
\text { Ciencia y la Cultura }\end{array}$ \\
\hline UPV & Universidad Politécnica de Valencia \\
\hline UT & Universidad de Twente \\
\hline
\end{tabular}




\section{Capítulo 1. Introducción}

\subsection{Antecedentes y justificación}

Desde el primer trabajo de Schumpeter (1911), el papel del emprendimiento en el crecimiento y desarrollo económico de los países y regiones ha suscitado un creciente interés por los académicos. El análisis de este fenómeno requiere del entendimiento de la relación entre emprendimiento, instituciones, y desarrollo económico para determinar el impacto de la actividad emprendedora en la región de estudio (Acs, 2010). Así mismo, requiere que la conceptualización del término emprendimiento y sus implicaciones sean congruentes entre sí. Sin embargo, no encontramos en la literatura sobre emprendimiento consenso sobre este término (J. W. Carland, Hoy, y Carland, 1988; Gartner, 1985). Esto complica, por un lado, 
su análisis en cuanto al impacto que este fenómeno tiene sobre el desarrollo económico y social y, por otro, la puesta en marcha de políticas y medidas de fomento apropiadas para contribuir al desarrollo económico y social a través del emprendimiento.

En este contexto, y considerando a las universidades como agentes clave en el proceso de desarrollo económico (Goldstein, 2009), resulta relevante el concepto de Universidad Emprendedora. En este tipo de universidades se combinan e integran las tradicionales actividades de educación e investigación con la contribución al desarrollo económico y social (Etzkowitz, 1998; Goddard, 1998), fruto de la creciente demanda de la sociedad a esta institución. Esta nueva consideración de la universidad como emprendedora requiere de un rediseño de su estrategia global, de modo que ésta le permita cumplir con los retos impuestos por su nuevo papel en la sociedad. El fomento y difusión de la cultura emprendedora en el seno de la universidad y a todos los niveles de la misma (enseñanza, investigación e incluso la propia gestión), se muestra como una pieza clave de dicha estrategia que favorece la contribución económica y social de la universidad de forma realmente efectiva.

Sin embargo, la falta de consenso entre el término emprendimiento y la divergencia existente entre la conceptualización del mismo y su aplicación práctica, ha llevado a la consideración generalizada de las universidades emprendedoras como aquéllas que realizan acciones de transferencia de tecnología o más concretamente fomentan la creación de empresas de base tecnológica. Sin embargo, la transformación de una universidad en emprendedora no se centra sólo en el fomento del emprendimiento, la creación de empresas de base tecnológica y el desarrollo de actividades de transferencia. Según Clark (1998; 2004) existen cinco elementos comunes que caracterizan a las universidades emprendedoras: un núcleo de gobierno fuerte, una periferia de desarrollo amplia, un centro académico motivado, una base de financiación diversificada y una cultura emprendedora integrada. 
Por tanto, según lo expuesto anteriormente, la caracterización de una universidad como emprendedora pasa, necesariamente, por analizar en qué medida está llevando a cabo cada una de sus misiones y la propia gestión de forma emprendedora así como el grado de consecución de su transformación según los cinco elementos que caracterizan a las universidades emprendedoras expuestos por Clark.

Los Programas de Apoyo al Emprendimiento (PAE), como servicios universitarios, suponen un pilar fundamental en el cumplimiento de los objetivos de cualquier universidad emprendedora (Arroyo-Vázquez and Van der Sijde, 2008). La importancia de estos servicios para el cumplimento de los objetivos relacionados con la Tercera Misión de la Universidad se refleja en varios factores: promueven la cultura emprendedora en todos los ámbitos; apoyan la creación de nuevas empresas innovadoras y/o de base tecnológica; apoyan el desarrollo de empresas recién creadas; ofrecen formación relacionada con la creación y gestión de empresas y promueven las relaciones universidad-empresa, entre otros factores (Arroyo-Vázquez and Van der Sijde, 2008). El rediseño de la estrategia global de la universidad como emprendedora, implica también un rediseño de la estrategia de los servicios universitarios, los cuales deben adaptarse también a los nuevos requerimientos y las necesidades de sus usuarios, convirtiéndose en servicios innovadores y emprendedores.

\subsection{Objetivo: el "qué" de la tesis}

En el contexto descrito anteriormente, el objetivo de la presente tesis consiste en ofrecer una propuesta metodológica para el análisis y la caracterización de universidades emprendedoras. Para alcanzar este objetivo principal se han fijado una serie de objetivos específicos que se presentan en modo de cuestiones concretas, relacionadas con los diferentes problemas identificados en los antecedentes: 
1. Con respecto a la divergencia entre la conceptualización de emprendimiento y su aplicación práctica:

1.1. ¿Existe una divergencia entre la conceptualización de emprendimiento y su aplicación práctica?

1.2. ¿Qué implicaciones tiene esta divergencia para los resultados, conclusiones y recomendaciones políticas?

2. En relación con la transformación y consideración de las universidades en emprendedoras y su reestructuración para atender a las nuevas necesidades:

2.1. ¿Cómo deben plantear las universidades el fomento del emprendimiento de modo que permita atender de forma óptima las necesidades de los emprendedores, la universidad y la propia sociedad?

3. Con respecto a la caracterización de la Universidad Politécnica de Valencia (UPV) como emprendedora

3.1. ¿Podemos considerar a la UPV como universidad emprendedora?

3.2. ¿Está cubriendo la UPV adecuadamente las necesidades del entorno y su comunidad?

\subsection{Metodología: el "cómo" de la tesis}

Cada una de las preguntas de investigación planteadas, contempla su propia metodología para dar respuesta a los objetivos específicos de la tesis a los que contribuye. No obstante, con objeto de dar unidad a la tesis, mostraremos en este apartado la metodología empleada para resolver cada una de las preguntas de investigación y cómo se integran y relacionan todas ellas para dar respuesta al objetivo general de la tesis.

A la hora de estudiar la divergencia entre la conceptualización de emprendimiento y su aplicación práctica, hemos llevado a cabo una 
revisión bibliográfica de la temática planteada, ya que la literatura existente sobre emprendimiento, tanto desde el punto de vista teórico como práctico, es lo suficientemente extensa y actualizada como para ayudarnos a arrojar luz sobre esta cuestión. Así, hemos empleado dicha revisión con objeto de arrojar claridad sobre la conceptualización del emprendimiento y términos vinculados, de modo que pudiéramos analizar, por un lado, la divergencia existente con su aplicación práctica y, por otro, su influencia en las conclusiones de los estudios realizados sobre el tema y las recomendaciones y decisiones políticas que se derivan de los mismos.

En cuanto al análisis de las universidades emprendedoras y su reestructuración, es necesario determinar los diferentes agentes del sistema que pueden influir en su funcionamiento y estudiar el modo en que llevan a cabo esa influencia. Para ello, proponemos una metodología basada en el modelo teórico de Fomento del Emprendimiento y Apoyo al Desarrollo de Empresas (FEyADE) expuesto en la presente tesis. Esta metodología se centra en los siguientes aspectos:

1. Determinación de las necesidades del entorno y los usuarios para el funcionamiento del modelo de FEyADE. Para ello agrupamos las necesidades en cinco categorías, que se corresponden con los capitales y servicios necesarios que deben cubrirse para el óptimo funcionamiento del modelo.

2. Identificación de los agentes involucrados

3. Determinación de cuál es la contribución de cada agente implicado, analizando qué necesidades satisface cada uno

4. Determinación de la contribución de cada agente a cada fase y actividad del modelo (colaboraciones entre agentes)

Para llevar a cabo nuestro análisis en este punto, se han confrontado las diferentes actividades de FEyADE con los diferentes agentes que pueden contribuir a su desarrollo y con las necesidades que deben satisfacer dichas actividades y agentes. Esto nos permite, extraer varios tipos de resultados de su análisis. Podremos saber si todas las necesidades están 
cubiertas; conocer qué agentes contribuyen en qué actividades; saber si la universidad debe mejorar en determinadas actividades y conocer con qué agentes debería aliarse para mejorar sus resultados.

Por último, con respecto a la caracterización de la Universidad Politécnica de Valencia (UPV) como emprendedora, nuestra metodología se centra en analizar el desarrollo de cada una de las misiones de la universidad así como su propia gestión para, posteriormente, contrastar los resultados con las características que, según la literatura, tienen las universidades emprendedoras. Con todo ello, obtenemos un mapa y caracterización de los puntos fuertes y débiles de la citada universidad como emprendedora.

Así mismo, con objeto de caracterizar el Instituto IDEAS ${ }^{1}$ como servicio innovador y emprendedor dentro de la UPV, hemos contrastado las características de este servicio con las definiciones expuestas en la literatura para los servicios innovadores y las universidades emprendedoras, lo que ha dado lugar a la caracterización de lo que hemos denominado servicios emprendedores-innovadores.

Con todo ello, hemos empleado diferentes metodologías a lo largo del presente estudio con objeto de dar respuesta a los diferentes tipos de cuestiones y al objetivo general de la tesis. Así, el objetivo general de la tesis se obtiene tras la puesta en común de los diferentes resultados parciales. Éstos, a su vez, se han obtenido mediante el empleo de una o varias metodologías o conjugando resultados anteriores con el empleo de dichas metodologías.

\subsection{Motivación y aportaciones: el "por qué" de la tesis}

El estudio del emprendimiento y su contribución al desarrollo económico y social despierta cada vez más interés entre académicos y políticos. Los académicos encuentran un campo de estudio con bastantes posibilidades y ${ }^{1}$ El Instituto IDEAS es el nombre actual que recibe el Programa IDEAS (Iniciativa para el Desarrollo de Empresas
Nuevas), que la UPV puso en marcha en 1992. 
que no ha sido aun suficientemente explotado. No podemos pasar por alto el hecho de que el emprendimiento, como fenómeno, actualmente se estudia en diferentes vertientes siendo quizás, la social, la que está recibiendo una especial atención por parte de los estudiosos del tema. Los políticos, por su parte, buscan en esta relación, alguna "fórmula mágica" que les permita impulsar el desarrollo económico y social, especialmente en los últimos tiempos, en los que acucia una severa crisis a nivel global. Sin embargo, se hace necesario arrojar claridad sobre los conceptos relacionados con emprendimiento y su contribución al desarrollo económico y social para poder extraer conclusiones sólidas sobre dicha relación y que, por una parte sienten unas bases sólidas de nuevo conocimiento $y$, por otra, sean válidas para impulsar convenientemente las políticas.

Es a este nivel de donde parte la motivación inicial de la presente tesis, ya que una conceptualización equivocada del emprendimiento y cómo fomentarlo, puede llevar (como así está ocurriendo en algunos casos) a la implementación de instrumentos y herramientas de políticas que no arrojen los resultados esperados.

Por otra parte, el fomento del emprendimiento en el contexto de la universidad emprendedora, como pieza clave en la contribución al desarrollo económico y social, requiere de un entendimiento de las necesidades que esta institución debe satisfacer, de su entorno y de los agentes que pueden contribuir a dicho objetivo. Entender cómo funcionan estas universidades y sus PAE, se vuelve crucial a la hora de gestionarlos adecuadamente de forma que contribuyan realmente a dicho desarrollo. Así, la caracterización de las universidades como emprendedoras de modo que nos permita disponer del conocimiento de un conjunto de puntos fuertes y débiles de estas instituciones a la hora de transformarse en emprendedoras, resulta clave para su adecuada planificación estratégica y posterior gestión, de modo que se optimice su contribución al desarrollo económico y social de su entorno. Tampoco podemos olvidar el hecho de 
que la sociedad cada vez demanda un papel más activo de las universidades en el desarrollo socioeconómico de su territorio de influencia.

Estas son las motivaciones que nos han guiado en la formulación del objetivo general de la tesis, cuya consecución, nos ha llevado por un camino, siguiendo la senda de los objetivos específicos marcados, a lo largo del cual hemos podido realizar modestas contribuciones y diversas aportaciones en el campo del emprendimiento. Conforme hemos ido avanzando en el desarrollo de la tesis, y por ende, profundizando en el conocimiento y estudio del tema, nos han surgido cuestiones y debates a los que hemos tratado de contribuir a través de los resultados obtenidos, tal como se ha expuesto en el epígrafe anterior. De este modo, para determinar cómo el emprendimiento universitario puede contribuir al desarrollo económico y social, se hizo necesario acotar la conceptualización de emprendimiento, entendiendo el origen de la relación entre emprendimiento y desarrollo económico. Por otro lado, tuvimos que analizar lo índices de medida del emprendimiento y su contribución al desarrollo económico, encontrando una discrepancia entre la conceptualización y los índices empleados para su análisis. Con objeto de salvar esta discrepancia, una primera contribución de la tesis se materializa en una conceptualización del término emprendimiento, que integra el punto de vista de los autores más destacados en la materia.

Avanzando por la senda referida al inicio de esta sección, la contribución de las universidades emprendedoras y sus PAE al desarrollo económico y social, requiere de la conjunción de los diferentes factores y agentes que intervienen en dicho proceso. Ello da pie a nuestra siguiente aportación: un modelo del fomento del emprendimiento en universidades emprendedoras. Esta aportación se concreta, tanto en la propuesta de modelo en sí mismo, como en una herramienta que permitirá analizar en qué medida se está aplicando el modelo y qué agentes están contribuyendo y cómo a la satisfacción de las necesidades. 
El último alto en nuestro camino, pero no por ello menos importante, nos lleva a analizar las características de las universidades emprendedoras, a través de la experiencia y el caso de la UPV. El análisis y la caracterización de la UPV como universidad emprendedora nos llevan a determinar sus puntos fuertes y débiles. Así mismo, a través del estudio del caso del Instituto IDEAS de la UPV, aportamos una caracterización de lo que hemos denominado "servicios emprendedores-innovadores", arrojando luz sobre los factores de éxito de los mismos, centrados, sobre todo en su gestión.

La unión de todos los puntos estudiados durante el recorrido de nuestra tesis, permite materializar una propuesta metodológica para el análisis y la caracterización de las universidades emprendedoras.

\subsection{Estructura del documento}

Una vez desarrollado el presente capítulo introductorio, el segundo de los capítulos se centrará en el marco teórico, donde se abordará la conceptualización del término emprendimiento y su relación con el desarrollo económico así como su estudio desde tres diferentes perspectivas aunque íntimamente relacionadas y que son el Evolucionismo, el Institucionalismo y el concepto de Sistema de Innovación.

El capítulo 3 está destinado al marco empírico donde abordaremos el estudio de las políticas de emprendimiento y su diseño y aplicación, las organizaciones y universidades emprendedoras y los programas de apoyo al emprendimiento como servicios innovadores en universidades emprendedoras.

En el siguiente capítulo, desarrollamos nuestra propuesta conceptual y modelo teórico de Fomento del Emprendimiento y Apoyo al Desarrollo de Empresas. En éste, como paso previo, tratamos el tema de la divergencia entre la conceptualización del término emprendimiento y su aplicación práctica y proponemos una conceptualización del término emprendimiento. 
Así mismo, analizamos el fomento del emprendimiento en la universidad española y exponemos nuestro modelo de FEyADE y la propuesta metodológica para su implantación.

El capítulo 5 se centra en el caso práctico de la Universidad Politécnica de Valencia (UPV), analizando cada una de sus tres misiones ${ }^{2}$ así como su gestión con objeto de caracterizar a esta universidad como emprendedora. Así mismo, nos centramos en la caracterización del Instituto IDEAS como servicio innovador y emprendedor dentro de la UPV. Para finalizar este capítulo, aplicamos el modelo de FEyADE al caso de la UPV, lo que nos permitirá obtener conclusiones sobre la contribución de los agentes, tanto internos como externos a la UPV, a la hora de cubrir las necesidades del entorno y de la propia comunidad universitaria respecto al fomento del emprendimiento.

En el último de los capítulos de la tesis se exponen las conclusiones generales de la misma, y las líneas de investigación futuras a partir de este trabajo.

\footnotetext{
${ }^{2}$ En referencia a las tres misiones de una universidad que describe la literatura y que posteriormente se presentan y hacen referencia a la formación, la investigación y la transferencia.
} 


\section{Capítulo 2. Marco Teórico-Conceptual}

El estudio y análisis de la relación entre emprendimiento y desarrollo económico se debe basar en la comprensión de la manera en que se relacionan emprendimiento, instituciones, y desarrollo económico, por un lado y, por otro, en la manera en que se define el término emprendimiento, y las implicaciones de su uso así como los indicadores que se diseñan y emplean para que su medida sea congruente con los términos con los que está relacionado. Bajo este contexto, proponemos un marco teórico y conceptual para nuestro estudio que contempla, en el espectro más general, la conceptualización del término emprendimiento y la relación entre emprendimiento y desarrollo económico. El estudio de esta relación nos conduce al estudio, análisis y comprensión de las Teorías Económicas 
Evolucionista e Institucionalista como aquellos cuerpos dogmáticos en los que más claramente se anclan los estudios teóricos sobre el emprendimiento. Pero tratando de ser más concretos, este capítulo se centra fundamentalmente en los aspectos teóricos que nos permiten entender el papel del emprendimiento en los sistemas de innovación. La razón se encuentra en que hemos considerado que el concepto de Sistema de Innovación y su modelización representa un marco completo en el que el emprendimiento y el papel del emprendedor tiene un papel destacado y permite integrar adecuadamente la idea de emprendedor con el desarrollo socioeconómico, sin menoscabo, claro está, de que otras teorías y enfoques también permiten establecer dicho vínculo.

\subsection{Conceptualización de Emprendimiento}

Debemos partir de un hecho que Gartner (1985) y Carland et al. (1988) ponen de manifiesto y que consiste en que no encontramos en la literatura un consenso claro sobre el término emprendimiento, bien sea por las diferentes corrientes y perspectivas desde la que se estudia, como por la falta de consenso en algunos aspectos de la conceptualización del término.

Si partimos de una definición estándar y consensuada como base del vocabulario, nos encontramos con que en español, el término emprendedor deriva de la voz castellana emprender, que proviene del latín, coger 0 tomar, aplicándose originalmente (tanto en España como en otros países) a los que entonces eran considerados aventureros, principalmente militares, término que posteriormente pasó a tener connotaciones comerciales. La palabra fue definida por primera vez en el Diccionario de Autoridades ${ }^{3}$ de 1732, como: "La persona que emprende y se determina a hacer y ejecutar, con resolución y empeño, alguna operación considerable y ardua".

\footnotetext{
${ }^{3}$ Entre 1726 y 1739 publica la Real Academia Española su primer repertorio lexicográfico, el «Diccionario de la lengua castellana, en que se explica el verdadero sentido de las voces, su naturaleza y calidad, con las frases o modos de hablar, los proverbios o refranes, y otras cosas convenientes al uso de la lengua [...]», conocido como el Diccionario de Autoridades.
} 
También se le describe como "Señor esforzado y emprendedor de hazañas notables, como su padre".

Ese sentido y evolución está estrechamente relacionado con el vocablo francés 'entrepreneur' que aparece a principios del siglo XVI. Posteriormente, a principios del siglo XVIII, los franceses extendieron el significado del término a los constructores de puentes y caminos y a los arquitectos. Así, L'Encyclopédie ${ }^{4}$ define el término 'entrepreneur' como: "se dice por lo general del que se encarga de una obra: se dice un emprendedor de manufacturas, un emprendedor de construcciones, un manufacturero, un albañil contratista". La traducción de la frase anterior es difícil, dado que el sentido de las palabras ha cambiado, pero se ha sugerido que el sentido de la frase francesa (a diferencia de la hispana) se relaciona con la persona que obtiene un contrato con otros y está a cargo de su ejecución, lo que en España se denominaba en aquellos tiempos "maestros de obra" o un contratista en su sentido original: quienes recibían contratos reales (en el sistema de la Casa de Contratación de Indias) y, en general, quienes contrataban la producción de algunos bienes por encargo. El elemento de riesgo no aparece aún, dado que tales personajes financiaban sus actividades sobre la existencia de un contrato con alguna autoridad y sus ingresos estaban, por lo general, asegurados (Pressman, 2013). Ya centrando el concepto en el terreno de la economía, como disciplina del conocimiento, nos encontramos con que los economistas clásicos Adam Smith, David Ricardo y John Stuart Mill, interpretaron el término como "Gerentes de negocios". En 1890, Alfred Marshall, reconoció formalmente la importancia de los emprendedores en los procesos productivos. Posteriormente, ese sentido de 'entrepreneur' se generalizó para identificar tomadores de riesgos económicos. Jean-Baptiste Say jugó un papel importante en esa generalización, haciendo explícito y coherente

\footnotetext{
${ }^{4}$ L'Encyclopédie o Dictionnaire raisonné des sciences, des arts et des métiers es una enciclopedia francesa editada entre los años 1751 y 1772 en Francia bajo la dirección de Denis Diderot y Jean Le Rond d'Alembert. Es considerada una de las más grandes obras del siglo XVIII, no sólo por ser la primera enciclopedia francesa, sino también por contener la síntesis de los principales conocimientos de la época, en un esfuerzo editorial considerable para su tiempo.
} 
ese nuevo sentido. Según este autor, un emprendedor es un agente económico que une todos los medios de producción: la tierra de uno, el trabajo de otro y el capital de un tercero y produce un producto. Mediante la venta de dicho producto en el mercado, paga la renta de la tierra, el salario de sus empleados, interés en el capital y su provecho es el remanente. Intercambia recursos económicos desde un área de baja productividad hacia un área de alta productividad y alto rendimiento (Say, 1803). En su Tratado de Economía Política, Say presentó al 'entrepreneur' como el que "dirige una empresa, especialmente un contratista, actuando como intermediario entre el capital y el trabajo". En esta acepción, Say identifica al 'entrepreneur' con empresario. Notó que habitualmente tales empresarios son tan pobres que no poseen siquiera parte del capital que emplean. Sin embargo, para él lo importante es que "el empresario está expuesto a todos los riesgos mientras que se aprovecha de todo lo que puede serle favorable" (Say, 1821). Esta concepción perduró hasta comienzos del siglo $\mathrm{XX}$ y se puede resumir como la del empresario propietario y gestor de empresas que asume riesgos.

No obstante, esta acepción empieza a cambiar con Joseph Schumpeter, quien sugiere que invenciones e innovaciones son la clave del crecimiento económico y quienes implementan ese cambio de manera práctica son los emprendedores (Schumpeter, 1911). Posteriormente profundizaremos en las ideas de Schumpeter acerca del emprendedor, pues es el autor clave del que se deriva la corriente de pensamiento económico estructuralistaevolucionista, que sienta las bases del concepto de Sistema de Innovación, base de este trabajo.

A partir de estas premisas, el estudio del emprendimiento se ha desarrollado hasta constituir una línea de investigación propia en el ámbito de la economía y la empresa en la que es posible diferenciar tres corrientes principales: la corriente económica, la socio-psicológica y la comportamental. Pasamos, a continuación, a hacer una breve descripción de los elementos clave que define cada una de estas tres corrientes. 
La corriente económica define emprendimiento como el proceso de obtener nuevas combinaciones en productos o procesos, rompiendo el equilibrio existente en el mercado y con un retorno incierto (Schumpeter, 1911). Para Schumpeter, el emprendedor es el motor de cambio y crecimiento económico, y el concepto está relacionado con sus habilidades y su propensión a generar innovaciones, llevando a cabo nuevas combinaciones que puedan tomar la forma de nuevos productos, procesos, mercados, formas organizativas, o fuentes de abastecimiento. Emprendimiento es, entonces, el proceso por el cual se llevan a cabo estas combinaciones de productos, procesos, mercados, etc. (Sharma y Chrisman, 1999). En esta misma línea, según Peter Drucker (1964), un emprendedor busca el cambio, responde a él y explota sus oportunidades. La innovación es una herramienta específica de un emprendedor, por ende un emprendedor efectivo convierte una fuente en un recurso (Drucker, 1985).

La corriente socio-psicológica se centra en las características personales de los emprendedores y las diferencias existentes entre ellos, considerando aspectos como la creatividad, la capacidad de asumir riesgos, la agresividad, el deseo de independencia, el control o la necesidad de logro (McClelland, 1961). McClelland define al emprendedor como alguien que ejerce algún control sobre los medios de producción y produce más de lo que consume, a fin de vender o cambiar este exceso para conseguir un ingreso individual o doméstico. Se encuentra que las características del emprendedor son, por una parte, un tipo especial de comportamiento y, por otra, un interés por ocuparse en actividades que implican emprender por su prestigio y por su riesgo. Desde la perspectiva socio-psicológica el factor clave es el individuo, presentando al emprendedor como el individuo que es capaz de tener una idea innovadora y transformarla para llevarla a cabo. En este ámbito, Kirzner identifica emprendimiento con detección de oportunidades y asunción de riesgos bajo incertidumbre. Según Kirzner, lo que caracteriza a un emprendedor, no es tanto que sea el dueño de un negocio o no, ni que corra un riesgo o innove, sino que es una persona que 
está alerta a las oportunidades, de los vacíos que dejan los mercados que no están en equilibrio y lo aprovecha en su propio beneficio. (Kirzner, 1973). Relacionado con estas características del emprendimiento, Kuratko y Hodgetts (2001) asocian la libertad y autonomía con este fenómeno y Yeoh y Jeong (1995) con proactividad e innovación. Esta corriente que estudia la diferencia de comportamiento entre emprendedores y no emprendedores ha sido abordada ampliamente en la literatura (Brockhaus, 1980; Carland, et al, 1984; Collins et al, 1964; Hornaday and Aboud, 1971; Howell, 1972; Litzinger, 1965; McClelland, 1961; Palmer, 1971; Schrier, 1975; Shapero, 1975, entre otros). Sin embargo, según Cochran, los sociólogos no han estudiado suficientemente al emprendedor y lo han dejado al criterio de los economistas. Así según este autor, "no podemos identificar la diferencia entre un emprendedor y un no-emprendedor en sentido económico, aunque sabemos que cuando un hombre de negocios innova, está actuando como un emprendedor. Lamentablemente, los sociólogos han estudiado al emprendedor mucho menos que los economistas" (Cochran, 1949). En la misma línea, Friederich Hayek pone de manifiesto el papel del emprendedor como ágil captador y utilizador de la información. Según este autor, la importancia del emprendedor radica en su habilidad para captar información que le lleve a encontrar oportunidades capaces de generar un beneficio (Hayek, 1948).

Por último, la corriente comportamental analiza el comportamiento del emprendedor al considerar que son las acciones, y no las características de los individuos, las que explican las actividades emprendedoras. Lo importante es "qué hacen" en vez de "cómo son" (Covin y Slevin, 1991). Desde esta perspectiva, se analizan aspectos relacionados con la creación y la dirección de nuevas empresas, la formulación de estrategias emprendedoras (Covin y Slevin, 1991) o los factores que facilitan el éxito de la actividad emprendedora (Antoncic y Hisrich, 2001; Zahra, 1993). La corriente comportamental ha tenido un gran desarrollo en los últimos años, pues ayuda a comprender y mejorar la gestión empresarial y el 
funcionamiento de los procesos emprendedores. Es precisamente en esta corriente donde se dan las mayores discrepancias sobre la conceptualización de emprendimiento. Así, para Gartner (1988), el emprendedor es el propietario de una pequeña empresa. Según esta interpretación se identificaría emprendimiento con el proceso de creación de pequeñas empresas. En este mismo sentido, encontramos las bases teóricas en las que descansa el Global Entrepreneurship Monitor (GEM) ${ }^{5}$. El GEM entiende el emprendimiento como un proceso que se inicia con la generación de una idea, continúa con las acciones de su puesta en marcha, se lanza al mercado, continúa con una fase de consolidación, y pasa a la fase consolidada cuando sobrevive más de tres años y medio en el mercado (Kelley et al, 2011). En esta definición podemos apreciar que se identifica, por tanto, emprendimiento con el proceso de creación de empresas. No obstante el GEM integra también en su metodología las capacidades emprendedoras de los individuos, ofreciendo una visión más amplia del proceso emprendedor, aunque limitada $e$ insuficiente (Audretsch, 2002; Baumol, et al, 2007; Godin, et al, 2008; Davis, 2006; Hindle, 2006). En una reciente revisión de su metodología, en 2011, el GEM incorpora el concepto de emprendimiento corporativo definiéndolo como "cualquier tipo de actividad emprendedora que se lleva a cabo desde o en organizaciones existentes tanto públicas como privadas que le permitan generar o sostener sus ventajas competitivas, mediante un adecuado uso de los recursos y un entorno que propicia la identificación y/o explotación de ideas innovadoras por parte de emprendedores corporativos" (Coduras et al, 2011). Esta definición sí contempla al emprendimiento como algo diferente a la mera creación de empresas. En contraposición con la identificación de emprendimiento con creación de empresas. Carland et al. (1988), concluyen que propietarios de pequeñas empresas y emprendedores no son lo mismo. Según estos autores, el emprendimiento se distingue de la simple creación de empresas

\footnotetext{
${ }^{5}$ De acuerdo con su propia definición, el Global Entrepreneurship Monitor (GEM) constituye la más importante red mundial sobre emprendimiento y tiene por objetivo hacer que la información de alta calidad sobre la iniciativa emprendedora esté disponible para el mayor público posible.
} 
principalmente, por la orientación hacia una estrategia empresarial basada en el crecimiento y la innovación. En su estudio Carland y sus colegas demostraron que los emprendedores se diferenciaban del resto de empresarios por rasgos de personalidad y comportamientos distintos (lo que enlazaría con la corriente socio-psicológica). Wennekers y Thurik (1999), siguiendo las ideas expuestas por Hebert y Link (1989), Bull y Willard (1993) y Lumpkin y Dess (1996), lo conceptualizan como la capacidad manifiesta y deseo de los individuos, ya sea por ellos mismos o mediante equipos, dentro o fuera de organizaciones existentes, de crear nuevas oportunidades económicas, esto es, nuevos productos, nuevas formas de organización, nuevos métodos de producción, etc., e introducir sus ideas en los mercados, haciendo frente a la incertidumbre y a otros obstáculos, adoptando decisiones sobre la localización y en la forma y uso de los recursos y de las instituciones. Como se puede comprobar, en esta definición se hace hincapié en el aspecto de comportamiento característico de los agentes económicos. Por tanto, a la hora de hablar de emprendedores no nos estamos refiriendo a una ocupación, sino a una actividad, en la que se tienen en cuenta los aspectos y circunstancias que rodean al individuo. Tampoco hay que asociarla con las pequeñas empresas. Este tipo de emprendedores también se encuentra en las grandes empresas, y se les suele denominar "intrapreneurs" o "corporate entrepreneurs". En este mismo sentido, Acs (2010), define el emprendimiento como una criatura compleja que se compone de múltiples dimensiones. Es distinto de las pequeñas empresas, el autoempleo, la artesanía, y las empresas habituales, no se asocia como un fenómeno de compras, cambio de titularidad o gestión de la sucesión.

De las diferentes perspectivas que hemos expuesto brevemente y desde las que se ha estudiado el emprendimiento, es la corriente económica la que guía los intereses de esta tesis, ya que nos centramos, fundamentalmente en la contribución al desarrollo económico que el emprendimiento puede aportar a los países y regiones. Sin embargo, tanto 
la corriente socio-psicológica como la comportamental aportan conceptos y visiones sobre el emprendimiento y la figura del emprendedor que nos resultarán fundamentales para entender cómo el emprendimiento puede contribuir al desarrollo económico de los territorios. En definitiva, hemos optado por escoger el enfoque económico en concreto en aras de una mejor profundización, pues el análisis que proponemos es más afín a dicho enfoque, pero somos perfectamente conscientes de que una visión amplia y realmente enriquecedora del papel del emprendedor en el desarrollo socioeconómico también precisa de una valoración de los aspectos sociopsicológicos y comportamentales de ese emprendedor puramente "económico".

\subsection{Emprendimiento y Desarrollo Económico}

A partir de finales de la década de los 60 del pasado siglo, el interés por la relación entre emprendimiento y desarrollo económico comenzó a intensificarse. Desde entonces, diversos autores han tratado de mostrar la influencia que el emprendimiento tiene sobre el desarrollo y crecimiento económicos de los países y/o las regiones (e.g: Baumol, 1968; Leff, 1979; Birch, 1979; Wennekers and Thurik, 1999; Reynolds et al, 2000; Acs and Storey, 2004; Karadeniz, 2006; Naudé, 2010; Acs and Audretsch, 2010).

Sin embargo, y aunque esta relación entre emprendimiento y crecimiento económico se ha dado con frecuencia por hecho, la naturaleza exacta de dicha relación y los canales que permiten que la actividad emprendedora influya en el crecimiento aún se desconocen en buena medida. Como hemos comentado a lo largo de esta tesis, ya en 1911, Schumpeter puso el emprendimiento en el centro del crecimiento económico. No obstante, con muy pocas excepciones, los emprendedores se han visto excluidos de los modelos formales del crecimiento económico y, durante mucho tiempo, los especialistas que trabajaban con modelos analíticos han descuidado el fenómeno del emprendimiento y simplemente lo han tratado como parte de 
los residuos que no se pueden atribuir a ningún input productivo susceptible de ser medido o que pueda ser fácilmente incorporado a una función de producción al uso (Baumol, 1993) ${ }^{6}$.

Por tratar de ser mínimamente sistemáticos en la presentación de los argumentos teóricos que debemos manejar, vamos a comenzar por mostrar la evolución del pensamiento Clásico-Neoclásico ${ }^{7}$ de la Economía en relación con el posible papel del emprendedor, como aquella escuela de pensamiento que ha supuesto la base teórica desde el inicio de la economía como ciencia social y que bien puede representar la ortodoxia en Economía para, posteriormente, presentar los hechos y elementos definitorios de la corriente de pensamiento Estructuralista-Evolucionista, con planteamientos alternativos y que queremos emplear como base para montar el presente estudio.

Desde un planteamiento económico de tipo Neoclásico, el interés por el crecimiento económico puede remontarse al menos a Adam Smith. No obstante, no fue hasta la II Guerra Mundial cuando los estudiosos del tema empezaron a prestarle particular atención a la necesidad del crecimiento sostenible en los países ricos y a la del desarrollo en los más pobres. Hasta entonces, se considera que el crecimiento económico es proporcional a la

\footnotetext{
${ }^{6}$ Dichos residuos hacen referencia fundamental al denominado "Residuo de Solow". Robert Merton Solow (23 de agosto de 1924, Nueva York, EE. UU.) es un economista estadounidense que se puede considerar uno de los padres de la corriente neoclásica del pensamiento económico y es especialmente reconocido por sus trabajos sobre teoría del crecimiento económico. En 1987 recibió el Premio Nobel de Economía. El residuo de Solow, representa una de sus contribuciones teóricas más notables y consiste en una interpretación de la Productividad Total de los Factores (Total Factor Productivity, TFP), como la diferencia entre la tasa de crecimiento de la producción y la tasa ponderada de incremento de los factores (trabajo, capital, ...). La TFP constituye una medida del efecto de las economías de escala, en que la producción total crece más que proporcionalmente al aumentar la cantidad de cada factor productivo. Una interpretación común es que la productividad total de los factores es una medida del efecto favorable de circunstancias que no intervienen directamente como factores de producción. Por ejemplo, un hecho comúnmente aceptado es que un año con buen tiempo tiende a acabar con un nivel de producción más alto, debido entre otros efectos a que la producción agrícola puede verse favorecida. Una variable como el tiempo atmosférico, que no está incluido entre los factores de producción, es una variable que afectaría a la TFP. Igualmente se considera que la mejora tecnológica y el aumento de eficiencia son dos de las variables que más contribuyen a la TFP. La mejora tecnológica tendría externalidades positivas que contribuirían indirectamente al aumento de la producción. De forma análoga, y retomando nuestro argumento, el papel de los emprendedores también contribuye a explicar la TFP y da contenido al llamado residuo de Solow aunque no fuera contemplado por él.

${ }^{7}$ La diferencia que se podría establecer entre economistas de corte clásico y los de corte neoclásico es más de tipo temporal: así, se tiende a considerar que Adam Smith, David Ricardo o Alfred Marshall son economistas clásicos, mientras que Robert Solow, Kenneth Arrow o Paul Romer, por citar algunos, se encuadran en la corriente de pensamiento neoclásica. En realidad, lo que muestra esa diferente denominación tiene que ver con una evolución en los elementos del modelo, pero no en la forma de defenderlo, pues en ambos casos está basado en una consideración matemática del comportamiento humano. Es decir, el comportamiento humano debe modelizarse matemáticamente para poder ser explicado en economía, con todo lo que ello implica.
} 
inversión, y no se contempla que el emprendimiento, la innovación o el cambio tecnológico puedan influir en el desarrollo económico. En 1957, Robert Slow publicó su modelo de crecimiento, en el que la producción económica estaba generada por la interacción del capital físico y del trabajo, y su crecimiento por el cambio tecnológico (Solow, 1957). El argumento que subyacía era que la inversión por sí sola no podría mantener el crecimiento debido a sus rendimientos decrecientes. Para Solow, el crecimiento a largo plazo solamente podría mantenerse a través del progreso tecnológico, y no con la inversión. Desafortunadamente el modelo de Solow no consiguió explicar los orígenes del crecimiento puesto que el cambio tecnológico quedaba fuera del contexto económico. Además, en su modelo no contempló la figura del emprendedor.

Hasta los años 80 y 90 no se produjo un cambio en la tendencia del desarrollo económico. A mediados de la década de 1980, un grupo de teóricos del crecimiento, insatisfechos con los modelos neoclásicos que enfatizaban los factores exógenos, pero que se pueden encuadrar dentro de la ortodoxia del pensamiento económico, favorecieron un modelo que sustituyó la variable de crecimiento exógeno (progreso técnico indeterminado), por uno cuyas variables determinantes de crecimiento estaban explicitadas en el modelo. La investigación inicial se basó en el trabajo de Kenneth Arrow (1962), Hirofumi Uzawa (1965) y Miguel Sidrauski (1967a y 1967b). Paul Romer (1986), Lucas (1988), y Rebelo (1991) omitieron el cambio tecnológico. En su lugar, el crecimiento en sus modelos se ligó a inversión en capital humano que provocaba un efecto spillover sobre la economía y reducía los rendimientos decrecientes de la acumulación de capital. Romer llevó más allá la idea de Solow considerando el progreso técnico. La teoría del crecimiento endógeno de Romer resolvió este aspecto incluyendo mecanismos que relacionaban el capital humano con la creación de nuevas tecnologías, de modo que el cambio tecnológico ya no se encontraba fuera del modelo, sino que más bien estaba determinado por las características descritas en el mismo 
(Jovanovic y Rob 1989, Romer 1990). En estos modelos, el gasto en I+D produce un conocimiento que a su vez conduce al cambio tecnológico y al crecimiento. No obstante, el conocimiento generado por los cambios tecnológicos se disemina a otros individuos aumentando de esta manera su capacidad de producir más invenciones. Así, se pone en marcha una externalidad positiva que permite un cambio tecnológico sostenible y posiblemente creciente a lo largo del tiempo (Romer 1986). La teoría neoclásica endógena implica por tanto, que las políticas que conduzcan a una mayor apertura económica, competencia, cambio e innovación, fomentarán el crecimiento.

Sin embargo, aunque el enfoque se desplazó de la inversión en capital físico a la inversión en capital humano, los modelos de crecimiento endógeno siguieron descuidando el papel del emprendimiento a la hora de generar crecimiento sostenible y desarrollo económico, más allá del esfuerzo que supone recomponer un modelo económico neoclásico basado en factores de producción de carácter muy elemental para incorporar el conocimiento incorporado en los trabajadores, como guiño al papel del emprendedor. Solamente a finales de la década de los noventa se hizo evidente que estos modelos no se podrían aplicar fácilmente a aquellos países donde el crecimiento ha sido notable en los últimos años incluso en ausencia de un gasto significativo en $I+D$, ni a países en los que un abundante gasto en $\mathrm{I}+\mathrm{D}$ ha generado un crecimiento bajo o nulo. Desde entonces, varios economistas interesados en las dinámicas de las pequeñas empresas y en las de nueva creación, empezaron a argumentar que el problema procedía del hecho de que, a pesar de ser muy útiles y sofisticados, estos modelos habían ignorado de nuevo el emprendimiento (Minniti y Levesque, 2008)

De hecho, en los últimos quince años, es cuando se ha empezado a comprender mejor cuáles son las características distintivas de los emprendedores (Lazear, 2005) y a incorporar el papel del emprendedor en los modelos de crecimiento. (Acs et al, 2004; 2005; Minniti y Levesque, 
2010). Entre los estudios que tienen en cuenta el papel del emprendedor, Michelacci (2003) propone un modelo de crecimiento endógeno, en el cual el cambio tecnológico precisa tanto de los investigadores que generan nuevas ideas, como de la figura del emprendedor que las transforma en innovación, es decir, en operaciones económicamente viables. Micchelacci demuestra que cuando los emprendedores obtienen rendimientos demasiados bajos de la innovación, se asignan muy pocos recursos al emprendimiento $y$, como resultado, debido a esta carencia de competencias emprendedoras, los rendimientos de la I+D son bajos.

Del mismo modo, Acs et al. (2004) afirman que uno de los grandes avances que ha aportado la teoría del crecimiento endógeno es la idea de que las inversiones en capital humano impulsan el crecimiento económico a través del desbordamiento de conocimiento. También afirman que la teoría del crecimiento endógeno no explica cómo ni por qué ocurren tales desbordamientos y que el vínculo que falta es el mecanismo que convierte el conocimiento en "conocimiento económicamente relevante". Dentro de este contexto sugieren la existencia de un filtro entre el conocimiento y el conocimiento económicamente relevante e identifican el emprendimiento como el mecanismo que hace esa conversión de conocimiento. Por lo tanto, se centran en el emprendimiento como vehículo que permite que se entable una relación entre el conocimiento y el conocimiento comercializable.

Según Brinkman (1995), el desarrollo económico implica "un proceso de transformaciones estructurales" que conducen a una trayectoria de mayor crecimiento global. El emprendimiento es un factor clave para el dinamismo en la economía permitiendo su adaptación a los cambios estructurales, convirtiendo los retos en oportunidades (Raposo et al., 2011), promoviendo nuevas empresas que crean trabajo, intensifican la competitividad e incrementan la productividad a través del cambio tecnológico y la innovación (Wong et al., 2005). Desde esta perspectiva, el emprendimiento 
entronca más claramente con la corriente de pensamiento EstructuralistaEvolucionista, la cual abordaremos en el siguiente epígrafe.

Al inicio de este capítulo caracterizamos a los procesos de innovación como el motor del desarrollo socioeconómico, y al emprendimiento como la herramienta clave para fomentar y generar dichos procesos. Sin embargo, para que los procesos de innovación y el emprendimiento puedan contribuir efectivamente al desarrollo económico, se requiere de un funcionamiento sistémico de los diferentes agentes que permita el adecuado flujo de conocimientos y recursos entre ellos. Esta idea nos conduce al empleo del concepto de Sistemas de Innovación (SI) como aquellos espacios socioculturales de identidad homogénea en los que se produce la generación de riqueza a través de múltiples, diversos, complejos e imprevisibles procesos de emprendimiento, gestión, aprendizaje y generación de nuevos conocimientos (Fernández de Lucio et al., 2000). Es pues esta idea la que impulsa el interés por analizar, desde el punto de vista económico, el papel del emprendedor y los comportamientos emprendedores como mecanismo que alimenta los procesos de desarrollo socioeconómico.

Partiendo de Gancia y Zilibotti (2005), Minniti y Levesque (op. cit.) demuestran que el alto crecimiento económico surge cuando aumenta el número de emprendedores-investigadores, emprendedores-imitadores o ambos. De modo más concreto, sostienen que los emprendedores son el elemento facilitador esencial del proceso de crecimiento. Ya sea imitando un producto o tecnología existentes o transformando una nueva invención en un cambio tecnológico comercializable, los emprendedores son los actores económicos que hacen que el crecimiento sea posible (Schumpeter 1934, Acs et al. 2004). El tipo de emprendedores que resulta más importante depende del tipo de país (Goel y Ram 1994, Gong y Keller 2003). Por ejemplo, en un país relativamente rico que se encuentra cerca de su frontera de posibilidades de producción, el crecimiento se genera por el aumento de la productividad. Para seguir siendo competitivo, dicho país 
necesitará de descubrimientos tecnológicos relativamente más originales. Por otro lado, un país caracterizado por una gran cantidad de recursos no explotados puede aumentar su riqueza mediante su movilización. Tal país puede especializarse en imitar la tecnología desarrollada en cualquier otro lugar y, dependiendo del nivel de desarrollo del país y del coste del cambio tecnológico, los emprendedores-imitadores pueden ser más importantes que los emprendedores-investigadores. La respuesta concreta a esta cuestión depende, naturalmente, de cada país.

Así, según Acs (2010), "emprendimiento se define como una interacción dinámica de las actitudes, actividades y aspiraciones que varía a lo largo de los diferentes niveles de desarrollo económico" ${ }^{8}$. Acs pone de manifiesto en esta definición que el emprendimiento se comporta de manera desigual a lo largo de las diferentes etapas del crecimiento económico. Las etapas a las que el autor se refiere, se corresponden con las definidas por Porter et al. (2001) en una concepción moderna de las etapas de crecimiento económico establecidas por Rostow (1960) que culminaban en la etapa de un alto consumo masivo. Porter, Sachs y Mc Arthur identificaron tres etapas de desarrollo económico: (1) Etapa basada en los factores; (2) Etapa basada en la eficiencia; y (3) Etapa basada en la innovación. Estos autores ponen el énfasis en la innovación como motor del desarrollo económico frente al concepto de crecimiento económico y consumo masivo de Rostow. Así mismo, Acs y Szerb (2009) ponen de manifiesto que la relación entre las instituciones y el emprendimiento varía entre las diferentes etapas de desarrollo, siendo el cambio institucional más importante en países con bajos niveles de desarrollo, mientras que el emprendimiento cobra importancia en niveles altos de desarrollo. La relación entre las instituciones y el emprendimiento nos llevará a tratar este fenómeno bajo el prisma de la teoría institucional. En definitiva, lo que pretendemos a continuación es desarrollar la idea que hemos plasmado de forma sintética en los párrafos anteriores para darle un contenido y desarrollo teórico a la

\footnotetext{
${ }^{8}$ Traducción propia del texto original.
} 
luz de la corriente de pensamiento Evolucionista-Estructuralista, junto con su bifurcación hacia el Institucionalismo.

\subsection{Teorías económicas sobre las que basar nuestro estudio del emprendimiento}

Tal como hemos visto, la literatura sobre el emprendimiento y los emprendedores se ha desarrollado a partir de conceptos como la innovación o la incertidumbre en la toma de decisiones, lo que aleja el estudio del emprendimiento, de las premisas de la economía ortodoxa (teorías clásica y neoclásica), situándolo, como ya hemos anunciado, dentro del marco de estudio de las teorías económicas evolucionista e institucional. Esto es así porque en el paradigma ortodoxo, el individuo no necesita asumir riesgos pues siempre toma decisiones en situaciones de información perfecta y completa y, en ausencia de tales situaciones, es cuando se producen los desequilibrios. Por lo tanto siempre puede buscar un equilibrio que es óptimo (paretianamente hablando ${ }^{9}$ ) y único. $Y$ si no lo encuentra es que hay circunstancias exógenas que impiden alcanzarlo. Por otro lado, dado que el "instrumental" que emplea dicho planteamiento es puramente matemático, el individuo emprendedor (como aquel que busca oportunidades y toma decisiones bajo situaciones de incertidumbre), no tiene sentido en un marco puramente ortodoxo.

Así pues, en este epígrafe trataremos las teorías económicas estructuralista-evolucionista e institucional como marco teórico en los que basar este estudio sobre emprendimiento. Con objeto de comprender mejor cómo el emprendimiento tiene cabida en estas teorías, expondremos las premisas de cada una de ellas, sus antecedentes e influencias y cómo el

\footnotetext{
${ }^{9}$ Vifredo Pareto (1848-1923), economista e ingeniero italiano estuvo preocupado por el estudio de la "optimalidad" en la asignación y distribución de recursos, preocupación que le llevó a introducir ciertas apreciaciones de tipo sociológico en su contribución a la economía (clásica) que, de alguna manera, contribuyeron a abrir el camino de la moderna microeconomía. De acuerdo con los principios paretianos sobre optimalidad, se entiende que una asignación de recursos resulta óptima si todos los individuos a los que afecta tal asignación están de acuerdo con ella y ninguno en desacuerdo o, si al menos uno está de acuerdo con la asignación a y los demás les resulta indiferente.
} 
emprendimiento es abordado desde el prisma de cada una. Así mismo, se trata la coexistencia y convergencia en economía de ambas teorías.

\subsubsection{Teoría Económica Estructuralista-Evolucionista}

La teoría Estructuralista-Evolucionista ${ }^{10}$ se centra en la conceptualización de los procesos de transición y de cambio económico e institucional, por medio de la innovación y la tecnología como principales factores influyentes en el crecimiento económico de las empresas en el largo plazo. Este fenómeno social surge en contraposición a la estática comparativa de la teoría ortodoxa, cuyo punto de partida es el individuo (agente económico).

Según la teoría ortodoxa, los individuos generalmente se definen como unidades con un objetivo común: la maximización a través de un comportamiento racional. El individuo (agente económico) se considera racional en el sentido de que el bienestar, tal y como se define en la función de utilidad, es optimizado según las oportunidades percibidas. Es decir, el individuo trata de alcanzar objetivos muy específicos y predeterminados en la mayor medida posible con el menor coste posible. Las únicas diferencias entre los individuos consisten en: i) el objetivo específico de la maximización (los individuos tienden a maximizar la utilidad y las empresas el lucro, por ejemplo); ii) las limitaciones que enfrentan en el proceso de maximización (los individuos podrían estar limitados por los ingresos o los precios de las materias primas y las empresas podrían estar limitadas por la tecnología o la disponibilidad de insumos).

En este sentido, el análisis neoclásico (como corriente más representativa de la ortodoxia en Economía) intenta demostrar que el libre juego de los mercados pretende maximizar las preferencias de los agentes teniendo en cuenta la limitación de los recursos de partida disponible. Este análisis es a

\footnotetext{
${ }^{10}$ La teoría Estructuralista-Evolucionista (de ahora en adelante y por simplicidad evolucionismo o teoría evolucionista) representa una corriente de pensamiento alternativa a la ortodoxia en Economía. Es decir, trata de romper con los principios que permiten explicar la Macroeconomía y la Microeconomía para buscar esa explicación al comportamiento de los agentes económicos con base en un comportamiento más próximo al del ser humano real, lo que dificulta considerablemente el uso de un instrumental puramente matemático. De acuerdo con esta corriente de pensamiento, tal y como indica Richard Lipsey (1994), el Estructuralismo es la parte que se ocupa de los aspectos macroeconómicos y el Evolucionismo de los microeconómicos. En definitiva, nos encontramos con las dos caras de la misma moneda.
} 
la vez descriptivo (en la medida que considera la organización social ordenada alrededor de los mercados), y normativo, toda vez que al libre funcionamiento de estos mercados permite obtener el "óptimo social". Vemos, pues, que el centro de la atención de este análisis está constituido por el mercado, en el seno del cual los agentes económicos realizan las operaciones, definidas como la maximización de sus preferencias bajo la limitación que supone la escasez. En este contexto, es lógico que la Economía fuera definida como "la ciencia que estudia las condiciones que debe satisfacer la conducta humana para conseguir un placer máximo con un costo mínimo en forma de penosidad" (Napoleoni, 1968).

A partir de estas premisas, los economistas ortodoxos alegan que la acción política no debe utilizarse para resolver los problemas del sistema económico. En lugar de ello, la solución debe pasar por una intervención sobre los objetivos y limitaciones de maximización. Es en este contexto en el que el capitalismo económico encuentra su justificación ya que la teoría económica ortodoxa considera a la economía global como la suma de los agentes que tratan de maximizar su utilidad o beneficio a través del intercambio.

Estos supuestos han sido sometidos a diversas críticas:

1) los estudios empíricos muestran que los agentes son heterogéneos y se caracterizan por diversas competencias, creencias y expectativas, así como por diferentes grados de acceso y capacidad de procesamiento de los flujos de información;

2) la incertidumbre a la que se enfrentan los agentes que operan en una economía capitalista no puede ser representada en términos de una distribución probabilística, ya que es "no-asegurable" y "nomensurable". Los mercados no pueden descartar la posibilidad de futuros "estados del mundo" cuya ocurrencia es el resultado no intencional -y parcialmente endógeno- de decisiones tomadas por agentes heterogéneos; 
3) es implausible que los agentes empleen procedimientos de maximización, probablemente ineficientes en contextos caracterizados por la complejidad, la incertidumbre y las "sorpresas";

4) por ende, es difícil definir un comportamiento "racional" único, aún para un observador externo que conoce toda la información que pueden aportar los mercados. Lo que está "bien" o "mal" para cualquier agente puede depender de comportamientos inciertos de todos los restantes agentes a través de vías que difícilmente puedan ser representadas;

5) la micro-heterogeneidad ${ }^{11}$ puede no estar adecuadamente representada al promediar "agentes representativos". Esto no implica que el sistema sea imposible de analizar o abordar teóricamente, ya que la variabilidad a escala micro es compatible con un orden macro. Es decir, es posible describir las características centrales y el funcionamiento del sistema sin necesidad de tener información sobre cada uno de sus componentes.

Estas críticas muestran las limitaciones de la teoría ortodoxa a la hora de abordar el fenómeno del emprendimiento. El emprendedor, no es un individuo promedio, sino que se representaría como un outlier o "valor atípico". Según Metcalfe (2002), la idea de individuo representativo de la teoría ortodoxa, no tiene sentido de ser en la economía de la innovación, ya que los outliers son los que explican la dinámica de los sistemas.

Este hecho, nos lleva a dirigir nuestra mirada hacia la teoría económica evolucionista, la cual surge, precisamente a raíz de las críticas a la teoría ortodoxa. La teoría económica evolucionista encuentra sus bases en:

1- La importancia del tiempo y la historia para entender la dinámica social: las acciones y decisiones pasadas tienen repercusión en el presente, es decir, lo que ocurre a lo largo del tiempo puede alterar el resultado final

\footnotetext{
${ }^{11}$ Por micro-heterogeneidad, se entiende la diversidad a nivel de individuos o componentes de un sistema
} complejo. 
2- La incertidumbre: las empresas actúan en un contexto de incertidumbre de acuerdo a reglas y comportamientos rutinarios que les permite enfrentar un ambiente en continuo cambio y altamente incierto.

3- Toma de decisiones constante: Los agentes se ven sujetos por un lado a tomar decisiones bajo una "racionalidad limitada" al no contar con la suficiente información; y por otro, a un comportamiento de "conducta satisfaciente" puesto que por las mismas rutinas y hábitos lo que se busca en última instancia es satisfacer determinadas metas.

Según Nelson (1995), una teoría evolucionista se caracteriza por: i) centrar el foco de atención en una variable -o un grupo de ellas- que cambia con el tiempo y que pretende entender el proceso dinámico que está detrás del cambio observado; ii) la variable o sistema en cuestión sufre variaciones parcialmente azarosas y existen mecanismos de selección sistemática entre esas variaciones; esto implica que se excluyen tanto las teorías completamente deterministas como aquellas en donde toda la acción es azarosa. El evolucionismo se concentra, entonces, en las propiedades de los sistemas donde la dinámica surge endógenamente por la emergencia persistente de innovaciones y en los cuales predominan las interacciones positivas. Esto se traduce en la preferencia por modelos no lineales, donde el orden y las estructuras son el resultado colectivo de fluctuaciones lejos del equilibrio (auto-organización). Por otra parte, el evolucionismo no asume necesariamente nociones gradualistas, ya que admite cambios abruptos, inestabilidades, revoluciones, etc., así como también en biología existen las discontinuidades (Dosi, 1991).

\subsubsection{Antecedentes de la teoría económica evolucionista}

La teoría evolucionista, desde una perspectiva general, tiene su origen en la obra de Charles Darwin, On the Origin of Species (1859) cuyo argumento se basa en que los seres vivos provienen de un origen común, a partir del cual se han producido múltiples ramificaciones. No obstante, para los intereses de la presente tesis, nos centraremos en la teoría económica 
evolucionista, la cual, si bien, se basa en parte en la biología, tiene características diferenciadoras. Estas diferencias existentes entre los procesos evolutivos biológico y económico se pueden resumir de acuerdo con las siguientes premisas: i) en economía, la creación de nueva variedad se orienta sistemáticamente hacia sitios que parecen apropiados al contexto. Mientras que la mutación a nivel genético es azarosa, frecuentemente la mutación económica es sujeto de cambios intencionales; ii) la evolución biológica es darwinista -sólo las características genéticas se transmiten-, mientras que la evolución económica es lamarckiana, ya que también se transmiten las características adquiridas. Esto ocurre debido a la capacidad de los seres humanos para codificar y almacenar el conocimiento; en consecuencia, el aprendizaje juega un rol crucial en la evolución económica; iii) los agentes económicos pueden anticipar futuros estados del ambiente selectivo; iv) la selección natural es independiente de las acciones de los organismos individuales. En cambio, los agentes económicos mejoran su habilidad para sobrevivir no sólo cambiando ellos mismos, sino también modificando el ambiente -el mecanismo selectivo(Chang, 1994; Metcalfe, 1995; Nelson y Winter, 1982; Nelson, 1995).

En 1843, Roscher, uno de los más distinguidos miembros de la Escuela Histórica Alemana, publicó su Grundriss zu Vorlesungen über die Staatswirtschaft nach Geschichtlicher Methode (Tratado de economía política de acuerdo con el método histórico), donde utilizó analogías y conceptos de la evolución biológica para analizar el comportamiento de las instituciones y los sistemas económicos (Roscher, 1843). En este mismo sentido, Alfred Marshall (1890), identificó varios puntos de coincidencia entre la biología y la economía, poniendo el acento en los cambios irreversibles de la actividad económica y sugiriendo la presencia de un tiempo real distinto del tiempo mecanicista, propio de la economía neoclásica ${ }^{12}$. Según este autor, las mismas condiciones en momentos

\footnotetext{
${ }^{12}$ Resulta chocante que uno de los considerados como padres de la Economía Clásica pueda ser "confundido" como economista estructuralista. De igual manera, otro supuesto padre de la Economía Clásica, Karl Marx puede ser interpretado sin demasiada dificultad en clave de pensamiento estructuralista e institucionalista, tal y como
} 
distintos no producen los mismos resultados y además, muy probablemente, nunca se vuelven a dar esas mismas condiciones.

Posteriormente, Gustav von Schmoller en su Grundiss der allgemeinen Volkswirtschaftslehre (Tratado general sobre economía política) (1908), hizo referencia a la importancia del tiempo y el espacio en el desarrollo de la economía. Este autor enfatizó sobre la importancia de la cultura en el desarrollo económico (en franca contraposición a los planteamientos de los economistas clásicos y neoclásicos), haciendo específicamente referencia a los aspectos biológicos, al analizar las relaciones entre las empresas y los sistemas económicos.

Thorstein Bunde Veblen, con su obra The Place of Science in Modern Civilization (1919) retomó las ideas evolucionistas originales y señaló que las organizaciones productivas operan según los mismos principios de herencia, variación y selección. La principal aportación y novedad se encuentra en la idea de que las sociedades se ven obligadas a modificar constantemente las preferencias individuales y de grupo en la medida en que se generan nuevos descubrimientos, se formulan nuevas teorías y se crean y comercializan nuevos inventos.

Otra fuente de inspiración para las ideas evolucionistas son algunos recientes avances en física, matemática y química, y en particular la llamada teoría de la "auto-organización". La auto-organización es un proceso en el que alguna forma global de orden o coordinación surge de las interacciones locales entre los componentes de un sistema inicialmente desordenado. Este proceso es espontáneo: no está dirigido ni controlado por ningún agente o subsistema dentro o fuera del sistema; sin embargo, las leyes seguidas por el proceso y sus condiciones iniciales pueden escogerse o ser causadas por un agente. El proceso es generalmente desencadenado por fluctuaciones aleatorias que son amplificadas por realimentación positiva. La organización resultante está completamente 
descentralizada o distribuida sobre todos los componentes del sistema; esta organización resulta típicamente muy robusta, capaz de sobrevivir y auto-reparar daños o perturbaciones sustanciales. En estos procesos se combinan la necesidad y el azar, generando trayectorias históricas únicas e irreversibles y en las cuales el futuro, en lugar de estar dado, se crea a lo largo de un sendero evolutivo (Prigogine, 1988).

Dejando un poco el camino de la biología y las ciencias naturales, la teoría económica evolucionista cuenta con antecedentes e influencias, cómo no podía ser de otro modo, desde el campo de la economía. En este sentido, los evolucionistas destacan la existencia de un conjunto de "aliados y antecedentes" de su propio enfoque. Entre otros, se citan a los analistas de la firma (Coase, Chandler, Penrose, Williamson), a Knight (en particular por su tratamiento de la incertidumbre) y a la escuela austríaca, que enfatiza la naturaleza esencialmente cambiante e imprevisible de los procesos de mercado (Hayek, 1973; Kirzner, 1973). El carácter evolucionista de las diversas vertientes del institucionalismo (el cual trataremos en el siguiente epígrafe) es, asimismo, enfatizado; de hecho, entre ciertas ramas modernas del institucionalismo y el evolucionismo existen relaciones estrechas $^{13}$.

Los evolucionistas Nelson y Winter (1982) afirman que sus "mayores deudas intelectuales" las tienen con Schumpeter y Simon. Simon se inscribe en la tradición "conductista", que trabaja con los conceptos de racionalidad limitada y procedural y con agentes que satisfacen, en lugar de

\footnotetext{
${ }^{13}$ Sin ánimo de ser demasiado prolijo en la explicación, pero sí alumbrando mínimamente una explicación a los elementos teóricos escogidos en esta tesis, se puede establecer un estrecho vínculo entre el evolucionismo, el estructuralismo y el institucionalismo a través de los autores más significativos en cada corriente de pensamiento. Así, el origen de los enfoques económicos de corte estructuralista se puede buscar en relación con los estudios sobre desarrollo y las diferencias entre los problemas estructurales e institucionales de los países desarrollados y aquellos en vías de desarrollo sin que se pueda ofrecer un planteamiento u origen únicos. Por otro lado, la corriente que actualmente se conoce como Economía Evolucionista sí cuenta con un cierto consenso en situar su origen en los trabajos de Friedrich August von Hayek. Concretamente, en su obra de tres volúmenes Law, Legislation and Liberty, escrita entre 1973 y 1979, trata la evolución de las instituciones políticas, legales, sociales y económicas originadas como consecuencia de un "orden espontáneo" fruto de la interacción de grupos de agentes descentralizados y heterogéneos que cuentan con un conocimiento limitado. Resulta interesante ver refundidas estas dos corrientes de pensamiento económico que, si bien tienen orígenes y fundamentos bien distintos, se pueden reconducir para alinearlos y emplearlos en un fin común: el estudio de las instituciones como determinante del comportamiento de los agentes económicos y, en definitiva, del crecimiento y desarrollo económico.
} 
maximizar, lo que representa una de las ideas clave para el evolucionismo. En cuanto a Schumpeter, Nelson y Winter afirman que su propio enfoque bien podría ser llamado neo-schumpeteriano ${ }^{14}$. Schumpeter señaló el carácter evolutivo del capitalismo y enfatizó las fuerzas endógenas que subyacen detrás del proceso de desarrollo, definiendo un escenario donde hay coevolución de tecnologías e instituciones. Joseph Alois Schumpeter, define la concepción dinámica de un sistema económico como la fuerza motriz del pensamiento evolucionista. Sus aportaciones están enfocadas en términos de los cambios institucionales y tecnológicos como el centro de la evolución. Así mismo, en la teoría del emprendimiento recogida en su obra Teoría del Desarrollo Económico, considera al emprendedor como el ente innovador de las organizaciones (Schumpeter, 1911). En su libro Business Cycles (1939), Schumpeter resalta el impacto potencial que las innovaciones ejercen sobre el conjunto de la economía y, adicionalmente, postula la existencia de dos tipos de individuos: los empresarios innovadores que, incapaces de prever el futuro, están dispuestos a enfrentarse a todos los riesgos para llevar a cabo innovaciones, y los imitadores que, simplemente, actúan como gestores rutinarios, siguiendo el camino abierto por los heroicos pioneros (Freeman, 1998). Así mismo, Schumpeter aporta al contexto evolucionista el concepto de "destrucción creativa", refiriéndose a la constante innovación que da paso al surgimiento de nuevas empresas con mayor competitividad, desapareciendo así la estructura empresarial más rezagada en el tiempo. Sin embargo, el planteamiento de que la evolución económica tiene lugar en forma cíclica, indica que por los mismos avances tecnológicos presentados por las nuevas generaciones, se van alterando las anteriores condiciones con el propósito de imponer otras nuevas que reporten mayor valor agregado (Schumpeter, 1942).

Sin embargo, pese a las afinidades reconocidas, son múltiples los puntos en los cuales los autores evolucionistas van no sólo a refinar, sino a discutir

\footnotetext{
${ }^{14}$ Con Shumpeter se inicia la escuela schumpeteriana acogida en la Joseph A. Schumpeter Society que publica la revista Journal of Evolutionary Economics.
} 
varias de las ideas adelantadas por Schumpeter, como son la distinción entre invención, innovación y difusión; las relaciones de causalidad entre estructuras de mercado y actividad innovadora; las vinculaciones entre ciencia y tecnología; el cambiante carácter del proceso innovador a lo largo de la evolución capitalista; la existencia o no de "ciclos de onda larga" en el desarrollo capitalista, entre otras.

En 1950, Armen Alchian, volvió a llamar la atención sobre la necesidad de fundamentar la conducta de los agentes económicos en la biología y en la teoría de la evolución, lo que había quedado un tanto olvidado después de Marshall y Veblen. Alchian sugiere la modificación del análisis económico neoclásico con la incorporación de hechos tales como la información incompleta y la incertidumbre de los pronósticos, hechos que, por su parte, ponen en duda que las empresas persigan la maximización de las utilidades (funciones de producción para el caso), ya que esa conducta es posible solamente en un contexto de certeza sobre las consecuencias de las decisiones, una circunstancia que no se da en el mundo real. Asimismo describe el contexto en que se desenvuelven las empresas como cambiante, donde el éxito está asociado a la supervivencia, por lo que el objetivo de las corporaciones es tener resultados positivos. Es decir, evitar las pérdidas que implicarían su desaparición, en lugar de obtener la maximización de los resultados, lo que no es posible en un contexto de incertidumbre. Analiza la situación de las empresas en un mundo totalmente aleatorio, y seguramente algunas de ellas aparecerían como exitosas al sobrevivir, aunque no hubieran hecho nada para ello. (Alchian, 1950)

Ya en la década de los setenta, Daly (1974), Boulding (1974) y Wilson (1975), argumentaron que las interacciones entre individuos, instituciones y su entorno son esenciales para el cambio económico.

Tras esta larga trayectoria de antecedentes e influencias, el evolucionismo económico tuvo su manifestación teórica concreta en 1982 con el trabajo de Nelson y Winter An Evolutionary Theory of Economic Change. En este 
trabajo, Nelson y Winter proponen una nueva teoría para analizar los fenómenos asociados al cambio económico, en contraposición a la corriente ortodoxa. Para estos autores la teoría ortodoxa es deficiente, inadecuada y errónea para comprender los cambios económicos, ya que presenta una percepción alejada de los cambios sociales, económicos, tecnológicos e institucionales que se generan en el entorno, producto del desarrollo de nuevos conceptos e ideas que surgen en la sociedad. En este sentido, la teoría clásica, sostiene que la economía es un fenómeno estático en el que el mercado es quien actúa para encontrar un equilibrio. Los evolucionistas en cambio, afirman que la economía es un fenómeno dinámico y cambiante, debido a la influencia de diferentes factores como la innovación y la tecnología. No obstante, para los evolucionistas, la mutación no es un proceso aleatorio, tal como lo sugiere Darwin, sino que, por el contrario, obedece a la acción decidida de las empresas que, para adaptarse y desarrollarse en el mercado, llevan a cabo procesos de innovación. Según esta noción, aquéllas organizaciones que desarrollan mejores técnicas o aplican métodos de gestión superiores a los de sus competidores, ya sea a través de una mayor capacidad de aprendizaje y/o del desarrollo de nuevas tecnologías no sólo consiguen una mayor expansión, sino que también pueden modificar la estructura del sistema económico en el que operan (Nelson y Winter, 1982).

Así mismo en su Teoría Evolucionista de la Empresa, Nelson y Winter (1982) postulan que:

- Las empresas poseen las capacidades y las reglas de decisión.

- Las rutinas organizacionales son análogas a las habilidades individuales.

- La subsistencia de las empresas depende de su capacidad de innovar.

- La ventaja de la innovación se obtiene por el ajuste de las rutinas. 
- Las empresas están diferenciadas tecnológicamente, con distintas habilidades en el "know-how" y trayectorias tecnológicas específicas y con diferentes capacidades de aprendizaje y mecanismos de procesamiento de información.

\subsubsection{Temáticas en las que ha influido el evolucionismo}

La economía evolucionista ha influido, principalmente en las áreas relacionadas a la interpretación del cambio tecnológico y económico. En ese sentido, las áreas más desarrolladas y que están relacionadas con los intereses de la presente tesis son las siguientes:

1) La teoría evolucionista de la empresa: la empresa es vista como una estructura organizativa real compuesta por un conjunto interrelacionado de seres humanos, que posee activos acumulados de diverso tipo, principalmente en forma de conocimiento, motivaciones principales (Motta, 2004). Las empresas desarrollan rutinas y hábitos de comportamiento que constituyen el principal elemento de permanencia y herencia instalado en la memoria organizacional de la empresa, lo que significa una inercia relativa en su conducta. Las rutinas constituyen el comportamiento racional de la empresa, en el sentido de que las conductas y procedimientos son considerados apropiados y efectivos en el contexto en que son usados. Las rutinas son el resultado del proceso de aprendizaje histórico que las empresas han emprendido y representan lo que saben y pueden hacer. Es decir, la empresa es vista como un cúmulo de conocimiento, tanto codificado como tácito, que se crea y acumula en un proceso continuo. Los procesos de búsqueda y de aprendizaje constituyen el principio de variación y mutación de las rutinas, el elemento de permanencia en la conducta de la empresa. Es así como, sobre la base de su conocimiento acumulado y activos específicos, emprenden procesos de aprendizaje basados en sus 
competencias acumuladas como respuesta a motivaciones internas y como respuesta a oportunidades y presiones externas.

2) La naturaleza del cambio tecnológico a nivel microeconómico: el cambio tecnológico es un fenómeno endógeno al comportamiento de la empresa y no un desplazamiento paramétrico exógeno a su conducta, como lo es en la teoría ortodoxa.

3) Dinámica industrial y cambio tecnológico: Paradigmas y Trayectorias Tecnológicas. El cambio tecnológico en la teoría evolucionista es conceptualizado como endógeno a la dinámica industrial, a través del estudio de los paradigmas y trayectorias tecnológicas. Es decir, se postula que existen patrones regulares del avance del conocimiento tecnológico definidos por un paradigma tecnológico determinado, que representa la heurística y las concepciones particulares compartidas por un conjunto de empresas sobre la 'manera de hacer las cosas' y de mejorarlas. Es decir, define los problemas relevantes y los patrones de investigación y desarrollo en un sector determinado, condiciona las oportunidades para desarrollar innovaciones y define los procedimientos para explotarlas. La adopción de los paradigmas depende de la naturaleza e intereses de las instituciones, las aplicaciones económicas, los criterios de selección del mercado y otros factores institucionales.

4) Sistemas de Innovación: se reconoce que las capacidades de aprendizaje e innovación de una sociedad están enraizadas en la estructura social e institucional con que cuenta una nación y, por lo tanto, su evaluación y estudio resulta fundamental para explicar el potencial tecnológico de un país. La importancia atribuida a los Sistemas Nacionales de Innovación ${ }^{15}$ yace en el reconocimiento del rol del aprendizaje institucional y los modos de transformación social

\footnotetext{
${ }^{15}$ El término Sistema Nacional de Innovación (SIN) aparece por primera vez en una publicación en el libro de Freeman (1987) sobre la innovación en Japón, aunque el propio Freeman (1997) señala que el término fue propuesto inicialmente por Lundvall, como título de una serie de artículos que habían de recogerse en el apartado 5 del libro de Dosi et al. (1988), (Arancegui, 2001).
} 
en la adaptación y desarrollo de las practicas tecnológicoorganizacionales, y que el conjunto de oportunidades y capacidades tecnológicas que definen las distintas modalidades de la estructura productiva condicionan el potencial de dinamismo tecnológico de una nación y sus posibilidades de generar empleo.

5) Tramas productivas, innovación y empleo: una trama productiva se define como el conjunto de relaciones personales, económicas, tecnológicas, sociales, políticas y de intercambio de activos tangibles e intangibles que se establecen alrededor de uno o varios núcleos tecnológicos y el conjunto de sus proveedores y clientes en un ambiente social determinado. El conjunto de vínculos entre los agentes puede crear lenguajes y códigos colectivos que pueden facilitar los procesos de coordinación y mejorar la especialización y división de actividades al interior de la trama. De este modo, la trama se instituye como un espacio generador de competencias sistémicas, ventajas competitivas dinámicas y cuasi-rentas, que impactan sobre el nivel y la calidad del empleo que la trama puede generar.

6) Crecimiento y desarrollo económico: según López (1998), es posible establecer tres vertientes de teorías evolucionistas del crecimiento. Una primera, que intenta estudiar la relación entre los patrones de cambio tecnológico y patrones de crecimiento a partir del análisis de la interrelación y competencia entre un conjunto heterogéneo de agentes con distintas capacidades de innovación e imitación en un contexto de economía cerrada. Una segunda apunta a comprender la manera en que se relacionan los esquemas de comercio y crecimiento con las dinámicas de innovación a nivel nacional, a fin de procurar explicar la persistencia observada en los patrones de desarrollo a nivel internacional. Una tercera intenta combinar las dos líneas anteriores de investigación en modelos de simulación que integran la dinámica micro y macroeconómica, a fin de analizar los patrones de convergencia y divergencia de los niveles de renta a 
nivel internacional. La teoría evolucionista del crecimiento se caracteriza por el estudio de la coevolución de las distintas dimensiones de la realidad social, tales como el cambio tecnológico, la acumulación de capital, la evolución del comportamiento de las empresas y el sistema socio-institucional. De este modo, se concibe al crecimiento como un fenómeno que trasciende lo puramente cuantitativo y como un proceso multifacético, introduciendo en el análisis dimensiones cualitativas dejadas de lado por la teoría ortodoxa o tomadas como fijas.

\subsubsection{El emprendimiento desde la perspectiva evolucionista}

Tal como hemos visto, Nelson y Winter (1982) proponen interpretar la innovación como un proceso evolutivo, en el que a partir de un estado de la naturaleza dado, en el que existen y se reproducen un cierto número de individuos, se producen mutaciones que diversifican los tipos de individuos, desencadenando mecanismos de selección que conducen a la supervivencia de los individuos más aptos (Azagra-Caro, 2004). Así mismo, hemos visto que el evolucionismo se centra en las dinámicas endógenas como consecuencia de la emergencia persistente de innovaciones. Estas innovaciones, según Schumpeter son promovidas por el emprendedor, figura que constituye el elemento dinámico del capitalismo y siendo, a su vez, el impulsor del cambio. Para Schumpeter el emprendedor no es sólo el fundador de una nueva empresa, sino también un innovador que rompe con la forma tradicional de hacer las cosas y con las rutinas establecidas. Debe ser una persona con dotes de liderazgo, y con un talento especial para identificar el mejor modo de actuar. El emprendedor tiene la habilidad de ver las cosas como nadie más las ve, motivando el cambio desde dentro, en lugar de esperar que le venga dado desde el mercado (Schumpeter, 1934). En este sentido la teoría económica evolucionista, nos proporciona un marco en el que ubicar el concepto del emprendimiento desde un punto de vista schumpeteriano, es decir, no como el estudio de la creación o 
gestión de empresas, sino como el fenómeno generador de innovaciones y que hace que las mismas tengan éxito en el mercado promoviendo el desarrollo económico y social de los territorios. Es decir, en tanto en cuanto, uno de los pilares del evolucionismo económico se sustenta en el surgimiento endógeno de dinámicas debido a la persistencia de innovaciones, se justifica el estudio del emprendimiento y de la figura del emprendedor (como generador, impulsor y promotor de dichas innovaciones) en el marco de esta teoría.

Así, según Casson (1982) el emprendimiento está relacionado con la manera de afrontar y crear incertidumbre y complejidad. Desde un punto de vista económico, la esencia tradicional del emprendimiento es generar y abordar nuevas e innovadoras combinaciones de "factores de producción" y "formas de hacer las cosas", lo cual se puede enmarcar dentro de las bases de la teoría evolucionista comentada en los epígrafes anteriores.

Por otra parte, la noción schumpeteriana de "destrucción creativa" que, según hemos visto, lleva a la innovación y renovación y se manifiesta en entornos de trabajo inciertos y complejos. Estos entornos de trabajo dinámicos y con altos niveles de cambio, emergen y exigen, por tanto, de la iniciativa emprendedora. Schumpeter considera los procesos de innovación como el motor del desarrollo socioeconómico, situando al emprendimiento como herramienta clave para fomentar y generar dichos procesos. De acuerdo con este autor una innovación consiste en la utilización productiva de un invento. En este sentido, existen cinco posibles tipos de innovaciones: (1) Introducción de nuevos bienes o de bienes de nueva calidad. (2) Introducción de un nuevo método productivo, ya existente en un sector, que no deriva de algún descubrimiento científico. (3) Apertura de un nuevo mercado. (4) Conquista de nuevas fuentes de oferta de materias primas. (5) Establecimiento de una nueva organización en una determinada industria (Schumpeter, 1934).

A la luz de los argumentos esgrimidos por la teoría evolucionista, en parte derivada del pensamiento schumpeteriano, resulta plausible que deseemos 
enmarcar el estudio del emprendimiento como motor del desarrollo socioeconómico, en la teoría económica evolucionista.

\subsubsection{Evolucionismo e Institucionalismo: coexistencia y convergencia en economía.}

Tal como hemos visto a lo largo de los epígrafes anteriores, el evolucionismo económico surge como crítica a la estática de la teoría económica ortodoxa. Así mismo, el origen de la teoría económica institucional podemos situarlo en la crítica a la teoría ortodoxa, su estática y al individuo racional de ésta ${ }^{16}$. Así pues podemos encontrar cierta convergencia en los inicios de ambas teorías. En este sentido, por ejemplo, el énfasis institucional sobre la rutina y el hábito encaja muy bien con los modelos de evolución desarrollados por Nelson y Winter (1982) y sus seguidores. Como el mismo Veblen (1899) sugirió, el paradigma evolutivo provee las bases para sintetizar tanto la continuidad como el cambio; la inercia y la novedad. Hábitos o rutinas se adaptan lentamente o se transforman conforme los agentes intentan mejorar sus propósitos. Adicionalmente existe un proceso de selección por el cual algunos hábitos y rutinas son retenidos e imitados, y otros quedan fuera de uso. El institucionalismo es congénitamente, por tanto, una "economía evolucionista".

Esta convergencia se hace evidente en los trabajos tardíos de Hayek (1988) y los recientes escritos de North (1990) en los que los orígenes y el desarrollo de las organizaciones e instituciones se ven como un proceso evolucionista

\footnotetext{
${ }^{16} \mathrm{El}$ uso de los términos institución y agente se puede considerar como indistinto. Existen diferentes ideas sobre lo que se debe entender por instituciones, algunas de las cuales emanan de la tradición germana que data de 1830, con Max Weber como uno de sus máximos representantes y que deriva hacia la Vieja Escuela Institucional Americana con autores como Thorstein Veblen, John Commons o Wesley Mitchell. Ambas ofrecen una interpretación de la idea de institución desde un solo ámbito, considerándola más como restricciones que sirven para delimitar un marco de intercambio, siendo la máxima expresión de ese marco el mercado. Por contra, interpretaciones más abiertas que constituyen la corriente de la Nueva Economía Institucional, plantean el término institución como aquello que "moldea y define las interacciones humanas" (Nelson y Nelson, 2002). No hay que perder de vista que la interpretación que buscan a este término es siempre bajo las lentes de la Teoría Económica Neoclásica.
} 
La teoría económica institucional considera que los individuos tienen racionalidad limitada, caracterizada por la incertidumbre y la falta de información en el proceso dinámico de relaciones humanas. Según los institucionalistas, el comportamiento de las personas está condicionado en gran medida por el entorno institucional. Dicho entorno institucional establece la estructura en la cual se desarrolla la interacción humana, ejerciendo influencia sobre la toma de decisiones de las personas, limitando o guiando las alternativas seleccionadas. A grandes rasgos, el enfoque institucional plantea que la sociedad contemporánea es un complejo de instituciones o formas habituales para organizar y regular la conducta de los individuos. En cierto modo, el desarrollo de las instituciones es un proceso competitivo, y su resultado determina qué formas de conducta son aceptadas y aprobadas por la comunidad. En un momento dado, la conducta de los individuos o grupos se desarrolla dentro de unos límites establecidos por la costumbre o por la ley (Homan, 1971). Así pues, no sólo las instituciones económicas, sino también las instituciones sociales y políticas tienen importancia en la determinación del comportamiento de las personas y en el desempeño económico.

En este sentido, proponemos como continuación al estudio del emprendimiento dentro de la teoría económica evolucionista, el institucionalismo económico como marco para el estudio del emprendimiento y, más concretamente de los factores determinantes del emprendimiento y sus aportaciones al desarrollo económico y social de los territorios.

\subsubsection{Teoría Económica Institucional}

La Teoría económica institucional se centra en la comprensión del papel del proceso evolutivo y las instituciones sociales en la formación del comportamiento económico. Esta teoría emplea el concepto "institución" de una manera muy amplia, entendiendo como tal cualquier fuerza o factor ideado por el hombre para configurar o guiar la interacción y el 
comportamiento humanos (Veciana, 1999). Las instituciones así entendidas constituyen las normas y reglas restrictivas que rigen en la sociedad, condicionando y dirigiendo el marco de relaciones que se producen en ella afectando, por tanto, al desempeño económico (Diaz et al, 2005).

Según Atkins (1932) podemos resumir los postulados del institucionalismo en cinco puntos:

1. El análisis económico debe centrarse en los comportamientos de grupo y no en los precios

2. Se debe poner más atención a las regularidades de las costumbres, hábitos y leyes en tanto que organizan la vida económica

3. Los individuos se ven influidos por motivaciones que no pueden ser medidas cuantitativamente

4. El comportamiento económico evoluciona constantemente y, en consecuencia, las generalizaciones económicas no deben dejar de especificar el tiempo y lugar al que se aplican

5. Es tarea del economista estudiar las fuentes de los conflictos de intereses en la estructura social existente, y este estudio forma parte del sujeto, el conflicto no es solamente una divergencia en relación a una norma hipotética.

\subsubsection{Evolución de la teoría económica institucional}

El pensamiento económico institucional se origina como una escuela de pensamiento estadounidense derivada de las obras de Thorstein Veblen, principalmente de The theory of the leisure class y The Theory of Business Enterprise (1904). Según Gruchy (1972) podemos distinguir entre dos generaciones de autores institucionales, los clásicos o de primera generación y los neoinstitucionales. Los autores institucionalistas clásicos (integrados además de Veblen, por John Commons, John Clark, Wesley Mitchell y John Hobson) conciben el sistema económico como parte del entramado institucional integrante de la cultura humana que determina el comportamiento en sociedad. No obstante, la economía institucional tomó 
varios caminos divergentes después de la obra de Veblen. Commons la enfocó hacia un programa para la reforma social, principalmente legislativa. Clark intentó aproximarse a la cara más social de la economía. Mitchell le añadió un componente cuantitativo y estadístico, mientras que Hobson se centró en los aspectos éticos del comportamiento económico. La primera generación de institucionalistas compartió sin embargo el interés por el análisis de las instituciones, su evolución y el cambio institucional, así como la preocupación por el estudio de los problemas sociales y económicos desde una perspectiva crítica y de reforma social (Urbano et al., 2007).

A mediados del siglo XX surge la corriente neoinstitucionalista, con autores como Clarence Ayres, Gunnar Myrdal y John Galbraith que dieron un importante impulso a la teoría institucional, considerando el sistema de valores de la cultura como guía de la economía (Veciana, 1999). Estos autores se orientan hacia la política centrándose en la problemática del capitalismo dirigido. Según estos autores, el avance de la economía permite una planificación eficaz que toma además en consideración el problema de los valores de la cultura (Valdés, 1996). Así, los autores neoinstitucionalistas se preocuparon, al igual que sus predecesores de la primera generación, por conseguir mejoras sociales aunque referidos a problemas distintos (como consecuencia de las diferentes épocas en las que vivieron), tales como los desequilibrios económicos y sociales así como la pobreza en zonas menos desarrolladas (Urbano et al, 2007).

A partir de la década de los ochenta, surge lo que algunos autores denominan nueva economía institucional (Dugger, 1990; Rutherford, 2001), en la que podemos ubicar a Williamson (1975) en el campo de la economía de las organizaciones, y a North (1990) en el ámbito de la teoría económica contemplando la historia como un proceso de evolución de las instituciones. North plantea que "las instituciones son las reglas de juego en una sociedad 0 , expresado más formalmente, las instituciones serían las limitaciones ideadas por las personas que dan forma a la interacción humana". Según North, las instituciones son los determinantes 
fundamentales del desempeño económico en el largo plazo. Este autor distingue entre instituciones formales e informales y analiza el modo en que éstas se aplican y evolucionan. Las instituciones formales comprenden las leyes, los reglamentos y los procedimientos gubernamentales, mientras que las informales incluyen las ideas, las creencias, las actitudes y los valores de las personas, o sea la cultura de una sociedad determinada (Urbano et al, 2007).

\subsubsection{Aplicación de la Economía Institucional al estudio del Emprendimiento}

Según Veciana “(...) la decisión de convertirse en empresario y, por tanto, la creación de nuevas empresas, está condicionada por factores externos o del entorno. Es decir, son los factores socioculturales o el marco institucional el que determina el espíritu empresarial y la creación de empresas en un determinado momento y lugar" (Veciana, 1999).

La actividad emprendedora no es el resultado de un cálculo frío de corte economicista y mucho menos de un acto espontáneo sin antecedentes causales. Si bien es un acto creativo de corte individual, la decisión se fundamenta en juicios que tienen vinculación con reglas morales y éticas (Robinson et al, 2003; Anderson y Smith, 2007), dentro de una estructura social en la que el sistema normativo de valores, influencia los comportamientos sociales (Begley y Tan, 2001).

Por otra parte, según Baumol (1990) y más recientemente Acs (2010), el emprendimiento puede ser productivo, improductivo o destructivo para la sociedad. El emprendimiento improductivo y destructivo varía entre diferentes países con el mismo nivel de desarrollo, como consecuencia de la cultura inherente en cada sociedad y su marco institucional.

Estas observaciones nos permiten enlazar con la teoría económica institucional (North, 1990, 2005) y su aplicación al análisis del emprendimiento. 
Concretamente, en el ámbito del emprendimiento, las instituciones (tanto formales como informales) pueden contraer o fomentar la creación de empresas (Álvarez y Urbano, 2011). Desde este punto de vista, muchos han sido los académicos que han propuesto el estudio del emprendimiento a través de la teoría institucionalista (Aidis et al, 2008; Alvarez, et al, 2011; Salimath and Cullen, 2010; Stephen, et al, 2005, 2009; Thornton, et al, 2011; Veciana y Urbano, 2008; entre otros). En este sentido, Gnyawali y Fogel (1994) estudian las condiciones del entorno en relación con el emprendimiento y proponen cinco dimensiones: (1) las políticas gubernamentales y los procedimientos, (2) factores socioeconómicos, (3) habilidades empresariales y de negocios, (4) apoyo financiero a las empresas, y (5) apoyo no financiero. Álvarez y Urbano (2011) distribuyeron estas dimensiones entre instituciones formales e informales según la teoría de North ${ }^{17}$, identificando los factores socioeconómicos con las instituciones informales y el resto de dimensiones con las formales.

Sin embargo, nuestro trabajo no se centra en el emprendimiento como sinónimo de creación de empresas, sino que lo considera como un fenómeno más amplio. El emprendimiento "abarca o engloba actos de innovación, renovación o creación organizacional que ocurren dentro o fuera de una organización existente" (Sharma y Chrisman, 1999). Este emprendimiento resulta en la creación de una nueva empresa o en nuevas actividades dentro de las organizaciones ya existentes, denominado emprendimiento corporativo (Burgelman, 1983).

La teoría institucional proporciona un marco teórico adecuado para el enfoque de las acciones emprendedoras, tanto las que derivan en creación de nuevas empresas como la que se llevan a cabo por parte de las organizaciones ya existentes (Bruton y et al., 2010), ya que ayuda a entender y tratar las diferentes formas de interacción, formales e informales, en el marco general de unas reglas del juego establecidas que

\footnotetext{
${ }^{17}$ En su obra Instituciones, cambio institucional y desempeño económico, North (1990) modifica los supuestos neoclásicos sobre la conducta de los individuos, destaca el papel de las instituciones informales, estudia los procesos de cambio institucional y desarrolla el concepto de "dependencia de la trayectoria"
} 
influyen en el desarrollo económico y en la actividad organizativa. Así pues, consideramos que el emprendimiento corporativo también debe ser considerado y estudiado para entender la contribución del emprendimiento al desarrollo económico y social de los territorios. Así, La teoría institucional se centra en los aspectos del contexto en el que están inmersas las organizaciones, haciendo hincapié en el conjunto de valores, normas o creencias que actúan como mitos racionales guiando el comportamiento de las organizaciones (Meyer y Rowan, 1977). Por tanto, la teoría institucional intenta aumentar el conocimiento sobre las relaciones sociales que establece la organización con otras organizaciones y con las instituciones con las que coexiste, señalando como factores de éxito la conformidad con las reglas y normas institucionales (DiMaggio y Powell, 1983; Meyer y Rowan, 1977; Tolbert y Zucker, 1996).

Por otra parte, la teoría institucional de North postula que las organizaciones u organismos están constituidos "por grupos de individuos unidos por un propósito común con el fin de lograr ciertos objetivos. Entre éstas, se incluyen las políticas, las económicas, las sociales y las educativas" (North, 1993). De esta manera, las organizaciones y sus individuos (entre los que se encuentran los emprendedores) participan, entre otras, en actividades políticas, económicas, sociales y educativas, siendo estos agentes los que dirigen el cambio institucional.

La teoría institucional ha demostrado ser un modelo teórico válido en la exploración de una amplia variedad de temas que van desde el institucionalismo económico y políticas sociales a la teoría de la organización (DiMaggio y Powell, 1991). El entorno institucional es cada vez más dinámico y cambiante, ejerciendo una presión sobre las organizaciones para que se adapten a las nuevas situaciones (Hoffmann, 1999; Kraatz y Moore, 2002), lo que demuestra su utilidad a la hora de investigar temas relacionados con el emprendimiento (Bruton y otros, 2010). 
Así pues, para los intereses de nuestro trabajo, la teoría institucional nos permite abordar el estudio del emprendimiento desde diferentes perspectivas. Por un lado, desde la perspectiva de las instituciones (tanto formales como informales) como marco en el que el emprendimiento juega un papel crucial en el desarrollo económico y, por otro, desde el punto de vista de las organizaciones y agentes implicados (entre los que encontramos a los emprendedores) como catalizadores del cambio institucional.

Haciendo una revisión sobre cómo la literatura ha tratado el emprendimiento desde la perspectiva institucionalista, este análisis se ha realizado de forma fragmentada y descriptiva (Urbano, 2006, Urbano y otros, 2007). Así podemos encontrar en la literatura diferentes líneas de trabajo empleadas por los investigadores en el análisis del entorno institucional y el emprendimiento.

La primera, cuyo origen se sitúa en los trabajos de Busenitz y otros (2000), analiza en diferentes países los perfiles institucionales de diferentes países de cara al emprendimiento. Este análisis, realizado a través de la diferenciación entre instituciones reguladoras, normativas y cognitivas de Scott (1995), clasifica los diferentes perfiles a través de una análisis sobre la existencia de programas de apoyo, de esquemas cognitivos compartidos y de una cultura innovadora en la sociedad (Gray y Cuevas, 2005; Manolova y otros, 2008). Su principal limitación se basa en centrarse únicamente en analizar el perfil del país sin detenerse en el posterior desarrollo emprendedor.

Una segunda línea de investigación utiliza el institucionalismo económico de North (1990) como factor condicionante de la creación de empresas. Esta línea ha resaltado la importancia del enfoque institucional como factor condicionante para el deseo y la intención de crear una nueva empresa (Stephen y otros, 2005; Urbano y otros, 2007; Veciana, 1999). 
El tercer enfoque se basa en el empleo de la teoría institucional para analizar los factores que condicionan las distintas estrategias de internacionalización de las empresas, analizando cómo la existencia de diferentes entornos institucionales influyen en las posibles estrategias de entrada en nuevos mercados y países o en la creación de nuevas empresas (Capelleras y otros, 2008; Child y Tsai, 2005; Yiu y Makino, 2002). Sin embargo, este análisis ha sido realizado teniendo en cuenta casi de forma exclusiva el entorno formal o regulador, a través de las reglas y las normativas existentes en cada país, y no otras dimensiones de interés en el marco de la teoría institucional.

Como hemos visto a lo largo de este epígrafe, la teoría institucional proporciona un marco teórico tanto para el emprendimiento como para las interacciones y relaciones sociales entre los agentes y las instituciones con objeto de alcanzar un mayor desarrollo económico. En nuestra tesis, estudiamos el emprendimiento como una de las herramientas clave para este desarrollo económico, lo que nos lleva a estudiar, en el siguiente epígrafe el papel del emprendimiento en los sistemas de innovación. Asimismo, otra de las importantes motivaciones que nos lleva a prestar especial atención a esta corriente del pensamiento económico radica en la vinculación que se puede establecer entre el Institucionalismo norteamericano que hemos descrito y el estructuralismo latinoamericano. Así, el economista de gran reconocimiento mundial, el brasileño Celso Furtado establece claros patrones de conducta emprendedora en su descripción del "homo economicus" latinoamericano (Mallorquín, 2001), generando una explicación al comportamiento de las estructuras económicas latinoamericanas basada en el institucionalismo y propiciando así la investigación en el incómodo espacio que existe entre la Economía y la Sociología. 


\subsection{El Emprendimiento en los Sistemas de Innovación}

El reconocimiento del componente institucional como una variable clave para explicar los procesos de cambio tecnológico y su impacto en el desarrollo económico constituye una de las principales aportaciones de los economistas evolucionistas y es, al mismo tiempo, uno de los aspectos que los neo-schumpeterianos han echado en falta en la obra de Schumpeter. A partir del análisis de este elemento, se ha desarrollado toda una línea de pensamiento, que tiene como uno de sus enfoques más representativos el relacionado con los Sistemas de Innovación (SI).

La aparición del enfoque de Sistema Nacional de Innovación (SNI) tiene su origen en la década de los 60, en los primeros debates de la OCDE sobre la teoría de sistemas (Godin, 2009). Posteriormente Freeman (1982) y Lundvall (1992) en Europa, y Nelson (1993) en Estados Unidos, desarrollaron una aproximación teórica a este enfoque. El enfoque de SI integra algunos de los elementos más característicos de la corriente evolucionista y aborda el análisis de aspectos poco tratados en los planteamientos neoclásicos tradicionales. La consideración de la innovación como un proceso dinámico y social basado en el aprendizaje y en la interacción (y su reconocimiento) entre los diversos agentes, así como el reconocimiento del carácter endógeno del cambio tecnológico y la capacidad del propio sistema económico para controlarlo y dirigirlo, son algunas de las características fundamentales de este enfoque. De dichas características, se deriva una relación de causalidad mutua entre las instituciones, la economía y la tecnología que está más acorde con la complejidad inherente a los procesos de innovación.

No obstante, las definiciones de estos autores (Freeman, Lundvall y Nelson) recogen matices diferentes. Así, mientras los enfoques de Freeman y Nelson están más orientados a la tecnología, Lundvall destaca que la clave de la innovación es el proceso de aprendizaje a través de la adaptación de los conocimientos existentes a las necesidades locales y específicas. Por otra parte, Nelson y sus colegas centraron su análisis en el 
papel de las empresas privadas, las universidades y el gobierno dentro del sistema, es decir, destacaron las capacidades tecnológicas mediante la inclusión únicamente de las organizaciones e instituciones que realmente influyen en el sistema.

De acuerdo con Jiménez-Sáez (2004), el concepto de SI considera el reconocimiento de las relaciones como la clave del estudio y análisis de la generación de conocimiento, su difusión en la economía y su aprovechamiento para impulsar el desarrollo económico de un determinado territorio.

Entre los estudiosos de los SI existen dos corrientes de pensamiento. Por un lado la de aquellos autores que abogan por una concepción simplificada del concepto (e.g. Freeman, Nelson, Lundvall), mientras que en el otro extremo se encuentran los autores que ponen un mayor énfasis en las complejidades internas del sistema (e.g. Patel y Pavitt, Metcalfe y Edquist). Así, podemos indicar que mientras los primeros entienden el sistema como aquel conjunto de actores (públicos y/o privados) y las relaciones existentes entre ellos, los segundos amplían los elementos constituyentes de dicho sistema, poniendo un mayor énfasis sobre el aspecto institucional y el papel que las políticas públicas pueden desempeñar en dicho sistema. Es decir, existen dos visiones, una centrada en los actores y una segunda centrada en el papel que las instituciones desempeñan dentro de dicho sistema.

El enfoque de los SI ha generado derivadas en los planteamientos complementarios centrados en los niveles regionales y sectoriales. Así, el enfoque de Sistema Regional de Innovación es una adaptación geográfica de la perspectiva de Sistema Nacional de Innovación (Cooke, 1992; Cooke et al, 1997; Braczyk et al, 1998; Autio, 1998; de la Mothe y Paquet, 1998; Doloreaux y Parto, 2005). Esta adaptación se produjo como una manera de captar las peculiaridades de diferentes lugares, aunque pertenezcan al mismo país.

Por otra parte, los autores que emplean un enfoque sectorial del SI han hecho hincapié en las características específicas de la innovación en los 
diferentes sectores, independientemente de su ubicación territorial (Breschi y Malerba, 1997). En este sentido resulta especialmente interesante para nuestro estudio las conclusiones de Malerba (2004) respecto a los sistemas sectoriales de innovación. Este autor, presta especial atención al conocimiento y su estructura considerando que la base de conocimiento es diferente en cada sector, lo que afectará a las actividades de innovación, la organización y al comportamiento de sus agentes. Malerba centra igualmente su idea en los procesos de generación de conocimiento, competencias, comportamiento y organización. Otro aspecto en el que Malerba hace especial hincapié, y que resulta de interés en nuestro trabajo, es el papel que las instituciones no empresariales tales como universidades, gobiernos $e$ instituciones financieras tienen en el establecimiento de las reglas de juego del SI, influyendo sobre los procesos de innovación y las actividades productivas de las empresas.

Con todo ello, las universidades, como centros de formación e investigación, se erigen como agentes clave en los SI. Desde nuestro punto de vista, el papel de la Universidad dentro del SI no se centra únicamente en la generación de nuevo conocimiento como resultado de la investigación, sino también como institución que contribuye a que se formen otros de los agentes del sistema. Esto le confiere un papel privilegiado y de responsabilidad desde el que se espera pueda catalizar el cambio cultural, a veces tan necesario, para dar el salto de un nivel de desarrollo determinado a otro superior. Es en este contexto en el que el emprendimiento, tal y como lo definimos en este trabajo, cobra importancia como catalizador de los procesos de innovación en los SI. Igualmente, las organizaciones emprendedoras, entre las que se pueden encontrar las propias universidades, como veremos en el siguiente capítulo, serán algunos de los agentes clave de los procesos de Innovación en los SI.

Para entender estos procesos y el papel que juega el emprendimiento y el emprendedor como agente en los SI, debemos conocer los modelos que permiten analizar dichos sistemas. En un sentido amplio, encontramos en 
la literatura dos modelos diferenciados: el Science-Technology-Innovation model (STI), que hace hincapié en las actividades de investigación y desarrollo como fuente de innovación; y el Doing-Using-Interacting model (DUI) que se inspira en una visión más amplia de la innovación, basada principalmente en las relaciones cliente-proveedor (Jensen et al., 2007). En el caso concreto de nuestro trabajo, nos basaremos en el modelo de los entornos de Fernández de Lucio y Castro (1995), basado fundamentalmente en el DUI. Como se muestra en la Figura 1, este modelo divide al $\mathrm{SI}$ en cuatro entornos que agrupan a los agentes con características similares. Así, el entorno productivo agrupa a las empresas productoras de bienes y servicios; el entorno científico que agrupa a los centros públicos y privados de investigación (entre los que se encuentran las universidades); el entorno financiero que recoge tanto a las entidades financieras como a las administraciones públicas en su papel financiador de la I+D; y el entorno tecnológico que reúne a centros e institutos tecnológicos, empresas de consultoría, ingeniería y de servicios avanzados. Una de las principales aportaciones de este modelo son las denominadas "Estructuras de Interfaz". Estas estructuras, si bien no son elementos activos de los procesos de innovación, ayudan a poner en comunicación a los agentes de los diferentes entornos. Como veremos a lo largo de este trabajo, los programas de emprendimiento, se consideran estructuras de interfaz, lo que les confiere un papel específico dentro del SI. Igualmente el modelo presenta las relaciones que deben darse entre los diferentes agentes. 
Figura 1: Modelo de Sistema de Innovación

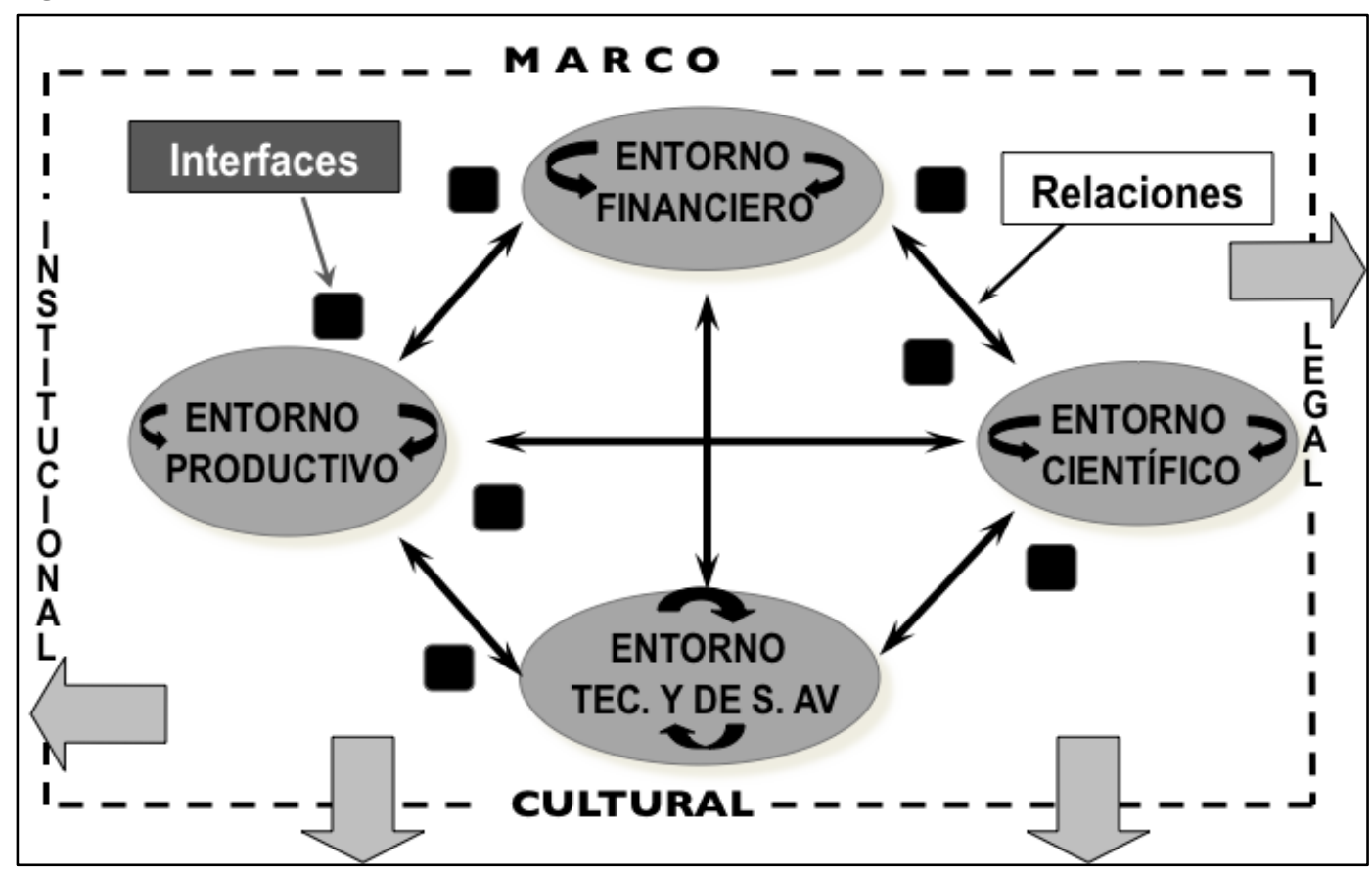

Fuente: Fernández de Lucio y Castro (1995)

En definitiva, este marco conceptual resulta muy "confortable" para poder dar cabida al estudio y análisis del papel que desempeñan las universidades como agentes que propician y promocionan los comportamientos emprendedores, contribuyendo así al desarrollo socioeconómico del territorio. 


\section{Capítulo 3. Marco Empírico}

Un detallado conocimiento y la comprensión del papel que las universidades emprendedoras con sus Programas de Apoyo al Emprendimiento (PAE) desempeñan en los procesos de desarrollo económico y social, requiere de un marco que contemple, por un lado, el tratamiento del emprendimiento por los respectivos gobiernos de ámbito local, nacional e incluso supranacional (si es el caso que les afecte) y, por otro, del estudio y análisis de la manera en que dichos gobiernos han contribuido a fomentar (o, a veces, contener) el desarrollo, tanto de universidades emprendedoras como de actividades relacionadas con el emprendimiento en su concepto más amplio. Para el caso que nos ocupa, la Universidad Española y, más concretamente, el caso de la Universidad 
Politécnica de Valencia, procederemos pues a analizar cómo se han ido gestando las diferentes políticas referentes al emprendimiento, tanto en Europa como en España y la Comunidad Valenciana. Éste será el aspecto tratado en el primer punto de este marco empírico. Para el análisis de caso español, nos detenemos especialmente en la Ley 14/2013, de 27 de septiembre de apoyo a los emprendedores y su internacionalización. Así mismo, presentamos un caso opuesto al español en cuanto a la gestión y aplicación de políticas de emprendimiento se refiere, con el objetivo de mostrar cómo las diferencias en la gestación y promoción política genera diferencias en los resultados que se alcanzan. Nos referimos al caso de la región de Twente, situada en el este de los Países Bajos.

La universidad emprendedora y su papel en el desarrollo económico y social de los territorios, representa el siguiente epígrafe de este capítulo. Más allá de describir las características propias de estas instituciones, proponemos un estudio centrado no sólo en la universidad emprendedora, sino en la universidad como organización emprendedora, con todos los matices que ello conlleva y que iremos desgranando en este segundo epígrafe. Con objeto de ofrecer claridad al lector sobre algunos términos que no siempre se emplean con total conocimiento de su significado, ofrecemos unas definiciones previas relativas a los términos Start-up, Spinoff y Empresa de Base Tecnológica (EBT). Aunque este tipo de discusión se puede considerar más de tipo teórico que empírico, la razón de ubicarlo en el presente capítulo de la tesis reside en que dichos términos surgen precisamente de la práctica y que su empleo inicial está asociado a la aparición de diferentes tipos de negocios a los que, con posterioridad, se les ha ido dando estas denominaciones, junto con una caracterización, por parte de los estudiosos del emprendimiento.

Dentro de las universidades emprendedoras, nos centramos en los servicios innovadores en dichas universidades, y más concretamente en los Programas de Apoyo al Emprendimiento (PAE), que representarán el centro de nuestro análisis. En dicho epígrafe proponemos el análisis de 
dichos servicios desde una perspectiva similar al de las universidades emprendedoras. Es decir equiparando las características que deben tener estos servicios a los de una universidad emprendedora, teniendo además en cuenta las características propias de los servicios innovadores según la literatura. Ello nos permitirá perfilar cómo se debe gestionar este tipo de servicios.

Por último, aportamos algunas reflexiones respecto al emprendimiento en los distintos aspectos tratados en el marco empírico y cómo influirán en nuestro posterior estudio de la Universidad Politécnica de Valencia.

\subsection{El emprendimiento en las políticas Europeas}

Como hemos indicado anteriormente, comenzamos por el análisis del contexto europeo pues es el terreno que afecta al estudio que aquí se presenta. Sin menoscabo de que en otros lugares, el fomento e impulso político ofrecido a esta actividad se haya producido de una manera diferente, consideramos que el caso europeo resulta especialmente interesante para el análisis y posterior valoración del caso concreto de la Universidad Politécnica de Valencia por una razón claramente geográfica.

El fomento del emprendimiento es un tema que desde el último cuarto del siglo XX, viene preocupando a los políticos de Europa. Este interés se desencadenó cuando los cambios estructurales de la economía desplazaron la ventaja comparativa europea desde las grandes empresas industriales a las actividades basadas en el conocimiento. En definitiva, al comienzo del siglo XXI, Europa necesita fomentar el dinamismo empresarial de un modo más eficaz. Necesita más negocios nuevos y prósperos que deseen beneficiarse de la apertura del mercado y embarcarse en empresas creativas o innovadoras de explotación comercial a mayor escala (European Commission, 2003). En este contexto, en 1997 se creó el grupo BEST (Business Environment Simplification Task Force), con el objetivo de preparar un informe independiente sobre las maneras de perfeccionar la legislación y eliminar los obstáculos innecesarios al 
desarrollo de las empresas europeas, en especial las PYME. Las recomendaciones que el grupo BEST dirigió en 1998 a la Comisión Europea sentaron las bases del «Plan de acción para promover el espíritu empresarial y la competitividad», aprobado el 29 de abril de 1999 (Comisión Europea, 2001). Este Plan se centraba en los siguientes ámbitos prioritarios:

- Educación para una sociedad con espíritu empresarial y formación,

- Acceso a la financiación,

- Acceso a la investigación y la innovación,

- Mejora de la difusión de los servicios de apoyo,

- Mejora de la administración pública

- Mejora del empleo y las condiciones de trabajo.

En otro ámbito, pero también relacionado con el emprendimiento, en 2000, el Consejo Europeo de Lisboa definió sus objetivos en cuestión de empleo, reforma económica y cohesión social. El objetivo central de la Agenda de Lisboa para 2010, era “convertir a la Unión Europea en la economía basada en el conocimiento más competitiva y dinámica del mundo, capaz de crecer económicamente de manera sostenible con más y mejores empleos y con mayor cohesión social". El Consejo reconoció la necesidad de una transformación radical de la economía, con el fin de crear unos 15 millones de nuevos puestos de trabajo para 2010. Para alcanzar estos objetivos es indispensable contar con un entorno favorable. En Junio de 2000, el Consejo adoptó la Carta Europea de las pequeñas empresas, en la que se establecen recomendaciones para que las pequeñas empresas aprovechen plenamente la economía del conocimiento. La Carta cubre diez áreas clave:

1. Educación y formación en el espíritu empresarial

2. Aceleración y abaratamiento de la puesta en marcha de empresas

3. Mejora de la legislación y la reglamentación

4. Disponibilidad de habilidades

5. Mejora del acceso en línea

6. Mejor aprovechamiento del mercado único 
7. Fiscalidad y cuestiones financieras

8. Promoción de la capacidad tecnológica de las pequeñas empresas

9. Uso de modelos de empresa electrónica próspera y apoyo de alto nivel a la pequeña empresa

10. Desarrollo de una representación más fuerte y eficaz de los intereses de las pequeñas empresas a escala comunitaria y nacional.

En 2003, la Comisión Europea publica el Libro Verde del Espíritu Emprendedor en Europa, que pone el acento en incentivar las inversiones, los empleos y el crecimiento a través del conocimiento, la innovación y el dinamismo en los negocios. El Libro Verde define el espíritu emprendedor como pluridimensional $\mathrm{y}$, aunque puede estar presente en diferentes contextos (económicos y no económicos), y en cualquier tipo de organización, se centra en el espíritu emprendedor en el contexto empresarial. En este trabajo, la Comisión Europea se plantea las directrices estratégicas para el fomento del Emprendimiento en Europa:

a. Enfoque coordinado de la política de fomento del emprendimiento

i. Coordinación de la política de fomento del emprendimiento entre todos los responsables políticos

ii. Aprender de los mejores

b. Tres pilares de acción para una sociedad empresarial

i. Derribar las barreras al crecimiento y el desarrollo empresarial

ii. Equilibrar los riesgos y las recompensas de la iniciativa empresarial

iii. Una sociedad que valora la iniciativa empresarial

Como ejemplo de coordinación de la política de fomento del emprendimiento entre los responsables políticos, el Libro Verde pone de manifiesto las buenas prácticas llevadas a cabo en este sentido en los Países Bajos y que trataremos más adelante. 
En junio de 2008, como continuación a la Carta Europea de la Pequeña Empresa, la Comisión presenta la Ley de la Pequeña Empresa (Small Business Act-SBA). El objetivo de la SBA es crear un nuevo marco político que integre todos los instrumentos existentes y desarrollar los contenidos de la "Carta Europea de la Pequeña Empresa», así como de la Comunicación «Una política moderna de la PYME para el crecimiento y el empleo». La SBA pretende mejorar el enfoque integral del emprendimiento en la UE aplicando la máxima "pensar primero a pequeña escala». Su objetivo es incidir en la elaboración de políticas de regulación de los servicios públicos, y promover el crecimiento de las PYME ayudándolas a afrontar los problemas que siguen obstaculizando su desarrollo.

En 2013, la Comisión presenta el Plan de Acción sobre Emprendimiento 2020. El Plan de Acción se presenta como un modelo de acción decisiva para liberar el potencial emprendedor de Europa y para eliminar los obstáculos existentes y revolucionar la cultura del emprendimiento en Europa.

El Plan de Acción del Espíritu Empresarial 2020 se basa en tres pilares principales:

- La educación y la formación empresarial

- Creación de un entorno donde los empresarios puedan florecer y crecer

- El desarrollo de modelos a seguir y llegar a grupos específicos cuyo potencial emprendedor no está siendo aprovechado en toda su extensión o que no se alcanzan por el método tradicional de apoyo a las empresas.

El plan de acción y sus acciones clave serán objeto de seguimiento por la Comisión a través de la competitividad y la política industrial y los mecanismos de gobernanza de la Ley de la Pequeña Empresa (SBA).

Este largo camino recorrido por la Unión Europea en materia de emprendimiento ha marcado, como no podía ser de otro modo, las políticas 
y acciones legislativas de los gobiernos de los países miembros. En este trabajo estudiaremos el caso español y, como contrapunto, el caso holandés.

\subsubsection{Políticas de Emprendimiento en España}

En el caso español el fomento del emprendimiento no ha gozado de un marco común, sino que se ha incorporado esta acción como un aspecto más a tratar dentro de los diferentes ámbitos de actuación pública, sea en el desarrollo local, educativo, laboral o industrial, y lo ha hecho también desde los diferentes estamentos político-administrativos de carácter territorial o institucional (Pérez Camarero et al, 2009). En el ámbito educativo, España asumió a partir del Consejo Europeo de Lisboa de 2000 el compromiso de promover el espíritu emprendedor en su sistema educativo. Tanto la Ley Orgánica de Calidad de la Educación (LOCE) de 2002, como la Ley Orgánica de Educación (LOE) de $2006{ }^{18}$ que la sustituye, recogen entre sus fines y objetivos la formación del emprendimiento como una competencia básica que se debe desarrollar a lo largo del proceso educativo. También en el ámbito de la Formación Profesional, la Ley Orgánica de las Cualificaciones y de la Formación Profesional, publicada en 2002 hace referencia explícita al fomento del espíritu emprendedor. En este caso se insta a la incorporación de acciones formativas encaminadas a capacitar para el desempeño de actividades empresariales y del empleo autónomo. Asimismo, desde 2004 la ordenación general de la Formación Profesional Específica (FPE) recoge entre sus fines el fomento del espíritu emprendedor, incorporando materias relativas al autoempleo y la creación y gestión de la pequeña empresa.

En el ámbito de la docencia universitaria, existen tanto programas de creación de empresas e iniciativas extracurriculares como iniciativas de formación reglada. Las iniciativas para la creación de empresas y el

\footnotetext{
${ }^{18}$ Posteriormente se publica la Ley Orgánica para la Mejora de la Calidad Educativa (LOMCE), sin embargo, esta Ley sólo modifica artículos específicos siendo los mismos fines y objetivos que la LOCE. Por este motivo no se hace mención específica en el texto a los fines y objetivos de la LOMCE.
} 
fomento del espíritu emprendedor están asentadas en el marco de las actuaciones de las universidades, aunque con distinto grado de desarrollo y profundidad. En el caso universitario es de destacar que existe mayor número de programas e iniciativas extracurriculares que iniciativas de formación reglada y que, las iniciativas regladas en la mayoría de casos están ubicadas en Facultades de Economía y Administración y Dirección de Empresas como parte intrínseca de su formación en gestión empresarial y no tanto con el objeto de fomentar el espíritu emprendedor en general. Dentro del ámbito universitario cabe destacar igualmente el fomento del emprendimiento entre el personal científico e investigador y la creación de Spin-off universitarias. Este tema trasciende al ámbito de la docencia para situarse en el ámbito científico y de las administraciones públicas, con unas características y legislaciones propias que comentaremos más adelante.

Sin embargo, el mayor esfuerzo en cuanto a medidas de fomento del emprendimiento se ha producido del lado del entorno jurídico, económico, empresarial y de mercado. La descentralización existente en España en muchas materias y la falta de coordinación y estrategias bien definidas a nivel estatal han provocado una proliferación de medidas muy diversas en estos ámbitos, que van desde las propias del desarrollo local y territorial, hasta las de carácter administrativo, fiscal, financiero 0 de $I+D+i$, promovidas en todos los niveles institucionales y geográficos. Estas medidas, encaminadas a alimentar el desarrollo económico en cada ámbito a través de facilidades, ayudas y subvenciones, han supuesto, en muchas ocasiones, más que un fomento del emprendimiento, una perpetuación de una política económica proteccionista que fomenta los mercados cautivos y debilita la productividad y competitividad empresarial (Pérez Camarero et al, 2009).

En un intento por establecer un marco común para las políticas de fomento de creación de empresas, y siguiendo la estela de la UE en el relanzamiento de los objetivos de Lisboa, propuesto en 2005, España puso en marcha en 2006 el Plan de Fomento Empresarial (PFE), integrado 
dentro del Plan Nacional de Reformas. Este programa, desarrollado por varios ministerios, abarca más de 50 medidas para potenciar la creación de empresas y el espíritu emprendedor. El PFE se marca los siguientes objetivos:

- Potenciar la iniciativa emprendedora en toda la sociedad. En particular, el Programa Nacional de Reformas se plantea como objetivo específico acelerar el ritmo de creación de empresas en torno a un $25 \%$ (del $10 \%$ al $12,5 \%$ ).

- Aumentar la creación de empresas innovadoras y de base tecnológica.

- Simplificar el entorno jurídico y administrativo en el que las empresas desarrollan su actividad.

- Potenciar la capacidad innovadora no tecnológica y la adopción de las tecnologías de la comunicación y de la información en todas las empresas.

- Aumentar la presencia internacional de las empresas españolas.

- Estimular el crecimiento de las empresas y su competitividad.

Para llevar a cabo estos objetivos se plantean una serie de medidas, que se agrupan en función de su carácter jurídico-administrativo, financiero, laboral, educativo y de fomento de la innovación. Una especial mención merece, dentro de las denominadas medidas educativas, la propuesta de reforma del Estatuto del Profesor Universitario, para que pueda participar en proyectos empresariales, permitiendo así avanzar en el campo de la universidad emprendedora, término que abordaremos a lo largo de la presente tesis. En este sentido, en España, los antecedentes normativos y en especial, lo relacionado con incompatibilidad de actividades para los investigadores y docentes, han generado grandes limitantes para la creación de empresas de base tecnológica (EBT). En España, la innovación tecnológica, la transferencia de conocimiento -y concretamente-, la creación de EBT desde el entorno universitario, se 
encuentran comprendidas en un amplio marco reglamentario entre las que cabe destacar:

- Ley Orgánica de Universidades (LOU) Ley 6/2001 (base legal modificada por la Ley 4/2007). Regula el sistema universitario español

- Ley de Incompatibilidades Ley 53/1984. Regula las Incompatibilidades del personal al servicio de las administraciones públicas

- Ley de Contratos de las administraciones públicas Real Decreto Legislativo 2/2000. Regula de manera general los contratos que celebren las administraciones públicas

- Profesorado universitario. Real Decreto 898/1985. Adopta el Régimen del Profesorado universitario

- Ley de Patentes Ley 11/1986 y sus modificaciones. Regula las patentes de invención y los modelos de utilidad. Está afectada por varias normas posteriores.

- Ley Propiedad Intelectual. Real Decreto Legislativo 1/1996 y sus modificaciones. Regulan la propiedad intelectual, incluyendo las obras literarias, artísticas y científicas

El 3 de mayo de 2007, entró en vigor la Ley Orgánica 4/2007 -de 12 de abril-, por la que se modifica la Ley Orgánica 6 de 2001, de universidades. La reforma se adopta como respuesta a las necesidades de adaptación de la legislación nacional, a un sistema universitario que reclama «mejorar su calidad, docente, investigadora y de gestión; fomentar la movilidad de estudiantes y profesores; profundizar en la creación y transmisión del conocimiento como eje de la actividad académica; responder a los retos derivados tanto de la enseñanza superior no presencial -a través de las nuevas tecnologías de la información y de la comunicación- como de la formación a lo largo de la vida, e integrarse competitivamente junto a los mejores centros de enseñanza superior» (Fuente: Exposición de Motivos Ley 4/2007). La Reforma de la LOU incorpora una serie de disposiciones 
que inciden positivamente en favorecer la creación de EBT en España, las cuales impactan en:

- La participación del personal universitario en las EBT,

- La motivación del personal para gestionar transferencia de conocimiento, incluyendo las EBT,

- El entorno general de las relaciones universidad-Empresa

Pasados dos años del PFE, la crisis económica que se inició en 2008 modificó el escenario y el programa de implantación del plan, incentivando y ampliando algunas medidas, sobre todo de corte financiero y liquidez para las PYME y suspendiendo otras como la reducción de aranceles. Los devastadores efectos de esta crisis económica impulsan en 2013 la Ley 14/2013, de 27 de septiembre de apoyo a los emprendedores y su internacionalización. Esta Ley tiene por objeto apoyar al emprendedor y la actividad empresarial, favorecer su desarrollo, crecimiento e internacionalización y fomentar la cultura emprendedora y un entorno favorable a la actividad económica, tanto en los momentos iniciales a comenzar la actividad, como en su posterior desarrollo, crecimiento e internacionalización. (Fuente: Título preliminar de la Ley). La Ley se centra en los siguientes aspectos (correspondientes a los distintos títulos de la misma):

1. Apoyo a la iniciativa emprendedora

2. Apoyos fiscales y en materia de la Seguridad Social a los emprendedores

3. Apoyo a la financiación de los emprendedores

4. Apoyo al crecimiento y desarrollo de proyectos empresariales

5. Internacionalización de la economía española

Como vemos, se centra sobre todo en los aspectos relacionados con la empresa, tanto desde el punto de vista de su creación como de su gestión y desarrollo. Incidiendo en los aspectos anteriormente mencionados, la Ley pretende una transformación del entorno emprendedor y resolver los problemas que dificultan la creación y desarrollo de nuevas empresas con 
objeto de crear un cambio de mentalidad en el que la sociedad valore más la actividad emprendedora y la asunción de riesgos. El resultado es un extenso documento de casi 100 páginas que requerirá para su desarrollo y ejecución la participación de múltiples agentes (centros educativos, notarios registradores, administraciones públicas, sistema financiero, etc.). Todo ello hace que la nueva ley se perfile como ambiciosa y excesivamente compleja. Para su éxito se requiere de recursos presupuestarios y acciones de diálogo y coordinación con los agentes sociales e institucionales que permitan abordar el aspecto sistémico de impulsar la mentalidad emprendedora (Sarasvathy y Venkataraman, 2011). Estos aspectos, no suficientemente contemplados en la Ley, hubieran dado lugar a una ley más innovadora, mejor estructurada y moderna, basada en planteamientos más actuales y amplios del fenómeno emprendedor (como fenómeno social y no sólo individual) relacionados con sus aspectos dinámicos, la necesidad de prestar más atención a sus fases iniciales y a los semilleros de proyectos innovadores y de alto valor añadido, la creación de valor compartido, pero sobre todo, de propuestas concretas para la creación de una verdadera cultura emprendedora que propicie dicho cambio de mentalidad. La Ley deja demasiados cabos sueltos para posteriores desarrollos. El proyecto GEM España, en su informe 2013 ha publicado un estudio con la valoración de expertos sobre esta nueva ley. Dicho informe recoge una valoración muy cauta sobre los logros que esperan de la ley. Se realizan algunas consideraciones positivas hacia aspectos concretos, pero abundan las críticas. Así mismo, las valoraciones cuantitativas sobre la eficacia de las medidas no alcanzan notas altas en ningún caso, y el efecto sobre el entorno emprendedor no llega al nivel medio de valoración que podría considerarse como aprobado. Con todo ello no parece que la acción legisladora sea suficiente para abordar el cambio de mentalidad e impulso del fenómeno emprendedor que persigue la ley. (Informe GEM España, 2013) 
Como contrapunto al caso español, su extensa cantidad de leyes y normativas, su fragmentación y escasa coordinación entre los diferentes agentes, estamentos, administraciones, gobiernos e instituciones, proponemos el caso de los Países Bajos y más concretamente el caso de la región de Twente.

\subsubsection{Políticas de Emprendimiento en la región de Twente}

En los Países Bajos se ha adoptado un enfoque coordinado del espíritu emprendedor que incluye una interacción entre diversos departamentos del gobierno, organismos públicos y propietarios de empresas. La participación de las regiones se consideró esencial, pues éstas intervienen directamente en la aplicación de la política de fomento del espíritu empresarial. Las regiones coincidieron con el Ministerio de Asuntos Económicos en la conveniencia de actuar conjuntamente en las cuestiones más importantes, tales como el fomento del espíritu empresarial en la educación superior y la simplificación del desarrollo de servicios integrados de apoyo (Comité Económico y Social Europeo, 2003).

Hasta 2003, la política de innovación en los Países Bajos (que engloba el emprendimiento) se caracterizó por su fragmentación, con diferentes ministerios encargados del apoyo a la innovación empresarial, y la financiación de la investigación y la ciencia. Adicionalmente, muchos otros ministerios tenían sus propios programas de innovación. En 2003 se estableció la Plataforma de Innovación, estructura que se encarga de la coordinación de la innovación y la política de innovación en los Países Bajos. La Plataforma cuenta con una estructura de tipo red, y con el apoyo de una oficina de proyectos, expertos y representantes de los sectores relevantes de la sociedad. La Plataforma de Innovación era principalmente una organización informal pero que tenía la condición formal de un comité del Consejo de Ministros. Uno de sus objetivos clave es el fomento del emprendimiento (Van Twist, M., van der Steen, M., y van Wijk, A, 2013). Más concretamente, se centra en el incremento de la capacidad 
empresarial y la mejora del espíritu emprendedor con el objetivo de impulsar la creación de nuevas empresas innovadoras y de rápido crecimiento. Con todo ello se pretende impulsar y mejorar la interacción entre las PYME y las instituciones basadas en el conocimiento.

Precisamente, la región de Twente, con su propia plataforma de innovación, es un claro ejemplo de cooperación entre los diferentes gobiernos, agentes e instituciones. Twente es una región con un desarrollo distintivo. Marcada por su fuerte pasado industrial, ha conseguido transformarse en una región que se caracteriza por estar ampliamente basada en la tecnología. Durante el siglo XIX y la primera mitad del XX, los sectores textil y metalúrgico de Twente estuvieron en constante crecimiento. En la década de los 50 , sin embargo, el sector textil regional entró en un período de declive estructural debido a la competencia de países con bajos salarios y a la pérdida de las colonias holandesas. Esta crisis conllevó una reducción del empleo del 80\% entre 1955 y 1980. Para contrarrestar el gran aumento del desempleo, los grupos de interés de la región se unieron para presionar al gobierno nacional y conseguir la instalación de un campus universitario en Twente. En 1964 la Universidad de Twente (UT) se abrió como un campus universitario de tecnología que ofrece grados en ingeniería mecánica, electrónica y química, así como en física y matemática aplicada. La fuerte herencia industrial de la zona y la universidad tecnológica fueron vistas como una combinación ideal para construir una economía regional basada en la tecnología moderna. Durante la década de 1970, estaba claro, sin embargo, que la región no podría crecer únicamente sobre la base de la tecnología. El desempleo seguía siendo elevado, mientras que las matrículas de la universidad se fueron estabilizando. Para diversificar la estructura económica, se realizaron inversiones en nuevos sectores de crecimiento, especialmente en servicios. En línea con esto, la UT estableció grados en ciencias sociales, tales como los estudios de gestión, administración pública y ciencias de la educación. Mientras tanto, también otros institutos de educación superior regionales se 
fueron expandiendo. La fabricación sigue siendo importante en la economía regional con alimentos, productos químicos, metal/electrónica, industria de defensa, transporte y construcción. En términos de clustering de alta tecnología, la región ahora tiene una reputación mundial por su desempeño en tecnología médica, telemática, nanotecnología y la ingeniería de tejidos. Pero el éxito de la región de Twente, se debe, sobre todo la interacción y cooperación existente entre los diferentes agentes. Twente tiene una historia de cuarenta años de cooperación intermunicipal. Desde 1966 las diferentes ciudades, pueblos y aldeas de Twente han tratado de unir fuerzas y trabajar juntos más estrechamente en beneficio del desarrollo regional. Con los años, las estrechas deliberaciones intermunicipales, las consultas y las iniciativas de cooperación han liderado el progreso de Twente. Por un lado, los municipios llegaron a conocer mejor las oportunidades y las sensibilidades de los demás, lo que lo diferencia de otras regiones en los Países Bajos. Por otro lado, sobre la base de las experiencias históricas, Twente ha sido capaz de establecer una red de ciudades y una Región. Ambos cuerpos son plataformas para la cooperación estratégica entre los municipios de la región. Desde 2001, Enschede, Hengelo, Borne y Almelo se han reunido en la Red Ciudad Twente (Netwerkstad Twente) para desarrollar visiones estratégicas y de forma conjunta proyectos emblemáticos regionales, tales como el Parque del Conocimiento Twente. Esta colaboración no se ciñe sólo a los órganos administrativos de la región, sino que se extiende hasta la población. Prueba de ello es que en la región de Twente el $89 \%$ de la población participa en una red socio-cultural local (por ejemplo, una asociación empresarial, el club de fútbol o la sociedad de la música), mientras que la media de Europa Occidental es del 26\%. (Sijgers et al, 2005). 


\subsection{Organizaciones y Universidades Emprendedoras}

En estrecha relación con la conceptualización del término emprendimiento visto en el marco teórico, encontramos el término de organización emprendedora. Este término nos ayudará a entender el funcionamiento de las universidades emprendedoras, que como ya hemos apuntado, conforman uno de los pilares de esta tesis.

En su obra Entrepreneurial Organization as a Factor in Economic Development, Harbison (1956) caracteriza a las organizaciones emprendedoras. Según este autor, las funciones de la organización emprendedora moderna (ya sean públicas o privadas) son: (1) gestión del riesgo y la incertidumbre económica; (2) planificación e innovación; (3) coordinación, administración y control; (4) supervisión de la rutina. Harbison pone el acento en las capacidades y habilidades de los emprendedores (sean o no los dueños de la empresa) integrándolas en lo que denomina recursos organizativos o de gestión, complementando el resto de recursos (trabajo y capital). Para este autor, la capacidad de construir modelos organizativos y de gestión es probablemente la habilidad crítica necesaria para el desarrollo industrial y económico a gran escala. Jelinek and Litterer (1995) dan un paso más en la definición de la organización emprendedora, con una concepción más amplia, aunque en la misma línea que la de Harbison. Para estos autores, la organización emprendedora tiene, al menos, tres propiedades básicas interconectadas entre sí: (1) gestión compartida, (2) mente abierta y alerta a las anomalías, y (3) capacidades superiores de absorción de la ambigüedad. En estrecha relación con la idea del emprendedor de Schumpeter, Jelinek and Litterer manifiestan que las organizaciones emprendedoras deben ir más allá del mero apoyo a los individuos emprendedores. Estas organizaciones deben ser capaces de reorganizarse para reconvertir sus recursos y personal hacia nuevos usos, aportando y gestionando nuevas ideas provenientes de diferentes fuentes. Argumentan que el verdadero reto del emprendimiento organizacional es que todos los miembros en la empresa deben estar involucrados en crear 
algo diferente y la organización debe apoyarlos insistentemente. Queda, por tanto, latente en esta concepción de organización emprendedora la integración de la idea de cultura emprendedora, definida por Gibb (1999) como el "conjunto de valores, creencias y aptitudes comúnmente compartidas en una sociedad, la cual sostiene que es deseable un modo de vida emprendedor apoyando continuamente la búsqueda de un comportamiento emprendedor efectivo por parte de los individuos 0 grupos". En la misma línea Audretsch y Keilbach (2004) definen el emprendimiento como aquel capital adicional al físico, humano y de conocimiento, a tener en cuenta en las organizaciones. Según estos autores el capital emprendedor sería un subcomponente del capital social.

Veremos que las universidades emprendedoras (presentadas en esta tesis como uno de los agentes clave para el fomento del desarrollo económico y social) se pueden considerar como un tipo de organización emprendedora. Sin embargo, es necesario realizar, en primer lugar algunas definiciones previas con objeto de comprender mejor el papel de estos agentes y de tratar de poner claridad sobre una serie de conceptos que se emplean indistintamente, y en ocasiones como sinónimos cuando en realidad no lo son.

\subsubsection{Definiciones y conceptos previos}

\section{Empresa de Base Tecnológica (EBT)}

No existe una única definición consensuada entre los autores para este término. Fue el Grupo Arthr D. Little en 1977 quien definió por primera vez las EBT, concibiéndolas como negocios propios independientes orientados a la explotación de un invento o innovación tecnológica, actividad que implica asumir riesgos tecnológicos considerables. Posteriormente, en los años 80, Rothwell (1986), define las EBT como una "categoría especial de pequeñas empresas..." que tienden a “...operar en áreas de tecnologías emergentes que cambian rápidamente y, que son muy innovadoras”. Por su parte, Simon (2003) las definió como "nuevas empresas que se basan en el 
dominio intensivo de conocimiento científico y técnico". Según la Office of Technology Assessment ${ }^{19}$, una empresa de base tecnológica (EBT) se define como una organización productora de bienes y servicios, comprometidos con el diseño, desarrollo y producción de nuevos productos o procesos de fabricación innovadores, a través de la aplicación sistemática de conocimientos técnicos y científicos. Estas definiciones nos dan una idea de a qué tipo de empresas nos referimos con el término EBT: podríamos definirlas como empresas innovadoras que generan o hacen un uso intensivo de conocimiento científico y técnico y que surgieron con el ánimo de explotar un resultado de investigación para la generación de nuevos productos, procesos o servicios.

\section{Start-Up}

Una empresa start-up, es una empresa que está arrancando, una empresa incipiente o, simplemente, empresa emergente. El término hace referencia a ideas de negocios que están empezando o están en construcción. Las start-ups comienzan como una idea de negocio creativa, sobre la cual se agregan elementos diferenciales a través de la innovación para, finalmente, emprender el negocio.

Generalmente se trata de iniciativas emprendedoras que contribuyen positivamente al desarrollo de entorno geográfico al promover prácticas asociadas a la innovación y al desarrollo de tecnologías. Crean puestos de trabajo para personal altamente cualificado y generan una mejor distribución de la riqueza. Es decir, son empresas emergentes apoyadas en la tecnología. Son ideas que innovan el mercado y buscan hacer de los procesos complicados algo más fácil de realizar, éstas van enfocadas a diferentes temas y usos.

Cualquier startup tiene un principio y un fin. Este final puede llegar por un sinfín de situaciones relacionadas con su desarrollo, tales como llegar a ser

\footnotetext{
${ }^{19}$ La Office of Technology Assessment (OTA) es una oficina del Congreso de los Estados Unidos de 1972 a 1995. El propósito de la OTA era proporcionar a los miembros y comités del Congreso un análisis objetivo y autorizado de los complejos problemas científicos y técnicos de finales del siglo XX, es decir, la evaluación de la tecnología.
} 
muy rentable, pasar a cotizar en la bolsa de valores o el dejar de existir como entidad independiente vía fusión o adquisición. En cualquier caso, una start-up sólo lo será durante el período de lanzamiento, durante los primeros años. Cuando la empresa está consolidada, no tiene sentido llamarse start-up.

\section{Spin-off}

El término Spin-off hace referencia a una empresa que surge de otra empresa o institución cuando uno o varios miembros de la misma deciden, con el apoyo de dicha institución, crear una nueva empresa para explotar una oportunidad de negocio a partir de resultados o desarrollos obtenidos en la empresa o institución matriz. Por tanto, el hecho de que una empresa sea Spin-off no implica, necesariamente que ésta sea una EBT. Cuando la Spin-off surge en el seno de una universidad, se denomina Spin-off universitaria. No existe consenso sobre qué tipos de empresas deben ser consideradas Spin-off universitaria. Algunos autores consideran que sólo aquéllas empresas promovidas por personal de la universidad (profesores, investigadores y personal técnico y de servicios), puede considerarse Spinoff universitaria. Otros autores, consideran que también deben incluirse dentro del término Spin-off universitaria a las empresas promovidas por estudiantes, como resultado de sus trabajos o proyectos fin de carrera, o simplemente para explotar una oportunidad de negocio que ha surgido fruto de los conocimientos adquiridos durante el transcurso de sus estudios. Sin embargo, la mayoría de autores se decantan por relacionar la spin-off universitaria con la creación de empresas a partir de resultados de investigación. Así, Shane (2004) define una spin-off universitaria como: "Una nueva empresa creada para explotar una parte de la propiedad intelectual generada en una institución académica." Para Druilhe y Garnsey (2004) las spin-offs universitarias son: "Las nuevas empresas que comercializan la tecnología punta generada en un departamento de una universidad y que cuentan con una aportación de capital riesgo." Iglesias (2010) realiza una búsqueda exhaustiva de las definiciones de spin-off y 
elabora su propia definición: "Una spin-off universitaria es una modalidad de empresa creada a partir del conocimiento y/o tecnologías desarrolladas en el seno de la universidad bien por grupos de investigación o miembros directamente vinculados con ello. Gracias a un acuerdo (transferencia de tecnología o conocimiento) pueden utilizar y explotar comercialmente los resultados de sus investigaciones contribuyendo al desarrollo económico regional. La utilidad última de una spin-off es convertir la investigación en productos o servicios prácticos para la sociedad sirviendo como punto de contacto entre el ámbito académico y el mercado".

El hecho de que la mayoría de empresas promovidas por personal de las universidades esté vinculada a la explotación de resultados de investigación, ha llevado a la identificación errónea de Spin-off universitaria con EBT. Relacionando el término Spin-off con el de Start-up, debemos tener en cuenta que en los primeros años de vida, una empresa Spin-off es también una Start-up. Sin embargo, pasados los primeros años, dejará de pertenecer a la categoría Start-up, mientras que siempre será una Spin-off de la empresa matriz de la que surgieron. Si además, cumple las características de las EBT, también pertenecerá a esta categoría de empresas.

\subsubsection{La Universidad como organización emprendedora}

Desde finales de los años ochenta, ante la irrupción del nuevo modelo neoliberal que obligó a las economías de casi todo el mundo a abrir sus mercados a la competencia externa y a reducir la intervención del Estado en ellas, muchas instituciones pertenecientes al sistema de educación superior debieron diseñar estrategias alternativas para captar recursos adicionales de fuentes no tradicionales para compensar la disminución de los recursos provenientes del Estado.

En la actual sociedad del conocimiento, las universidades se convierten, cada vez más y de manera más directa, en promotoras del desarrollo económico. Desde hace algún tiempo varias de ellas lo han hecho de 
manera indiscutible y sus logros se reconocen a nivel global. El caso posiblemente más conocido es el de la Universidad de Stanford en la promoción del Sillicon Valley, aunque este proceso viene desarrollándose en un sinnúmero de universidades de los distintos países bajo una dinámica propia que responde de manera directa a las necesidades de su entorno y a las tendencias globales.

Según Fernández et al., (2000) se pueden distinguir cinco tipos de universidades:

- Académica, que es aquélla en la que fundamentalmente se imparte docencia, razón por la cual las decisiones y los recursos se orientan exclusivamente hacia la mejora de la actividad docente.

- Clásica, en la que se compaginan las actividades docentes con las de investigación, con un reconocimiento institucional y de la comunidad académica sobre la importancia de éstas últimas y la consiguiente asignación de recursos a estas actividades.

- Social, que se arroga un papel activo para la discusión y resolución de problemas de la sociedad en la cual se inserta.

- Empresarial, considera que los conocimientos, además de ser difundidos mediante los cauces docente y científico habituales, tienen un "valor" de mercado y, por tanto, son susceptibles de ser vendidos, por lo que enfoca una parte de sus actividades docentes y de I+D con criterios empresariales y se preocupa de gestionar eficazmente la cooperación con la sociedad.

- Emprendedora, tiene aspectos comunes con la empresarial pero con un matiz importante en sus objetivos; más que como un bien económico objeto de intercambio, utiliza el conocimiento como un potencial al servicio de los objetivos de su entorno socioeconómico. Esto es, un recurso que, adecuadamente gestionado, le permite desempeñar un papel más activo en su contexto social. 
Como hemos apuntado, hoy día el papel de las universidades en la sociedad va más allá de las actividades de enseñanza e investigación (Etzkowitz, 1998). Cada vez más, la sociedad demanda de éstas una mayor implicación en el proceso de desarrollo económico y social del territorio, dando lugar a la denominada universidad emprendedora, la cual combina e integra las tradicionales actividades de educación e investigación con la contribución al desarrollo económico y social, lo que viene a denominarse Tercera Misión (Etzkowitz, 1998; Goddard, 1998).

La transformación de la universidad tradicional hacia una Universidad Emprendedora es estudiada por Clark en universidades europeas (Clark, 1998) y en otras de distintos continentes (Clark, 2004). Su primer estudio de la universidad emprendedora se basa en la observación de cinco universidades europeas entre los años ochenta y mediados de los noventa $^{20}$. En este estudio Clark encuentra cinco elementos comunes que suponen un cambio en la estructura organizativa de la Universidad a los que llama "sendas de transformación". Según este autor, desde el punto de vista organizativo y de gestión, las universidades emprendedoras tienen en común un núcleo de gobierno fuerte, una periferia de desarrollo amplia, un centro académico motivado, una base de financiación diversificada y una cultura emprendedora integrada (Clark, 1998). Estas cinco características les permiten a las universidades emprendedoras generar su transformación con base en acciones innovadoras que las impulsan a desarrollar una cultura emprendedora dentro de la institución, en la actitud proactiva del personal y en la forma en que sus agentes asumen sus actividades con el entorno. Clark no formula, sin embargo, la dependencia y la relación existente y necesaria entre estas cinco características para la transformación de la universidad tradicional en emprendedora.

\footnotetext{
${ }^{20}$ Dichas instituciones fueron: la Universidad de Warwick (Inglaterra), la Universidad de Joensuu (Finlandia), la Universidad de Twente (Holanda), la Universidad de Strathclyde (Glasgow, Escocia) y la Universidad de Chalmers (Gothenburg, Suecia).
} 
Posteriormente Clark (2004) publica un nuevo estudio realizado alrededor de todo el mundo, en el que documenta $14 \operatorname{casos}^{21}$ para analizar las formas de transformación y las dinámicas de cambio por medio de las cuales las universidades dan respuesta a los requerimientos que demanda la sociedad de la información. En dicho estudio Clark acrecienta su esquema conceptual con base en lo observado en sus análisis. En resumen la universidad emprendedora dispone de:

- Tres grandes grupos de fuentes de financiación diferenciados:

- Fuentes complementarias y adicionales de origen gubernamental, que pueden estar unidas a nuevos proyectos 0 actividades.

- Fuentes privadas relacionadas con entidades sin ánimo de lucro y gremios de profesionales, entre otros. Este aspecto supone además la relación con otros actores sociales.

- Fuentes autogeneradas por la universidad a través de distintos mecanismos como venta de servicios y patentes, entre otros.

- Un grupo directivo reforzado que promueve la autodirección del sistema mediante un esquema de centralización descentralizada, pero compartiendo las responsabilidades de la dirección con los diferentes grupos de interés.

- Una estructura organizacional en la que sus unidades clásicas se complementan con nuevas unidades internas y externas, transversales, con perfiles profesionales y estructuras novedosas

\footnotetext{
${ }^{21}$ En el nuevo estudio, Clark incluye las cinco universidades europeas del primer estudio publicado en 1998 , además de tres universidades de África (Universidad de Makerere, Uganda), América Latina (Pontificia Universidad Católica de Chile) y Australia (Monash University) y seis universidades norteamericanas (Universidad de Stanford, MIT, Universidad de Michigan, UCLA, Universidad Estatal de Carolina del Norte e Instituto de Tecnología de Georgia).
} 
que generen cambio en las unidades burocráticas que han permanecido estáticas y sin vocación de servicio $^{22}$.

- Una esencia académica que fortalezca los diferentes departamentos para atraer profesores, estudiantes y otros recursos que impulsen el desarrollo de la institución y vinculen a aquéllos segmentos que necesitan convertirse en emprendedores para aportar en mejor medida al desarrollo organizacional.

- Una cultura emprendedora unificada en torno a un conjunto de ideas, creencias y valores de la universidad que dan identidad propia en un mundo competitivo.

Para Clark (1998, 2004) las Universidades Emprendedoras son aquellas que maximizan el potencial de comercialización de sus ideas y crean valor en la sociedad. Asume que este tipo de universidades son organizaciones muy flexibles que se insertan en su entorno al responder de manera coherente, estratégica y oportuna ante las exigencias que éste les hace, sin que ello signifique una amenaza para su misión académica tradicional. Para insertarse en dicho entorno, la Universidad Emprendedora realiza modificaciones en su cultura y en su estructura organizacional, con el ánimo de generar una respuesta más proactiva, innovadora y ágil, que dé origen a una diversidad de líneas de estudio, nuevas áreas de investigación, nuevos centros de investigación y otras instancias que gestionan la relación entre la universidad, la economía y la sociedad.

Tal como hemos visto y según se pone de manifiesto en la literatura sobre tercera misión de la universidad (Mollas Gallart et al, 2002), la universidad emprendedora debe atender a un amplio número de actividades relacionadas con sus tres misiones: la docencia, la más tradicional desde su creación; la investigación, derivada de la universidad Humboldtiana; y,

\footnotetext{
${ }^{22}$ Tradicionalmente los procesos de relación con el medio y la venta de servicios se han concentrado en los departamentos y facultades de ingeniería y administración. En el caso de la universidad emprendedora, todos los departamentos y facultades pueden "descubrir el valor educacional, y también económico, de transformarse en una unidad emprendedora” (Clark 1998). Para ello es necesario que puedan combinar los estándares académicos de la disciplina con una visión hacia las necesidades del entorno.
} 
recientemente, la "tercera misión", que surge para destacar e incrementar la contribución al desarrollo socioeconómico de su entorno (Sánchez, 2012). Todas estas actividades deben ser gestionadas conjuntamente de forma emprendedora (Arroyo-Vázquez et al, 2010). Es decir, las universidades emprendedoras, también comparten las propiedades de las organizaciones emprendedoras (gestión compartida, mente abierta y capacidades de absorción de la ambigüedad). También requiere, siguiendo la línea establecida por Clark, la creación de una cultura emprendedora que involucre a todos sus miembros en la consecución de sus fines.

Así pues, como ya habíamos adelantado, podemos considerar la definición de universidad emprendedora como una evolución del concepto de organización emprendedora. Según Etzkowitz (1983, 2004), Clark (1998, 2004), y O'Shea et al. (2007), entre otros, la universidad emprendedora puede ser entendida como una organización flexible que interactúa con su entorno social y económico adaptándose a los cambios y buscando recursos adicionales de financiación para la investigación y la enseñanza. La universidad emprendedora combina, por tanto, sus tradicionales actividades de enseñanza e investigación con la interactuación con su entorno social y económico con objeto de contribuir a su desarrollo (Etzkowitz, 1998).

Entre las nuevas actividades atribuidas a las universidades emprendedoras y relacionadas con su "tercera misión" encontramos la de transferencia de tecnología a la sociedad. Dado que entre estas actividades de transferencia se encuentra la creación de spin-off universitarias, creemos conveniente profundizar en estas actividades y lo que ello supone para la universidad. 


\subsubsection{Transferencia de Tecnología y Universidades Emprendedoras}

Tecnología es un término que engloba todo aquello relacionado con los activos intangibles vinculados al proceso productivo de una organización. Desde una perspectiva empresarial, la tecnología es el conjunto de conocimientos e información propios de una actividad que pueden ser utilizados de forma sistemática para el diseño, desarrollo, fabricación y comercialización de productos, o la prestación de servicios, incluyendo la aplicación adecuada de las técnicas asociadas a la gestión global.

La Association of University Tecnology Managers (AUTM) define la transferencia de tecnología como el proceso por el cual se transfieren los resultados científicos de una organización a otra con el propósito de conseguir su posterior desarrollo y comercialización. Este proceso incluye generalmente:

- La identificación de nuevas tecnologías.

- La protección de dichas tecnologías a través de patentes.

- Las estrategias de desarrollo y comercialización bien sea mediante la concesión de licencias a empresas del sector privado o bien mediante la creación de nuevas empresas de base tecnológica.

La transferencia tecnológica universitaria se refiere al proceso mediante el cual se autoriza el uso, con fines lucrativos, de una invención o propiedad intelectual surgida de la investigación académica, a otra entidad o empresa.

Según el Manual para la transferencia de tecnología editado por el Ministerio de Industria, Comercio y Turismo (MICYT, 1992), la transferencia de tecnología universitaria va más allá de la comercialización de patentes derivadas de la protección de los nuevos descubrimientos universitarios.

Desde una perspectiva más amplia, la transferencia de tecnología universitaria incluye: 
- La venta o licencia de patentes, modelos e inventos

- La venta o licencia de software y de otras aplicaciones informáticas

- Las actividades de asistencia técnica

- Las actividades de investigación y desarrollo (I+D)

- La formación especializada y capacitación de personal

Las actividades universitarias de transferencia de tecnología son cada vez más importantes tanto para el desarrollo económico de su entorno geográfico como para la obtención de ingresos para la universidad. El análisis de Friedman y Silberman (2003) concluye que los cuatro factores que mejoran la transferencia de tecnología de las universidades son:

- El sistema de incentivos económicos para el profesorado que realiza actividades de transferencia tecnológica

- La ubicación de la universidad en una región con una elevada concentración de empresas de alta tecnología

- La misión de la universidad con un claro apoyo a la transferencia tecnológica

- La experiencia de la oficina de transferencia de tecnología de la universidad

La creación de empresas, como parte de la estrategia de transferencia de tecnología de la Universidad, se ha convertido en uno de los objetivos actuales de los políticos y autoridades académicas (Etzkowitz, 1998, 2003; Etzkowitz y Leydesdorff, 1997, 2000; Etzkowitz et al., 2000; Roberts y Malone, 1996; OCDE, 1998, 2001; Carayannis et al., 1998; Steffensen et al., 2000, Bray y Lee, 2000; Birley, 2002; Shane, 2002; Siegel et al., 2003). Además de los efectos positivos que tiene la creación de cualquier tipo de empresas en la economía, existen una serie de razones que han llevado al 
emprendimiento desde el ámbito universitario a alcanzar una gran relevancia. Entre estos motivos se encuentran los siguientes:

- Son una fuente de transferencia de conocimiento

- Producen retornos económicos

- Provocan crecimiento y desarrollo económico local

- Provocan diversos cambios en la cultura universitaria

- Incrementan la interacción entre la Universidad y su entorno

Según hemos visto, la creación de spin-off universitarias, es una de las vías para la transferencia de tecnología por parte de las universidades. Sin embargo, y a pesar de que la definición de Clark sobre universidad emprendedora vista en el epígrafe anterior ofrece una perspectiva amplia del concepto de universidad emprendedora, existe cierta tendencia a identificar a la universidad emprendedora con la creación de spin-off universitarias. Así encontramos la creencia generalizada de que cuanto mayor es el número de empresas spin-off que una universidad es capaz de crear, tanto más emprendedora es esta universidad (Arroyo-Vázquez et al, 2010). Esto vincula nuevamente el concepto de emprendimiento al de creación de empresas, cuando pasamos del espectro teórico al práctico, esta vez relacionado con las universidades. En este sentido, estamos de acuerdo con Clark (2004) cuando afirma que "el emprendimiento en universidades no debería ser visto como un sinónimo de comercialización". Nuestra postura, acorde con esta afirmación de Clark, se basa en la conceptualización de la universidad emprendedora como organización emprendedora (según Jelinek and Litterer, 1995) que integra una cultura emprendedora y que interactúa con su entorno socioeconómico respondiendo a sus necesidades, reorganizando y coordinando los diferentes recursos (físicos, humanos, y de gestión) para ofrecer soluciones a corto, medio y, sobre todo, a largo plazo. Así mismo, según Clark (2004) la universidad tiene un importante papel en la formación de valores emprendedores entre sus estudiantes, pues desde una perspectiva más amplia a la meramente empresarial, los emprendedores comparten valores 
comunes aunque pueden actuar en diversos campos del desarrollo humano y no solamente como creadores de empresa. Es decir, si tenemos en cuenta que en la universidad se forman los futuros profesionales de todos los ámbitos (políticos, empresarios, ingenieros, médicos, abogados, etc.), esta institución tiene una responsabilidad a la hora de formar en habilidades y valores emprendedores de ámbito general y no sólo empresarial.

En este sentido, Arroyo-Vázquez y Van der Sijde (2008) proponen un modelo integral para el fomento del emprendimiento en universidades que recoge no sólo el apoyo a la creación de empresas, sino el mantenimiento de una cultura emprendedora dentro de la propia universidad. Este modelo, sin embargo se basa en la premisa de que existe en la universidad un cierto nivel de cultura emprendedora. En este sentido los PAE, como servicios innovadores dentro de las universidades emprendedoras, juegan un papel fundamental tanto en el propio desarrollo de la universidad como emprendedora como en la contribución de las actividades relacionadas con el emprendimiento al desarrollo económico y social del territorio.

\subsection{Servicios Innovadores en Universidades Emprendedoras: los Programas de Apoyo al Emprendimiento}

Como hemos visto a lo largo de este capítulo, para que la universidad pueda atender adecuadamente las demandas de la sociedad y ser reconocida como emprendedora, es necesaria una fase de transformación no sólo en cuanto a objetivos y estrategias de la universidad, si no en su propio comportamiento y cultura, tanto a nivel institucional como personal. Esta misma filosofía es perfectamente aplicable al caso de los servicios universitarios, ya que la transformación de la universidad en emprendedora no puede darse sin la transformación de los servicios y del resto de agentes que la componen. Por tanto, debemos encontrar la base de la innovación en los servicios universitarios en los factores que identifican a una 
universidad como emprendedora. En este sentido, las definiciones de “organización flexible que interactúa con su entorno social y económico adaptándose a los cambios y buscando recursos adicionales de financiación" y la de "cultura emprendedora integrada tanto en la institución como en la actitud y la forma en que sus agentes desempeñan sus actividades" (Clark 1998), son totalmente válidas para el caso de un servicio iconlleva que una gran parte de las actividades de innovación en servicios esté orientada a la adaptación de los servicios a las necesidades de los clientes o usuarios.

- El contenido intensivo en información de las actividades de servicios y de producción. Este factor confiere una gran importancia a la generación y uso de las tecnologías de la información en las actividades de innovación de las empresas de servicios.

- El papel fundamental de los recursos humanos como factor básico de competitividad. El papel fundamental del factor humano en la organización y provisión de los servicios se asocia a grandes inversiones en recursos humanos y, por ello, las actividades de formación de las empresas deben ser consideradas como fuente de mejora de las capacidades tecnológicas de las empresas de servicios

- La importancia de los factores organizativos en el rendimiento de las empresas. Cada vez hay más evidencia de que la actividad innovadora en servicios es de esta naturaleza (Gallouj, 1998; Sundbo y Gallouj, 1998; Miles, 1994; Teece, D.J. 1996).

La gestión del PAE como servicio innovador en el marco de una universidad emprendedora, precisa incorporar y adoptar estas características, influyendo convenientemente en los aspectos mencionados y teniendo en cuenta las necesidades y características de la tercera misión de su universidad. 
Centrándonos en las actividades que deben desarrollar los PAE, ArroyoVázquez y Van der Sijde (2008), identifican dos tareas críticas. La primera es el Fomento del Emprendimiento, que integra, por un lado, el proceso de dinamización (Castro Martínez et al, 2001) de los agentes implicados hacia un comportamiento emprendedor en el ámbito de la creación y desarrollo de empresas y, por otro, el acercamiento a dicho ámbito de las actividades de investigación y enseñanza relacionadas con el emprendimiento y temas afines. En esta definición, el concepto dinamización es entendido como aquel cambio de comportamiento que 'mueve a alguien a hacer algo' (Castro Martínez et al, 2001). De acuerdo con estos autores, se deben promover dos actividades dentro del proceso de dinamización: la sensibilización y la motivación, por una parte, y la provisión de recursos y facilidades (servicios) por otra. La segunda tarea clave propuesta por los autores es el Apoyo al Desarrollo de Empresas, que definen como "el proceso que recoge la búsqueda, reconocimiento y desarrollo de oportunidades de negocio, la puesta en marcha de la empresa, así como el posterior desarrollo y crecimiento de la misma”.

En cuanto a las actividades de los PAE, existe una gran cantidad de literatura alrededor del proceso de fomento del emprendimiento y apoyo al desarrollo de empresas (FEyADE) en las universidades, sin embargo, la gran mayoría aborda sus actividades de forma separada, no como un proceso único ni en un sentido amplio. Como ejemplo, podemos citar que el fomento del emprendimiento en muchas universidades suele ser considerado sólo como la promoción de la transferencia de conocimiento desde las universidades a través de la creación de empresas spin-off. Por otro lado, el proceso de apoyo al desarrollo de empresas en las universidades sólo suele ser considerado cuando éste está relacionado con las empresas spin-off en las que existen derechos de propiedad intelectual (DPI) de la universidad o ésta participa en su accionariado. Algunos autores consideran que este proceso comienza con la protección del DPI y finaliza con la valorización del mismo a través de acuerdos de participación en la 
spin-off (e.g Cuyvers y Zimmermann, 2002). Sin embargo, y en oposición a estos enfoques, el siguiente Capítulo se centra en la propuesta de un modelo integral para el FEyADE en universidades.

\subsection{Reflexiones sobre el emprendimiento en el marco empírico propuesto}

De lo expuesto sobre las políticas relacionadas con el fomento del emprendimiento tanto en Europa como en España, se desprende una persistente vinculación del concepto emprendimiento con creación y desarrollo de empresas, e incluso, siendo más exhaustivos, con pequeñas y medianas empresas. Las políticas de fomento del emprendimiento se centran exclusivamente en potenciar la creación de PYME y facilitar su gestión, financiación e internacionalización. Las referencias a la formación relacionada con emprendimiento y la creación de una cultura emprendedora se encaminan igualmente hacia la formación en gestión y hacia el fomento del espíritu empresarial, respectivamente. En este último caso, es destacable la transformación de lo que, en un principio comienza denominándose espíritu emprendedor cuando se parte de los fundamentos teóricos, a espíritu empresarial cuando se plasman en políticas y legislación específicas.

Esta visión empresarial del emprendimiento, se refleja en políticas "cortoplacistas", impulsadas por situaciones coyunturales y que pretenden poner por bandera al emprendimiento como la panacea que resolverá el problema del desempleo y de la recesión económica en tiempos de crisis. Sin embargo, mientras no se incida en cuestiones de fondo como son la creación de una cultura emprendedora en sentido amplio, el fomento de un espíritu emprendedor e innovador y la formación a lo largo de la vida en competencias emprendedoras, con independencia de si se es o no empresario, no se incidirá de forma efectiva en el desarrollo económico. Las políticas que se ponen en marcha inciden principalmente en las 
instituciones formales pero prácticamente se olvidan de las informales. Además se centran en "convencer" a los individuos para que creen empresas o autoempleo con objeto de disminuir la cifra de desempleo, valiéndose para ello de facilidades en el proceso de creación y gestión de empresas, pero sin crear un verdadero fomento del emprendimiento en todos los ámbitos y no sólo en lo que a creación y desarrollo de empresas se refiere.

En el caso español, las políticas destinadas al fomento del emprendimiento se han llevado a cabo de forma desestructurada y descoordinada en muchos casos. Hasta 2013 no se cuenta con una ley de emprendimiento propiamente dicha. Sin embargo esta ley, al igual que ocurre en el caso europeo, se centra en el ámbito empresarial y no contempla el fomento del emprendimiento a nivel global. Como hemos visto, la ley identifica emprendimiento con creación y desarrollo de empresas, desarrollando muy poco lo referente a cultura empresarial.

Centrándonos en el caso del fomento del emprendimiento en universidades y en las universidades emprendedoras, históricamente la legislación ha restringido la posibilidad a los profesores universitarios de formar parte de las actividades de gestión y/o administración de las spin-off universitarias. Paradójicamente, las políticas intentaban fomentar la creación de empresas de base tecnológica y spin-off universitarias, pero no solucionaban las barreras legales que existían a tal efecto. Tras años de reivindicación por parte de las universidades, finalmente se ha diseñado una ley que levanta estas barreras y que ha supuesto un verdadero empuje a la creación de este tipo de empresas y a la universidad emprendedora en general. Es de reseñar que las políticas relacionadas con el emprendimiento universitario se han construido fundamentalmente en modo bottom-up. Es decir, se han creado partiendo de propuestas de las propias universidades que reclamaban soluciones para una situación que se volvía insostenible: se les exigía una mayor contribución al desarrollo económico a través de la transferencia de conocimientos a la sociedad, pero sin embargo, se les 
bloqueaba uno de los mecanismos para dicha transferencia, las spin-off, como consecuencia de las barreras para que el profesorado pudiera participar en las mismas.

Centrándonos en el caso de las universidades emprendedoras, estas instituciones se caracterizan, como hemos puesto de manifiesto, por mucho más que por la mera creación de spin-off. Entre estas características cabe destacar la existencia de una cultura emprendedora integrada tanto en la institución como en la actitud y la forma en que sus agentes desempeñan sus actividades. Sin embargo, existe una creencia generalizada a identificar universidad emprendedora con creación de spin-off.

El camino hacia la transformación de una universidad en emprendedora debe pasar por la transformación de sus servicios en emprendedores. En este sentido, los PAE juegan un papel fundamental a la hora de contribuir, no sólo a esta transformación, sino al desarrollo económico y social de su entorno ayudando así a la consecución de los objetivos de su universidad como emprendedora.

Sin embargo, tanto la universidad como los propios servicios, se ven influidos y dirigidos por las políticas relacionadas tanto con el emprendimiento como con la gestión universitaria. Así, hemos visto como la consecución de los objetivos relacionados con la tercera misión de la universidad se ha visto coartada por las limitaciones legales impuestas al profesorado universitario. Por otra parte, el fomento del emprendimiento desde políticas "cortoplacistas" y que no tienen en cuenta una definición global del término (centrándose como hemos visto en la esfera empresarial) conlleva la puesta en práctica de acciones cuyos resultados no serán los esperados en materia de desarrollo económico y social. Todo ello será objeto de estudio de la presente tesis en los próximos capítulos. 


\section{Capítulo 4. Propuesta Conceptual y Modelo} Teórico

En este capítulo, realizaremos aportaciones y propuestas de carácter teórico en el ámbito del emprendimiento. En primer lugar, analizaremos la divergencia entre el concepto de emprendimiento y su aplicación empírica, a través del análisis de la literatura existente al respecto, analizando las implicaciones que esta divergencia tiene sobre los aspectos políticos. Con todo ello, realizaremos una propuesta de conceptualización de emprendimiento, basada en lo estudiado en la literatura sobre este fenómeno y sobre la que basaremos el análisis y los resultados de la presente tesis. 
Una vez establecida la base conceptual sobre la que trabajar, nos centraremos en el fomento del emprendimiento en la universidad española: en qué han consistido las actividades de fomento del emprendimiento en este ámbito y cómo se ha desarrollado históricamente, haciendo especial hincapié en las barreras y limitaciones que han existido para la creación de spin-off por parte de las universidades públicas españolas. Con todo ello, proponemos un modelo integral para el fomento del emprendimiento universitario que acompañamos con una propuesta metodológica para la aplicación de dicho modelo y su posterior análisis.

\subsection{Divergencia entre conceptualización y análisis empírico en los estudios sobre emprendimiento}

Según Karadeniz (2006), encontramos tres roles básicos del emprendedor: innovar (Schumpeter, 1911), detectar oportunidades aprovechables, y asumir riesgos asociados a la incertidumbre (Kirzner, 1973). A su vez, Nasution et al. (2011), identifican emprendimiento con libertad y autonomía; proactividad e innovación; y propensión a la asunción de riesgos controlados. Según sus respectivas definiciones, el desarrollo de estos roles no implican necesariamente que el emprendedor deba ser el dueño de la empresa. Según la conceptualización de emprendedor y emprendimiento en la literatura (Drucker, 1986; Ireland et al, 2003; Shane y Venkataraman, 2000, entre otros) lo que identifica al emprendedor es su habilidad para poner en práctica estos roles, no el hecho de que sea o no el dueño de la empresa. Sin embargo, a la hora de analizar y medir el impacto del emprendimiento en el desarrollo económico, encontramos en la literatura, como hemos puesto de manifiesto en el marco teórico, constantes referencias a la figura del emprendedor como dueño de una empresa y a la identificación de emprendimiento con creación de empresas. La propia OCDE en sus diferentes intentos por ofrecer una definición del término emprendimiento y/o emprendedor ha identificado, de uno u otro modo, emprendimiento con creación de empresas. Así Strategy (1998) define emprendimiento como la posibilidad de reunir recursos para 
explotar oportunidades de negocio. Definido de este modo, el emprendimiento es, para la OCDE, el centro del crecimiento económico. Desde nuestro punto de vista esta definición resulta incompleta, ya que no hace ninguna referencia al emprendedor innovador de Schumpeter, y limita las oportunidades a las de negocio. Sin embargo, la OCDE explica la contribución del emprendimiento al desarrollo económico a través de la generación de nuevas ideas y de la innovación, lo cual no resulta muy coherente con su propia definición. Más recientemente, en 2008, Ahmad y Seymour (2008) redactan para la OCDE una nueva definición de emprendedor: "Los emprendedores son las personas (propietarios de negocios) que buscan generar valor, a través de la creación o expansión de la actividad económica, mediante la identificación y explotación de nuevos productos, procesos o mercados". Esta definición, además de identificar emprendedor con dueño de empresa, vuelve a ser confusa e insuficiente: cualquier dueño de una empresa podría explotar nuevos productos, procesos o mercados, sin necesidad de ser emprendedor (no se indica que sea el dueño de la empresa quien haya desarrollado las habilidades necesarias para obtener estas innovaciones). En un trabajo posterior, (Ahmad y Hoffmann, 2008), la OCDE desarrolla un marco para la dirección y medición del emprendimiento en el que, si bien se basa en la definición anterior de emprendedor, diferencia entre empresas de alto crecimiento y "empresas gacela" y pone de manifiesto la importancia de las habilidades del emprendedor sobre el impacto final del emprendimiento.

Esta misma divergencia entre la conceptualización del término emprendedor y la explicación de su importancia para el desarrollo económico la hemos podido apreciar en los estudios revisados en el marco teórico. La gran mayoría de los estudios que relacionan emprendimiento y desarrollo económico identifican, a la hora de realizar sus análisis, emprendimiento con creación de empresas. Sin embargo, el argumento empleado en estos estudios para relacionar emprendimiento con desarrollo económico se fundamentan en la habilidad del emprendedor para 
desempeñar sus habilidades: autonomía, proactividad, innovación, detección de oportunidades y asunción de riesgos en situación de incertidumbre.

Es cierto que estas habilidades contribuirán mejor al desarrollo económico poniéndolas en práctica en el ámbito empresarial, dando como resultado innovaciones que impliquen un mayor crecimiento y beneficio para la empresa, lo que a su vez se traducirá en un incremento del empleo y competitividad para la misma, que repercutirá en la economía de su país o región. Pero ¿es necesario que el emprendedor sea el promotor y dueño de la empresa para contribuir con sus habilidades al desarrollo económico? Desde nuestro punto de vista, y tal como habíamos apuntado anteriormente, no. Lo que promueve realmente el desarrollo económico a través del emprendimiento son las habilidades del emprendedor, no el hecho de que éste promueva o cree la empresa. El emprendedor puede desarrollar sus habilidades en el ámbito empresarial sin necesidad de ser el promotor de la empresa, pero para ello, es necesario hacerlo dentro de organizaciones emprendedoras que permitan el desarrollo personal, intelectual, innovador y emprendedor de sus individuos. La falta de estas organizaciones en las que desarrollarse, es lo que mueve a muchos emprendedores a crear su propia empresa para dar rienda suelta a sus innovaciones (Jelinek y Litterer, 1995). Este hecho es el que probablemente ha detonado la identificación en muchos casos de emprendedores con empresarios, cuando ni todos los emprendedores son empresarios, ni viceversa.

En la Tabla 1 se muestra cronológicamente con qué asocian emprendimiento los principales autores, mostrando una amplia falta de consenso y una gran disparidad de conceptos con los que asociar emprendimiento. 
Tabla 1: Conceptualización de emprendimiento según principales autores

Autor

\begin{tabular}{|c|c|}
\hline Schumpeter, 1911 & $\begin{array}{l}\text { Habilidades y propensión a generar innovaciones, } \\
\text { llevando a cabo nuevas combinaciones que puedan } \\
\text { tomar la forma de nuevos productos, procesos, } \\
\text { mercados, formas organizativas, o fuentes de } \\
\text { abastecimiento }\end{array}$ \\
\hline Harbison, 1956 & $\begin{array}{l}\text { Capacidades y habilidades de los emprendedores (sean } \\
\text { o no dueños de la empresa) }\end{array}$ \\
\hline Kirzner, 1973 & $\begin{array}{l}\text { Detección de oportunidades y asunción de riesgos bajo } \\
\text { incertidumbre }\end{array}$ \\
\hline Carland et al, 1988 & $\begin{array}{l}\text { Estrategia empresarial basada en el crecimiento y la } \\
\text { innovación }\end{array}$ \\
\hline Gartnet, 1988 & Propiedad de una pequeña empresa \\
\hline Yeoh y Jeong, 1995 & Proactividad e Innovación \\
\hline Strategy, 1998 (OCDE) & $\begin{array}{l}\text { Posibilidad de reunir recursos para explotar } \\
\text { oportunidades de negocio }\end{array}$ \\
\hline Kelley et al, 2001 (GEM) & $\begin{array}{l}\text { Proceso que se inicia con la generación de una idea, } \\
\text { continúa con las acciones de su puesta en marcha, se } \\
\text { lanza al mercado, continúa con una fase de } \\
\text { consolidación, y pasa a la fase consolidada cuando } \\
\text { sobrevive más de tres años y medio en el mercado }\end{array}$ \\
\hline Kuratko y Hodgetts, 2001 & Libertad y Autonomía \\
\hline Audretsch y Keilbach, 2004 & Capital adicional al físico, humano o de conocimiento. \\
\hline Wong et al, 2005 & $\begin{array}{l}\text { Promoción de nuevas empresas que crean trabajo, } \\
\text { intensifican la competitividad e incrementan la } \\
\text { productividad a través del cambio tecnológico y la } \\
\text { innovación }\end{array}$ \\
\hline Karadeniz, 2006 & $\begin{array}{l}\text { Innovación, Detección de oportunidades aprovechables y } \\
\text { asunción de riesgos asociados a la incertidumbre }\end{array}$ \\
\hline $\begin{array}{l}\text { Ahmad y Seymour, } 2008 \\
\text { (OCDE) }\end{array}$ & $\begin{array}{l}\text { Propiedad de negocio; generación de valor a través de la } \\
\text { creación o expansión de la actividad económica, } \\
\text { mediante la identificación y explotación de nuevos } \\
\text { productos, procesos o mercados }\end{array}$ \\
\hline Baumol, 1990 & $\begin{array}{l}\text { Ingenio y creatividad en la búsqueda de métodos que } \\
\text { aumenten la riqueza, poder o prestigio }\end{array}$ \\
\hline Acs, 2010 & $\begin{array}{l}\text { Criatura compleja que se compone de múltiples } \\
\text { dimensiones. "Es diferente al concepto de pequeñas } \\
\text { empresas, autoempleo, artesanía y los negocios } \\
\text { habituales; no se asocia como un fenómeno con compras } \\
\text { de participaciones, cambio de titularidad o gestión de la } \\
\text { sucesión". }\end{array}$ \\
\hline Naude, 2011 & $\begin{array}{l}\text { Recurso, proceso y forma a través de los cuales se } \\
\text { utilicen las oportunidades existentes en el mercado } \\
\text { mediante la creación y crecimiento de nuevas empresas }\end{array}$ \\
\hline Nasution et al, 2011 & $\begin{array}{l}\text { Libertad y autonomía; proactividad e innovación; y } \\
\text { propensión a la asunción de riesgos controlados }\end{array}$ \\
\hline Raposo et al & Conversión de retos en oportunidades \\
\hline
\end{tabular}


Como podemos observar en la Tabla 1, algunos autores identifican emprendimiento con creación de empresas, pero la gran mayoría lo asocian a conceptos que, si bien pueden relacionarse con el mundo empresarial, no necesariamente están ligados a la puesta en marcha de una empresa. Algunos autores, de hecho hacen una clara distinción entre emprendimiento y creación de empresas.

Sin embargo, lo que queremos poner de manifiesto en esta tesis es que, a la hora de evidenciar empíricamente la contribución del emprendimiento al desarrollo económico de los países y regiones, los estudios se centran exclusivamente en las cifras de creación y crecimiento de empresas. Así, según Naudé (2013), las bases de datos más importantes para medir el emprendimiento son: La Organización Internacional del Trabajo, que mide el autoempleo; el GEM, que mide la creación de empresas; y el Banco Mundial, que mide el registro de nuevas empresas. Según este mismo autor, los estudios que utilizan estas bases de datos han puesto al descubierto dos conjuntos de resultados. En primer lugar, hay una falta de una evidencia empírica clara de que el emprendimiento impulse el crecimiento económico, la productividad, o el empleo. Los estudios encuentran una mezcla de resultados. En segundo lugar, parece haber una relación en forma de $U$ entre el emprendimiento y el nivel de desarrollo económico de un país, medido por el PIB per cápita.

Si, como hemos comprobado en la conceptualización del término emprendimiento, la mayoría de autores lo asocian a conceptos que no necesariamente están ligados en exclusiva a la creación de empresas, encontramos una clara divergencia entre la conceptualización del término y la forma en la que se mide su papel en el desarrollo económico. En este sentido encontramos que para que las conclusiones puedan reflejar fielmente la realidad sería necesario realizar una medida más acorde con la conceptualización del término emprendimiento y su justificación como motor del desarrollo. De lo contrario, se están basando las conclusiones en 
estudios que analizan un conjunto de datos que no reflejan la realidad de lo que se quiere medir, tal como se muestra en la Figura 2.

Figura 2: Divergencia entre base teórica y análisis empírico del emprendimiento

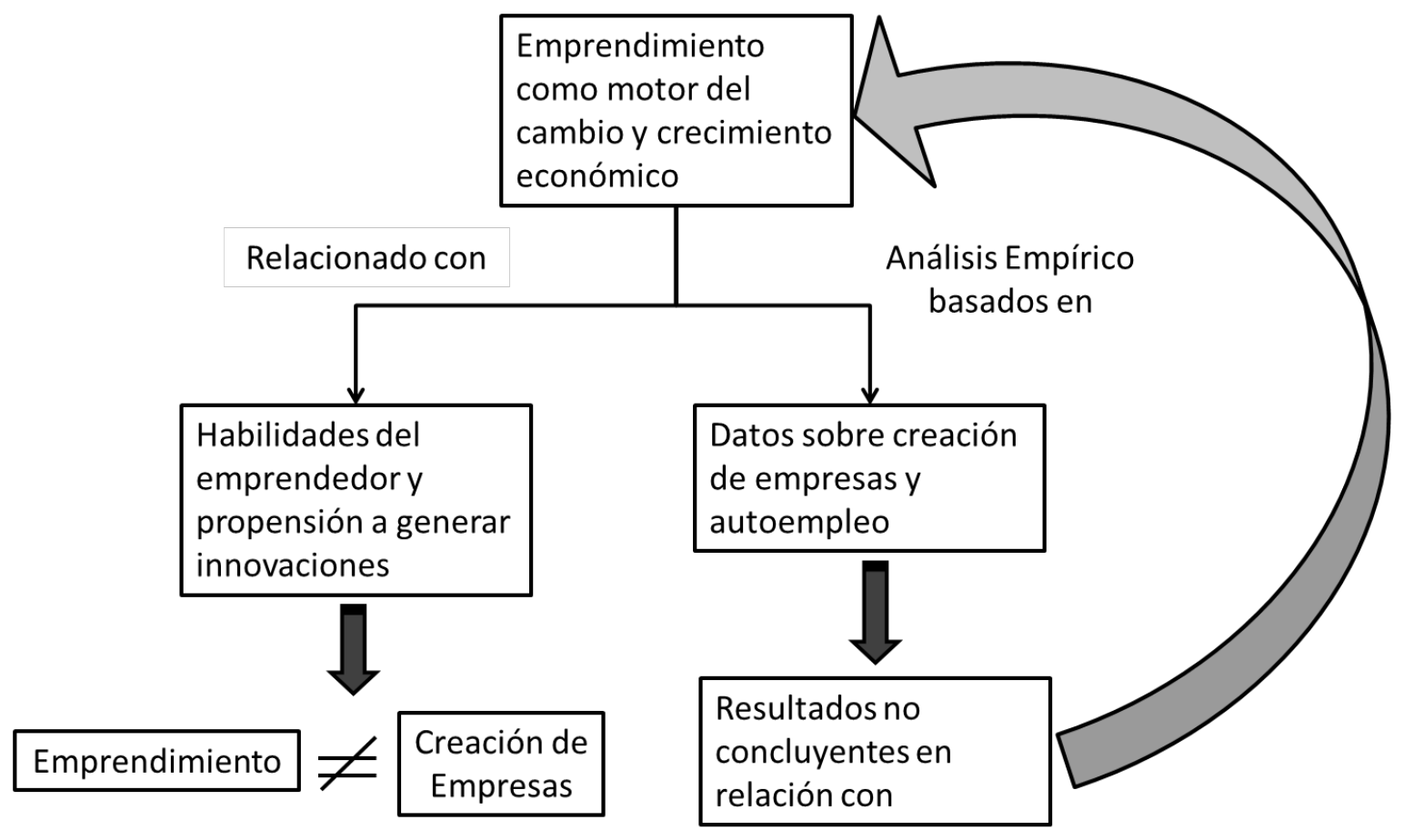

Fuente: Elaboración propia

En lo que a los objetivos de la presente tesis se refiere, esta divergencia está relacionada con el concepto de universidad emprendedora y con lo que las universidades entienden por fomento del emprendimiento, como veremos en los siguientes epígrafes. Además, esta divergencia, como se muestra a continuación, conlleva ciertas implicaciones a nivel político que afectan al fomento del emprendimiento como herramienta para el desarrollo económico y social. 


\subsubsection{Implicaciones para los resultados, conclusiones y recomendaciones}

Para analizar el impacto del emprendimiento sobre el desarrollo económico y/o social de un país es necesario emplear índices de medida coherentes con la conceptualización del término emprendedor y con los razonamientos teóricos que vinculan emprendimiento y desarrollo económico, de lo contrario, las conclusiones a las que nos lleven los estudios realizados no explicarán el impacto de la actividad emprendedora ni podrán ser comparados entre sí.

La mayoría de los índices de medida propuestos para evaluar la actividad emprendedora, se basan en cifras explicativas de la actividad empresarial (número de empresas creadas, intencionalidad de crear empresas, número de nuevas empresas) y no de la actividad emprendedora propiamente dicha. No queremos decir con esto que la actividad empresarial no tenga impacto sobre el desarrollo económico y que no deba ser estudiada en su globalidad. Lo que queremos apuntar con nuestra observación es que son términos diferentes que explican comportamientos diferentes. Esto debe reflejarse en las conclusiones de sus estudios y, sobre todo, a la hora de realizar recomendaciones políticas, ya que el fomento de una $u$ otra actividad tendrán impactos diferentes en el desarrollo económico, requiriendo además de instrumentos distintos.

Esta última observación sobre las recomendaciones políticas nos lleva a reflexionar sobre la repercusión que puede tener la identificación del fenómeno emprendimiento con creación de empresas. Según lo expuesto anteriormente, esta vinculación puede llevar a una interpretación miope de la relación entre emprendimiento y desarrollo económico, dando lugar a planteamientos políticos no acordes con los objetivos perseguidos. En este sentido, tal como hemos apuntado en el marco empírico, esta vinculación entre emprendimiento y creación de empresas está llevando a responsables políticos a poner en marcha acciones para promover la 
creación de empresas como motor del desarrollo económico. Esta relación (emprendimiento y creación de empresas), cierta en algunos casos, no es generalizable y requiere de la aclaración y diferenciación de conceptos como emprendimiento, empresario, emprendedor, actividad empresarial, actividad emprendedora, empresa innovadora y organización emprendedora. Sólo de este modo se podrán identificar las acciones apropiadas según el objetivo perseguido en cada caso y acorde con las implicaciones de cada concepto para el desarrollo económico.

Un ejemplo de esto lo encontramos en Acs y Szerb (2010), quienes con objeto de comprender mejor el fenómeno emprendedor, proponen The Global Entrepreneurship and Development Index (GEDI), un índice independiente basado en índices como el GEM, The Ease of Doing Business Index, The Global Competitiveness Index, y The Index of Economic Freedom (Djankov et al, 2002; Miller y Holmes, 2010; Porter et al, 2001; Sala-i-Martin et al., 2007). El GEDI se construye a partir de tres subíndices: 1) actitudes emprendedoras; 2) actividades emprendedoras; y 3) Aspiraciones emprendedoras. Estos autores definen el subíndice "actividad emprendedora" como puesta en marcha de empresas en el sector de media y alta tecnología industrial a partir de emprendedores formados en la detección de oportunidades de negocio en un entorno más o menos competitivo. Queremos poner el acento en que según esta definición, se identifica actividad emprendedora con:

1. Creación de empresas

2. El sector de media y alta tecnología industrial

3. Formación de emprendedores para la detección de oportunidades de negocio

4. Competitividad

Vemos nuevamente una falta de correspondencia en la literatura entre la conceptualización del término emprendedor y los indicadores empleados para medir su impacto en el desarrollo económico. Analizando esta definición de actividad emprendedora, podemos inferir que un intento 
político por fomentar el desarrollo económico a través de la actividad emprendedora, según esta definición, podría llevarnos a poner el acento en la creación de empresas en el sector de media y alta tecnología industrial. En un país desarrollado, esta política tendría probablemente efectos positivos sobre el desarrollo económico. Sin embargo, ¿qué ocurriría al intentar implementar este tipo de políticas en países en vías de desarrollo? ¿Tendría el mismo efecto? Por otro lado, ¿se circunscribe la actividad emprendedora únicamente a sectores industriales de media y alta tecnología?

Respecto a las primeras cuestiones, los estudios sobre el desarrollo económico en países en vías de desarrollo (Acs y Amorós, 2008; LópezClaros et al, 2006, entre otros) nos indican que andar el camino hacia la etapa basada en la innovación requiere que estos países sienten las bases adecuadas para que la innovación y el emprendimiento puedan actuar como catalizadores de este cambio. El afianzamiento de estas bases pasan necesariamente por:

- Solucionar los problemas relativos a las instituciones informales (corrupción, estabilidad política, modelos de referencia, etc.) y fortalecerlas (Alvarez y Urbano, 2011).

- Combinar las políticas basadas en la eficiencia con políticas dirigidas al fomento del emprendimiento y la innovación (Acs y Amorós, 2008)

Este segundo paso pasa necesariamente por la definición del término emprendimiento. Sólo si entendemos el emprendimiento basado en las habilidades del emprendedor como motor del cambio y no sólo como mecanismo para la creación de empresas, se podrán implementar las medidas apropiadas para hacer del emprendimiento una pieza clave para el desarrollo económico en estos países.

En cuanto a la cuestión de la vinculación entre emprendimiento y el sector industrial de media y alta tecnología, queremos ilustrarlo con el caso de INDITEX, una empresa española del sector tradicional textil que hoy en día 
se ha convertido, gracias a la habilidad emprendedora de su creador, en uno de los mayores imperios del mundo generando un desarrollo económico y social sin precedentes en el territorio donde se ubica (Blanco y Salgado, 2004). Por tanto, circunscribir, a la hora de realizar estudios empíricos, la actividad emprendedora a sectores de media-alta tecnología, implicaría la realización de estudios que pueden quedar incompletos y llegar a conclusiones poco exactas.

Con todo ello, pretendemos arrojar luz sobre la importancia de una correlación entre la conceptualización teórica del término emprendimiento y su posterior aplicación a la hora de establecer índices que pretendan medir el impacto de esta actividad sobre el desarrollo económico de las regiones y países.

\subsubsection{Una propuesta de conceptualización sobre emprendimiento}

Tras analizar la amplia literatura sobre la conceptualización del término emprendimiento constatamos que no existe un consenso entre los investigadores. No obstante, tras lo expuesto en el marco teórico y en este mismo apartado, consideramos que se hace necesaria ofrecer una visión sobre el concepto emprendimiento a los efectos de la presente tesis. Así pues, consideramos al emprendedor como a un individuo que goza de cierta libertad y autonomía, proactivo, con actitudes y habilidades que fomentan la innovación (en cualquiera de los aspectos estipulados por Schumpeter), la detección de oportunidades y la asunción controlada de riesgos en situación de incertidumbre. Desde nuestro punto de vista podemos definir estas habilidades como emprendedoras. Desde este prisma, consideramos que ni todos los emprendedores son empresarios ni todos los empresarios son emprendedores (ver Fig. 3). 
Figura 3: Emprendedores vs Empresarios

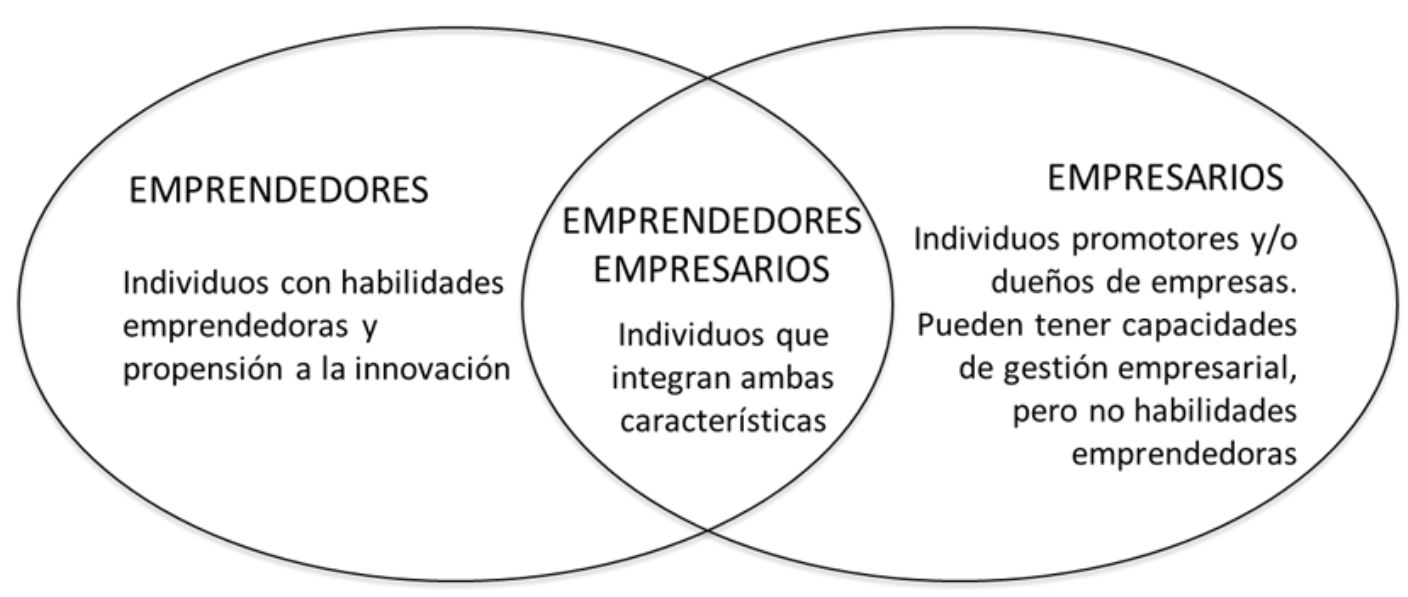

Fuente: Elaboración propia

Definimos, por tanto, el emprendimiento como el proceso por el que se detectan nuevas oportunidades y/o se ponen en marcha acciones encaminadas a detectar oportunidades y/o generar nuevas actividades innovadoras, ya sean empresas, productos, procesos, formas de comercialización o formas de gestión, pudiendo asumir para ello riesgos controlados en situación de incertidumbre. Nuestro concepto de emprendimiento muestra una visión amplia que integra conceptos como el emprendimiento social (Dees, 1998) y el emprendimiento corporativo e intraemprendimiento (Antoncic y Hisrich, 2000; Vesper, 1990).

Teniendo en cuenta esta conceptualización de emprendimiento y las divergencias mencionadas en este epígrafe, nos proponemos estudiar el fenómeno del fomento del emprendimiento en la universidad española y su contribución al desarrollo socioeconómico. Para ello, tendremos que tener en cuenta el concepto de universidad emprendedora y de servicios innovadores y emprendedores que hemos descrito en el marco empírico. 


\subsection{El Fomento del emprendimiento en la universidad española}

Las universidades españolas han estado tradicionalmente alejadas del entorno empresarial y de las necesidades de dicho entorno. $\mathrm{Ni}$ los empresarios han recibido suficiente formación técnica, ni los técnicos han recibido suficiente formación ni estímulos relacionados con el emprendimiento. En este sentido, las universidades han dirigido tradicionalmente sus esfuerzos en formar empleados que trabajen por cuenta ajena, sin preocuparse demasiado por la formación de emprendedores y empresarios (Dalmau Porta et al, 2003).

La primera iniciativa de fomento del espíritu emprendedor y creación de empresas desde una universidad española se realizó en el año 1992 cuando la Universidad Politécnica de Valencia (UPV), puso en marcha el Programa IDEAS (Iniciativas para el Desarrollo de Empresas Nuevas) con el objetivo de estimular a la comunidad universitaria para la creación de spin-off, convirtiéndose en el único programa de esta naturaleza en España hasta el año 1997. En esta fecha se establecen otros tres programas de creación de empresas en la Universidad Complutense de Madrid, la Universidad Pública de Navarra y la Universidad de Euskadi, iniciándose una tendencia creciente que tuvo su máximo nivel en el año 2000 con la creación de 10 nuevos programas. Actualmente todas las universidades españolas poseen un programa de fomento del emprendimiento y creación de spin-off universitarios.

Sin embargo, no todos los programas de emprendimiento universitario se centran en los mismos objetivos, ni dirigen sus actividades a los mismos colectivos. De hecho, tal como hemos venido abogando a lo largo del presente trabajo, fomento del emprendimiento y apoyo a la creación de empresas no son lo mismo. La mayoría de universidades españolas se centran en este último aspecto sin tener en cuenta el concepto de emprendimiento en su amplitud. Si concretamos aún más, algunas 
universidades se centran sólo en la creación de spin-off como mecanismo de transferencia de conocimiento, sin prestar atención al resto de actividades relacionadas con emprendimiento y que pueden orientarse a toda la comunidad universitaria y no sólo a profesores e investigadores. En la Tabla 2 se muestra los programas de fomento de emprendimiento o apoyo a la creación de empresas en las universidades públicas españolas y el tipo de actividades que encontramos entre sus servicios. Hemos dividido las actividades en tres:

- Asesoramiento: Incluye apoyo al desarrollo del plan de negocio y asesoramiento durante el proceso de creación y desarrollo de la empresa

- Formación: este grupo recoge la formación específica sobre emprendimiento, talleres, cursos, masters, etc., relacionada con emprendimiento.

- Emprendimiento: con esta denominación queremos reflejar las actividades relacionadas con el fomento de la cultura emprendedora más allá del asesoramiento, formación y creación de empresas. Contempla investigación en aspectos relacionados con emprendimiento (entendido como lo hemos definido en esta tesis) así como acciones destinadas a fomentar un espíritu innovador y emprendedor (que no sólo empresarial) entre la comunidad universitaria. 
Tabla 2: Actividades de FEyADE en Universidades Públicas Españolas

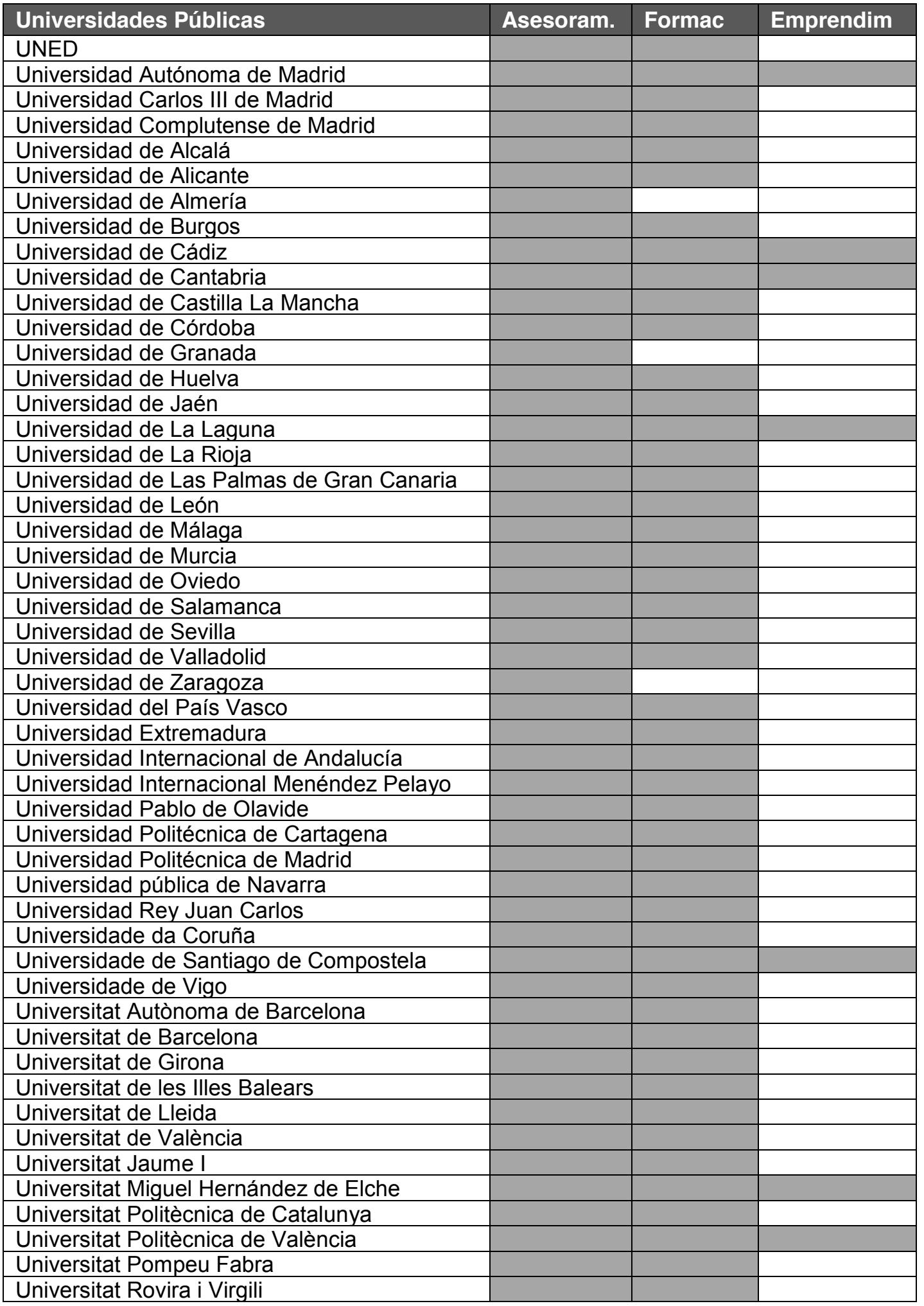

\section{Fuente: elaboración propia}


Como vemos, la mayoría de las universidades integran actividades relacionadas con el apoyo a la creación de empresas y la formación en emprendimiento (la mayoría de ellas orientada a cómo crear y gestionar una empresa). Sin embargo muy pocas se centran también en cómo implantar una cultura emprendedora dentro de la propia universidad. De las 50 universidades públicas, tan sólo 7 , realizan actividades de las que hemos denominado emprendimiento. La mayoría de estas universidades se centran en acciones de investigación sobre el fenómeno. Tan sólo es destacable el caso de la Universidad de La Laguna, que contempla un programa específico para formar a profesores que quieran inculcar la cultura emprendedora en las aulas y un grado en Desarrollo Emprendedor que va más allá de formar gestores de empresas, teniendo en cuenta las habilidades del emprendedor en su concepto amplio. Es de mencionar que todas las universidades poseen un programa para asesoramiento a creación de spin-off a partir de resultados de investigación, como consecuencia de la puesta en marcha de la Ley Orgánica 4/2007, de reforma de la Ley 6/2001, como veremos en un epígrafe posterior. Así mismo, destacamos que muchas universidades realizar sus actividades de FEyADE en colaboración con otras instituciones externas (gobiernos regionales, CEEl, entidades financieras, fundaciones, etc.), lo que refuerza nuestra visión de colaboración para la obtención de resultados óptimos que veremos en el epígrafe 4.3.

Como hemos abogado a lo largo de la presente tesis, una universidad emprendedora debe atender de forma emprendedora a sus tres misiones, lo que conlleva trabajar en todos los ámbitos del emprendimiento y no centrarse únicamente en la creación de empresas. Así pues, en los siguientes epígrafes, nos referiremos a la incorporación del emprendimiento como actividad formativa en las universidades (como parte de la primera misión de la universidad) y al apoyo a la creación de empresas, y más concretamente las spin-off universitarias como parte de la segunda y tercera misión. 


\subsubsection{Formación emprendedora y en emprendimiento}

Tal como hemos ido indicando a lo largo de la presente tesis, la universidad emprendedora debe atender a un amplio número de actividades relacionadas con sus tres roles básicos: enseñanza, investigación y contribución al desarrollo socioeconómico; y, al mismo tiempo, tienen que ser gestionadas como un todo. Todas estas actividades, incluyendo la gestión, deben ser desarrolladas por la universidad acorde con su denominación de emprendedora, lo que implica que una gran variedad de agentes, instrumentos e infraestructuras deben estar involucrados en las mismas. Este cambio de paradigma conlleva implicaciones para todas y cada una de las tres actividades que se le atribuye a una universidad emprendedora. En el caso de la actividad docente, estas implicaciones tienen que ver con:

- Los objetivos y resultados esperados

- La planificación de las materias

- Los requisitos a cumplir por el profesorado

- $\quad$ El proceso de enseñanza-aprendizaje y evaluación

En cuanto a los objetivos de la actividad docente, la forma de entender la docencia pasa de ser la lección magistral a un conjunto de mecanismos entre los que encontramos además de dicha lección magistral, conocimiento de los agentes con los que se supone el alumno interactuará, de forma que la visión de la docencia pasa de la mera teoría a un conjunto de teoría y práctica con una clara aplicabilidad. Por tanto, como resultado del proceso enseñanza-aprendizaje obtendremos titulados formados no sólo en materias teóricas y prácticas, sino también en capacidades y comportamientos innovadores y emprendedores.

Así pues, la planificación de las materias deberá tener en cuenta los nuevos objetivos y resultados esperados, incluyendo actividades que permitan el autoaprendizaje y la formación en las capacidades 
anteriormente mencionadas. En la determinación y elaboración del temario, sería deseable que participaran empresarios y profesionales relacionados con la materia a impartir, titulados recientes y demás agentes que pudieran aportar conocimientos prácticos, experiencias y vivencias, de forma que el temario cubra una serie de necesidades que van más allá de la mera transmisión de conocimientos. Así pues, para llegar a la redacción final del temario se hace necesaria una serie de subetapas y retroalimentaciones hasta determinar las materias a impartir y el esquema del curso. El coordinador de las materias será el encargado de establecer las "reglas del juego" conectando todas las piezas del puzzle y estableciendo, tras analizar las necesidades de las empresas y la sociedad, cuáles son las especificaciones sobre las que trabajarán para redactar los temarios.

Otra implicación de la transición hacia la universidad emprendedora es el cambio en el propio docente. Debemos entender la docencia de una universidad emprendedora como la impartida por un profesional con una vasta base de conocimientos, pero que mantenga siempre viva la conexión con el mundo profesional y empresarial en relación con aquella materia que imparte. De esta manera garantizaremos un proceso de enseñanzaaprendizaje basado en experiencias tal y como habíamos indicado anteriormente. En este sentido cobra especial interés la posibilidad de que el propio docente sea empresario o lleve a cabo una actividad profesional estrechamente vinculada con la materia que imparte. De igual modo la posibilidad de que profesionales y empresarios puedan transmitir su experiencia y conocimientos a través de las aulas, se presenta como una herramienta útil para la docencia en universidades emprendedoras.

Por último, la consideración de universidad emprendedora conlleva implicaciones en el proceso de enseñanza/aprendizaje. Este proceso presenta un claro carácter bipolar, donde en un extremo se encuentra la enseñanza cuyo protagonista principal es el profesorado y en el opuesto, el aprendizaje con el alumnado como protagonista. Como es evidente, estos términos no son lo mismo, pero en realidad no viene a representar más que 
las dos caras de una misma moneda y, por tanto, resultan indisociables. En el informe sobre educación presentado a la UNESCO en 1996 y coordinado por Jacques Delors, se indica que los cuatro pilares en los que se basa la educación son:

- $\quad$ Aprender a conocer, actividad más tradicional de la enseñanza a través de la transmisión de conocimientos del profesor al alumno, aunque complementada con nuevos aspectos.

- Aprender a hacer, visión práctica de la misma, mediante la capacitación del estudiante para enfrentarse a determinadas tareas.

- $\quad$ Aprender a vivir juntos, desarrollando la comprensión del otro y los valores del pluralismo y la percepción de las formas de interdependencia, sin renunciar a las propias ideas.

- $\quad$ Aprender a ser, supone el desarrollo de la personalidad, de la autonomía personal, del juicio y de la responsabilidad.

Pero las reflexiones sobre el proceso de enseñanza/aprendizaje no son nuevas, "la primera finalidad de la enseñanza fue formulada por Montaigne: es mejor una mente bien ordenada que otra muy llena. /.../ Una mente bien formada es una mente apta para organizar los conocimientos y de este modo evitar su acumulación estéril' (Morin, 2001). La labor como profesores ante los estudiantes está limitada por el espacio y el tiempo. No se puede pretender transferirles todo lo que se considere que deben saber simplemente por el mero hecho de contárselo. Debemos traspasar las barreras del tiempo y enseñarles a que quieran y puedan continuar aprendiendo al abandonar las aulas, deben aprender a aprender. Cuando los alumnos se conviertan en profesionales es probable que los instrumentos de que dispongan en el ejercicio de su actividad y las técnicas y métodos que empleen sean sensiblemente diferentes a las que se les haya podido describir y transmitir desde la universidad. Lo que importa, no es tanto poseer una información determinada, sino fundamentalmente 
haber adquirido la capacidad para descubrir y saber encontrar esa información. Concebido así el proceso educativo, la misión encomendada al educador cambia, pasando en gran medida a transformarse en un director y organizador de la situación de aprendizaje. Todo ello implica una importante dosis de capacidad emprendedora, entendida desde una conceptualización amplia.

Debemos tener en cuenta que el concepto de aprender implica tanto el asimilar y reconstruir conocimientos, como adquirir y usar destrezas y desarrollar actitudes. Por ello, al enunciar los objetivos que se quieren alcanzar en la programación docente se deberá tener en cuenta plantear objetivos de cada uno de estos ámbitos:

- Cognoscitivo: relacionados con las informaciones y comprensiones

- Psicomotriz: relacionados con los hábitos, habilidades y destrezas

- Afectivo: relacionados con las actitudes, intereses e ideales

La siguiente cita resume perfectamente lo que debería ser la actividad docente en la universidad, una actividad, que según esta definición podríamos denominar como emprendedora. "Quienes la inventaron, concibieron la Universidad ante todo como un lugar de diálogo; de discusión franca de las ideas; de intercambio creativo de pareceres; de exploración de los modos de pensar más aptos para aportar comprensión. No era una pasiva y memorística transmisión de conocimientos, sino un ejercitarse en adquirir la musculatura mental necesaria para vivir inteligentemente" (de Andrés Argente, 2002). Si esto es así, no nos desviemos de su filosofía inicial y, sobre todo, no nos escudemos en el elevado número de estudiantes para ejercer nuestra actividad de forma innovadora y emprendedora. 


\subsubsection{Innovación y Emprendimiento en la Educación Superior}

La incorporación de módulos formativos sobre innovación y emprendimiento en la Educación Superior está estrechamente relacionada con la tercera misión de la universidad: su contribución al desarrollo económico y social del territorio. Pero, ¿cómo y por qué existe dicha relación? Hemos de preguntarnos cuál es el motivo por el que debemos plantearnos la incorporación de dicha formación en la universidad.

En estrecha relación con el debate expuesto sobre la conceptualización del término emprendimiento y su aplicación práctica y, del mismo modo que existe una tendencia a vincular emprendimiento con creación de empresas, también existe la tendencia a identificar la formación en innovación y emprendimiento con dar a conocer el proceso de creación de empresas entre los universitarios, es decir, enseñar a crear empresas. Sin embargo, ni una universidad emprendedora es aquella que crea muchas empresas, como ya hemos apuntado varias veces, ni la enseñanza en innovación y emprendimiento debe limitarse sólo a mostrar cómo crear y gestionar empresas.

Los motivos por los que una universidad emprendedora debería plantearse la incorporación de formación sobre innovación y emprendimiento en sus titulaciones son varios:

- Sensibilizar y dinamizar hacia la creación de empresas desde las aulas

- Fomentar la cultura emprendedora y de innovación

- Formar futuros emprendedores en todos los ámbitos

La creación de empresas innovadoras y de base tecnológica es uno de los motores del crecimiento económico de cualquier región desarrollada. Pero para que estas empresas existan, deben existir emprendedores con una idea de negocio de la que posteriormente surgirán estas empresas. En España existe aún un amplio rechazo entre los jóvenes hacia la creación de 
empresas, en cierto modo, por desconocimiento de lo que ello implica, y porque creen que el proceso y los trámites para su puesta en marcha y gestión son demasiado complicados, lo cual no deja de ser cierto si lo comparamos, por ejemplo, con los trámites necesarios en Estados Unidos. Por ello, la formación sobre innovación y emprendimiento en las universidades se presenta como una potente herramienta de sensibilización y dinamización hacia la creación de empresas por parte de jóvenes titulados universitarios, al incorporarse como una materia más en sus planes de estudios y presentándose como una salida profesional alternativa al empleo por cuenta ajena. Ello hará que los jóvenes se familiaricen con el mundo empresarial, conozcan mejor sus posibilidades y pierdan, en cierta medida, el miedo a ser empresarios.

Sin embargo, este no es el único motivo que nos lleva a la incorporación de módulos formativos sobre innovación y emprendimiento en la educación superior. El fomento de la cultura emprendedora y de innovación, se presenta como otro de los objetivos a tener muy en cuenta. Siguiendo la misma línea argumental del concepto de cultura emprendedora definido por Gibb (1999), la docencia en innovación y emprendimiento debe fomentar la capacidad de los estudiantes de resolver problemas, toma de decisiones y comunicación, su voluntad de asumir responsabilidades, cooperar y trabajar en red, capacidad de autoaprendizaje, proactividad e iniciativa, preparación para asumir riesgos controlados, etc. (Arroyo-Vázquez y Jiménez-Sáez, 2008).

Ello nos lleva al tercero de los objetivos mencionados anteriormente: la formación de futuros emprendedores. En la universidad se forman los futuros empresarios, trabajadores por cuenta ajena, funcionarios, investigadores, docentes, altos cargos, dirigentes políticos, etc. Así pues, en la medida en que consigamos que estos futuros profesionales se formen como emprendedores e innovadores en todos los ámbitos, estaremos contribuyendo a la construcción de una sociedad formada y dirigida por emprendedores y basada en la innovación. 
Así pues, y respondiendo a la pregunta planteada al inicio de este apartado, la incorporación de módulos formativos sobre innovación y emprendimiento en la educación superior tiene implicaciones en cuanto a la contribución económica y social del territorio. Contribución económica en cuanto fomenta la creación de empresas innovadoras, de alto potencial y de base tecnológica, por parte de titulados universitarios. Contribución social en cuanto favorece el fomento de la cultura emprendedora y la generación de profesionales emprendedores e innovadores en todos los ámbitos que favorecen el desarrollo social basado en la innovación y el emprendimiento.

La incorporación de estos módulos formativos requiere de la implantación de un proceso que, como hemos apuntado en el marco teórico del presente trabajo, conlleva la colaboración e implicación de los distintos agentes del ecosistema universitario, tanto internos como externos a las universidades. Dicho proceso deberá contemplar el diseño de los planes de estudio, materias y titulaciones acorde con cada uno de los objetivos planteados en este apartado y con las características de cada universidad. Una vez diseñado los planes de estudio, el siguiente paso deberá ser la determinación de las herramientas, profesorado y metodologías más adecuadas para cada caso. En este sentido, debemos tener en cuenta que las características del entorno determinarán, en gran medida, las necesidades formativas de éste, lo que deberá tenerse en cuenta a la hora de desarrollar y poner en práctica el proceso de incorporación de la innovación y el emprendimiento en cada una de las universidades. 


\subsubsection{Creación de spin-off universitarias}

Dada la importancia que, según hemos visto en la literatura, tiene la creación de spin-off universitarias, para el desarrollo económico de las regiones, y la importancia que las universidades están dando a este mecanismo de transferencia de conocimientos, creemos conveniente detenernos en analizar cómo han tenido que afrontar las universidades españolas la creación de este tipo de empresas, dada la situación legal y normativa existente en España. El apoyo a este tipo de empresas entronca con dos de las misiones de la universidad. Por un lado, respecto a la investigación, proporciona vías adicionales e incentivos para el desarrollo de actividades de investigación relacionadas directamente con el entorno empresarial. Por otro lado, dada la actividad de transferencia de conocimiento implícita en la creación de este tipo de empresas, se atiende a las necesidades de la tercera misión de contribución al desarrollo económico y social del territorio.

El desarrollo de las spin-off universitarias puede contemplarse como una iniciativa de apoyo público a la innovación de base tecnológica. Además de otras posibles ayudas públicas, la universidad que apoya la iniciativa incurre en un coste de oportunidad nada despreciable. Un ejemplo de ello es, en su caso, la liberación de los profesores-empresarios de sus obligaciones docentes y de producción de conocimiento libre. La creación de empresas a partir de la actividad investigadora universitaria implica la transferencia de un conocimiento y unos resultados de investigación, desarrollados como consecuencia de la función investigadora y docente del personal de la universidad y financiados, total o parcialmente, con fondos públicos y sobre cuya explotación tiene la institución universitaria unos derechos reconocidos por el actual marco jurídico. Por tanto se hace especialmente necesario valorar adecuadamente los riesgos de supervivencia de las empresas que reciben los apoyos públicos. Detrás de ellas existen costes de oportunidad para los recursos colectivos que reciben las nuevas empresas con la expectativa de que el éxito tecnológico 
y comercial de la iniciativa de beneficios públicos y privados suficientes como para compensar dichos costes.

Sin embargo, en el caso de la universidad española, en especial en la universidad pública, la creación de spin-off por parte del profesorado no ha sido una cuestión asequible desde el punto de vista legal y normativo. Tal como hemos apuntado en el marco empírico, históricamente han existido una serie de restricciones legales para que los profesores universitarios puedan convertirse en promotores de una spin-off.

Así, por aplicación de la Ley 53/1984, de 26 de diciembre, de Incompatibilidades del Personal al Servicio de las Administraciones Públicas, existían las siguientes limitaciones para todos los profesores universitarios que tienen la condición de funcionarios (catedráticos y profesores titulares de Universidad, catedráticos y profesores titulares de escuelas universitarias), en virtud del art., 12 párrafos b y d:

- Prohibición para todos de pertenencia a consejos de administración u órganos rectores de Empresas o entidades privadas siempre que la actividad de las mismas esté directamente relacionada con las que gestione el Departamento, Organismo o entidad (...)

- No podían tener una participación superior al $10 \%$ en el capital de las empresas o sociedades a que se refiere el párrafo anterior.

Por otro lado en virtud de la Ley de Contratos de las Administraciones Públicas, aprobada por Real Decreto Legislativo 2/2000, de 16 de junio existe la prohibición de contratar con la administración a:

- Las personas físicas o los administradores de persona jurídica sujetas a la Ley de incompatibilidades 53/1984, alcanzando dicha prohibición igualmente a los cónyuges, personas vinculadas con análoga relación de convivencia afectiva y descendientes de las personas a que se refiere el párrafo 
anterior, siempre que, respecto a estos últimos, dichas personas ostenten su representación legal.

Estas restricciones suponían en la práctica que el promotor de la spin-off universitaria, que habitualmente es un funcionario con reconocido prestigio y trayectoria, no pudiera crear la empresa relacionada con su ámbito de investigación. Esto suponía una desincentivo importante para que los investigadores universitarios promovieran este tipo de empresas.

En este sentido, la Ley Orgánica 4/2007, de reforma de la Ley 6/2001, introdujo un régimen específico para la creación de este tipo de empresas, levantando determinadas restricciones en cuanto a la participación del personal docente e investigador de la Universidad, en unos supuestos, y según unos procedimientos, en los que la Universidad tiene un especial protagonismo.

Así, en la disposición adicional vigésimo cuarta de dicha ley se establece una modificación de la Ley 53/1984, de 26 de diciembre, de incompatibilidades del personal al servicio de las Administraciones públicas. El texto de esta disposición reza como sigue:

Las limitaciones establecidas en el artículo 12.1 b y d de la Ley 53/1984, de 26 de diciembre, de incompatibilidades del personal al servicio de las Administraciones públicas, no serán de aplicación a los profesores y profesoras funcionarios de los cuerpos docentes universitarios cuando participen en empresas de base tecnológica, promovidas por su universidad y participadas por ésta o por alguno de los entes previstos en el artículo 84 de esta Ley, creadas a partir de patentes o de resultados generados por proyectos de investigación realizados en universidades, siempre que exista un acuerdo explícito del Consejo de Gobierno de la Universidad, previo informe del Consejo Social, que permita la creación de dicha empresa. 
En este acuerdo se debe certificar la naturaleza de base tecnológica de la empresa, y las contraprestaciones adecuadas a favor de la universidad. El Gobierno regulará las condiciones para la determinación de la naturaleza de base tecnológica de las empresas a las que se refiere el párrafo anterior.

En definitiva, y tras la aprobación de esta modificación en las restricciones, podemos concluir que se puede eliminar la prohibición que tenía el profesor funcionario de la universidad para poseer más de un $10 \%$ en el capital de una empresa y también la prohibición de pertenencia al órgano de administración, de una empresa cuya actividad esté directamente relacionada con la que gestiona el departamento, organismo, entidad en que presta los servicios el personal afectado (art 12.1.b, de la misma Ley), siempre que se cumplan todos y cada uno de estos requisitos:

- Que la empresa a crear sea de base tecnológica. Las condiciones para determinar dicha naturaleza tecnológica debe establecerlas el Gobierno, lo cual no se ha establecido cuando se aprobó la Disposición adicional $24^{\mathrm{a}}$.

- Que dicha empresa sea participada por la Universidad, partiendo de patentes o resultados de investigación susceptibles de explotación comercial. Es decir, debe haber existir contrato de transferencia de tecnología.

- Que exista acuerdo explícito del Consejo de Gobierno que admita la creación de dicha empresa, previo informe del Consejo Social de la Universidad.

Por tanto, aun habiéndose aprobado esta nueva disposición hay que esperar hasta que se hiciera un desarrollo de la misma con la definición de EBT para poder aplicarla.

En otro orden de cosas, con la modificación de la LOU, en su nueva redacción del art.80, se permite la excedencia temporal para ese tipo de 
profesores y para ese tipo de empresas descritos en la disposición vigésimo cuarta, de hasta 5 años para que se incorpore a dicha empresa, con reserva de puesto de trabajo y antigüedad. En este caso también se requiere una normativa del gobierno que regule las condiciones y procedimiento para dicha concesión.

Hasta la fecha de defensa de la presente tesis no se ha aprobado por parte del gobierno español ningún desarrollo normativo que permita aplicar totalmente lo expuesto en la disposición adicional $24^{\mathrm{a}}$. Así las cosas, las universidades han tenido que ingeniárselas para poder seguir con sus actividades de creación de spin-off, y poder levantar las restricciones mencionadas sin contravenir la ley.

Bajo este panorama, las universidades españolas se pusieron en marcha para cumplir los requisitos que la ley les exigía para poder crear las spin-off y cumplir con su parte de la normativa. En concreto, se pusieron en marcha para crear las normativas internas que regularan la creación de estas empresas en las universidades, cumpliendo así con uno de los requisitos establecidos por la ley. Sin embargo, y aunque las universidades han solicitado insistentemente al Gobierno un desarrollo que defina EBT, tal como se exige en la normativa, éste aún no se ha dado como tal. Hasta 2011, con la publicación de la Ley $2 / 2011$, de 4 de marzo, de Economía Sostenible, no se publicó lo que se puede denominar una definición de EBT que sirviera a los efectos de aplicación de la disposición 24a. Así en el artículo 56 de la citada Ley se regula la cooperación de los agentes públicos de ejecución con el sector privado a través de la participación en empresas innovadoras de base tecnológica. En este artículo se especifica en qué tipo de empresas denominadas innovadoras de base tecnológica pueden participar los organismos públicos (incluidas las universidades). Por tanto, desde la publicación de la Ley de Economía Sostenible, las universidades disponen de un sustento jurídico para aplicar plenamente lo dispuesto en la disposición adicional $24^{\mathrm{a}}$. En dicha Ley de Economía Sostenible, se indica que: 
Los organismos públicos de investigación, las universidades y los demás agentes incluidos en el ámbito de aplicación de este Capítulo, podrán participar en el capital de sociedades mercantiles cuyo objeto social sea la realización de alguna de las siguientes actividades:

a) La investigación, el desarrollo o la innovación.

b) La realización de pruebas de concepto.

c) La explotación de patentes de invención y, en general, la cesión y explotación de los derechos de la propiedad industrial e intelectual.

d) El uso y el aprovechamiento, industrial o comercial, de las innovaciones, de los conocimientos científicos y de los resultados obtenidos y desarrollados por dichos agentes.

e) La prestación de servicios técnicos relacionados con sus fines propios.

(...)La participación de los Organismos Públicos de Investigación en el capital de las sociedades mercantiles a que se refiere el apartado 1 de este artículo cuyo capital sea mayoritariamente de titularidad privada requerirá la autorización previa del Departamento Ministerial al que estén adscritos.

Así pues, las universidades españolas han incluido entre sus actividades de transferencia el apoyo a la creación de spin-off universitarias a partir de resultados de investigación, con las posibilidades y limitaciones que establece la legislación.

No obstante, más allá de las cuestiones que se especifican en la legislación, las universidades, en especial las públicas, deben tener en cuenta una serie de cuestiones relacionadas con la creación de spin-off universitarias. 
Las EBT surgidas como spin-off de las universidades $u$ organismos de investigación, se pueden definir, atendiendo a todo lo visto anteriormente como:

Empresas generadas fundamentalmente por graduados, profesores, investigadores o por iniciativa del propio organismo (universidad o centro de investigación), cuyo negocio tiene como base el conocimiento, la innovación o la tecnología generada por la propia actividad investigadora de dicho organismo.

Estas empresas reúnen las siguientes características a tener en cuenta a la hora de estudiar las implicaciones de las mismas en las universidades $u$ organismos de investigación que las promueven:

- $\quad$ Emprendedores-Investigadores: el equipo promotor está formado en gran medida por personal investigador de la universidad o centro de investigación. En el caso de universidades públicas y organismos públicos de investigación, la participación de este personal en las EBT puede estar sometido a una serie de restricciones legales, según cada país.

- Apoyo explícito del organismo de investigación o universidad: la creación de la EBT es secundada por la entidad matriz mediante un apoyo explícito y con la consideración institucional de "sector estratégico", destinado al desarrollo económico como función social de la universidad u organismo de investigación.

- $\quad$ Participación de la entidad matriz en el accionariado de la EBT. En la mayoría de casos se da una participación de la universidad u organismo de investigación en la EBT. Esta participación puede ser a cambio de un aporte económico o de activos (como consecuencia de la transferencia de conocimientos y resultados que son propiedad del organismo a la futura EBT, por ejemplo). Ello conllevará una serie de consideraciones a tener en cuenta, sobre todo en el caso de universidades y organismos públicos. 
- Gran componente de I+D: Nacen para comercializar una nueva tecnología o un resultado de investigación

- $\quad$ Potencial económico: su componente innovadora y, en muchos casos, su asociación a nuevas tecnologías, ofrece un potencial económico elevado y un alto valor añadido.

Por todo lo anterior, a la hora de plantear y conformar una EBT surgida con la intención de explotar resultados de investigación, la universidad debe tener en cuenta las siguientes implicaciones:

\section{Activos que se gestionan en la creación de EBT}

La creación de EBT se sustenta sobre la gestión de las capacidades y resultados de I+D disponibles, en particular:

- Nuevos conocimientos

- Nuevas capacidades o nuevas tecnologías

- Nuevos productos y servicios, en forma de know-how, tecnología formalizada, patentes o propiedad intelectual

- $\quad$ Recursos: personal, infraestructuras, espacios, etc.

Todo ello conforma los activos y recursos derivados de la actividad investigadora de la universidad u organismo de investigación y, por tanto, constituyen patrimonio institucional, que en caso de tratarse de organismos y universidades públicas, se tratará de patrimonio público.

Por otra parte, cuando se promueve la creación de EBT y se actúa, por tanto, en el ámbito de la gestión empresarial (ámbito privado), debe tenerse en cuenta que:

- Se está gestionando patrimonio de la institución (especial atención al caso de instituciones públicas).

- $\quad$ En el caso de universidades y organismos públicos, se gestionan recursos públicos, siendo exigible una absoluta transparencia en el proceso y en la rendición de resultados. 
- En la medida en que se gestionan capacidades y resultados generalmente de excelencia científica, se actúa normalmente sobre áreas estratégicas de la universidad $\mathrm{u}$ organismo de investigación $\mathrm{y}$, por tanto, sobre ámbitos de importante trascendencia institucional.

- Se "juega" con la imagen de la universidad u organismo de investigación y, por tanto, sobre el valor, proyección y credibilidad de sus capacidades de investigación (cuando una EBT fracasa, fracasa la capacidad investigadora de la institución).

En consecuencia, corresponde a la institución liderar y gestionar esta estrategia, así como promover y rentabilizar coherentemente su puesta en valor con el objetivo de rentabilizar el valor de la actividad investigadora, a partir de:

- La cesión de tecnología y servicios tecnológicos a la EBT que se convierte en un socio estratégico en el desarrollo de la I+D institucional

- La gestión de Unidades de Negocio "propias" que permiten un mayor rendimiento de las inversiones en investigación

- Promover el papel y valor de la universidad u organismo de investigación como agente activo en el desarrollo local, promoviendo la creación de riqueza, empleo de calidad y la diversificación y modernización del tejido económico.

- Facilitar la movilidad de los investigadores entre empresas y universidad $u$ organismos de investigación, lo que permite el reconocimiento de las necesidades tecnológicas de las empresas y de la sociedad en general

- $\quad$ Promover salidas profesionales para investigadores y egresados

- Ampliar y reforzar los clústeres del entorno, e incluso vincular y estimular la investigación en estos ámbitos 
Cuándo promover una spin-off universitaria basada en la investigación

A pesar de las motivaciones anteriormente expuestas sobre la creación de una spin-off, la universidad debe valorar si la creación de la EBT es la mejor vía para realizar la transferencia de conocimiento a la sociedad. En este sentido, la EBT se debe promover sólo cuando:

- Se disponga de un producto, tecnología o servicio innovador, validado y maduro comercialmente.

- La creación de una empresa genere mayor rentabilidad institucional que cualquier otra fórmula de transferencia.

- No exista un socio o cliente empresarial al que transferir el resultado, pero sí existe un entorno accesible y el ámbito de negocio responde a oportunidades reales.

- Se opere sobre ámbitos de desarrollo estratégico bien a nivel local (tecnologías o capacidades de interés en el desarrollo de sectores locales) o a nivel institucional (demostración y consolidación de áreas de investigación estratégicas para la institución)

- No se genere competencia desleal en el entorno empresarial local.

- El desarrollo de la EBT externalice capacidades institucionales de forma congruente con la estrategia del grupo investigador. Debe atenderse a que la creación de una empresa no descapitalice tecnológicamente a los grupos de investigación que la promueven. Así mismo, la creación de la EBT debe ser congruente con la política institucional. Por ello, deberá tenerse cuidado de que la nueva empresa no atente contra los valores o iniciativas institucionales existentes o compita deslealmente con otras iniciativas o estrategias de la institución o de otras unidades de investigación 
Así pues, la universidad u organismo de investigación deberá regular la creación de EBT a partir de su actividad investigadora, de modo que se fomente la creación de EBT entre los investigadores, se regulen las cuestiones que implican a la institución en la creación de estas empresas y se atienda a la actual legislación sobre la materia.

La implicación de las universidades y organismos de investigación en la creación de EBT, así como las peculiaridades de este tipo de empresas, hacen que sea necesario poner en marcha un proceso para su definición y posterior desarrollo, algo más complejo que para las empresas habituales. Esta complejidad viene determinada, sobre todo por el proceso de detección y transferencia de tecnología desde la universidad u organismo de investigación a la EBT y las condiciones de participación y vinculación a la misma.

\subsection{Hacia un modelo integral de Fomento del Emprendimiento Universitario}

En estrecha relación con el concepto de cultura emprendedora definido por Gibb (1999) y, atendiendo a las actividades que la universidad emprendedora debe desarrollar como parte de su tercera misión, identificamos dos tareas críticas. La primera es el Fomento del Emprendimiento, que integra, por un lado, el proceso de dinamización (Castro Martínez et al, 2001) de los agentes implicados hacia un comportamiento emprendedor en el ámbito de la creación y desarrollo de empresas y, por otro, el acercamiento a dicho ámbito de las actividades de investigación y enseñanza relacionadas con el emprendimiento y temas afines. En esta definición queremos destacar que el concepto 'dinamización' es entendido como aquel cambio de comportamiento que 'mueve a alguien a hacer algo' (Castro Martínez et al, 2001). De acuerdo con estos autores, se deben promover dos actividades dentro del proceso de dinamización: la sensibilización y la motivación, por una parte, y la 
provisión de recursos y facilidades (servicios) por otra. La segunda tarea clave es el Apoyo al Desarrollo de Empresas, que definimos como el proceso que recoge la búsqueda, reconocimiento y desarrollo de oportunidades de negocio, la puesta en marcha de la empresa, así como el posterior desarrollo y crecimiento de la misma. En nuestra opinión estas dos actividades deben desarrollarse de forma conjunta, dentro de un marco integral ya que, la mayoría de los agentes están involucrados en ambas actividades y, además, las tareas a llevar a cabo en cada una de ellas se pueden ver beneficiadas de las sinergias entre dichos agentes, mejorando de este modo el proceso de fomento del emprendimiento y apoyo al desarrollo de empresas (FEyADE) considerado como un todo. Por tanto, la consideración sistémica de dicho proceso refuerza todos sus elementos y proporciona el marco apropiado para la obtención de resultados óptimos a través de la creación de redes entre los distintos agentes y actores implicados en el mismo.

Existe una gran cantidad de literatura alrededor de los procesos de emprendimiento en las universidades, sin embargo, la gran mayoría aborda sus actividades de forma separada, no como un proceso único ni en un sentido amplio. Como ejemplo podemos citar que el fomento del emprendimiento suele ser considerado sólo como la promoción de la transferencia de conocimiento desde las universidades a través de la creación de empresas spin-off. Por otro lado, tal como hemos visto en el Capítulo 3, el proceso de apoyo al desarrollo de empresas en las universidades sólo suele ser considerado cuando éste está relacionado con las empresas spin-off en las que existen DPI de la universidad o ésta participa en su accionariado. En oposición a este enfoque, Dalmau et al. (2003) consideran el proceso de FEyADE en las universidades como un proceso único en el que se deben desarrollar diversas actividades relacionadas entre sí con el objetivo de promover la creación de nuevas empresas por parte de estudiantes, egresados y personal de la universidad. 
Este modelo, que consta de cinco fases: sensibilización, construcción de la 'Célula de Oportunidad de Negocio' ${ }^{23}$, preincubación, incubación y explotación, tiene en cuenta no sólo las fases de reconocimiento, desarrollo y explotación de la oportunidad, sino también el proceso de sensibilización previo a la identificación de la oportunidad de negocio. Sin embargo este modelo no considera el proceso de FEyADE de forma que los agentes y actores (tanto internos como externos a la universidad) estén involucrados en el mismo y trabajen en red para desarrollar dicho proceso. Por otra parte, el objetivo del proceso de sensibilización considerado por estos autores es únicamente sensibilizar a los emprendedores sobre el proceso, pero no involucra ni tiene en cuenta la sensibilización del resto de agentes del proceso. Rasmussen y Borch (2006) ofrecen un enfoque diferente a través del desarrollo de capacidades dinámicas dentro de la universidad: nuevos patrones, el equilibrio entre el pasado, el presente y el futuro, la integración de recursos y la integración y creación de nuevos recursos de conocimiento. Una vez más la atención se pone únicamente sobre la creación de spin-off basadas en resultados de investigación, sin embargo, estos autores tienen en cuenta que en el proceso están involucrados distintos agentes, tanto internos como externos a la universidad, y que éstos tienen, en parte, objetivos contrapuestos.

Un enfoque alternativo que debemos tener en cuenta es el modelo de Emprendimiento en Red de Nikos $^{24}$ (Nikos, 2004) desarrollado desde la Universidad de Twente y que ya se ha presentado. Dicho modelo considera el desarrollo de sus actividades en el campo del emprendimiento a través de cuatro nodos: investigación, enseñanza, apoyo al desarrollo de empresas y formación y consultoría. Creemos que este modelo ofrece una visión más amplia, ya que tiene en cuenta actividades adicionales a la creación de spin-off así como diferentes agentes y redes para su desarrollo.

\footnotetext{
${ }^{23}$ Estos autores definen la Célula de Oportunidad de Negocio como la integración de los tres elementos necesarios para construir una nueva empresa: la idea de negocio, el equipo emprendedor y los recursos. Argumentan que estos elementos son como la 'célula' inicial de una nueva empresa.

${ }^{24}$ Nikos se corresponde con el acrónimo del Instituto Holandés para el Emprendimiento Intensivo en Conocimiento, localizado en la Universidad de Twente, en los Países Bajos.
} 
El proceso emprendedor considerado en Nikos está dividido en tres fases: el reconocimiento de la oportunidad, el desarrollo de la oportunidad y la creación de valor. Como podemos observar, la sensibilización está fuera de este proceso y, por tanto, fuera del modelo de Emprendimiento en Red de Nikos, no obstante este modelo ofrece un punto de vista lo suficientemente amplio como para ser útil a nuestros propósitos.

Con objeto de cubrir las carencias detectadas en los modelos anteriores, la presente tesis propone un modelo integral para el FEyADE en universidades emprendedoras que tiene un funcionamiento sistémico que refuerza todos sus elementos y proporciona el marco apropiado para la obtención de resultados óptimos a través de la creación de redes entre los distintos agentes y actores implicados en el mismo. Hemos basado nuestro enfoque integral en el modelo de Nikos así como en el comportamiento emprendedor de la Universidad de Twente, ya que consideramos que el tratamiento conjunto de estos dos modelos junto con la consideración de actividades de dinamización completa nuestros requerimientos para el proceso de FEyADE. Dicho modelo y su funcionamiento conformarán la base del análisis de las actividades relacionadas con el emprendimiento en las universidades en el presente trabajo.

Tal como hemos visto a lo largo de la presente tesis, el fomento del emprendimiento requiere de una visión global que integre las diferentes acepciones de la conceptualización de emprendimiento que hemos definido para este trabajo. A su vez, la universidad emprendedora, por definición, debe contemplar la colaboración y las relaciones con su entorno socioeconómico. En este contexto, el proceso de FEyADE debe ser presentado como un enfoque integral del proceso que tenga en cuenta las diferentes actividades y agentes implicados en el mismo, respondiendo a su vez a las necesidades y requerimientos de la universidad como organización emprendedora.

Bajo estas premisas, proponemos un modelo para el proceso de FEyADE construido alrededor de cuatro pilares básicos, los cuales reflejan las 
actividades y tareas que deben desarrollarse para la puesta en marcha de dicho modelo. Queremos hacer hincapié en la consideración genérica de nuestra propuesta, pudiendo ser necesaria su adaptación y reajuste para su aplicación a cada caso concreto con el objetivo de hacerlo operativo acorde con las características de cada universidad. El modelo que proponemos para el FEyADE se muestra en la Figura 4, donde se representan, por una parte, las distintas áreas que debemos promover para obtener un proceso integral y, por otra, las actividades que tendremos que llevar a cabo dentro de cada una.

Figura 4: Representación del modelo de FEyADE

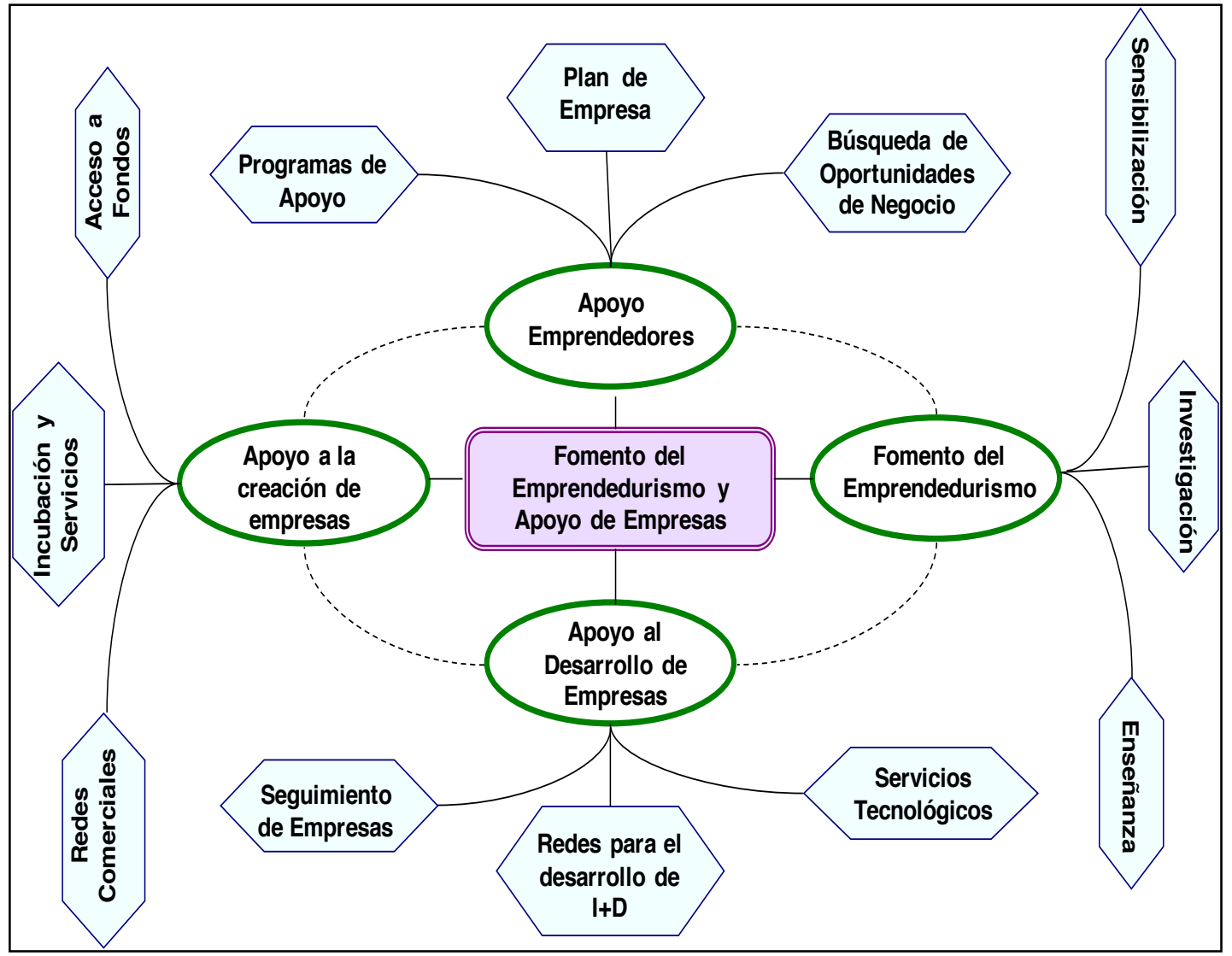

Fuente: Arroyo-Vazquez, y van der Sijde (2008)

Los objetivos y descripciones de cada una de las áreas y actividades se desarrollarán en las siguientes secciones. Antes de realizar dicha descripción, queremos hacer hincapié en que la fase de Fomento del Emprendimiento es de suma importancia para el correcto funcionamiento 
del modelo. Por tanto, pondremos especial atención en esta área y su descripción. Muchos de los modelos encontrados en la literatura no tratan este tema, posiblemente porque dan por supuesto que la existencia de una apropiada cultura emprendedora dentro de su contexto es suficiente para fomentar el emprendimiento. Sin embargo, consideramos necesario exponer en detalle y enfatizar la necesidad de fomentar actividades de sensibilización y dinamización hacia el emprendimiento ya que, de otra forma, los fundamentos del modelo fallarían y la puesta en marcha del mismo no proporcionaría unos resultados óptimos.

\subsubsection{Fomento del Emprendimiento}

El funcionamiento del modelo bajo condiciones óptimas requiere de una estrategia de fomento del emprendimiento que integre tanto las actividades de sensibilización y dinamización de los distintos agentes implicados en el modelo, como las actividades que faciliten un mejor conocimiento mutuo y una mayor interacción entre la investigación y la enseñanza con las actividades de creación y desarrollo de empresas. En la Figura 5 se muestran las actividades clave de esta etapa así como los objetivos (o grupos objetivo) que debemos perseguir en cada una de ellas. 
Figura 5: Fomento del Emprendimiento en el modelo de FEyADE

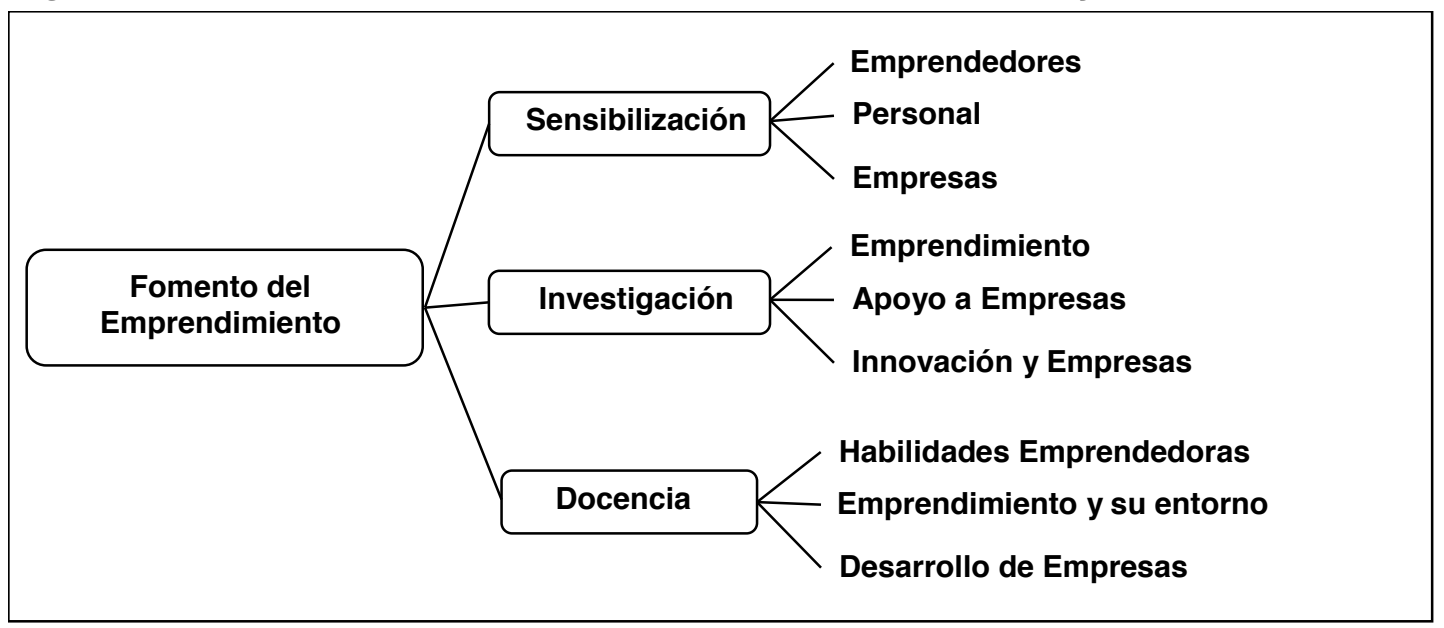

Fuente: Arroyo-Vazquez, y van der Sijde (2008)

El fomento del emprendimiento, dentro de nuestro modelo, se basa en la promoción de las actividades de sensibilización, investigación y enseñanza. Con respecto a las actividades de sensibilización, éstas están dirigidas no sólo a emprendedores, sino también al personal universitario implicado en el proceso, así como a las propias empresas. En cuanto a la sensibilización dirigida a emprendedores (entendidos aquí como aquéllas personas que podrían poner en marcha una empresa), el objetivo es informarles sobre el proceso y sus posibilidades, presentándoles la creación de una empresa como una opción a tener en cuenta como salida profesional o para explotar los resultados de investigación.

En el segundo grupo objetivo, se incluye al personal de las universidades y parques científicos, sean investigadores, docentes o personal de administración y servicios (incluyendo al equipo de gobierno de la propia universidad y parque científico) que están involucrados como agentes en el proceso. El objetivo de las acciones de sensibilización dirigidas a este grupo no es ya la creación de empresas (ya que en este caso estarían contemplados en el grupo anterior), sino la creación y promoción de un comportamiento proactivo hacia el apoyo al emprendimiento. En este sentido, los investigadores deberían ser proactivos, por ejemplo, ayudando a los emprendedores a comprender mejor los aspectos tecnológicos de su futura empresa o aconsejándoles sobre cómo implementar la I+D en la 
misma. Este comportamiento tendría también repercusiones sobre el grupo investigador ya que le permitirá estrechar lazos con una futura empresa, lo que le ayudará a conocer mejor el mercado y a consolidar una relación que, en un futuro se podría traducir en acuerdos y contratos de I+D para dicho grupo de investigación.

Las empresas e instituciones constituyen el otro grupo objetivo a tener muy en cuenta en esta etapa de sensibilización. En este caso, el objetivo es promover la implantación de una cultura emprendedora en las empresas así como la creación de una actitud proactiva hacia la cooperación en las actividades de apoyo al emprendimiento. Por otra parte, de acuerdo con Grant et al. (1996) es necesario sensibilizar a las empresas sobre las actividades que realiza la universidad, así como sobre las posibilidades y expectativas de colaboración entre ambos colectivos. En otras palabras, debemos hacer ver a la empresa cómo puede utilizar las actividades de la universidad en su propio beneficio y sensibilizarles para que sean capaces de pedir ayuda a esta institución para resolver determinados problemas (enseñándoles cómo hacerlo). De este modo, la empresa, a su vez, ayudará a la universidad a dirigir sus actividades hacia objetivos con una mayor utilidad práctica y real para el colectivo empresarial, cumpliendo mejor con los requerimientos de su tercera misión.

Así mismo, la sensibilización en el ámbito empresarial estaría orientada al intraemprendimiento visto como el desarrollo de acciones emprendedoras (no necesariamente de creación de nuevas empresas) dentro de las empresas, de tal modo que permitan a sus empleados dar rienda suelta a su espíritu emprendedor de modo que beneficie la productividad y los resultados de la empresa en la que trabajan.

En cuanto a los objetivos relacionados con las actividades de investigación en el ámbito del FEyADE, éstos deben perseguir un mayor conocimiento mutuo e interacción entre la comunidad científica, los servicios técnicos y los propios emprendedores y empresas que permita avanzar mejor en el conocimiento del campo del emprendimiento en un sentido amplio 
(habilidades y comportamiento emprendedor, razones por las que los emprendedores deciden crear una nueva empresa, intraemprendimiento, emprendimiento social, etc.). Otra línea de investigación que consideramos importante en esta etapa y en la que se debería trabajar de forma conjunta es la relacionada con las estructuras de apoyo a las empresas. El objetivo, en esta ocasión, es encontrar nuevos mecanismos, actividades y herramientas para apoyar el emprendimiento y el desarrollo de empresas. Finalmente, proponemos también la colaboración en cuanto a la investigación relacionada con la innovación y la empresa en general. Como podemos observar, los objetivos de las actividades de investigación están enfocados hacia la mejora, aprovechamiento y soporte del propio modelo. Por tanto, para poder sacar el máximo rendimiento de estas actividades se hace necesaria la conexión de las mismas con el resto de actividades del proceso y la existencia de redes de cooperación entre los distintos agentes involucrados.

En cuanto a las actividades docentes el objetivo es similar al de la investigación. Se trata de que pueda existir un mayor conocimiento mutuo entre los agentes involucrados en la enseñanza universitaria tanto en $1^{\mathrm{er}} \mathrm{y}$ $2^{\circ}$ ciclo como en $3^{\mathrm{er}}$ ciclo y los agentes involucrados en actividades de apoyo a la creación y desarrollo de empresas. Con esta colaboración e interacción de los distintos agentes se pretende que las actividades de enseñanza en el ámbito del emprendimiento no sea sólo mostrar a los alumnos el proceso de creación de una empresa y las etapas, recursos y habilidades necesarias para su puesta en marcha (lo que hemos denominado enseñanza en habilidades emprendedoras), sino también formar a profesionales que puedan apoyar y asesorar tanto a los emprendedores (enseñanza en emprendimiento y su entorno) como a las empresas (enseñanza en desarrollo de empresas). Además, como hemos apuntado en epígrafes anteriores, la formación debe impartirse de forma emprendedora y fomentando entre los alumnos el espíritu emprendedor más allá de la dinamización hacia la creación de empresas. La consecución 
de estos objetivos favorecerá la existencia, a largo plazo, tanto de una generación de emprendedores debidamente formados para la creación de su empresa, como de técnicos profesionales con un amplio conocimiento sobre las peculiaridades y características de la creación y desarrollo de empresas en el entorno universitario, mejorando en definitiva el rendimiento global del proceso.

Como hemos podido observar, las actividades propuestas en esta etapa están relacionadas con todo el proceso, ofreciendo y recibiendo retroalimentación del resto de áreas y actividades del modelo, replicando en cierto modo el mecanismo descrito en el modelo interactivo de innovación (Kline y Rosenberg, 1986). De acuerdo con el planteamiento del modelo de Kline y Rosenberg, el funcionamiento óptimo de nuestro modelo dependerá de un apropiado Fomento del Emprendimiento ${ }^{25}$. El éxito de esta etapa es una condición necesaria, pero no suficiente, para el éxito del modelo en su conjunto. El funcionamiento del modelo se muestra en la Figura 6 en la que se ilustra cómo esta etapa influye y se ve influida por el resto de elementos del modelo.

Figura 6: Funcionamiento del modelo de FEyADE.

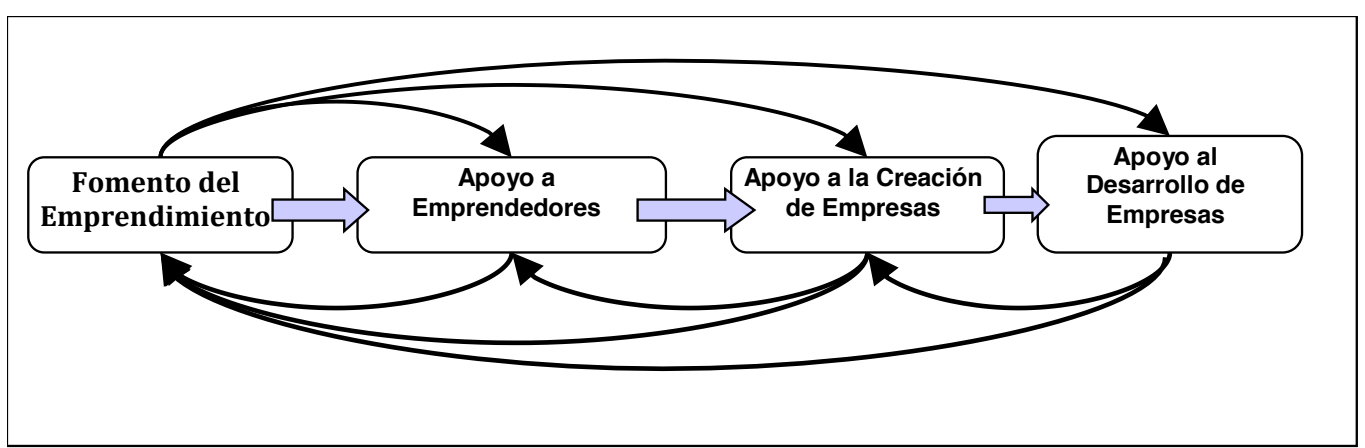

Fuente: Arroyo-Vazquez, y van der Sijde (2008)

\footnotetext{
${ }^{25}$ No obstante hemos de tener en cuenta que el modelo de FEyADE que proponemos descansa sobre la premisa de la existencia de un cierto nivel de integración de la cultura emprendedora en la universidad en la que se pretende aplicar, siendo ésta la primera condición necesaria para el funcionamiento óptimo del modelo.
} 


\subsubsection{Apoyo al Emprendimiento}

Esta etapa integra las actividades que deben ser llevadas a cabo para ofrecer apoyo a los emprendedores durante el proceso de planificación de la futura empresa y desarrollo del plan de negocio, teniendo en cuenta que en esta etapa la empresa todavía no está compitiendo en el mercado. Los objetivos y actividades de esta etapa aparecen reflejados en la Figura 7. Consideramos que esta etapa debe contemplar lo que hemos denominado 'búsqueda de oportunidades de negocio', que incluye tanto el estudio de las tendencias y características de los distintos sectores y mercados (lo que nos permitirá ofrecer un mejor servicio $y$ asesoramiento a los emprendedores), como la construcción de un observatorio de resultados de investigación que nos permita detectar a tiempo aquellos resultados susceptibles de ser comercializados y analizar si la creación de una spin-off es el mecanismo óptimo para su comercialización.

\section{Figura 7: Apoyo al Emprendimiento.}

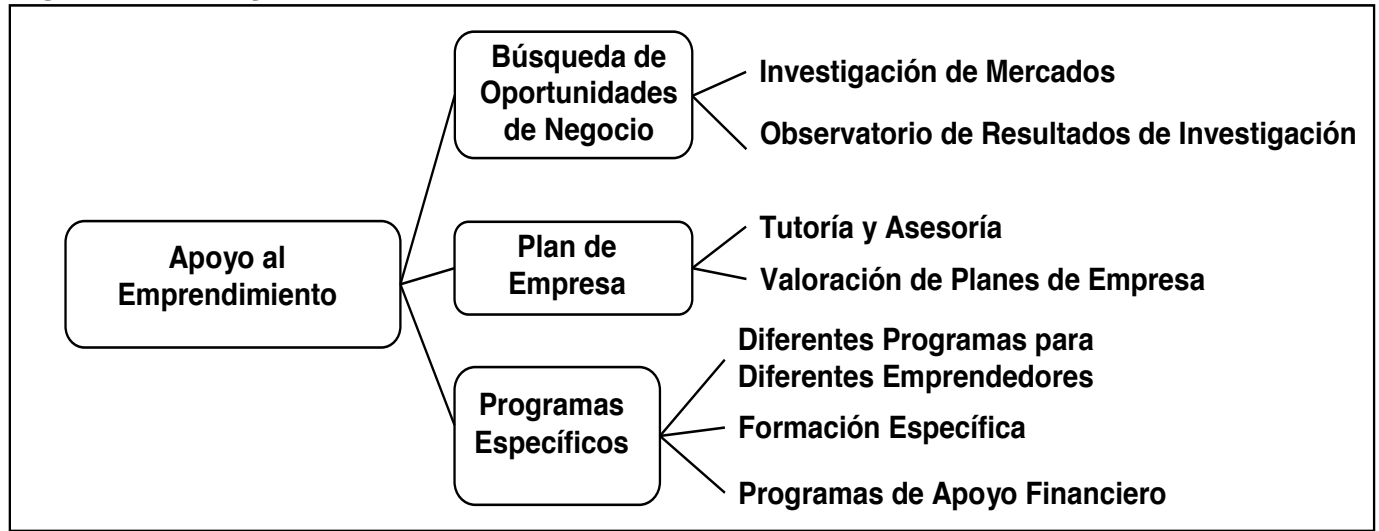

Fuente: Arroyo-Vazquez, y van der Sijde (2008)

El desarrollo del plan de empresa es una actividad dura y, en la mayoría de casos dilatada en el tiempo, que el emprendedor deberá desarrollar por sí mismo, ya que de este modo le servirá, no sólo como herramienta de planificación de su futura empresa, sino también como formación indispensable sobre todo lo que concernirá a la misma. Los temas sobre los que se debe trabajar durante el desarrollo del plan de empresa son diversos: estrategia, gestión, contabilidad, obligaciones fiscales, marketing, etc. Sin embargo, en la mayoría de casos, los emprendedores carecen de 
la formación necesaria en todos estos temas básicos para el adecuado funcionamiento de la empresa, lo que hace que la tutorización y asesoramiento sean actividades cruciales en esta etapa para guiar a los emprendedores en esta larga tarea. Una vez completado el plan de empresa, se requiere una valoración del mismo para determinar en qué medida es viable el negocio. En la mayoría de casos la respuesta a esta pregunta aparece durante el desarrollo del plan de empresa y son los mismos emprendedores los que se dan cuenta por sí mismos de la viabilidad o inviabilidad del negocio.

En esta etapa consideramos que se deben diseñar diferentes programas para atender a diferentes tipos de emprendedores e ideas de negocio (autoempleo, empresas de alta tecnología, comercialización de resultados de investigación, etc.), ya que en cada caso se deberán satisfacer necesidades distintas. De igual modo, para complementar y completar la formación que supone el desarrollo del plan de empresa, es necesaria la puesta en marcha de actividades de formación específicas (con objetivos y contenidos distintos a la docencia reglada descrita en la etapa anterior) dirigidas a emprendedores y empresarios. Por último, en esta etapa se tiene en cuenta la necesidad de ofrecer programas de apoyo financiero, previos a la puesta en marcha de la empresa (por ejemplo premios, subvenciones, préstamos a interés 0 , etc.), lo que atraerá a emprendedores con buenas ideas de negocio y con un alto potencial de crecimiento.

\subsubsection{Apoyo a la creación de empresas}

Esta etapa abarca todas aquellas actividades de apoyo a la nueva empresa durante su creación y adaptación al mercado. El objetivo de la misma es la vigilancia y apoyo de la empresa durante un periodo en el que se la considera altamente vulnerable. Tanto en esta etapa como en la siguiente, cobran especial importancia las redes y contactos que pueda desarrollar la nueva empresa, por lo que gran parte de las actividades irán encaminadas 
a prestar apoyo en este aspecto, como podemos observar en la Figura 8, dónde se ilustran las actividades de apoyo a la creación de empresas.

Figura 8: Apoyo a la Creación de Empresas.

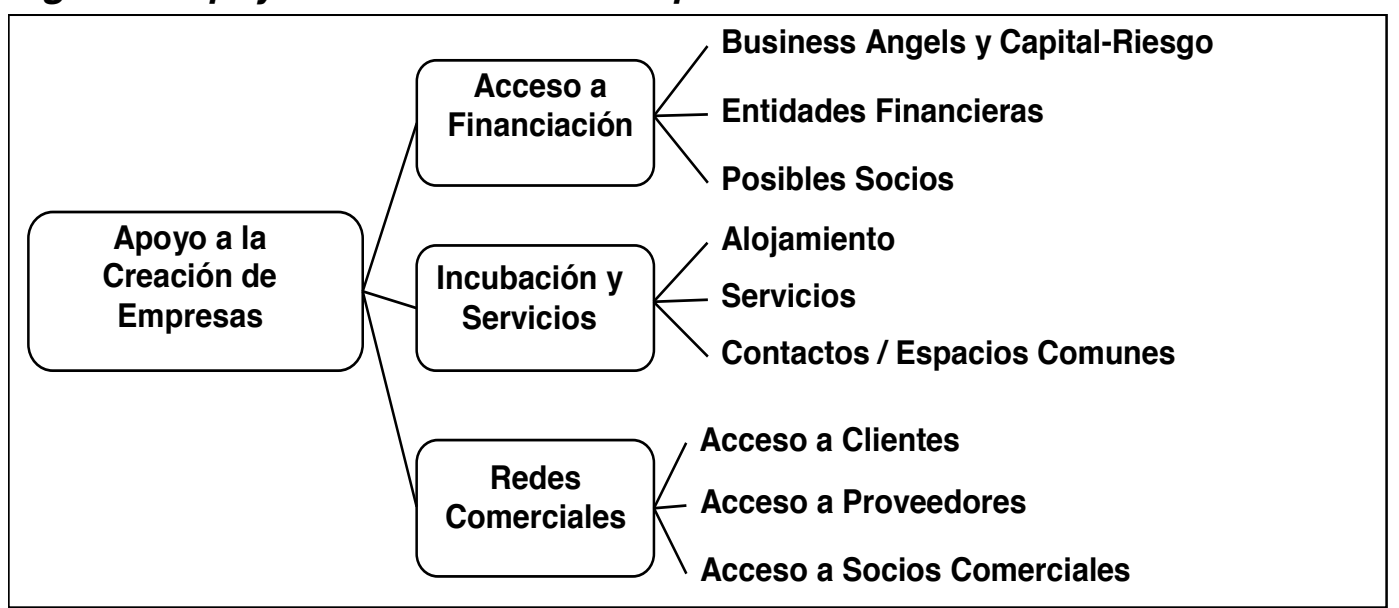

Fuente: Arroyo-Vazquez, y van der Sijde (2008)

Una de las actividades que debemos tener en cuenta en esta etapa, es el acceso a financiación, para lo que se hace necesario facilitar a la empresa contactos con 'business angels' y capital riesgo, entidades financieras y posibles socios que estuvieran interesados en participar en la empresa. El acceso a incubación y servicios relacionados constituye un apoyo de gran importancia durante los primeros años de vida de la empresa, no sólo por la disposición de espacios en los que ubicar las instalaciones y el ahorro que supone el disponer de servicios generales compartidos con otras empresas alojadas, sino también por el contacto, relaciones y aprendizaje mutuo que puede producirse al estar varias empresas nuevas en un espacio común. Por último, durante estos primeros años, la empresa debe desarrollar su red comercial a través del contacto con clientes, proveedores y socios comerciales, pudiendo los agentes involucrados en el proceso ofrecer información, apoyo y relaciones en este sentido, facilitando así el lanzamiento de la empresa al mercado. 


\subsubsection{Apoyo al Desarrollo de Empresas}

Desde nuestro punto de vista, las universidades emprendedoras no sólo deben apoyar la creación de nuevas empresas y su lanzamiento al mercado, sino mantener también una relación fluida con estas nuevas empresas ofreciéndoles apoyo y servicios durante la etapa de desarrollo y crecimiento. Por ello, en esta etapa proponemos la realización de un seguimiento y "mentorización" de la empresa durante sus primeros años así como el apoyo posterior para facilitar su crecimiento si ésta lo requiriera.

Durante esta fase es necesario y conveniente que la empresa entre en contacto con diversos socios para el desarrollo de actividades de I+D que permitan su crecimiento y desarrollo. El proceso de construcción de este tipo de redes no es tarea fácil, por lo que la empresa necesitará del apoyo tanto de la universidad como del resto de agentes para llevar a cabo esta actividad. Además, en esta etapa, la empresa necesitará apoyo tecnológico y servicios avanzados. De acuerdo con nuestra propuesta de modelo, las actividades llevadas a cabo durante esta etapa serán de gran ayuda para el establecimiento de relaciones entre la empresa y el resto de agentes del modelo, entre los que cabe destacar tanto la universidad como su parque científico.

La Figura 9 muestra las actividades llevadas a cabo en esta etapa final del modelo. 
Figura 9: Apoyo al Desarrollo de empresas

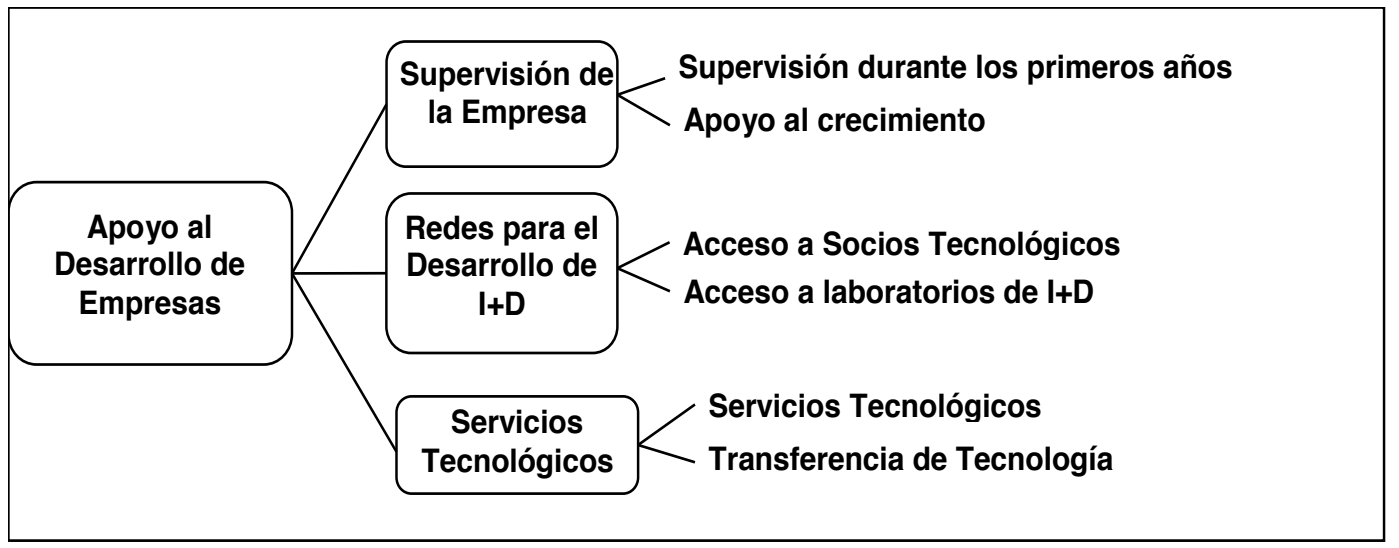

Fuente: Arroyo-Vazquez, y van der Sijde (2008)

El funcionamiento óptimo del modelo prevé la participación de emprendedores y agentes en cada una de las etapas del mismo. Este hecho debería producir el afianzamiento de relaciones entre todos los integrantes del mismo, lo que se traducirá en nuevo conocimiento y experiencias que podrán ser incorporados al modelo, cerrando así el ciclo y creando un clima de cooperación que mejorará la contribución social de la universidad emprendedora.

En este apartado hemos mostrado las diferentes actividades y objetivos en cada una de las áreas del proceso de FEyADE. Sin embargo, es necesario tener en cuenta que las herramientas específicas en cada actividad deberán desarrollarse de acuerdo con las características de cada universidad. Por tanto, algunas actividades $u$ objetivos podrían ser modificados o reorientados. No obstante, creemos que las cuatro principales áreas (Fomento del Emprendimiento, Apoyo a Emprendedores, Apoyo a la Creación de Empresas y Apoyo al Desarrollo de Empresas) deben mantenerse en el modelo para conservar su enfoque integral, de forma que permita la obtención de los resultados óptimos del mismo. Sin embargo, en el corto plazo, podremos obtener algunos resultados (incluso muy buenos resultados) si sólo se llevan a cabo algunas de las actividades propuestas en el modelo. Podemos considerar el caso de la UPV como un ejemplo de esta situación, donde se han obtenido muy buenos resultados 
en términos de número de nuevas empresas creadas $^{26}$ por estudiantes, egresados y personal de la universidad, llevando a cabo un proceso de creación de empresas que no contemplaba todas las actividades principales ni a todos los agentes del proceso de FEyADE. Según nuestra tesis, la aplicación de nuestro modelo a este caso permitiría que estos buenos resultados mejoraran en el largo plazo, tanto a nivel cuantitativo como cualitativo.

\subsection{Propuesta metodológica para la implantación del modelo de FEyADE}

En muchos casos, las actividades y tareas que hemos descrito en nuestro modelo, se llevan a cabo por diferentes servicios que a su vez dependen de diferentes estructuras tanto internas como externas a la universidad. Si además añadimos que muchas veces el personal y los servicios involucrados poseen intereses contrapuestos, la gestión del modelo hacia un objetivo común se convierte en una tarea casi heroica. Por tanto, se hace necesaria una herramienta que facilite el diseño estratégico y la colaboración de los diferentes agentes, en la que sea posible alcanzar los objetivos tanto a nivel individual como colectivo. Con nuestra propuesta ofrecemos una herramienta que cumple dichos requisitos.

De acuerdo con Kirwan et al. (2006) el proceso emprendedor puede ser analizado bajo un contexto de sistema social (Parsons, 1964) en el que están implicados cuatro mecanismos, relacionados con los capitales específicos necesarios. Estos capitales se definen como capital estratégico, capital económico, capital cultural y capital relacional. Las necesidades de los emprendedores y empresas a lo largo del proceso de FEyADE se pueden agrupar en estos cuatro capitales, a los que hemos añadido una nueva categoría: alojamiento y servicios. Sin embargo, no es necesario

\footnotetext{
${ }^{26}$ La UPV ha apoyado la creación de casi 500 nuevas empresas desde que en 1992 se pusiera en marcha el Programa IDEAS (ahora Instituto IDEAS).
} 
considerar esta nueva categoría en la primera etapa del modelo, Fomento del Emprendimiento, ya que las actividades llevadas a cabo en la misma no están relacionadas con esas necesidades. En la Tabla 3 se muestra el alcance de cada uno de los capitales poniéndolos en relación con los recursos necesarios para cubrir cada uno de ellos.

Tabla 3: Capitales, alcance y recursos necesarios

\begin{tabular}{|c|l|l|}
\hline Capitales Necesarios & \multicolumn{1}{|c|}{ Alcance } & \multicolumn{1}{c|}{ Recursos } \\
\hline Capital Estratégico (CS) & $\begin{array}{l}\text { Definición y logro de } \\
\text { objetivos estratégicos }\end{array}$ & $\begin{array}{l}\text { Poder, autoridad, influencia, } \\
\text { concentración en estrategias }\end{array}$ \\
\hline Capital Económico (CE) & Optimización económica & Dinero y Financiación \\
\hline Capital Cultural (CC) & $\begin{array}{l}\text { Establecimiento de } \\
\text { patrones e } \\
\text { institucionalización de } \\
\text { símbolos compartidos }\end{array}$ & $\begin{array}{l}\text { Valores, Organización, } \\
\text { Conocimiento, Habilidades, } \\
\text { Experiencia, Tecnología }\end{array}$ \\
\hline Alojamiento y Servicios (AS) & $\begin{array}{l}\text { Interacciones Entre Actores } \\
\text { física }\end{array}$ & $\begin{array}{l}\text { Múltiples contactos a diferentes } \\
\text { niveles que permitan rellenar } \\
\text { vacios estructurales, que sean } \\
\text { cohesivos, bien a niveles } \\
\text { formales o informales }\end{array}$ \\
\hline
\end{tabular}

Fuente: adaptado de Groen (2005).

Para analizar cuál debería ser la contribución de los distintos agentes involucrados en el modelo, tendremos en cuenta las necesidades contempladas en la Tabla 3, de tal forma que la contribución de cada uno de los agentes irá encaminada a satisfacer dichas necesidades. Por tanto, nuestra propuesta metodológica se basa en la determinación de la contribución de cada agente para cubrir cada uno de los capitales en cada una de las etapas del modelo. Así pues, nuestra propuesta metodológica se desarrolla en tres fases:

1. Identificación de los agentes involucrados

2. Determinación de cuál es la contribución de cada agente implicado, analizando qué necesidades satisface cada uno 
3. Determinación de la contribución de cada agente a cada fase y actividad del modelo (colaboraciones entre agentes)

En la Tabla 4 se muestra una lista de agentes que pueden estar involucrados en el proceso. No hacemos distinción entre agentes internos o externos, ya que, los agentes externos en una universidad, pueden ser internos en otras. Por ejemplo, en algunas universidades, las actividades de transferencia se llevan a cabo a través de una fundación externa, mientras que en otras, por un servicio interno. Así mismo, es posible, que para algunos casos concretos haya agentes que no sean relevantes o que no aparezcan en el listado otros que no lo son. Como hemos advertido en la exposición del modelo, tanto el modelo como su propuesta metodológica deberán ajustarse a las necesidades y circunstancias de la universidad y entorno en el que se aplique. Por tanto, a la hora de implantar el modelo en cada caso concreto será necesario indicar qué agentes son los externos e internos y exponerlos con más detalle.

Tabla 4:Posibles agentes a considerar en el proceso de FEyADE

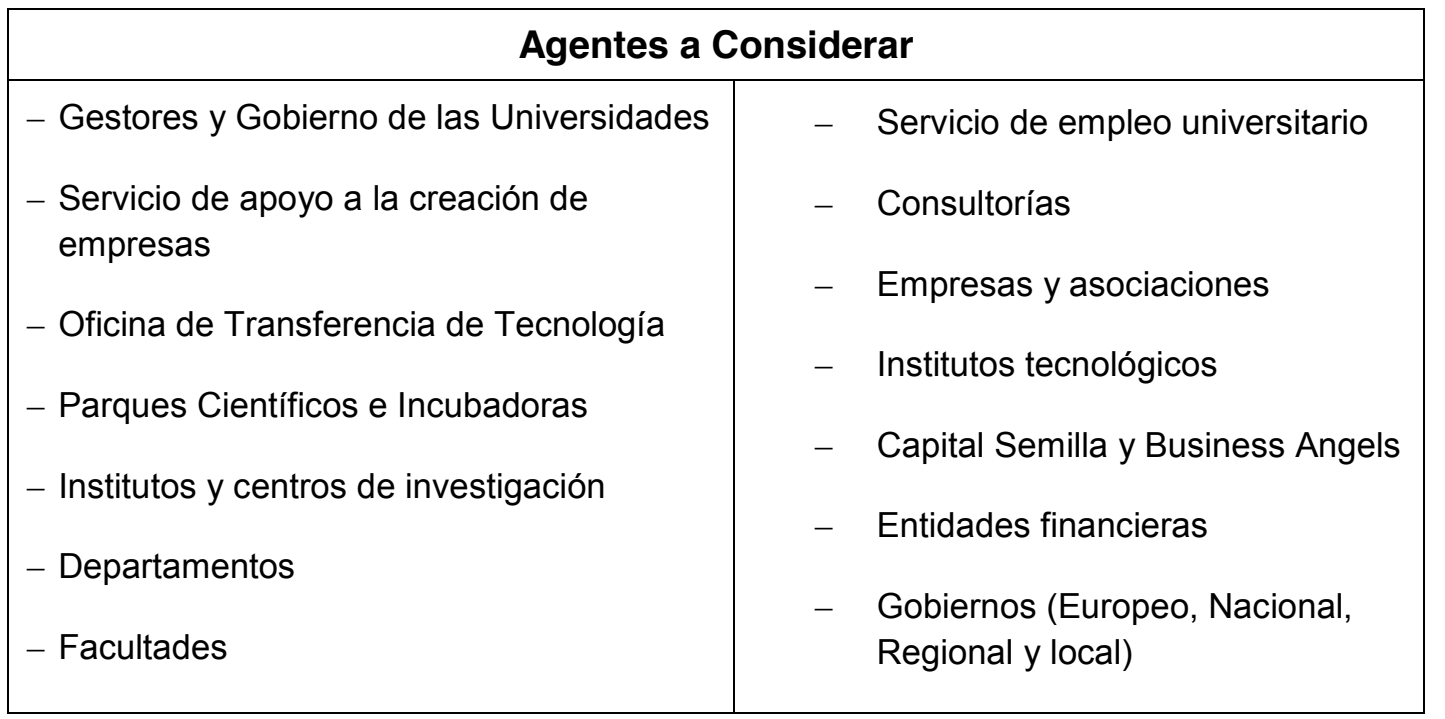

Fuente: Arroyo-Vazquez, y van der Sijde (2008)

Con objeto de analizar cuál debería ser la contribución de cada uno de los agentes en el proceso, tendremos en cuenta los diferentes capitales descritos en la Tabla 3 en cada una de las etapas de nuestro proceso. Por tanto, tenemos que analizar la contribución de cada agente en cada uno de 
los capitales y para cada una de las etapas. En nuestro modelo, sólo si se tienen en cuenta las contribuciones de todos los agentes (tanto internos como externos) se cubrirán todos los capitales necesarios para su óptima implantación.

Podemos representar estas contribuciones según se muestra en la Tabla 5, donde podemos identificar quién (agente) participa en qué (etapa del modelo) y cómo (qué capital provee).

Tabla 5: Contribución de los agentes al proceso de FEyADE

\begin{tabular}{|c|c|c|c|c|c|c|c|c|c|c|c|c|c|c|c|c|c|c|c|}
\hline \multirow[b]{2}{*}{ AGENTES } & \multicolumn{4}{|c|}{$\begin{array}{c}\text { Cultura } \\
\text { Emprendedora }\end{array}$} & \multicolumn{5}{|c|}{$\begin{array}{l}\text { Entrepreneurship } \\
\text { Support }\end{array}$} & \multicolumn{5}{|c|}{$\begin{array}{l}\text { Business Launch } \\
\text { Support }\end{array}$} & \multicolumn{5}{|c|}{$\begin{array}{c}\text { Business Develop } \\
\text { Support }\end{array}$} \\
\hline & CS & CE & CC & CR & cs & CE & Cc & CR & AS & CS & CE & CC & CR & AS & Cs & CE & Cc & CR & AS \\
\hline \multicolumn{20}{|c|}{ Gobierno UPV } \\
\hline \multicolumn{20}{|c|}{$\begin{array}{l}\text { Serv Apoyo Creac } \\
\text { Emp }\end{array}$} \\
\hline \multicolumn{20}{|l|}{ OTRI (CTT) } \\
\hline \multicolumn{20}{|l|}{ Incubadora } \\
\hline \multicolumn{20}{|c|}{\begin{tabular}{|l} 
Institutos \\
Investigación
\end{tabular}} \\
\hline \multicolumn{20}{|c|}{ Departamentos } \\
\hline \multicolumn{20}{|l|}{ Facultades } \\
\hline \multicolumn{20}{|l|}{$\begin{array}{l}\text { Servicio de } \\
\text { Empleo }\end{array}$} \\
\hline \multicolumn{20}{|c|}{$\begin{array}{l}\text { Consultarías } \\
\text { Externas }\end{array}$} \\
\hline \multicolumn{20}{|c|}{$\begin{array}{l}\text { Asociaciones } \\
\text { Empresas }\end{array}$} \\
\hline \multicolumn{20}{|c|}{$\begin{array}{l}\text { Institutos } \\
\text { Tecnológicos }\end{array}$} \\
\hline \multicolumn{20}{|c|}{$\begin{array}{l}\text { Capital Riesgo y } \\
\text { BA }\end{array}$} \\
\hline \multicolumn{20}{|l|}{\begin{tabular}{|l|} 
Entidades \\
Financieras
\end{tabular}} \\
\hline Gobiernos & & & & & & & & & & & & & & & & & & & \\
\hline
\end{tabular}

Fuente: Arroyo-Vazquez et al (2010)

Dando un paso más podemos desgranar más el análisis si consideramos las actividades descritas en el modelo para cada una de las etapas y, especificamos para cada agente, qué capital debería cubrir en dicha etapa. De este modo se puede determinar en qué actividades y sobre qué capitales deberían colaborar los diferentes agentes para la adecuada implantación del proceso, tal como se muestra en la Tabla 6. 
Tabla 6: Cooperación entre agentes y contribución a las actividades del proceso de FEyADE

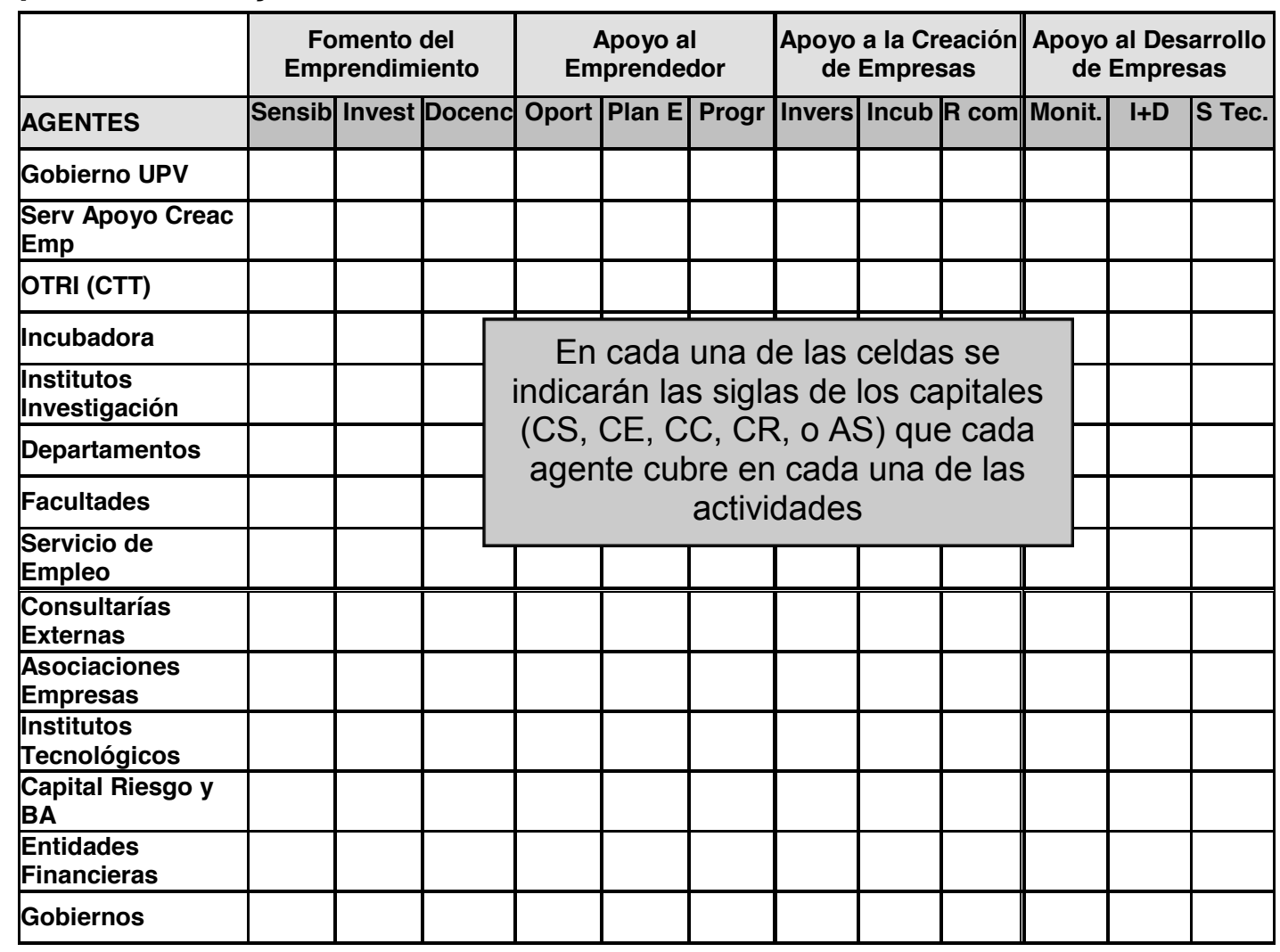

Fuente: Elaboración Propia.

Así mismo, esta propuesta metodológica nos permitirá no sólo determinar cómo implantar el modelo y qué estrategia seguir, sino que también, si la utilizamos como análisis de un caso, determinar qué capitales se están quedando sin cubrir o qué actividades no se están llevando a cabo de forma óptima. 


\section{Capítulo 5. Análisis: el caso de la Universidad} Politécnica de Valencia (UPV)

Como hemos venido apuntando a lo largo de la presente tesis, nuestro análisis se centrará en el caso de la Universidad Politécnica de Valencia (UPV) como universidad emprendedora. En este capítulo, con objeto de arrojar luz sobre las cuestiones e hipótesis planteadas en el primer capítulo de la tesis, abordaremos dos cuestiones. Por un lado realizaremos un análisis de la UPV como universidad emprendedora, y por otra aplicaremos y analizaremos el modelo de FEyADE para el caso de la UPV.

Para estudiar el grado de compromiso de la UPV como universidad emprendedora realizaremos un análisis de la evolución histórica del fomento del emprendimiento en esta universidad, identificando los cambios legislativos 
a nivel nacional y las decisiones estratégicas a nivel universidad originada por dichos cambios y que han influido en el las acciones relacionadas con el fomento del emprendimiento en la UPV llevadas a cabo por el Instituto IDEAS.

Continuando con el análisis de la UPV como universidad emprendedora, nos centraremos en estudiar cómo desarrolla esta universidad cada una de sus tres misiones así como la propia gestión y en qué medida estas actividades están contribuyendo a la caracterización de esta universidad como emprendedora. Proponemos a continuación una caracterización de la UPV como universidad emprendedora basada en el análisis anterior y que muestra las debilidades y fortalezas de esta universidad para ser considerada emprendedora. Para finalizar el primer epígrafe de este capítulo, realizamos un análisis del Instituto IDEAS de la UPV como servicio innovador y emprendedor.

En el segundo epígrafe de este capítulo, aplicaremos y analizaremos el modelo de FEyADE para el caso de la UPV, identificando qué agentes del entorno (tanto interno como externos a la UPV) están involucrados en el desarrollo de dicho proceso. Para finalizar, mostramos cuál es la contribución de cada uno de los agentes en las diferentes fases y etapas de modelo para el caso de la UPV.

\subsection{Análisis de la UPV como universidad emprendedora}

Con objeto de analizar el caso de la UPV como universidad emprendedora mostraremos la trayectoria de la UPV en lo que a fomento del emprendimiento se refiere y analizaremos sus actividades como universidad emprendedora.

Antes de analizar las actividades de la UPV como universidad emprendedora, creemos conveniente conocer cómo se define la UPV a sí misma y cómo ha orientado su estrategia en materia de emprendimiento. De este modo podremos establecer si existe una coherencia entre la visión y los objetivos de la propia universidad y sus actividades como universidad emprendedora. Para ello, nos centraremos en los dos planes estratégicos que ha lanzado la UPV: el 
Plan 2007-2014 y el Plan 2015-2020, estando este último sólo en su fase de diseño y aún pendiente de su implementación.

La Universidad Politécnica de Valencia lanzó su primer plan estratégico en 2007 y abarcaba el período 2007-2014. En dicho plan estratégico, se exponía como uno de los propósitos de la UPV, convertirse en una universidad innovadora y emprendedora, líder a nivel mundial. Así mismo, la UPV se define en dicho plan como:

"...una universidad emprendedora y de innovación, que practica eficaces mecanismos de difusión científica y tecnológica, destaca en la formación de investigadores y en la creación de empresas de base tecnológica"

En este plan estratégico, las acciones relacionadas con emprendimiento se enmarcan dentro del Objetivo II.2: incrementar y mejorar la calidad de las actividades de transferencia tecnológica e innovación. Más concretamente, dentro de este objetivo, encontramos el Plan de Acción Emprende cuya finalidad es capitalizar el conocimiento de la UPV, articulando nuevas opciones de transferencia de tecnología mediante la creación de empresas de base tecnológica.

En 2014, finalizado este plan estratégico, se diseña el plan estratégico 20152020. En este plan, no se hace mención expresa al carácter emprendedor de la UPV, tal como ocurría en el plan anterior. Sin embargo, esto no significa que se haya dejado de lado las acciones relacionadas con emprendimiento. Al igual que en el caso anterior, estas acciones se enmarcan dentro del objetivo (denominados en este plan Retos Estratégicos), de Transferir sus resultados a nivel nacional e internacional (RE 3). Según este Plan Estratégico, en el contexto del Reto 3, "La UPV es un referente a nivel nacional y europeo en emprendimiento, con proyección en Latinoamérica, y dispone de un ecosistema emprendedor inteligente $y$ validado con start-ups de éxito, reconocido como seña de identidad propia y que atrae recursos y talento."

Dentro de este reto, encontramos el Proyecto Emprender, el cual contempla los siguientes objetivos: 
Objetivo 1. Personas/Talento: Promover la atracción y el desarrollo del talento para emprender. Crear equipos de alto potencial y fomentar el liderazgo

Objetivo 2. STARTUPV: Promocionar y consolidar el ecosistema emprendedor de la UPV con impacto en su entorno. Dinamizar y cohesionar su función con los centros (Plan de Emprendimiento Global).

Objetivo 3. GLOBAL: Potenciar la creación de STARTUPs y SPINOFFs globales

Objetivo 4. Valorización de la investigación: Orientar la investigación hacia resultados de investigación de alto valor añadido explotables en consonancia con el H2020, y por tanto susceptibles de ser transferidos en forma de spin-off UPV. Es decir, fomentar una I+D+i "emprendedora" con potencial para su transformación en una empresa de base tecnológica.

Objetivo 5. Smart Entrepreneuship: Evolución del ecosistema emprendedor de la UPV hacia un ecosistema emprendedor inteligente.

Objetivo 6. Alianzas: Estrechar lazos con Centros de Emprendimiento de referencia internacional para proyectar a nuestros emprendedores y potenciar la capacidad de capturar talento tanto en España como en América Latina.

Objetivo 7. Habilidades: fomentar que las habilidades transversales más propias del emprendimiento, como la creatividad, liderazgo e iniciativa, permeen en la formación reglada del alumno.

Según se manifiesta en los planes estratégicos analizados, la visión de la UPV como universidad emprendedora ha perdido protagonismo entre el plan 20072014 y el 2015-2020. Mientras en el primer Plan Estratégico se exponía claramente la visión de la UPV como universidad emprendedora, en el plan que ahora comienza, esta visión queda expuesta de forma más velada y camuflada entre las acciones de transferencia. En ambos casos, sin embargo podemos ver cómo la propia UPV identifica el concepto universidad emprendedora con la 
actividad de transferencia de resultados a la sociedad y enmarca las acciones de emprendimiento dentro de este objetivo. Así mismo, vemos que las acciones concretas relacionadas con el emprendimiento en ambos casos se centran en el proceso de apoyo a la creación y desarrollo de empresas, haciendo especial hincapié en las empresas de base tecnológica. En el segundo Plan, es de destacar la mención a la formación en habilidades y la colaboración en este sentido con los centros (facultades y escuelas). Sin embargo, se puede deducir del objetivo 1: Personas/Talento que el foco está puesto en la creación de equipos para creación de empresas más que la formación a nivel transversal en habilidades emprendedoras desde una perspectiva global. Es decir, el objetivo sigue siendo crear empresarios más que profesionales emprendedores en cualquier ámbito, independientemente de que creen o no su empresa. En un esfuerzo por cubrir este vacío, el objetivo 7: Habilidades, se centra en la formación transversal en temas relacionados con creatividad, liderazgo e iniciativa, en la formación reglada. Sin embargo, las acciones concretas a poner en marcha en este sentido, se circunscriben a cursos MOOC, lo cual siendo una buena herramienta y suponiendo un buen modo de comenzar, resulta insuficiente para la implantación de esta formación transversal en emprendimiento en la formación reglada. En cualquier caso, habrá que analizar cómo se implanta finalmente este plan estratégico ya que en estos momentos está en sus inicios.

Una cuestión a destacar en la descripción de los objetivos del Proyecto Emprender es la definición de I+D+i "emprendedora" en el Objetivo 4. Según lo expuesto en este objetivo, el fomento de una investigación emprendedora se centra en la creación de Empresas de Base Tecnológica. No obstante, como veremos más adelante, creemos que el fomento del emprendimiento en la segunda misión (investigación) va más allá de la creación de spin-off a partir de resultados de investigación.

Del análisis de los planes estratégicos diseñados por la UPV, podemos destacar que esta universidad se marca entre sus fines estratégicos (de forma 
explícita o implícita) el ser una universidad emprendedora. Pero ¿está poniendo en marcha las acciones apropiadas para ello?

Con objeto de estudiar en qué grado la UPV puede considerarse una universidad emprendedora, según lo expuesto en el marco teórico y empírico de esta tesis, procederemos a analizar, tanto la evolución histórica del fomento del emprendimiento en la UPV como las características de esta universidad y del modo en que desarrolla, tanto sus tres misiones, como la propia gestión. Con ello, podremos extraer conclusiones que nos permitan describir los puntos fuertes y débiles de la UPV como universidad emprendedora.

\subsubsection{Evolución histórica del fomento del emprendimiento en la UPV}

La Universidad Politécnica de Valencia fue la primera universidad española en disponer de un programa de fomento del emprendimiento (Programa IDEAS). Desde su creación en 1992, hasta la actualidad, el Programa IDEAS ha sufrido diversos cambios de organización, estructura y dependencia orgánica, todo ello como consecuencia de la propia evolución de la UPV en su proceso de transformación hacia una universidad emprendedora. Para poder analizar en qué medida estos cambios han influido en la gestión y los resultados de IDEAS, es necesario entender la evolución de la universidad y del propio programa dentro de ella, así como las motivaciones de dichos cambios. Nos centraremos en los cambios a nivel de universidad que afectan directa o indirectamente a la evolución del Programa IDEAS, su gestión y resultados.

La UPV tuvo desde sus inicios una clara orientación hacia las actividades de cooperación con el entorno socioeconómico. En 1971, tan sólo tres años después de su constitución, estableció sus primeros contratos con empresas y en 1982, fruto de un convenio entre la UPV y el Instituto Nacional de Empleo surge el Centro de Orientación e Información al Empleo, COIE, en materia de inserción laboral de los titulados de la UPV. 
No obstante estos primeros avances, por entonces, el marco legal e institucional español dificultaban enormemente las relaciones universidadempresa. La Ley de Reforma Universitaria, aprobada en 1983, vino a eliminar estas dificultades y favoreció la relación de la Universidad con su entorno socioeconómico a través de convenios y contratos de investigación y desarrollo. Con ánimo de dar respuesta a las necesidades de gestión administrativa que esta actividad comenzaba a precisar, se creó en 1986 el Gabinete de I+D, dependiente del Vicerrectorado de Asuntos Económicos, Investigación y Desarrollo Tecnológico.

El crecimiento de las actividades de contratación de servicios de I+D y de formación, unido al interés por situar las relaciones con su entorno en un lugar prioritario, condujo en 1989 a la creación de dos unidades ejecutivas:

- El Centro de Transferencia de Tecnología, CTT, en materia de investigación y transferencia de conocimientos.

- El Centro de Formación de Postgrado, CFP, en materia de formación continua.

Es en este contexto, cuando surge en 1992 el Programa IDEAS en el seno del CTT, y como parte de su estrategia de dinamización. IDEAS comenzó como un programa dirigido a todas aquellas personas emprendedoras de la UPV dispuestas a plantearse su salida laboral creando su propia empresa, aprovechando su nivel de cualificación, para hacerlo como una empresa de base tecnológica (Fernandez de Lucio et. al, 1999).

Tras unos años en los que la actividad de estas unidades (CTT, CFP y COIE ) creció de manera considerable, la UPV crea en 1996 una unidad de coordinación de estos centros denominada Centro de Relaciones con el Entorno Socioeconómico (CERES) con objeto de diseñar nuevas estrategias para mejorar sus relaciones con el entorno y potenciar el carácter emprendedor de la UPV. Este hito supone un cambio importante en la organización del Programa IDEAS, aún dependiente del CTT y que, hasta ese momento, no había tenido un director y presupuestos propios. En 1996, coincidente con la creación del CERES, se incorpora al Programa IDEAS un director con un perfil 
profesional (no docente universitario), con experiencia en gestión empresarial y se dota al programa de un presupuesto propio. Es de resaltar que los servicios integrados en el CERES (incluido el Programa IDEAS dependiente del CTT), están dirigidos y gestionados por personal experto y con amplia experiencia profesional en gestión, y no como una actividad accesoria del personal docente e investigador.

EI CERES continuó como unidad integrante de estos servicios y dependiente del Vicerrectorado de Investigación hasta el año 2001. En este año concurren una serie de hitos significativos en la evolución de la UPV, y que influirán directamente en la actividad, organización y futuro del Programa IDEAS. En 2001, y tras la reelección del equipo de gobierno de la Universidad, desaparece definitivamente el CERES pasando cada una de sus unidades a conformar un servicio independiente. Pero este cambio organizativo no supuso únicamente la independencia de los servicios, sino su ubicación en diferentes Vicerrectorados: el CTT y el CFP pasaron a depender del Vicerrectorado de Investigación, Desarrollo e Innovación; La Agencia UPV para el Empleo pasó a denominarse Servicio Integrado de Empleo (SIE), integrándose en el Vicerrectorado de Empleo; el Programa IDEAS se independizó definitivamente del CTT, pasando a integrarse en el Instituto para la Creación y Desarrollo de Empresas (ICDE) y dependiendo del Vicerrectorado de la Fundación UPV.

La independencia del Programa IDEAS del CTT supuso la creación de la figura del Director del ICDE, bajo la denominación de Director de Área, un cargo de gestión para docentes universitarios, de rango inferior al de Vicerrector, pero del que dependen directamente los Jefes de Servicio (profesionales de la gestión y que no son docentes). Este hecho supone que a partir de este momento, el Programa IDEAS tenga, de facto, dos directores: un director académico y un director técnico y de gestión que depende orgánicamente del director académico.

El siguiente hito importante en la organización de la UPV, y que afecta directamente a la organización del Programa IDEAS, se produce en 2005, con las nuevas elecciones y el cambio del equipo de gobierno, incluida la elección 
de un nuevo rector, sustituyendo al que llevaba 25 años continuados en su cargo. Este cambio supuso la renovación completa del equipo de gobierno y un nuevo cambio de vicerrectorado del Programa IDEAS. A partir de 2005, el ICDE-Programa IDEAS pasará a depender del Vicerrectorado de Empleo. Este cambio tuvo como consecuencia el cambio del director de área del Programa IDEAS, ya que estos directores son cargos académicos nombrados directamente por el Vicerrector del que dependen. Además, desapareció la figura del director del programa IDEAS al considerarse que el ICDE y el programa IDEAS eran el mismo servicio, desapareciendo así la dualidad de directores y quedando la gestión del servicio bajo la responsabilidad de un docente universitario.

Otro hito que ha tenido una repercusión importante, ya no sólo a nivel de la UPV, si no de cualquier universidad pública española, fue la aprobación de la Ley Orgánica 4/2007, de reforma de la Ley 6/2001. Tal como hemos visto en el capítulo anterior, esta ley supuso una oportunidad para impulsar la creación de spin-off universitarias a partir de resultados de investigación. Además, esta ley supuso que las Universidades, y entre ellas la UPV, redactaran una normativa propia para la creación de empresas a partir de resultados de investigación. En el caso de la UPV, la redacción de la normativa, implicó el trabajo conjunto de varios vicerrectorados y servicios:

- El Instituto IDEAS (dependiente de la Dirección Delegada de Empleo)

- EI CTT (dependiente del Vicerrectorado de I+D)

- El Parque Científico (Dependiente del Vicerrectorado de Coordinación y Planificación Económica)

En el caso de IDEAS, supuso la creación específica de un área para el apoyo a la creación de empresas spin-off UPV.

En 2013, tras el nuevo cambio de rector en la UPV, se crea la Dirección Delegada de Emprendimiento y Empleo en la que se integran el Servicio Integrado de Empleo y el Instituto IDEAS. Con la creación de esta Dirección Delegada, la UPV pretende integrar las diferentes iniciativas relacionadas con 
el emprendimiento dentro de un mismo Vicerrectorado ${ }^{27}$. Esto supone que la UPV desarrolla un plan de emprendimiento global, denominado Poli[emprende], dependiente del Instituto IDEAS que pretende aglutinar todas las iniciativas de emprendimiento impulsadas desde la institución. No obstante, tras analizar las acciones previstas en dicho plan, vemos que se centran nuevamente en formación y apoyo para la creación y desarrollo de empresas e incubación, más que en el fomento de una cultura emprendedora integral.

Para ilustrar toda esta evolución, la Figura 10 muestra cómo los diferentes cambios en la legislación han ido provocando modificaciones en los planteamientos estratégicos de la UPV, reflejándose, a su vez, en los diferentes cambios orgánicos que ha sufrido el Programa IDEAS desde su constitución:

${ }^{27}$ La Dirección Delegada de Emprendimiento y Empleo se asimila a un vicerrectorado y tiene las mismas competencias que éste. 
Figura 10: Cambios orgánicos en IDEAS y su motivación según cambios a nivel estatal y UPV

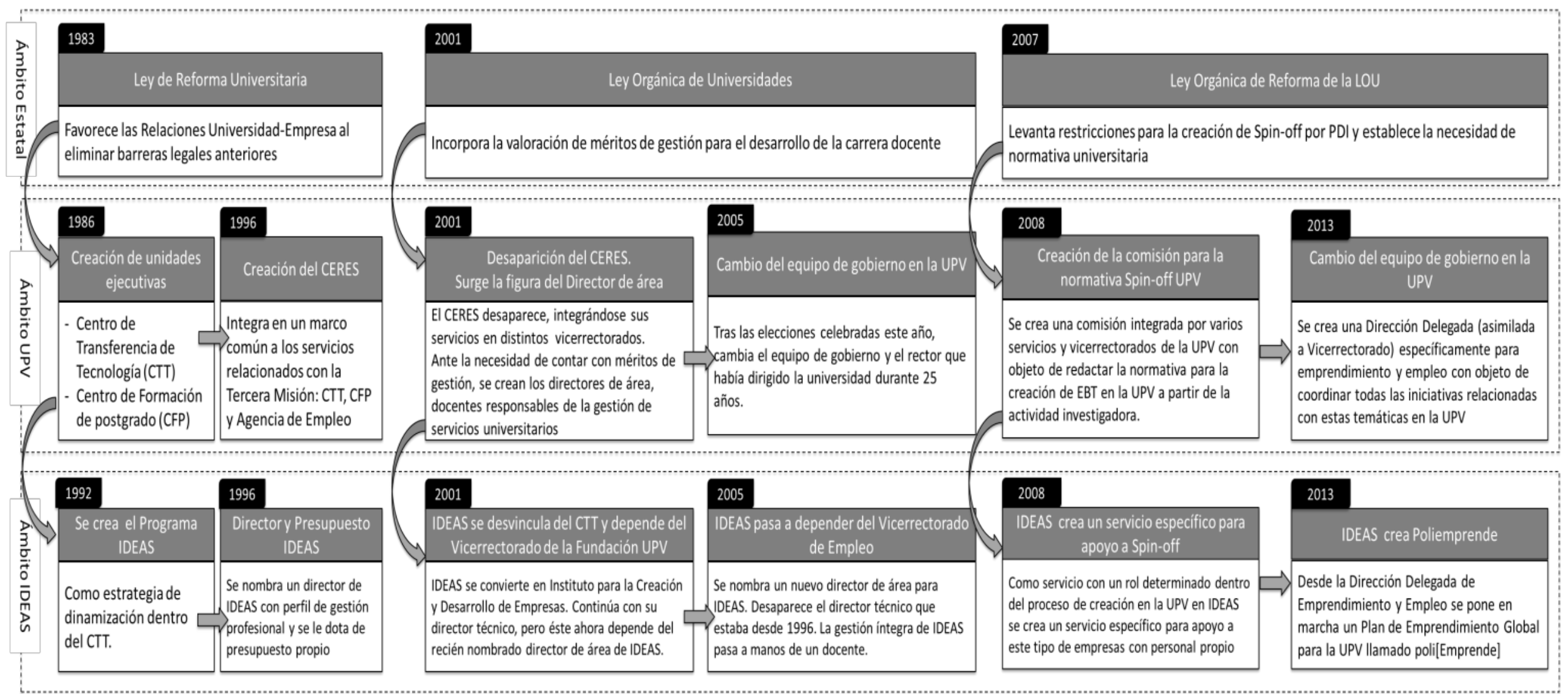

\section{Fuente: Elaboración propia}


Esta evolución y cambios orgánicos, tiene su reflejo, por un lado en los planes estratégicos (como ya hemos visto) así como en las actividades de la UPV como universidad emprendedora. Así mismo, centrándonos en el Instituto IDEAS como programa de fomento del emprendimiento en la UPV, los cambios a nivel normativo e institucional también han tenido su reflejo en las actividades desarrolladas por este servicio desde sus inicios hasta la actualidad. En los siguientes epígrafes nos centraremos en analizar las características de la UPV como universidad emprendedora, así como la evolución de IDEAS como servicio de apoyo al emprendimiento en la UPV.

Así mismo, como hemos visto, la UPV tiene un planteamiento estratégico encaminado a convertirse en universidad emprendedora. De acuerdo con lo expuesto en el marco teórico y empírico, ser una universidad emprendedora significa actuar de acuerdo con tres objetivos básicos: atender mediante respuestas innovadoras a las nuevas demandas sociales de formación; incrementar la actividad investigadora en interacción con el entorno socioeconómico; y participar activamente en el desarrollo de la sociedad. Todo ello sobre la base de una mayor cooperación con socios diversos -tanto nacionales como extranjeros-, un aumento de la eficiencia de los servicios, un sistema de financiación diversificado y una evaluación continuada de la calidad de todas sus acciones.

Con objeto de evaluar en qué grado la UPV puede considerarse una universidad emprendedora, en los siguientes epígrafes mostraremos cómo se han ido llevando a cabo cada una de las tres misiones en esta universidad y en qué medida es acorde con la definición de universidad emprendedora.

\subsubsection{Formación innovadora y emprendedora en la UPV}

La UPV se define en sus estatutos como universidad emprendedora con una clara orientación hacia el desarrollo económico y social de la Comunidad Valenciana y del Estado. Por ello se preocupa especialmente por incorporar en sus planes de estudio (tanto en grado como en posgrado) materias relacionadas con la innovación y el emprendimiento. Las Tablas 7 y 8 muestran 
las diferentes asignaturas relacionadas con innovación y emprendimiento impartidas en la UPV tanto en grado como en posgrado.

Tabla 7: Asignaturas sobre innovación y emprendimiento en titulaciones de grado oficiales de la UPV (Grado)

\begin{tabular}{lll}
\hline \multicolumn{1}{c}{ ASIGNATURA } & TITULACIÓN (Grado) & Departamento \\
\hline Innovación y Emprendimiento & $\begin{array}{l}\text { Grado en Ingeniería en } \\
\text { Tecnologías Industriales }\end{array}$ & $\begin{array}{c}\text { Proyectos de Ingeniería } \\
\text { Innovar y Emprender }\end{array}$ \\
$\begin{array}{lll}\text { Grado en Ingeniería } \\
\text { Biomédica }\end{array}$ & $\begin{array}{l}\text { Organización de Empresas } \\
\text { Proyectos de Ingeniería }\end{array}$ \\
$\begin{array}{l}\text { Emprendedores y creación de } \\
\text { empresas }\end{array}$ & $\begin{array}{l}\text { Grado en Ingeniería } \\
\text { Informática }\end{array}$ & Organización de Empresas \\
\hline
\end{tabular}

\section{Emprendedores y creación de empresas}

Creación de empresas

Creación de empresas

Creación de empresas

Creación de empresas
Grado en Administración y

Dirección de Empresas
Organización de Empresas

Organización de Empresas
Grado en Comunicación Audiovisual
Grado en Turismo

Grado en Ingeniería de

Sistemas de

Telecomunicación, Sonido e Imagen

Grado en Ciencias

Ambientales
Organización de Empresas

Organización de Empresas
Grado en Administración y Dirección de Empresas
Organización de Empresas

Organización de Empresas

Grado en Ingeniería de

Organización Industrial

Organización de Empresas
Competitividad
en la empresa

Creación y administración de empresas
Grado en Ingeniería en

Diseño Industrial y

Desarrollo de Productos
Organización de Empresas

Innovation management and entrepreneurship

Fuente: elaboración propia 
Tabla 8:Asignaturas sobre innovación y emprendimiento en Titulaciones oficiales UPV (Posgrado)

\begin{tabular}{|c|c|c|}
\hline ASIGNATURA & TITULACIÓN (Posgrado) & DEPARTAMENTO \\
\hline $\begin{array}{l}\text { Innovación y Emprendimiento } \\
\text { orientación química }\end{array}$ & $\begin{array}{l}\text { Máster Universitario en } \\
\text { Sensores para Aplicaciones } \\
\text { Industriales }\end{array}$ & Proyectos de Ingeniería \\
\hline $\begin{array}{l}\text { Innovación y Emprendimiento } \\
\text { orientación electrónica }\end{array}$ & $\begin{array}{l}\text { Máster Universitario en } \\
\text { Sensores para Aplicaciones } \\
\text { Industriales }\end{array}$ & Proyectos de Ingeniería \\
\hline $\begin{array}{l}\text { Dimensiones y contextos de la } \\
\text { cultura de la innovación }\end{array}$ & $\begin{array}{l}\text { Master Universitario en } \\
\text { Cultura Científica y de la } \\
\text { Innovación }\end{array}$ & Proyectos de Ingeniería \\
\hline $\begin{array}{l}\text { Diseño, planificación y } \\
\text { ejecución de proyectos de } \\
\text { fomento de la cultura de la } \\
\text { innovación }\end{array}$ & $\begin{array}{l}\text { Master Universitario en } \\
\text { Cultura Científica y de la } \\
\text { Innovación }\end{array}$ & Proyectos de Ingeniería \\
\hline $\begin{array}{l}\text { Emprendimiento y gestión de } \\
\text { la innovación y la tecnología }\end{array}$ & $\begin{array}{l}\text { Máster Universitario en } \\
\text { Ingeniería Industrial }\end{array}$ & $\begin{array}{l}\text { Organización de Empresas } \\
\text { Proyectos de Ingeniería }\end{array}$ \\
\hline $\begin{array}{l}\text { Creación de empresas y } \\
\text { emprendimiento }\end{array}$ & $\begin{array}{l}\text { Máster Universitario en } \\
\text { Arquitectura }\end{array}$ & Organización de Empresas \\
\hline $\begin{array}{l}\text { Emprendimiento y creación de } \\
\text { empresas }\end{array}$ & $\begin{array}{l}\text { Máster Universitario en } \\
\text { Edificación }\end{array}$ & Organización de Empresas \\
\hline Innovation management & $\begin{array}{l}\text { Máster Universitario en } \\
\text { Gestión de Empresas, } \\
\text { Productos y Servicios }\end{array}$ & Organización de Empresas \\
\hline $\begin{array}{l}\text { Desarrollo de habilidades } \\
\text { directivas y gestión de } \\
\text { equipos de alto rendimiento }\end{array}$ & $\begin{array}{l}\text { Máster Universitario en } \\
\text { Dirección de Empresas } \\
\text { (MBA) }\end{array}$ & Organización de Empresas \\
\hline Gestión de la Innovación & $\begin{array}{l}\text { Máster Universitario en } \\
\text { Dirección de Empresas } \\
\text { (MBA) }\end{array}$ & Organización de Empresas \\
\hline Iniciativa Emprendedora & $\begin{array}{l}\text { Máster Universitario en } \\
\text { Dirección de Empresas } \\
\text { (MBA) }\end{array}$ & Organización de Empresas \\
\hline
\end{tabular}

Fuente: elaboración propia 
A pesar del esfuerzo por incorporar este tipo de asignaturas, hemos de destacar que, si bien hay un número considerable de ellas en diversas titulaciones, no existe una coordinación real entre dichas asignaturas de modo que se preste un enfoque único y consensuado que permita inculcar una verdadera cultura emprendedora en el alumnado. De hecho, asignaturas con temáticas muy similares y que deberían impartir contenidos similares, se imparten en diferentes titulaciones por distintos departamentos y profesores sin coordinación entre sí. Por otra parte, muchas, de las asignaturas orientadas a emprendimiento en realidad muestran cómo se debe desarrollar un plan de negocio y crear una empresa, sin prestar mayor atención a una conceptualización amplia del fenómeno tal como la hemos presentado en esta tesis. Todo ello hace que, el impacto que la implantación de estas asignaturas puede tener sobre el fomento de una verdadera cultura emprendedora entre los alumnos, se vea bastante reducido.

Además de las asignaturas regladas, la UPV cuenta con una amplia formación complementaria en materias relacionadas con innovación y emprendimiento. Una gran parte de esta formación es impartida a través del Instituto IDEAS para la Creación y Desarrollo de Empresas, que desde el año 2000 presenta un programa específico de formación para emprendedores y empresarios, cuyos cursos son convalidables por créditos de libre elección para los alumnos de la UPV. Los cursos y talleres impartidos por el Instituto IDEAS se imparten con una metodología eminentemente práctica, dirigida a satisfacer las necesidades específicas de los jóvenes emprendedores y suplir las carencias formativas en materia de innovación y emprendimiento que, en muchas ocasiones tienen los recién titulados. Para cumplir con este objetivo, el Instituto IDEAS ofrece el programa "Formando Emprendedores", cuyos cursos se agrupan en cursos para el desarrollo personal, desarrollo directivo y la gestión empresarial. Alternativamente, ofrece talleres prácticos de oportunidad de negocio y estudio de viabilidad, gestión de PYME y el curso on-line "Emprender con Éxito". Es de destacar que estos cursos, y en especial los talleres tienen una gran demanda, generando en todas sus ediciones lista de espera de alumnos interesados. Este hecho pone de manifiesto la necesidad que tienen los alumnos de cursar materias relacionadas con el emprendimiento. A modo de ejemplo, citaremos 
que durante el período 2000-2006 el Instituto IDEAS impartió un total de 263 cursos a 5.709 alumnos, mientras que sólo en 2010 impartió 40 cursos a 4.771 alumnos (Millet Roig y Talón Renuncio, 2014)

Si bien la formación específica impartida en la UPV relacionada con innovación y emprendimiento resulta más próxima a lo que entendemos por fomento de la cultura emprendedora y con contenidos claramente orientados hacia las necesidades de los alumnos y lo que requiere el mercado profesional, sigue estando descoordinada y falta de una verdadera orientación hacia el fomento de una cultura emprendedora más allá del fomento de la creación de empresas. Desde la formación de IDEAS se intenta, en cierto modo, alcanzar este objetivo con talleres y cursos orientados a fomentar las habilidades emprendedoras, pero resultan claramente insuficientes y con un objetivo más orientado hacia la creación de empresas que hacia el fomento de la cultura emprendedora en general.

Si echamos un vistazo a las páginas web de las universidades españolas, vemos que están proliferando másteres y títulos propios relacionados con emprendimiento y desarrollo empresarial. Ahondando un poco más sobre los contenidos de dichos programas, comprobamos, una vez más, cómo el objetivo es guiar al alumnado en el proceso de puesta en marcha de su propia empresa. En algunos casos se obtiene formación sobre habilidades emprendedoras de carácter más amplio, pero la gran mayoría se centra en el aspecto empresarial, incluyendo casos y empresarios de éxito. En esta misma línea, la UPV ha lanzado recientemente el Máster en Emprendimiento y Liderazgo, como título propio de la UPV. Una vez más, este máster se centra en formar en cómo crear y gestionar una empresa, más que en fomentar el espíritu emprendedor. En nuestra opinión, toda esta formación es enriquecedora y contribuye al fomento de un tipo de emprendimiento, pero en cierto modo se está "empezando la casa por el tejado". Estamos intentando que personas que no han sido formadas con una metodología innovadora en unos valores y una cultura emprendedora desde un punto de vista amplio, se lancen al mundo empresarial creando su propia empresa. Desde nuestro punto de vista, si se inculca una formación innovadora $y$ en habilidades emprendedoras en todos los ámbitos y de manera transversal en todos los 
niveles y titulaciones, la formación sobre creación y desarrollo de empresas será mucho más fructífera, estableciendo además los pilares para la consolidación de una verdadera cultura emprendedora en la Universidad.

Respecto a la innovación en formación y el desarrollo de esta misión de forma emprendedora e innovadora, podemos destacar en la UPV varias acciones que merecen nuestra atención desde esta perspectiva.

En primer lugar debemos hacer mención al Instituto de Ciencias de la Educación (ICE), un servicio de la UPV orientado a prestar apoyo tanto al profesorado como al alumnado en materia de innovación docente.

En cuanto a los servicios para el profesorado, según reza en su web, el ICE tiene como finalidad principal desarrollar la profesionalización de la docencia universitaria, teniendo como referencia el perfil de profesor y sus competencias.

Esta finalidad se concreta en los siguientes objetivos:

- Proponer a la Comunidad Universitaria acciones de formación que den respuesta a las necesidades de los diferentes colectivos y a la política educativa de la Universidad.

- Dar respuesta a las demandas en formación, tanto individuales como de equipos docentes.

- Facilitar la comunicación e intercambio de experiencias y conocimiento sobre docencia universitaria, generando una cultura profesional basada en la docencia.

- Acompañar a profesores y colectivos en su proceso de mejora docente.

- Diseñar, implementar y evaluar todas las acciones que se desarrollen.

- Analizar el impacto de la formación en la calidad de la docencia y en la profesionalización del profesorado.

- Proponer criterios y sistemas de acreditación y reconocimiento de la calidad de la docencia.

Para llevar a cabo estas tareas la sección está organizada del modo siguiente: formación, innovación, asesoramiento, evaluación formativa y recursos.

El ICE organiza además periódicamente acciones formativas que se caracterizan por ofrecer a los profesores la oportunidad de adquirir, asimilar y aplicar los saberes que les preparen para un ejercicio profesional más eficiente 
y satisfactorio. En este sentido, la oferta actual se centra, por una parte, en servir de apoyo al proyecto institucional sobre Competencias Transversales, proporcionando herramientas para que el profesorado pueda incorporar el desarrollo de las mismas en el transcurso habitual de sus clases; y, por otra parte, en facilitar conocimientos y modos de proceder que reviertan en un mejor desarrollo de la tarea docente.

Otra herramienta estrechamente relacionada con la innovación y el emprendimiento en formación, son los servicios multimedia de la UPV. Estos servicios contemplan un amplio abanico de herramientas y personal técnico a disposición del profesorado que les permite incorporar de forma cómoda y amena las nuevas tecnologías a su labor pedagógica. Entre los servicios que se ofrecen, encontramos:

- Videoapuntes: permite la grabación automática en vídeo de las clases presenciales. Mediante este servicio el usuario programa de forma anticipada la grabación de sus clases y una vez realizada la grabación ésta aparecerá disponible para su visualización en la correspondiente asignatura de PoliformaT. El docente puede revisar la grabación y decidir si se hace pública a sus alumnos o no. También tendrá acceso a distintas herramientas como la edición del vídeo recortando éste para eliminar algunas secciones o introducir descansos.

- Polimedia: es un sistema diseñado en la UPV para la creación de contenidos multimedia como apoyo a la docencia presencial, que abarca desde la preparación del material docente hasta la distribución a través de distintos medios (TV, Internet, CD, etc.) a los destinatarios. Polimedia es un sistema de producción de materiales educativos de calidad que está integrado con todas las herramientas del aula virtual de la UPV (PoliformaT). Se trata sistema completamente innovador y único, disponible sólo en la UPV y que además lleva asociado un plan de incentivos económicos para motivar al profesorado a su uso.

- Cursos masivos abiertos online (MOOC): El movimiento de cursos "on-line" abiertos y masivos (MOOC en inglés) nació hace apenas un 
año en Estados Unidos, cuando la Universidad de Stanford ofreció el primer curso de estas características en el que se matricularon 160.000 estudiantes de 190 países. Con respecto a la clásica formación "on-line", los MOOC presentan algunas diferencias: por definición son gratuitos y están abiertos a todo aquel que se inscriba, prácticamente sin límite de participantes ( $\mathrm{y}$, por lo tanto, las tecnologías deben estar preparadas para dar soporte de manera simultánea a miles de usuarios de todo el mundo). En cuanto a la metodología, se trata de un modelo didáctico cooperativo, donde se espera que los alumnos colaboren y aporten contenidos. Al terminar, deben superar un examen tipo test y reciben un certificado digital. Los MOOC se basan en la integración de tecnologías ya existentes: el vídeo en red, la evaluación automática a distancia y los foros de preguntas y respuestas moderados por el profesor. Es precisamente el uso de esta última herramienta, unido a la forma en que los usuarios utilizan hoy internet, lo que permite crear comunidades de alumnos dispersas que comparten conocimientos y experiencias, que se ayudan unos a otros y que dan a la formación "on-line" un nuevo enfoque colaborativo que favorece el aprendizaje. La UPV lidera la oferta de MOOC en el ámbito nacional, claramente por delante del resto de universidades españolas (le siguen la Universidad Nacional de Educación a Distancia UNED y la Universidad de Cantabria). Más de 140.000 alumnos ya han utilizado la plataforma, y casi 20.000 de ellos han completado con éxito los cursos.

Todas estas herramientas y servicios ponen de manifiesto la apuesta de la UPV por la innovación y el emprendimiento en su misión docente, facilitando el desarrollo de la actividad docente de un modo innovador, dinámico. Con ello se potencia una metodología más dinámica que fomenta la interacción entre los alumnos y los docentes y facilita la adquisición de habilidades transversales.

No obstante, podemos observar que, al igual que ocurre en otros ámbitos, no existe una coordinación clara entre los diferentes servicios, de modo que se ofrezca una visión global y una estrategia de emprendimiento e innovación docente claramente consensuada. 
Por otra parte, si nos centramos en la valoración de la formación recibida por los alumnos UPV, según el resultado de las encuestas realizadas a los titulados UPV del curso 2013/2014 por el observatorio de empleo (Dirección Delegada de Emprendimiento y Empleo, 2014):

- El 89,81\% de los titulados están satisfechos con la formación recibida y otorgan a dicha formación una nota de 6,87 sobre 10 . $(91,09 \% / 6,88$ : curso 2012/2013)

- El 98,36\% de los encuestados volvería a cursar estudios universitarios. (97,95\%: curso 2012/2013)

- El 93,01\% de los titulados volvería a cursar estudios en la UPV. (93,49\%: curso 2012/2013)

- El 75,94\% de los encuestados volvería a cursar la misma titulación. (76,28\%: curso 2012/2013)

Si nos centramos en la opinión que tienen las empresas sobre la formación y capacidades adquiridas por los titulados UPV que contratan, según el último informe del Observatorio de Empleo sobre la empleabilidad de los titulados UPV, se constata que las valoraciones de las competencias que poseen los titulados universitarios cuando se incorporan a la empresa son siempre inferiores a las valoraciones de las competencias demandadas para desempeñar su puesto de trabajo. Es decir, existe un déficit de competencias de los titulados universitarios desde el punto de vista del empleador. Resulta destacable que más de la mitad de las competencias estudiadas no alcanzan la nota media de 5 (UPV, 2010). En la Tabla 9 se muestran las competencias demandadas por las empresas y la valoración que otorgan al alcance de las mismas por los titulados UPV a la hora de incorporarse al puesto de trabajo. En sombreado hemos destacados aquellas competencias que tienen una valoración por debajo de 5 . 
Tabla 9: Valoración de las competencias de los titulados UPV al incorporarse a la organización.

\begin{tabular}{|c|c|c|c|}
\hline Competencia & $\begin{array}{l}\text { Valoración } \\
\text { media }\end{array}$ & Competencia & $\begin{array}{l}\text { Valoración } \\
\text { media }\end{array}$ \\
\hline C1. Dominio del área de su titulación & 6,198 & $\begin{array}{l}\text { C13. Capacidad para hacer valer la } \\
\text { autoridad }\end{array}$ & 4,487 \\
\hline C2. Conocimiento de otras áreas & 4,816 & $\begin{array}{l}\text { C14. Capacidad para utilizar } \\
\text { herramientas informáticas }\end{array}$ & 7,072 \\
\hline C3. Pensamiento analítico & 5,526 & $\begin{array}{l}\text { C15. Capacidad para encontrar nuevas } \\
\text { ideas }\end{array}$ & 5,564 \\
\hline $\begin{array}{l}\text { C4. Capacidad para adquirir } \\
\text { conocimientos }\end{array}$ & 6,730 & $\begin{array}{l}\text { C16. Predisposición para cuestionar } \\
\text { ideas propias y ajenas }\end{array}$ & 5,241 \\
\hline C5. Capacidad para negociar & 4,620 & $\begin{array}{l}\text { C17. Capacidad para presentar en } \\
\text { público ideas, informes, etc. }\end{array}$ & 4,753 \\
\hline $\begin{array}{l}\text { C6. Capacidad para trabajar bajo } \\
\text { presión }\end{array}$ & 5,152 & C18. Capacidad para redactar informes & 5,070 \\
\hline $\begin{array}{l}\text { C7. Capacidad para detectar nuevas } \\
\text { oportunidades }\end{array}$ & 4,880 & $\begin{array}{l}\text { C19. Capacidad para trabajar con } \\
\text { idiomas extranjeros }\end{array}$ & 4,556 \\
\hline $\begin{array}{l}\text { C8. Capacidad para coordinar } \\
\text { actividades }\end{array}$ & 4,975 & C20. Conocimiento del valen-ciano & 4,785 \\
\hline $\begin{array}{l}\text { C9. Capacidad para usar el tiempo de } \\
\text { forma efectiva }\end{array}$ & 5,450 & $\begin{array}{l}\text { C21. Capacidad para gestionar } \\
\text { proyectos }\end{array}$ & 4,810 \\
\hline C10. Capacidad para trabajar en equipo & 6,527 & $\begin{array}{l}\text { C22. Conocimientos de la cultura de la } \\
\text { calidad }\end{array}$ & 4,664 \\
\hline $\begin{array}{l}\text { C11. Capacidad para movilizar las } \\
\text { capacidades de otros }\end{array}$ & 4,620 & $\begin{array}{l}\text { C23. Capacidad para gestionar la } \\
\text { mejora continua }\end{array}$ & 4,835 \\
\hline C12. Capacidad para hacerse entender & 5,583 & MEDIA & 5,257 \\
\hline
\end{tabular}

Fuente: Estudio de Empleabilidad de Titulados de la Universitat Politècnica de València 2010

\subsubsection{Investigación y Relaciones Universidad-Empresa en la UPV}

Siguiendo con el análisis de en qué medida la UPV desarrolla de forma emprendedora cada una de sus tres misiones, nos centramos en este epígrafe en las actividades de investigación y relación con el entorno productivo.

La UPV desarrolla sus actividades de investigación a través de diferentes estructuras de investigación:

- Departamentos

- Institutos Universitarios de Investigación (propios, mixtos y concertados) 
- Centros de Investigación (propios, mixtos, concertados y en red)

En cada una de estas estructuras existen diversos grupos de investigación desde los que se lleva a cabo la actividad investigadora. Esta organización permite desarrollar la labor de investigación con estructuras diferenciadas tanto orgánicamente como presupuestariamente de las propias de formación (departamentos, escuelas y facultades). Al mismo tiempo, estas estructuras disponen de espacios propios adaptados a las necesidades del personal investigador, lo cual favorece la cooperación entre investigadores, el intercambio de conocimientos y el desarrollo de nuevas ideas y temas de investigación. Además, estas estructuras cuentan con otras estructuras de apoyo a la investigación, de carácter transversal como son el CTT, el centro de microscopia electrónica y el servicio de radiaciones.

Por otra parte cabe destacar que la UPV dispone de un amplio programa de apoyo a la investigación que contempla tanto programas propios de ayudas como apoyo a través de gestores de I+D y otros servicios de apoyo.

En cuanto a las actividades de transferencia, como hemos comentado a lo largo de esta tesis, la UPV ha sido desde sus inicios una universidad orientada a relacionarse con su entorno socioeconómico. Así, desde sus inicios estableció relaciones contractuales con el entorno productivo basadas en sus resultados de investigación. Sin embargo, para que estas actividades de transferencia se dieran de forma sistemática y continuada en el tiempo, fue necesario implantar una estrategia de dinamización del personal investigador acompañada por una serie de medidas de apoyo y normativas que reforzaran dicha estrategia. En este sentido, la UPV fue la primera universidad española en contar con una Oficina de Transferencia de Resultados de Investigación (OTRI), denominada CTT, cuya misión era la de prestar servicio al profesorado universitario con objeto de que fuera proactivo hacia las relaciones con su entorno socioeconómico y promover la transferencia de resultados de investigación.

Para ello se puso en marcha una estrategia de dinamización hacia la innovación (Castro et al, 2001). Esta estrategia estaba específicamente dirigida a fomentar una actitud favorable a la cooperación con empresas entre los grupos de investigación. La estrategia de dinamización se desarrolló sobre tres 
pilares básicos: comunicar el mensaje (que incluye actividades de información y de formación dirigidas a los investigadores); catalizar el proceso (prestando a los investigadores y empresas una asesoría personalizada en los diversos aspectos de la gestión de la cooperación) y facilitarlo, mediante la disponibilidad de normas y procedimientos eficaces.

Por tanto, en el desarrollo de la segunda misión desde una perspectiva innovadora que contribuye a la construcción de una universidad emprendedora, la UPV cuenta, por un lado, con una organización y estructura interna que favorece el desarrollo de las actividades de I+D orientada hacia las necesidades del entorno. Por otro lado, la UPV pone al servicio de sus investigadores una serie de servicios de apoyo a la investigación y la transferencia de conocimientos integrados en el Centro de Apoyo la Innovación, la investigación y la transferencia de tecnología (CTT).

\subsubsection{La Tercera Misión en la UPV}

Tal como hemos definido a lo largo de esta tesis, la tercera misión de la universidad se centra en la contribución al desarrollo económico y social del su entorno. En este sentido, la UPV cuenta con una serie de servicios que contribuyen al alcance de esta tercera misión.

Además de lo que ya hemos comentado sobre las relaciones de la UPV con el entorno productivo en materia de transferencia de tecnología, cabe destacar que la UPV cuenta con la Ciudad Politécnica de la Innovación (CPI). La CPI es el Parque Científico de la UPV y se construye, según reza en su página web, como un modelo de red de colaboración abierta, de configuración flexible, que aglutina a agentes públicos y privados que comparten su conocimiento y sus recursos de manera voluntaria. La Red de la Ciudad Politécnica de la Innovación es consecuencia del compromiso de la UPV con el desarrollo económico de la Comunidad Valenciana, de su tradición de cooperación con entidades públicas y privadas de todo el mundo, y de su posición de liderazgo como polo de innovación en España. La Red de la CPI se estructura en tres planos de actuación complementarios: el local, en el que participan más de 25 ayuntamientos, agrupaciones empresariales y entidades promotoras de la 
provincia de Valencia, el nacional, con colaboraciones con más de 100 entidades públicas y privadas del sistema de I+D+i español, y el internacional, con colaboraciones con más de 200 entidades públicas y privadas de investigación y de promoción de la innovación de todo el mundo.

En el plano local, la CPI se articula en torno a tres tipos de agentes principales: los Centros de Investigación, las Antenas de Innovación y los Centros de Innovación Empresarial. Los primeros representan la totalidad del potencial de I+D+i de la UPV, se ubican en los campus de la de la UPV en Valencia, Gandía y Alcoi, e integran a más de 3.000 investigadores sobre un total $140.000 \mathrm{~m}^{2}$ de infraestructuras científicas. Los segundos, las Antenas de Innovación, están gestionados por Ayuntamientos y Agrupaciones Empresariales, y tienen como misión dinamizar la relación entre los distintos elementos de la Red y su tejido empresarial más próximo. Por último, los Centros de Innovación Empresarial son espacios de gestión privada destinados a la ubicación preferente de empresas de base tecnológica; en la actualidad alojan una población flotante de unas 40 empresas. La gestión de la Red y la dinamización de la cooperación entre sus actores es responsabilidad de la Fundación Ciudad Politécnica de la Innovación, entidad sin ánimo de lucro promovida por la Universidad Politécnica de Valencia, entre cuyos patronos de referencia se encuentra el Grupo Santander.

Sin embargo, si tenemos en cuenta la contribución al desarrollo económico y social de la tercera misión, también consideramos que servicios como el Servicio Integrado de Empresas (SIE) y el Programa IDEAS contribuyen activamente a dicho objetivo.

Así, el SIE es el órgano impulsor y gestor de cuantas iniciativas se adoptan en materia de empleo en la UPV y tiene como objetivo contribuir a la mejor inserción laboral de sus titulados. En este sentido, desde este servicio se hace un esfuerzo por comprender las necesidades del entorno en materia de conocimientos y capacidades de sus titulados ofreciendo una visión, tanto de las necesidades del entorno, como de la satisfacción de las empresas e instituciones con los titulados UPV en cuanto a conocimientos y capacidades. Además, el SIE gestiona todas las prácticas de los estudiantes de la UPV en empresas y se preocupa por conectar a la UPV y sus estudiantes con el futuro 
mercado laboral, tanto nacional como extranjero. Para ello dispone de un foro de empleo anual, además de otras herramientas como la orientación profesional y formación para el empleo, gestión de las cátedras de empresa, y el observatorio de empleo. Con ello, la UPV pretende contribuir al desarrollo económico y social aportando titulados a las empresas que contribuyan a su crecimiento y desarrollo a través de la aportación de capacidades y conocimientos específicos y especializados.

Otro de los servicios con los que la UPV pone en marcha su tercera misión es IDEAS. Si bien hablaremos de este servicio con detalle en el epígrafe 5.2, queremos hacer aquí hincapié en cómo este servicio puede contribuir a la tercera misión de la universidad.

Según reza en su página web, El Instituto IDEAS para la Creación y Desarrollo de Empresas es el órgano impulsor y gestor de cuantas iniciativas empresariales nazcan en la UPV. La misión del Instituto IDEAS es fomentar y desarrollar la cultura emprendedora en la UPV, sensibilizar y dinamizar a la comunidad universitaria en la creación y soporte de nuevas empresas, y apoyar la creación y desarrollo de empresas innovadoras y de base tecnológica en la Comunidad Valenciana. El Instituto IDEAS es, además, la unidad responsable de informar, orientar y asesorar a la comunidad universitaria sobre el proceso de creación de empresas en la UPV, en el marco de la "Normativa sobre Creación de Empresas en la Universitat Politècnica de València a partir de la Actividad de Investigación Universitaria”.

Según esta definición, y dejando para un análisis posterior la consideración de que IDEAS tiene como misión fomentar y desarrollar la cultura emprendedora en la UPV, el Instituto IDEAS tiene como objetivo central el apoyo a la creación y desarrollo de empresas en la UPV. Desde esta perspectiva, y en tanto en cuanto pone a disposición de la comunidad universitaria una serie de servicios y herramientas con objeto de salvaguardar, en la medida de los posible, la viabilidad de las futuras empresas, podemos considerar que IDEAS es una herramienta más con la que la UPV contribuye al desarrollo económico y social de su territorio, al incrementar el tejido empresarial con empresas que, si bien no son todas basadas en la investigación, si se pueden denominar innovadoras, o al menos que han surgido con cierta garantía de éxito y 
contribución económica y social. Contribución económica como consecuencia de su aportación al tejido productivo y, contribución social, en la medida en que cada una de estas nuevas empresas es susceptible no sólo de generar el autoempleo para sus promotores, sino de generar empleo para otras personas. Además, dado el carácter innovador de muchas de las empresas y el riguroso ejercicio de planificación empresarial al que son sometidas durante el proceso de creación y/o desarrollo en IDEAS, estas empresas contribuyen en muchas ocasiones a resolver problemas de índole social o, cuanto menos, a mejorar el funcionamiento diario de los ciudadanos. Entre 1992 y 2013, IDEAS ha atendido a casi 6.000 emprendedores habiendo apoyado en este mismo período la creación y desarrollo de 640 empresas.

\subsubsection{Gestión y Financiación de la UPV}

La UPV cuenta con los siguientes órganos de gobierno:

\section{Órganos de gobierno unipersonales}

- Rector: es la máxima autoridad académica de la Universidad y, como tal, la representa en toda clase de actos y negocios jurídicos. Ejerce la dirección, gobierno y gestión de la Universidad, desarrolla las líneas de actuación aprobadas por los órganos colegiados y ejecuta sus acuerdos. Le corresponden cuantas competencias no sean expresamente atribuidas a otros órganos.

- Vicerrectores y directores delegados: son nombrados por el rector entre los profesores que prestan servicios en la Universidad. Coordinan y dirigen las actividades del sector que tienen encomendado, bajo la autoridad del rector, quien puede delegar en ellos las funciones que considere oportunas.

- Secretario general: es el fedatario público de los actos y acuerdos de la Universidad y asiste al rector en tareas de organización y administración. Entre otras funciones, redacta y custodia las actas de las sesiones de los órganos colegiados, expide certificaciones, da publicidad a los acuerdos que se adoptan y vela por que se cumplan. 
- Gerente: le corresponde la gestión de los servicios administrativos y económicos de la Universidad bajo la dependencia y supervisión del rector, que es quien lo propone y nombra de acuerdo con el Consejo Social. El gerente tendrá dedicación a tiempo completo y no podrá ejercer funciones docentes.

\section{Órganos de gobierno colegiados}

- Consejo Social: es el órgano de participación de la sociedad en la Universidad. Supervisa las actividades de carácter económico de la Universidad y el rendimiento de sus servicios; promueve la colaboración de la sociedad en la financiación de la Universidad, y las relaciones entre ésta y su entorno cultural, profesional, económico y social al servicio de la calidad de la actividad universitaria.

- Claustro Universitario: es el máximo órgano de representación de la comunidad universitaria. Está integrado por el rector, el secretario, el gerente y trescientos miembros de la comunidad universitaria (entre ellos directores de centro, profesores, alumnos, personal de administración y servicios, ayudantes y personal de investigación...). Le corresponde la elaboración de los Estatutos y las demás funciones que le atribuye la LOU.

- Consejo de Gobierno: es el órgano de gobierno de la Universidad y se reúne al menos una vez cada tres meses. Entre otras funciones, establece las líneas estratégicas y programáticas de la Universidad -así como las directrices y procedimientos para su aplicación- en los ámbitos de organización de las enseñanzas, investigación, recursos humanos y económicos y elaboración de los presupuestos.

La gestión diaria de la universidad se lleva a cabo a través de los directores de área (docentes con cargos de gestión en servicios universitarios), directores de facultades y escuelas, directores de departamento y directores de las diferentes estructuras de investigación. Se trata de una gestión bastante descentralizada que permite una cierta flexibilidad a la hora de organizar y estructurar los servicios de modo que permita atender mejor las necesidades, tanto del entorno, como de los propios usuarios. 
No obstante queremos destacar una cuestión que ya pusimos de manifiesto en epígrafes anteriores y que hace referencia a la aparición de la figura del director de área. Esta figura surge de la necesidad de otorgar cargos de gestión a los docentes universitarios que les permita cumplir con los requisitos de promoción académica, según la valoración curricular establecida por la LOU. Esto supone en la práctica que, a partir de 2001, diversos servicios universitarios se agrupen en áreas, surgiendo la figura del director de área: un docente cuyo rango está por debajo del vicerrectorado y por encima del jefe de servicio y que se responsabiliza de uno o varios servicios. En nuestra opinión esto supone una duplicidad de cargos, un nivel jerárquico adicional que añade rigidez a la organización y resta eficiencia a estos servicios. Además, ha supuesto ciertos conflictos en aquéllos casos en los que el director de área sólo tiene a su cargo un solo servicio que ya dispone de un jefe de servicio profesional. Hemos de tener en cuenta que el director de área es, además un profesor universitario, con su correspondiente carga docente e investigadora. En una universidad emprendedora o que quiera aspirar a serlo, los servicios universitarios y su gestión deben ser profesionales, lo cual no es muy compatible con directores que no pueden dedicarse plenamente a la función de gestión por tener otras obligaciones que le son propias como son la docencia y la investigación.

Estrechamente relacionado con la profesionalización, calidad y mejora continua de los servicios universitarios, es de destacar el programa PEGASUS de la UPV. PEGASUS es el programa de mejora en la gestión de la administración y los servicios universitarios de la UPV impulsado desde la Gerencia. El programa PEGASUS dio comienzo en el año 2006, y se integró posteriormente como uno de los planes que conforman el Plan Estratégico de la UPV 20072014.Sus objetivos son:

- Proporcionar a los usuarios servicios que satisfagan sus necesidades y expectativas

- Establecer un sistema de mejora continua de los servicios universitarios de la UPV. 
- Implantar un sistema de retribución por productividad del Personal de Administración y Servicios de la UPV.

La puesta en marcha del programa PEGASUS implicó a todos los servicios universitarios llevando a cabo las siguientes acciones:

- Identificando y documentando los procesos que se llevan a cabo en las diferentes Unidades administrativas y de gestión de la UPV.

- Estableciendo un sistema de indicadores de rendimiento y percepción.

- Elaborando las Cartas de servicio.

- Implantando un sistema de sugerencias, quejas y felicitaciones sobre los servicios prestados.

La implantación del programa se llevó a cabo por las unidades administrativas, técnicas $y$ de gestión que, de una u otra manera, prestan apoyo a las actividades docentes y de investigación, u otras complementarias a éstas. Así mismo, la implantación de este programa ha permitido la mejora en la calidad de los servicios universitarios dotando a la organización de una mayor flexibilidad y orientación a las necesidades del usuario. Así mismo, gracias al plan de retribución del personal de administración y servicios vinculado al mismo, se consigue una mayor motivación de los empleados.

Desde el punto de vista de la financiación, la UPV ha sido consciente desde sus inicios de la necesidad de disponer de una financiación diversificada más allá de la dotación presupuestaria que recibe por parte del gobierno autonómico. En este sentido, la UPV, sostiene una importante actividad de transferencia basada en la explotación de resultados de investigación que le reporta autofinanciación, la cual se complementa con los ingresos por matrículas y cursos. La financiación proveniente de mecenazgo, es aun prácticamente inexistente, aunque se está trabajando en ella desde hace algunos años.

En la Figura 11 se puede ver la distribución de la financiación de la UPV según el presupuesto 2015. En la figura se divide dicho presupuesto en los tres tipos de financiación que, según Clark (2004), debe integrar el presupuesto de una universidad emprendedora: 
- Financiación Gubernamental: proveniente de la dotación gubernamental y de otros estamentos políticos

- Financiación Autogenerada: proveniente de las actividades de la universidad (formación, actividades de transferencia, subvenciones competitivas, gestión de su patrimonio, etc.)

- Financiación Privada: proveniente de actividades de mecenazgo y patrocinio de empresas privadas

Figura 11: Distribución de la financiación de la UPV para el año 2015.

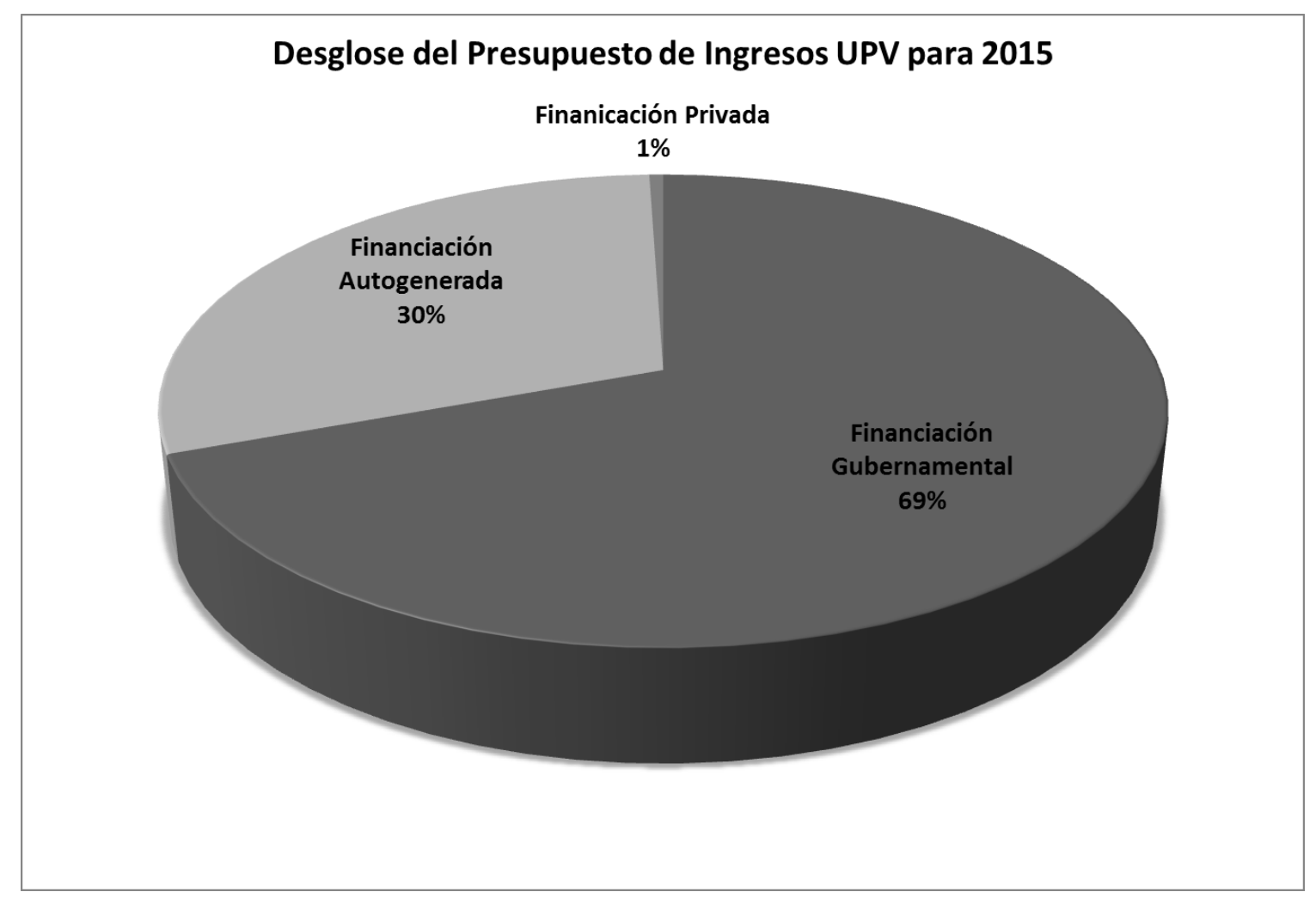

Fuente: Elaboración propia a partir del Presupuesto de la UPV para 2015

Como podemos observar en la figura anterior, la financiación de la UPV sigue siendo principalmente gubernamental (casi el 70\%), mientras que la financiación privada es prácticamente inexistente. 


\subsubsection{Caracterización de la UPV como universidad emprendedora}

Con objeto de analizar en qué medida la UPV puede considerarse una universidad emprendedora, en este epígrafe confrontaremos la definición de Universidad Emprendedora expuesta en el marco empírico con la forma en que la UPV lleva a cabo sus actividades, para posteriormente elaborar una tabla con los puntos fuertes y débiles de la institución en cada una de las características consideradas para la universidad emprendedora.

La primera de las características consideradas por Clark $(1998 ; 2004)$ es la existencia de un núcleo directivo fuerte que favorezca la autodirección, fomente la descentralización y la responsabilidad compartida. En este sentido, la UPV dispone de un sistema de gestión que ofrece un amplio grado de autonomía a los responsables, tanto de los servicios universitarios, como a los directores de departamentos, centros y estructuras de investigación. La implantación del sistema PEGASUS supone un paso adelante hacia la autodirección y la responsabilidad compartida. Así mismo, Existe una clara descentralización en la gestión económica, a través de centros de costes que gestionan los propios investigadores y responsables de servicios, centros y estructuras. Esta descentralización permite una gestión flexible y ágil, pero a la vez sujeta a una normativa y reglas de juego establecidas por el equipo de gobierno. Así mismo, podemos afirmar que en la UPV existe una responsabilidad compartida con los diferentes grupos de interés, como consecuencia de esta descentralización. No obstante todo lo anterior, como hemos visto a lo largo de la presente tesis, este sistema de gestión se ve muchas veces condicionados por la legislación estatal, la cual no permite el desarrollo y el fomento de determinadas actividades al funcionariado público. Así mismo, se está dando una creciente burocratización y control de algunas actividades y procesos, sobre todo en materia económica, que limita la flexibilidad y agilidad en la gestión.

En lo referente a la segunda de las características de la universidad emprendedora, Organización flexible orientada a las necesidades del entorno y que complementa las unidades clásicas con nuevas unidades transversales, hemos de partir del hecho de que la UPV es una institución pública, en la que la mayoría de los empleados son funcionarios públicos. Esto dificulta, en cierto modo, la flexibilidad organizacional de la institución. La existencia de unidades 
transversales de apoyo como el CTT, IDEAS, CFP, ICE etc. que hemos ido mencionado, permiten una mayor orientación de las actividades tradicionales de formación e investigación hacia las necesidades del mercado. No obstante, una cuestión que no favorece precisamente la profesionalización de las unidades es el nombramiento de los directores de área como responsables de servicios que deben profesionalizarse. La puesta en marcha del programa PEGASUS es un ejemplo del esfuerzo de la UPV por intentar adaptarse a las necesidades del entorno. Por su parte, los diferentes servicios y unidades, de forma individual realizan un esfuerzo de flexibilización y adaptación a las necesidades, como veremos en el caso concreto de IDEAS, algunos epígrafes más adelante.

La tercera de las características establecida por Clark hace referencia a una financiación diversificada (gubernamental, privada y autogenerada). En este sentido, si bien la UPV es una universidad pública que cuenta con una dotación presupuestaria pública proveniente del presupuesto de la Generalitat Valenciana, desde sus inicios se ha preocupado por disponer de una financiación diversificada, basada tanto en las actividades de transferencia, como en proyectos de I+D. Además en los últimos años, se está haciendo un esfuerzo por captar financiación proveniente de mecenazgo, lo cual aún sigue siendo el "talón de Aquiles" de la UPV. No obstante, estos esfuerzos no parecen suficientes si observamos que casi el $70 \%$ de la financiación es gubernamental y que la privada representa un escaso $1 \%$. No obstante la financiación autogenerada alcanza una buena ratio (30\% del total).

Referente a la siguiente característica, la existencia de un centro académico motivado, la UPV, a través de diferentes servicios como el CTT, el ICE, IDEAS, el SIE, etc., y de diversos programas de incentivos tanto económicos como académicos, realiza una amplia labor de dinamización y motivación del personal docente e investigador con objeto de contribuir a un mayor desarrollo de la organización. Esto se ve reflejado en los resultados no sólo académicos, sino de investigación y transferencia. Por otro lado, como hemos constatado en el análisis de los resultados de la formación, se hace necesaria una implantación de formación transversal en habilidades y capacidades emprendedoras. Si bien la UPV dispone de una oferta bastante amplia de 
formación en materia de innovación y emprendimiento, tanto reglada como de formación permanente, ésta se centra principalmente en capacidades y habilidades dirigidas hacia la creación y gestión de empresas. Así mismo, según lo expuesto en el último informe de empleabilidad de los titulados UPV, esta formación no parece ser suficiente ya que la satisfacción de las empresas con las capacidades adquirida por los titulados está bastante por debajo de sus expectativas. Para cubrir esta deficiencia se hace necesario disponer de personal docente capaz de despertar estas habilidades y capacidades entre el alumnado.

La última de las características a analizar en una universidad emprendedora es la existencia de una cultura emprendedora integrada, lo cual implica la existencia de un conjunto de valores y creencias compartidos y de un comportamiento emprendedor de la comunidad universitaria. En este sentido, hemos constatado que en la UPV se identifica emprendimiento con fomento para la creación y desarrollo de empresas, por lo que las acciones orientadas al fomento del emprendimiento se centran en este ámbito. Si bien existe un vicerrectorado de emprendimiento, no hay una coordinación a nivel institución ni una visión global de todos los aspectos que integran la cultura emprendedora, más allá del fomento y apoyo a la creación y desarrollo de empresas. Por otra parte, aunque en la UPV existe un fuerte sentimiento de pertenencia por parte de los diferentes colectivos de la comunidad universitaria y una identificación con sus valores, la falta de coordinación en cuanto a cultura emprendedora se refiere, en parte por una interpretación errónea del concepto emprendimiento, hace que no exista una cultura emprendedora totalmente integrada.

En la Tabla 10, se muestra un resumen de lo expuesto, señalando los puntos fuertes y débiles de la UPV como universidad emprendedora. 
Tabla 10: Fortalezas y Debilidades de la UPV como universidad emprendedora.

Característica Universidad

Emprendedora

\begin{tabular}{ll} 
Núcleo Directivo Fuerte \\
- & Autodirección \\
- & Descentralización \\
- & Responsabilidad \\
& compartida \\
\hline $\begin{array}{l}\text { Organización flexible } \\
\text { orientada a las necesidades }\end{array}$
\end{tabular}

del entorno

- Complementa unidades clásicas con nuevas unidades transversales y profesionales

- Visión hacia las necesidades del entorno

Financiación Diversificada

- Gubernamental

- Privada

- Autogenerada

Centro Académico Motivado

Cultura emprendedora integrada

- Conjunto de valores y creencias compartidos

- Comportamiento emprendedor de la comunidad universitaria
Puntos fuertes UPV

Puntos débiles UPV

- Sistema de gestión que ofrece un amplio grado de autonomía

- Implantación del sistema PEGASUS

- Descentralización en la gestión económica

- Responsabilidad compartida

- Existencia de unidades transversales de apoyo como el CTT, IDEAS, CFP, ICE,etc.

- Esfuerzo de adaptación a las necesidades del entorno (PEGASUS; servicios innovadores, etc)

- Amplio abanico de actividades de formación continua y transferencia que otorgan un buen $\%$ de financiación autogenerada

- Amplia labor de dinamización y motivación del personal docente e investigador (ICE, CTT, IDEAS...)

- Incentivos Académico y Económicos

- Implantación de formación en innovación y emprendimiento, aunque con limitaciones

- Existencia de un vicerrectorado de emprendimiento

- Existencia de un programa de apoyo a la creación de empresas pionero en la universidad española

- Fuerte sentimiento de pertenencia por parte de los diferentes colectivos de la comunidad universitaria
- Creciente burocratización y control de los procesos y actividades, sobre todo desde el punto de vista económico

- Flexibilidad organizacional limitada por el carácter público de la universidad

- Directores de área (PDI) como responsables de servicios que deben profesionalizarse

- Desequilibrio entre los tres tipos de financiación

- Financiación privada prácticamente inexistente

- Falta formación transversal en habilidades $y$ capacidades emprendedoras más allá de creación y desarrollo de empresas

- Falta de correlación entre las capacidades de los titulados y la demanda de las empresas emprendimiento con fomento para la creación de empresas

- Falta de coordinación a nivel institución y de una visión global de todos los aspectos que integran la cultura emprendedora

- no existe una cultura emprendedora totalmente integrada
- Identificación de 
Tal como se muestra de lo expuesto en la tabla anterior y en el análisis previo, la UPV cuenta con fortalezas que deberá seguir explotando en aras de consolidarse como universidad emprendedora. Sin embargo, y a pesar de los esfuerzos manifiestos en los diferentes ámbitos (formación, investigación, relaciones con el entorno y la propia gestión), la UPV debe superar una serie de debilidades que limitan su desarrollo como universidad emprendedora. En especial, debe atender al desequilibrio existente en las fuentes de financiación así como en la implantación de una cultura emprendedora. Este último aspecto pasa necesariamente por comprender qué implica ser una universidad emprendedora y asumir que debe desarrollar todas y cada una de sus actividades atendiendo a dicha premisa y no sólo preocuparse por el fomento de actividades relacionadas con la creación y desarrollo de empresas o la transferencia de conocimiento. Tal como apuntó Clark, y como hemos demostrado en nuestro análisis, crear muchas empresas, no convierte a una universidad en emprendedora.

\subsubsection{El Instituto IDEAS de la UPV como servicio innovador y emprendedor}

Como hemos apuntado en epígrafes anteriores, la UPV cuenta desde 1992 con IDEAS, el primer programa de apoyo a la creación de empresas en una universidad española. Durante los cinco primeros años (1992-1996), IDEAS fue una unidad operativa y prestaba apoyo a los emprendedores de la UPV que querían crear su empresa. Sin embargo, no es hasta 1997 cuando las actividades se compilan y existen registros con fines informativos y a partir de 2001, se convierte en Instituto IDEAS, independizándose del CERES y el CTT, en el que nació (véase la Figura 10). Con objeto de analizar las diferentes actividades y su impacto, hemos clasificado las actividades de IDEAS de acuerdo con cuatro categorías:

- Emprendedores y apoyo a la creación de empresas

- Comunicación y difusión

- Formación

- Proyectos y colaboraciones 
En la Tabla 11 podemos ver la evolución de las diferentes actividades de IDEAS según estas categorías para cada uno de los años entre 1997 y 2011.

Para cada año, aparecen sombreadas las diferentes actividades que se han desarrollado en las cuatro categorías anteriores.

Tal como se muestra en esta tabla, desde su creación, este servicio ha ido evolucionando para adaptarse a las necesidades de sus usuarios, las de la propia universidad y en definitiva, de su entorno. La evolución del Instituto IDEAS a lo largo de sus 23 años de vida, ha seguido una trayectoria que ha permitido la transición paulatina y la incorporación de nuevos servicios a medida que los usuarios los demandaban o la propia universidad lo requería. 
Tabla 11: Evolución de las actividades de IDEAS por años (1997-2011).

\begin{tabular}{|c|c|c|c|c|c|c|c|c|c|c|c|c|c|c|c|c|}
\hline Categoría & Actividades & 97 & 98 & 99 & 00 & 01 & 02 & 03 & 04 & 05 & 06 & 07 & 08 & 09 & 10 & 11 \\
\hline \multirow{15}{*}{$\begin{array}{l}\text { Emprendedores y apoyo a la } \\
\text { creación de empresas }\end{array}$} & Test de pautas de comportamiento emprendedor & & & & & & & & & & & & & & & \\
\hline & Revisión y documentación del Plan de Empresa & & & & & & & & & & & & & & & \\
\hline & Software Plan Empresa & & & & & & & & & & & & & & & \\
\hline & Seguimiento personalizado & & & & & & & & & & & & & & & \\
\hline & Asesoramiento contable y fiscal & & & & & & & & & & & & & & & \\
\hline & Búsqueda en base de datos y otros recursos & & & & & & & & & & & & & & & \\
\hline & Apoyo y asesoramiento para premios & & & & & & & & & & & & & & & \\
\hline & Incubadora Virtual & & & & & & & & & & & & & & & \\
\hline & Tiendas Virtuales y asesoramiento en comercio electrónico & & & & & & & & & & & & & & & \\
\hline & Apoyo al desarrollo de empresas & & & & & & & & & & & & & & & \\
\hline & Información y apoyo para subvenciones & & & & & & & & & & & & & & & \\
\hline & Estudios de Marketing y nuevas oportunidades de negocio & & & & & & & & & & & & & & & \\
\hline & Legislación Spin-off & & & & & & & & & & & & & & & \\
\hline & Creación de redes de negocios y apoyo financiero & & & & & & & & & & & & & & & \\
\hline & Premios IDEAS & & & & & & & & & & & & & & & \\
\hline \multirow{9}{*}{ Comunicación y Difusión } & Conferencias en escuelas y facultades & & & & & & & & & & & & & & & \\
\hline & Jornadas de motivación empresarial & & & & & & & & & & & & & & & \\
\hline & Marketing IDEAS & & & & & & & & & & & & & & & \\
\hline & Stand en Foroempleo UPV & & & & & & & & & & & & & & & \\
\hline & Organización de conferencias & & & & & & & & & & & & & & & \\
\hline & Programa IDEAS TV & & & & & & & & & & & & & & & \\
\hline & Stands informativos en facultades y escuelas & & & & & & & & & & & & & & & \\
\hline & Programa de sensibilización al profesorado & & & & & & & & & & & & & & & \\
\hline & Participación en el Día de la Persona Emprendedora CV & & & & & & & & & & & & & & & \\
\hline
\end{tabular}




\begin{tabular}{|c|c|c|c|c|c|c|c|c|c|c|c|c|c|c|c|c|}
\hline Categoría & Actividades & 97 & 98 & 99 & 00 & 01 & 02 & 03 & 04 & 05 & 06 & 07 & 08 & 09 & 10 & 11 \\
\hline \multirow{7}{*}{ Actividades formativas } & Formación en comportamiento emprendedor & & & & & & & & & & & & & & & \\
\hline & Curso para el desarrollo del plan de empresa & & & & & & & & & & & & & & & \\
\hline & Colaboración en formación oficial & & & & & & & & & & & & & & & \\
\hline & Programa Formando Emprendedores & & & & & & & & & & & & & & & \\
\hline & Taller de oportunidades de negocio y estudio de viabilidad & & & & & & & & & & & & & & & \\
\hline & Taller de gestión de PYME & & & & & & & & & & & & & & & \\
\hline & Curso on-line emprender con éxito & & & & & & & & & & & & & & & \\
\hline \multirow{6}{*}{$\begin{array}{l}\text { Proyectos y otras } \\
\text { colaboraciones }\end{array}$} & Colaboración con otras instituciones & & & & & & & & & & & & & & & \\
\hline & Proyectos nacionales y regionales & & & & & & & & & & & & & & & \\
\hline & Proyectos europeos & & & & & & & & & & & & & & & \\
\hline & Libros y otras publicaciones & & & & & & & & & & & & & & & \\
\hline & $\begin{array}{l}\text { Formación específica en emprendimiento para otras } \\
\text { instituciones }\end{array}$ & & & & & & & & & & & & & & & \\
\hline & $\begin{array}{l}\text { Colaboración en otros eventos y premios para } \\
\text { emprendedores }\end{array}$ & & & & & & & & & & & & & & & \\
\hline
\end{tabular}

\section{Fuente: Elaboración propia}


Actualmente, según su página web, IDEAS cuenta con los siguientes servicios:

- Difusión de la cultura emprendedora: organización de distintas acciones de difusión de la cultura emprendedora y la creación de empresas (charlas en facultades y escuelas UPV, eventos para emprendedores dentro y fuera de la UPV, premios y concursos, Programa de TV-UPV, etc.)

- Asesoramiento para la creación de empresas: apoyo a la creación de empresas innovadoras. Servicio de atención personalizado para informar, orientar y asesorar a los emprendedores sobre el proceso de creación de empresas, desde el nacimiento de la idea de negocio hasta la consolidación del proyecto empresarial. Tutorización, apoyo y seguimiento para el desarrollo del Plan de Empresa y análisis de la viabilidad. Asesoramiento en las diferentes etapas de la puesta en marcha de la empresa.

- Ventanilla única spin-off UPV: información, orientación y asesoramiento a la comunidad universitaria sobre el proceso de creación de empresas a partir de la actividad investigadora en la UPV, gestionando las solicitudes y ejerciendo de enlace entre el equipo promotor y el resto de servicios de la Universidad. Apoyo y tutorización para el desarrollo del Plan de Empresa y asesoramiento en las diferentes etapas de la puesta en marcha de la spin-off.

- Apoyo al desarrollo de empresas: apoyo y asesoramiento a las empresas IDEAS en su crecimiento, y desarrollo de ventajas competitivas en el mercado. Apoyo y asesoramiento en la búsqueda de financiación, en forma de Fondos de Capital Riesgo, Business Angels, financiación bancaria, socios empresariales, etc. Servicio de consultoría en Tecnología de la Información y las Comunicaciones (TIC) que aumente el nivel de crecimiento y desarrollo de la empresa. Diversificación empresarial mediante el desarrollo de nuevas líneas de negocio y su correspondiente plan de viabilidad. 
Organización de actividades de desarrollo para las empresas IDEAS (presentaciones empresas, comités de expertos, encuentros,...)

- Formación a emprendedores y empresarios: promoción y organización de cursos específicos para emprendedores y empresarios sobre gestión empresarial, desarrollo personal y habilidades directivas. Atención e información a los alumnos sobre los cursos de formación específica y jornadas ofertados por el Instituto IDEAS. Resolución de dudas concretas (horario, fechas, matrícula, certificados, etc.).

- Consultoría técnica y capacitación a entidades: capacitación y consultoría técnica dirigido a otras universidades o/y entidades externas en cualquier temática relacionada con el emprendimiento.

- Programa StartUPV: este programa pone a disposición de emprendedores, start-ups, alumnos, asesores y mentores una red de espacios de trabajo y co-creación para llevar a cabo las iniciativas y proyectos empresariales que lo necesiten. Los proyectos, start-ups y empresas podrán disfrutar de las instalaciones de STARTUPV situadas en la CPI, la Casa del Alumno y Espacios [EMPRENDE] (situados en cada una de las escuelas, facultades y campus de la UPV)

En cuanto a los recursos, el Instituto IDEAS cuenta con financiación de la Universidad Politécnica de Valencia ${ }^{28}$. En cuanto a la búsqueda de financiación adicional, desde 2004 hasta el año 2011, el Instituto IDEAS disponía de un gestor de proyectos cuya misión era detectar posibles vías de financiación alternativas a través de subvenciones, colaboraciones, contratos, etc. A partir de 2011 no aparece en el organigrama de la web la figura del gestor de proyectos, por lo que no podemos confirmar si se siguen desarrollando este tipo de actividades. Así mismo, desde 2007 y hasta 2011, las actividades del Instituto IDEAS cuentan también con el

\footnotetext{
${ }^{28}$ EI Instituto IDEAS figura como una partida de gasto en los presupuestos de la Universidad Politécnica de Valencia.
} 
patrocinio de una entidad financiera, lo que supone una importante inyección de recursos. No obstante, cabe destacar que este patrocinio vino dado por una negociación desde el gobierno de la propia universidad, más que de la búsqueda activa de patrocinadores por parte del servicio. Así, durante el período 2007-2011, la estructura financiera del servicio se divide equitativamente en tres fuentes de financiación: la dotación de la propia universidad; proyectos y contratos; patrocinio de empresas.

Respecto a la flexibilidad de los servicios, el Instituto IDEAS tiene como vocación ayudar al emprendedor con todos los medios disponibles. Como servicio universitario tiene un horario de atención al público; sin embargo, la cultura emprendedora integrada en los miembros del equipo humano y técnicos de IDEAS, flexibiliza este horario para que se puedan atender a emprendedores fuera del mismo, siendo conscientes de las limitaciones de tiempo y horario de los usuarios.

En cuanto al tipo de servicio prestado también se ofrece flexibilidad. Efectivamente, los emprendedores tienen siempre problemas distintos para los que hay que explorar soluciones distintas y, en ocasiones innovadoras. En el Instituto IDEAS se intentan reinventar constantemente los servicios para que se adapten a sus necesidades y, en el caso de no poder satisfacerlo adecuadamente, se ponen en contacto con las personas 0 entidades apropiadas.

Con objeto de analizar en qué medida el Instituto IDEAS puede considerarse un servicio emprendedor e innovador, en la Tabla 12 se muestran los requisitos establecidos en la literatura y puestos de manifiesto en el apartado anterior, indicando la forma en la que el Instituto IDEAS ha adoptado cada uno de ellos: 
Tabla 12: Implementación de las características de servicios innovadores en el Instituto IDEAS

\begin{tabular}{|c|c|}
\hline Característica & Aplicación al caso del Instituto IDEAS \\
\hline $\begin{array}{l}\text { Búsqueda alternativa de } \\
\text { financiación }\end{array}$ & $\begin{array}{c}\text { Financiación no sólo de la UPV, sino también: } \\
\text { - } \quad \text { Proyectos, contratos y subvenciones } \\
\text { - } \quad \text { Patrocinio de otras entidades y empresas }\end{array}$ \\
\hline Organización flexible & $\begin{array}{l}\text { La estructura organizativa, los horarios y los servicios se han } \\
\text { flexibilizado para poder adaptarse a las necesidades de los } \\
\text { usuarios, por un lado, y permitir la interactuación con el resto de } \\
\text { agentes y la generación de nuevos procesos y procedimientos, por } \\
\text { otro. }\end{array}$ \\
\hline Interacción con el entorno & $\begin{array}{c}\text { Colaboración con otros agentes del entorno, como: } \\
\text { - } \quad \text { Entidades públicas } \\
\text { - } \quad \text { Empresas y asociaciones empresariales } \\
\text { - } \\
\text { - Entidades financieras e inversores } \\
\text { Parques científicos, tecnológicos y universidades }\end{array}$ \\
\hline $\begin{array}{l}\text { Cultura emprendedora } \\
\text { integrada }\end{array}$ & $\begin{array}{l}\text { Fomento de la creatividad, compromiso e innovación en la forma } \\
\text { de atender a los emprendedores y empresas. Para poder atender } \\
\text { los requerimientos del servicio, durante el período estudiado } \\
\text { (hasta 2011) existe una cultura emprendedora integrada en las } \\
\text { propias personas que ofrecen el servicio y que ha sido fruto de un } \\
\text { proceso llevado a cabo desde los inicios del programa. }\end{array}$ \\
\hline $\begin{array}{l}\text { Adaptación a las } \\
\text { necesidades de los } \\
\text { usuarios }\end{array}$ & $\begin{array}{l}\text { El Instituto IDEAS posee una carta de servicios que evoluciona } \\
\text { constantemente para adaptarse a las necesidades de los usuarios. } \\
\text { La filosofía no es "esto es lo que ofrecemos", sino "qué es lo que } \\
\text { el emprendedor necesita y cómo lo podemos satisfacer". } \\
\text { Constantemente surgen nuevos servicios a partir de una } \\
\text { necesidad de algún emprendedor o empresa. }\end{array}$ \\
\hline $\begin{array}{l}\text { Empleo de las } \\
\text { tecnologías de la } \\
\text { información }\end{array}$ & $\begin{array}{l}\text { Desde sus comienzos las TIC se han considerado prioritarias. Se } \\
\text { cuenta con servicios on-line, con programas informáticos para el } \\
\text { asesoramiento, con un centro comercial virtual, programa de } \\
\text { televisión propio, herramientas de videoconferencias, implantación } \\
\text { de las últimas tendencias (web } 2.0 \text {, blogs interactivos, etc.). } \\
\text { Actualmente, atendiendo a las necesidades de los emprendedores } \\
\text { también se ha adaptado el asesoramiento para que, a través de } \\
\text { las nuevas tecnologías se puedan intercambiar información, e } \\
\text { incluso asesorar on-line para evitar desplazamientos innecesarios } \\
\text { a los emprendedores. }\end{array}$ \\
\hline $\begin{array}{l}\text { Formación y capacitación } \\
\text { de RRHH }\end{array}$ & $\begin{array}{l}\text { El equipo técnico del Instituto IDEAS recibe formación constante y } \\
\text { capacitación relacionada con sus actividades. Además de la } \\
\text { formación continua que ofrece la propia universidad, desde IDEAS } \\
\text { se promueve la asistencia a conferencias, charlas y cursos por } \\
\text { parte del personal técnico para que su formación redunde en una } \\
\text { mejora de los servicios y, por ende de los resultados finales. }\end{array}$ \\
\hline
\end{tabular}

Fuente: Elaboración propia 


\subsection{Aplicación del modelo de FEyADE al caso de la UPV}

Con objeto de analizar en qué medida, las actividades de FEyADE se están aplicando de forma que cubran todas las necesidades de los emprendedores en la UPV, analizaremos el caso a través de la metodología propuesta en el capítulo anterior. Para ello, seguiremos los pasos expuestos:

1. Identificación de los agentes involucrados en el proceso para el caso de la UPV

2. Determinación de cuál es la contribución de cada agente implicado, analizando qué necesidades satisface cada uno

3. Determinación de la contribución de cada agente a cada fase y actividad del modelo (colaboraciones entre agentes)

\subsubsection{El entorno de la UPV: identificación de los agentes involucrados}

Como hemos visto en los epígrafes anteriores, la UPV es una universidad que se relaciona con su entorno socioeconómico a través de diversos servicios y entidades propias. Sin embargo, a la hora de poner en marcha un proceso de FEyADE, se deben tener en cuenta no sólo los agentes internos a la propia UPV, sino también a los agentes externos que no sólo se beneficiarán de los resultados del proceso, sino que pueden contribuir para que los mismos sean óptimos. En este sentido, hemos identificado los agentes internos y externos a la UPV que deberían participar de dicho proceso y contribuir así a los resultados finales. Esta diferenciación entre internos y externos, mostrará en las siguientes etapas de nuestro análisis la relevancia que, para las universidades emprendedoras y el éxito de su tercera misión, tienen los agentes externos a la misma, así como las relaciones y redes necesarias entre agentes internos y externos. La Tabla 13 muestra los agentes involucrados en el proceso de FEyADE para el caso de la UPV. 
Tabla 13: Agentes involucrados en el proceso de FEyADE en la UPV

\section{Internos a la UPV}

\section{Externos a la UPV-CPI}

- Consultorías Externas

- Asociaciones y Empresas

- Institutos Tecnológicos

- Redes de Business Angels y Capital Riesgo

- Entidades Financieras

- Gobiernos (Europeos, Nacionales, Regionales y Locales)

- Facultades

- Servicio Integrado de Empleo de la UPV (SIE)

\section{Fuente: elaboración propia}

Los emprendedores y empresas, usuarios del proceso, deberían ser también considerados como agentes del mismo. Sin embargo, no se han tenido en cuenta en la anterior enumeración al considerar que, como usuarios e interesados, estarán involucrados en todas las actividades y tendrán relación (directa o indirecta) con todos y cada uno del resto de agentes, por lo que su inclusión en el análisis sería redundante y no aportaría datos significativos.

En relación con los agentes internos a la UPV, hemos de señalar que el servicio de apoyo a la creación de empresas en la UPV no depende del Centro de Transferencia de Tecnología (como ocurre en muchas universidades españolas), sino que, como hemos visto a lo largo de esta tesis, está constituido por un servicio independiente, el Instituto IDEAS, especial y específicamente diseñado para prestar apoyo a la creación de nuevas empresas cuyas iniciativas provengan de estudiantes, egresados y personal de la universidad así como para apoyar la creación de nuevas empresas cuyo objetivo sea la explotación de resultados de investigación de la UPV.

Con respecto a los institutos de investigación y departamentos, hemos de diferenciar entre aquellos que centran sus actividades y líneas de investigación en temas relacionados con la socioeconomía, y el resto, que en el caso de la UPV tienen una orientación más tecnológica, o de 
ingeniería. Los primeros, podrían estar más involucrados en la etapa de Fomento del Emprendimiento, especialmente en lo que a investigación y docencia relacionada con emprendimiento y desarrollo de empresas se refiere. El resto de institutos y departamentos deberían tener también un papel activo en el proceso, especialmente en aquellas actividades que requieren apoyo relacionado con el conocimiento tecnológico. Por otra parte, estos departamentos e institutos pueden convertirse en usuarios del modelo cuando deciden crear empresas spin-off para explotar sus resultados de investigación.

El Servicio Integrado de Empleo (SIE) aparece entre los agentes del modelo ya que desempeña un papel activo a la hora de facilitar mano de obra cualificada a las empresas. Este servicio es especialmente significativo durante los primeros años de vida de la empresa, cuando éstas requieren recursos humanos cualificados a tiempo parcial ya que no pueden hacer frente a los gastos que supone un empleado a tiempo completo ni tienen un volumen de trabajo tal que así lo requiera. En estos casos el SIE puede proveer a las empresas de estudiantes en prácticas, cuyo perfil, salario y tareas que pueden desempeñar se adaptan perfectamente a las necesidades de las empresas en sus inicios. Esta relación permite además que, una vez la empresa haya superado su fase inicial y requiera de personal a tiempo completo, el estudiante en prácticas pueda formar parte de la plantilla de la empresa, por lo que esta situación no debe verse como beneficiosa sólo para la empresa sino también para el estudiante y la propia universidad.

Con respecto a los agentes externos, hemos de destacar el papel de los institutos tecnológicos, ya que la Comunidad Valenciana está dotada con una de las redes de institutos tecnológicos más importantes de España. Esta red está fundamentalmente localizada en Paterna (Valencia) y tiene en conjunto un total de 13 institutos tecnológicos y 5.300 empresas asociadas que ofrecen servicios a 11.100 clientes. Por tanto, el papel de estos institutos se presenta como crucial para el proceso de FEyADE. 


\subsubsection{Contribución de los agentes: cobertura de necesidades}

Una vez que ya conocemos cuáles son los agentes involucrados en el proceso de FEyADE de la UPV, el siguiente paso para su implementación es el análisis de la contribución de cada uno de estos agentes al proceso. La Tabla 14 muestra el resultado de este ejercicio para el caso de la UPV. Según podemos extraer de la Tabla 14, el agente que más interviene en cada una de las etapas y que más capitales aporta es IDEAS, como no podía ser de otro modo, ya que es el servicio destinado al fomento del emprendimiento y apoyo a la creación de empresas en la UPV. Del análisis también podemos constatar que en todas las etapas intervienen varios agentes, tanto internos como externos. Esto mismo podemos ver qué ocurre si analizamos la intervención de los agentes en cada uno de los capitales por etapa, salvo en el caso de Alojamiento y Servicios, que no interviene ningún agente externo. Es de destacar que, para las etapas de Apoyo al emprendedor, Apoyo a la Creación de Empresas y Apoyo al Desarrollo de Empresas, los agentes externos tienen una fuerte presencia en la aportación del capital cultural. También es destacable que en la primera etapa, la de Fomento del Emprendimiento, los capitales son cubiertos en su mayoría por agentes internos a la UPV, mientras que en el resto de etapas, la participación está bastante más equilibrada. Si analizamos la cobertura de los diferentes capitales, podemos constatar que el capital que goza de mayor cobertura es el Capital Relacional, seguido por el Capital Cultural. El Capital Estratégico y Económico, con valores similares entre sí, tienen una cobertura claramente inferior a los anteriores, mientras que Alojamiento y Servicios queda claramente alejado de todos ellos. 
Tabla 14: Contribución de los agentes de la UPV al proceso de FEyADE

\begin{tabular}{|c|c|c|c|c|c|c|c|c|c|c|c|c|c|c|c|c|c|c|c|}
\hline \multirow[b]{2}{*}{ AGENTES } & \multicolumn{4}{|c|}{ Fomento del Emprendimiento } & \multicolumn{5}{|c|}{$\begin{array}{c}\text { Apoyo al } \\
\text { Emprendedor }\end{array}$} & \multicolumn{5}{|c|}{ Apoyo a la Creación de Empresas } & \multicolumn{5}{|c|}{ Apoyo al Desarrollo de Empresas } \\
\hline & CS & CE & CC & CR & CS & CE & CC & CR & AS & CS & CE & CC & CR & AS & CS & CE & CC & CR & AS \\
\hline Gobierno UPV & - & - & - & & & - & & & & - & - & - & & & - & - & - & & \\
\hline IDEAS & - & - & - & - & - & - & - & - & - & - & - & - & - & - & - & - & - & - & \\
\hline OTRI (CTT) & - & & & - & - & & & - & & - & & - & - & & & & - & - & \\
\hline $\begin{array}{l}\text { Parque } \\
\text { Científico (CPI) }\end{array}$ & & & & - & & & & - & - & & & & - & - & & & & - & - \\
\hline $\begin{array}{l}\text { Institutos } \\
\text { Investigación }\end{array}$ & - & & - & - & & & - & - & & & & - & - & & & & - & - & \\
\hline Departamentos & - & & - & - & & & & & & & & & & & & & - & - & \\
\hline Facultades & - & & & - & . & & & - & - & & & & & - & & & & & \\
\hline $\begin{array}{l}\text { Servicio de } \\
\text { Empleo }\end{array}$ & & & & - & & & & - & & & & - & - & & & & & . & \\
\hline $\begin{array}{l}\text { Consultarías } \\
\text { Externas }\end{array}$ & & & & & & & - & & & & & - & & & & & - & & \\
\hline $\begin{array}{l}\text { Asociaciones y } \\
\text { Empresas }\end{array}$ & & & - & - & & & - & - & & & & - & - & & & & - & - & \\
\hline $\begin{array}{l}\text { Institutos } \\
\text { Tecnológicos }\end{array}$ & & & & - & & & - & - & & & & - & - & & - & & - & - & \\
\hline $\begin{array}{l}\text { Capital Riesgo y } \\
\text { BA }\end{array}$ & & & & & - & & - & & & - & - & - & - & & & - & - & - & \\
\hline $\begin{array}{l}\text { Entidades } \\
\text { Financieras }\end{array}$ & & - & & & & - & & & & & - & & & & & - & & & \\
\hline Gobiernos & . & - & & & . & - & & & & & - & & & & & $\square$ & & & \\
\hline
\end{tabular}

Fuente: elaboración propia 
La siguiente figura muestra la cobertura de cada uno de los capitales en el que aparece la frecuencia con la que cada uno de estos capitales se ha cubierto por los agentes internos y externos, según el ejercicio mostrado en la Tabla 14.

\section{Figura 12: Cobertura de los Diferentes Capitales por los Agentes Implicados}

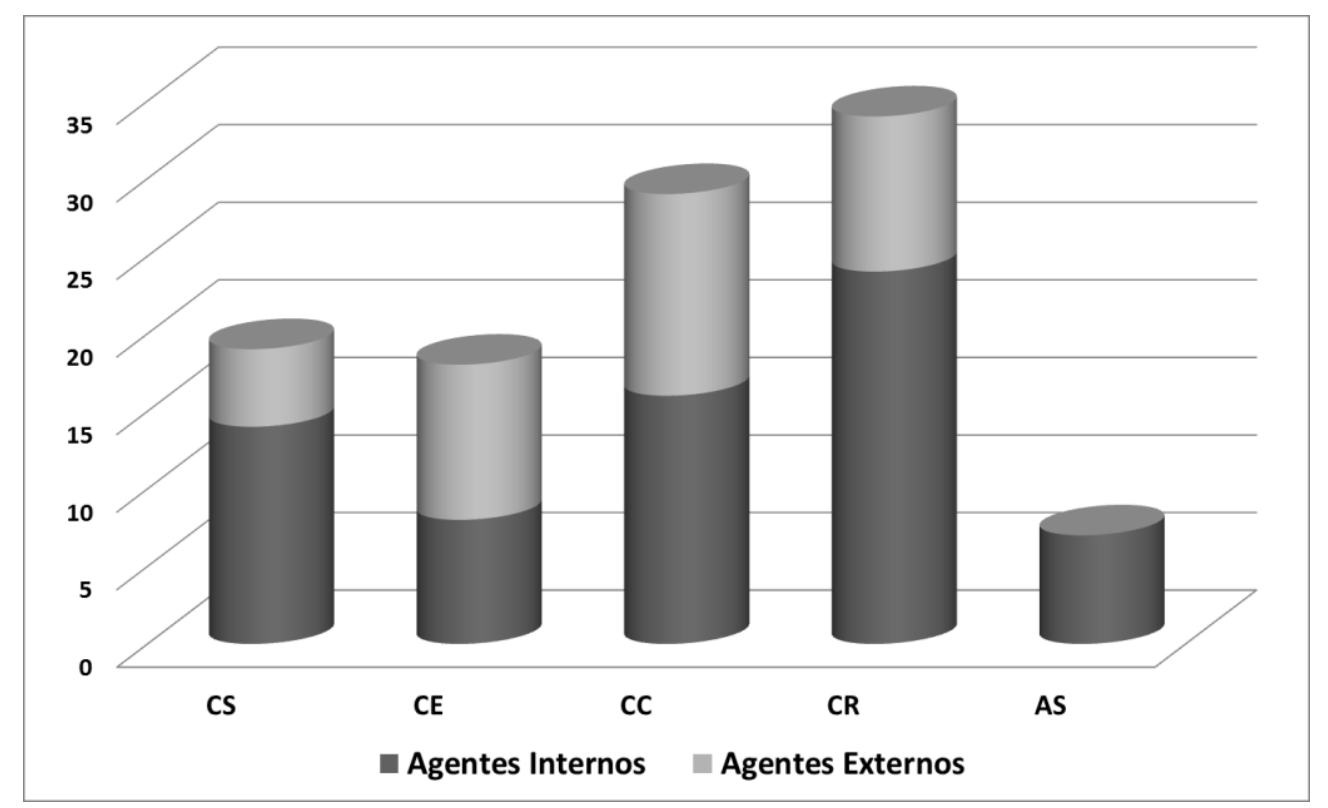

Fuente: elaboración propia

No obstante, para la adecuada implementación del modelo de FEyADE en universidades, no sólo necesitamos saber cuál es la contribución de cada agente, sino en qué actividad del modelo se lleva a cabo dicha contribución. Una vez más, necesitamos tener en cuenta las características de los agentes y sus objetivos individuales para desarrollar nuestro análisis. Los resultados para el caso de la UPV se muestran en la Tabla 15 donde hemos integrado los capitales descritos en la Tabla 3 y la contribución de cada agente mostrada en la Tabla 14. 
Tabla 15:Cooperación entre agentes y contribución a las actividades de FEyADE en la UPV

\begin{tabular}{|c|c|c|c|c|c|c|c|c|c|c|c|c|}
\hline \multirow[b]{2}{*}{ AGENTES } & \multicolumn{3}{|c|}{$\begin{array}{l}\text { Fomento del } \\
\text { Emprendimiento }\end{array}$} & \multicolumn{3}{|c|}{$\begin{array}{c}\text { Apoyo al } \\
\text { Emprendedor }\end{array}$} & \multicolumn{3}{|c|}{$\begin{array}{l}\text { Apoyo a la Creación } \\
\text { de Empresas }\end{array}$} & \multicolumn{3}{|c|}{$\begin{array}{l}\text { Apoyo al Desarrollo } \\
\text { de Empresas }\end{array}$} \\
\hline & Sensib & Invest & Docenc & Oport & Plan E & Progr & Invers & Incub & Recom & Superv & $1+D$ & s Tec. \\
\hline Gobierno UPV & CS CE & CS CE & CS CE & & & CE & & & & & & \\
\hline $\begin{array}{l}\text { Serv Apoyo } \\
\text { Creac Emp }\end{array}$ & $\begin{array}{l}\text { CS CC } \\
\text { CE CR }\end{array}$ & cs cc & cs cc & $\begin{array}{c}\text { CS CC } \\
\text { CE CR } \\
\text { AS }\end{array}$ & $\begin{array}{c}\text { CS CC } \\
\text { CE CR } \\
\text { AS }\end{array}$ & $\begin{array}{c}\text { CS CC } \\
\text { CE CR } \\
\text { AS }\end{array}$ & $\begin{array}{c}\text { CS CC } \\
\text { CE CR } \\
\text { AS }\end{array}$ & $\begin{array}{c}\text { CS CC } \\
\text { CE CR } \\
\text { AS }\end{array}$ & \begin{tabular}{|c|} 
CS CC \\
CE CR \\
AS
\end{tabular} & $\begin{array}{l}\text { CS CC } \\
\text { CE CR }\end{array}$ & & \\
\hline OTRI (CTT) & $\begin{array}{c}\mathrm{CS} \\
\mathrm{CC} C \mathrm{CR}\end{array}$ & CS CR & cs c & $\begin{array}{c}\text { Cs cc } \\
\text { CR }\end{array}$ & CR & $\begin{array}{c}\text { Cs cc } \\
\text { CR }\end{array}$ & $\begin{array}{c}\text { Cs CC } \\
\text { CR }\end{array}$ & CR & CC CR & $\begin{array}{c}\text { CS CC } \\
\text { CR }\end{array}$ & $\begin{array}{l}\text { Cs cC } \\
\text { CR }\end{array}$ & $\begin{array}{l}\text { Cs CC } \\
\text { CR }\end{array}$ \\
\hline $\begin{array}{l}\text { Parque } \\
\text { Científico (CPI) }\end{array}$ & CR & & & & CR AS & CR AS & & AS & CR & CR AS & CR AS & $\begin{array}{l}\text { CR } \\
\text { AS }\end{array}$ \\
\hline $\begin{array}{l}\text { Institutos } \\
\text { Investigación }\end{array}$ & CR & CS & & CC CR & CC CR & CC CR & & CR & cc & CC & $\begin{array}{l}\text { Cs CC } \\
\text { CR }\end{array}$ & $\begin{array}{c}\text { Cs CC } \\
\text { CR }\end{array}$ \\
\hline Departamentos & CR & $\begin{array}{c}\mathrm{CS} \\
\mathrm{CC} C R\end{array}$ & $\begin{array}{c}\mathrm{CS} \\
\mathrm{CC} \text { CR }\end{array}$ & & & & & & & CC & CR & CR \\
\hline Facultades & & & CS CR & & & $\begin{array}{c}\mathrm{CC} \text { CR } \\
\text { AS }\end{array}$ & & AS & & & & \\
\hline $\begin{array}{l}\text { Servicio de } \\
\text { Empleo }\end{array}$ & CR & & & CR & & & & CR CC & CR CC & Cc & cc & \\
\hline $\begin{array}{l}\text { Consultarías } \\
\text { Externas }\end{array}$ & & & & & cc & & & & cc & cc & & cc \\
\hline $\begin{array}{l}\text { Asociaciones y } \\
\text { Empresas }\end{array}$ & CR & CC & CC & CR & CC CR & CR & CR & CR & CC CR & CC CR & CC CR & CC CR \\
\hline $\begin{array}{l}\text { Institutos } \\
\text { Tecnológicos }\end{array}$ & CR & CR & & CR CC & CR & CR & & CR & $\begin{array}{l}\text { CS } \\
\text { CR }\end{array}$ & & $\begin{array}{c}\text { Cs CC } \\
\text { CR }\end{array}$ & $\begin{array}{l}\text { Cs CC } \\
\text { CR }\end{array}$ \\
\hline $\begin{array}{l}\text { Capital Riesgo } \\
\text { y BA }\end{array}$ & & & & cc & cs cc & & $\begin{array}{l}\text { CS CC } \\
\text { CE CR }\end{array}$ & & CR & CR CC & CE & CE \\
\hline $\begin{array}{l}\text { Entidades } \\
\text { Financieras }\end{array}$ & CE & & & & & CE & CE & & CE & & CE & CE \\
\hline Gobiernos & CS CE & CS CE & CS CE & & & CS CE & CE & & & & CE & CE \\
\hline
\end{tabular}

\section{Fuente: elaboración propia}

Un análisis pormenorizado de la Tabla 15 nos permite ver qué agentes están cubriendo, para cada una de las actividades del modelo, cada uno de los capitales. Esto nos muestra, en primer lugar, qué agentes deberían cooperar para el desarrollo de dicha actividad y en segundo lugar qué tipo de aportación realiza cada uno de ellos, en función del capital que está cubriendo. Así mismo, nos permite comprobar si existe alguno de los capitales por cubrir en alguna actividad. Debemos tener en cuenta que, el hecho de que varios agentes estén contribuyendo a una determinada 
actividad mediante la cobertura de uno o varios capitales, no significa necesariamente que lo estén haciendo de forma coordinada y en cooperación. Así, como hemos visto en el caso de la UPV, en la actividad docente relacionada con el emprendimiento, varios agentes tanto internos como externos, están contribuyendo, pero no existe una coordinación que permita dar un enfoque común para dicha actividad.

Así mismo, según podemos observar en la Tabla 15, durante las primeras etapas del proceso, cuando la empresa aún no está constituida, la contribución de los agentes internos a las universidades resulta más intensa. Sin embargo, en las dos últimas etapas, en las que la empresa compite en el mercado, la contribución de los agentes externos cobra un mayor protagonismo. También podemos observar que cada actividad es desarrollada por varios agentes tanto internos como externos a la UPV. Este hecho apoya, una vez más nuestra tesis: para obtener los resultados óptimos del modelo es necesario que éste sea considerado y construido bajo un enfoque sistémico e integral.

En estudios más pormenorizados del caso, la realización de este análisis nos permitirá identificar las redes que deberían existir entre los diferentes agentes, mostrando tanto las actividades en las que deberían cooperar como la contribución de cada uno en dichas actividades, lo que, en definitiva resulta ser una herramienta de utilidad para la implantación del modelo de FEyADE en universidades emprendedoras. No obstante, las herramientas y actuaciones específicas deben ser diseñadas para cada caso, atendiendo a las características propias, objetivos y necesidades de cada universidad. 


\section{Capítulo 6. Conclusiones y Líneas Futuras}

En este capítulo, trataremos de dar respuesta a las diferentes preguntas de investigación expuestas en la introducción a la tesis, así como atender al objetivo general de la misma.

Así mismo, con objeto de ofrecer una continuidad a este trabajo, se proponen unas líneas de investigación que se prevén abordar en el futuro, relacionadas con el tema de la tesis.

\subsection{Resultados y conclusiones}

La relación entre emprendimiento y desarrollo económico ha sido y está siendo ampliamente tratada en la literatura. Sin embargo, no existe consenso sobre la definición del término emprendimiento y, por ende, sobre 
el modo en que el resultado de esta relación debe medirse. A este respecto, nuestro trabajo pone de manifiesto no sólo esta carencia, sino la divergencia conceptual existente a la hora de definir emprendimiento y justificar su contribución al desarrollo económico. Al mismo tiempo, contribuimos a la literatura sobre el tema con una definición amplia del concepto.

Esta divergencia entre la motivación teórica de los estudios y los índices de medida que se emplean a la hora de analizar la contribución al desarrollo económico y social del emprendimiento, está derivando en conclusiones que, en algunos contextos conllevan actuaciones políticas erróneas o no del todo acertadas para promover el desarrollo de países y regiones a través del emprendimiento.

En este sentido, se hace necesario el establecimiento de índices de medida que contemplen un espectro amplio del concepto emprendimiento y que no se limite únicamente al estudio del fenómeno de creación y desarrollo de empresas y de las habilidades y actitudes necesarias para crear una empresa. Esto supone desarrollar índices que integren el emprendimiento corporativo y las habilidades emprendedoras en general. A su vez se debería ser capaz de discriminar aquellos datos relativos a la creación de empresas y autoempleo que no se consideren emprendimiento por carecer de habilidades innovadoras.

En respuesta, por tanto, a las preguntas plateadas en relación a la divergencia entre la conceptualización de emprendimiento y su análisis empírico, hemos de concluir:

1.1 ¿Existe una divergencia entre la conceptualización de emprendimiento y su aplicación práctica?

Sí, existe una divergencia clara entre la conceptualización y su aplicación práctica.

1.2 ¿Qué implicaciones tiene esta divergencia para los resultados, conclusiones y recomendaciones políticas? 
Esta divergencia está desembocando en una interpretación miope de la relación entre emprendimiento y desarrollo económico, dando lugar a planteamientos políticos no acordes con los objetivos perseguidos. Los políticos se basan en los planteamientos teóricos de la relación entre emprendimiento y desarrollo económico para establecer sus estrategias. Sin embargo, a la hora de materializarlas, se centran en los indicadores de medida, los cuales ponen el acento en la creación de empresas y el autoempleo como sinónimos de emprendimiento. Como hemos visto, este planteamiento es erróneo ya que emprendimiento y creación de empresas no son sinónimos.

En el caso concreto de las universidades, esta divergencia tiene consecuencias en cuanto a la consideración del término universidades emprendedoras, ya que conlleva a que se identifique universidad emprendedora con aquéllas que desarrollan actividades de transferencia de conocimiento y apoyo a la creación de empresas. Como hemos visto, esta consideración es errónea ya que, las universidades emprendedoras tienen una serie de características que implican el desarrollo de cada una de sus tres misiones y la propia gestión de manera emprendedora.

Esta implicación enlaza directamente con las conclusiones relativas a la siguiente pregunta de investigación. Ser una universidad emprendedora implica mucho más que apoyar la creación de empresas para explotar sus resultados de investigación. Detrás de este nuevo rol en las universidades se encuentra el fomento de una cultura emprendedora y un comportamiento en consecuencia entre sus agentes y estructuras. En este contexto, el proceso de FEyADE resulta crucial para dichas instituciones, debiendo involucrar a los diferentes agentes, estructuras e instrumentos, tanto internos como externos, a través de la creación de un marco común. Por tanto, es necesario un enfoque sistémico e integral del proceso que tenga en cuenta todos estos elementos. 
Así, en respuesta a la pregunta plateada en relación con la transformación y consideración de las universidades en emprendedoras y su reestructuración para atender a las nuevas necesidades:

2.1. ¿Cómo deben plantear las universidades el fomento del emprendimiento de modo que permita atender de forma óptima las necesidades de los emprendedores, la universidad y la propia sociedad?

En la presente tesis hemos presentado un modelo para el FEyADE que contempla un amplio proceso emprendedor basado en el fomento del emprendimiento y apoyo al emprendedor así como en la creación, desarrollo y crecimiento de empresas. Hemos hecho especial hincapié en el Fomento del Emprendimiento como etapa crucial para el funcionamiento óptimo del modelo. Para ilustrar nuestro enfoque, hemos presentado su aplicación al caso de la Universidad Politécnica de Valencia (UPV). Esta aplicación ha mostrado cómo se puede implementar el modelo en la UPV: identificando los agentes implicados (tanto internos como externos) en el proceso de FEyADE, analizando cuál es la contribución de cada uno de los agentes e identificando la cooperación y contribución de los mismos a las actividades del proceso. Finalmente hemos destacado la necesidad de diseñar herramientas específicas para cada una de las actividades atendiendo a las propias características, objetivos y necesidades de cada universidad.

Estos resultados demuestran que la obtención de resultados óptimos del modelo está directamente relacionada con su consideración sistémica e integral: sólo la implicación real de todos los agentes y la creación de redes entre ellos para llevar a cabo las distintas actividades, satisfará adecuadamente las necesidades de los emprendedores y empresas así como los propios requerimientos del modelo. Así pues, hemos demostrado que la consideración del modelo como sistémico e integral es una herramienta útil para la mejora del proceso de FEyADE en universidades emprendedoras. 
No obstante existen una serie de retos para la implantación del modelo en universidades. La implantación y desarrollo del modelo de FEyADE en universidades emprendedoras implica influir y ser influido por los entornos en los que estas universidades se encuentran ubicadas. En este sentido podemos afirmar, de acuerdo con O'Shea et al. (2007), que el éxito (o fracaso) de una universidad emprendedora no depende sólo de las actividades que ésta lleve a cabo, sino que es también consecuencia de la evolución del entorno y de sus características históricas, económicas, culturales, etc. Por lo tanto, a la hora de implantar el modelo, debemos considerar algunos retos relacionados con las características de la Comunidad Valenciana. En este sentido, hemos de destacar que la Comunidad Valenciana tiene un sistema de innovación débil, con un tejido industrial formado principalmente por PYME de sectores tradicionales y con un déficit de personal con estudios superiores (Fernández de Lucio et al, 2001). Por otra parte, existe una falta significativa de relaciones estructurales entre los organismos públicos de investigación y la industria, lo que implica una carencia de redes efectivas (tanto a nivel formal como informal) entre los organismos de investigación y la comunidad empresarial (Todt et al, 2007; Fernández de Lucio et al, 1999). A estos factores debemos añadir el hecho de que, en la mayoría de casos, las empresas no saben cómo pueden cooperar con las universidades y el resto de instituciones públicas de investigación y, en muchas ocasiones, tanto las universidades como las empresas piensan que no tienen nada que aprender las unas de las otras.

También debemos prestar atención a las características del sistema universitario y su normativa. A este respecto, el marco legal en España, como hemos visto a lo largo de esta tesis, no ha sido tradicionalmente favorable para la promoción de actividades empresariales entre los investigadores. Tan sólo a partir de su modificación en 2008, podemos decir que se ha abierto una puerta real a la creación de empresas de base tecnológica a partir de la investigación universitaria. Por otra parte, existe 
una estricta regulación y falta de incentivos para el desarrollo de la enseñanza universitaria por parte de cualquier profesional distinto del personal docente e investigador universitario. Otra cuestión a tener en cuenta dentro del sistema universitario español es la rivalidad existente entre determinados agentes a la hora de desarrollar algunas actividades, lo que implica una falta de cooperación entre ellos.

La creación y desarrollo de una cultura emprendedora en el entorno universitario así como su diseminación entre los distintos agentes a través de actividades de sensibilización se presenta como un mecanismo crucial para la superación de estos retos. Sin embargo, ésta no es una tarea fácil y, lo que es más importante, el proceso de implantación es largo, por lo que el modelo no ofrecerá resultados a corto plazo, teniendo que esperar algunos años antes de poder comprobar y obtener datos relevantes sobre el correcto funcionamiento del mismo. Este hecho contrasta con los resultados a corto plazo que normalmente esperan los equipos rectorales de las universidades. Por tanto, es necesario un compromiso a largo plazo por parte de los dirigentes tanto políticos como de universidades para que el modelo pueda ser implantado de forma óptima.

Para la adecuada implantación del modelo propuesto se requiere, por tanto, que la universidad tenga una cierta consolidación de sus características como emprendedora. Esto nos lleva a la cuestión de la caracterización de la universidad como emprendedora, que en la presente tesis hemos mostrado con el caso de la UPV y que nos lleva a la resolución de la siguiente cuestión:

\section{1. ¿Podemos considerar a la UPV como universidad emprendedora?}

La UPV cuenta con fortalezas que deberá seguir explotando en aras de consolidarse como universidad emprendedora. Sin embargo, y a pesar de los esfuerzos manifiestos en los diferentes ámbitos (formación, investigación, relaciones con el entorno y la propia gestión), la UPV debe 
superar una serie de debilidades que limitan su desarrollo como universidad emprendedora. En especial, debe atender al desequilibrio existente en las fuentes de financiación así como en la implantación de una cultura emprendedora. Este último aspecto pasa necesariamente por comprender qué implica ser una universidad emprendedora y asumir que debe desarrollar todas y cada una de sus actividades atendiendo a dicha premisa y no sólo preocuparse por el fomento de actividades relacionadas con la transferencia de conocimientos y la creación y desarrollo de empresas. Tal como apuntó Clark, y como hemos demostrado en nuestro análisis, crear muchas empresas o realizar muchas actividades de transferencia, no convierte a una universidad en emprendedora.

Con todo ello hemos de reconocer que la UPV tiene una buena base para convertirse por derecho propio en una universidad emprendedora que contribuya al desarrollo económico y social de su territorio. El análisis de cada una de sus misiones por separado demuestra que se están llevando a cabo acciones encaminadas a la generación de una cultura emprendedora dentro de la universidad, pero que, por el momento ésta no está totalmente consolidada. El problema de fondo es que, en muchas ocasiones, los responsables no son conscientes de qué tipo de actividades pueden contribuir al desarrollo de dicha cultura y centran su atención en las acciones de apoyo al desarrollo y creación de empresas. Es decir, consideran que tener una cultura emprendedora dentro de la universidad es equivalente a fomentar y apoyar la creación de empresas. Esto es consecuencia, como hemos ido demostrando a lo largo de la presente tesis, de la identificación del término emprendimiento con creación y desarrollo de empresas así como las habilidades necesarias para crear y gestionar una empresa.

Por tanto, no podemos concluir que la UPV sea una universidad emprendedora, según la definición de la literatura para este término. Esto no debe suponer un menosprecio a la importante labor que esta universidad está desarrollando en el ámbito del fomento de la creación y 
desarrollo de empresas desde hace casi 25 años, ni a su importante actividad en transferencia de conocimiento. La tercera misión de la Universidad está claramente desarrollada en este sentido, pero eso no la convierte en una universidad emprendedora desde un punto de vista amplio.

Por otra parte, como hemos visto en el análisis, a la hora de caracterizar a esta universidad como emprendedora, los puntos fuertes de la UPV superan a los débiles y, estando éstos claramente identificados, el camino para la transformación definitiva, ha quedado esbozado con el presente trabajo. Cierto que la implantación de la cultura emprendedora generalizada en la universidad no se consigue de forma inmediata y que requiere de un cambio cultural que no suele ser fácil ni rápido, pero como hemos visto, la UPV cuenta con una base sólida para conseguirlo. La toma de conciencia de lo que implica ser una universidad emprendedora debería ser el primer paso, seguido de una coordinación de las actividades como universidad emprendedora que abarque no sólo el apoyo a la creación y desarrollo de empresas, sino cada una de las tres misiones y su propia gestión.

Así mismo, hemos podido constatar que la UPV cuenta con un servicio de fomento del emprendimiento y apoyo al desarrollo de empresas (IDEAS) que podemos considerar como innovador y emprendedor según las premisas de la literatura. Además, este servicio si bien está claramente orientado a la creación y desarrollo de empresas, cuenta con una metodología y trayectoria en formación en habilidades emprendedoras, sensibilización y dinamización de emprendedores (entendidos como futuros empresarios) que puede suponer un buen punto de partida para la conseguir la implementación de la cultura emprendedora a nivel general. Todo ello supone una clara ventaja para la transformación definitiva de la UPV en emprendedora, siempre y cuando se lleven a cabo la planificación e implementación de las acciones apropiadas.

3.2. ¿Está cubriendo la UPV adecuadamente las necesidades del entorno y su comunidad en cuanto al FEyADE? 
Tras la aplicación del modelo de FEyADE al caso de la UPV, podemos concluir que esta universidad desarrolla sus actividades de FEyADE teniendo en cuenta no sólo a los agentes internos a la universidad, sino también a los externos, participando en todas las etapas varios agentes, tanto internos como externos. Así mismo, cuando realizamos el análisis más pormenorizado indicado qué necesidades (capitales) cubre cada agente, observamos que cada uno de los capitales necesarios está cubierto por varios agentes, tanto internos como externos.

De este análisis podemos concluir que la UPV tiene un modelo de FEyADE que permite cubrir adecuadamente las necesidades, tanto del entorno como de la comunidad universitaria, aunque para extraer conclusiones más detalladas, sería necesario realizar un análisis más exhaustivo que queda fuera de los objetivos de la presente tesis y que formará parte de las líneas de investigación futuras.

\subsection{Líneas de Investigación Futuras}

La presente tesis nos permite abrir la puerta a una serie de líneas de investigación que se podrían abordar en un futuro por la doctoranda, como continuidad del presente trabajo.

Así, ahondando en el tema de la divergencia entre la conceptualización de emprendimiento y su análisis empírico a la hora de estudiar su contribución al desarrollo económico y social de los territorios, proponemos la siguiente línea de investigación:

- Análisis de la contribución del emprendimiento al desarrollo económico y social en los territorios. Propuesta de indicadores e índices de medida.

Respecto a la caracterización de las universidades emprendedoras, proponemos ahondar en el análisis y caracterización de las mismas a través de un estudio comparativo de las universidades españolas que 
permita a su vez analizar la contribución de las mismas al desarrollo económico y social de sus territorios y regiones. Para ello proponemos una investigación en la siguiente línea:

- Análisis comparativo y caracterización de las universidades españolas como emprendedoras.

- Contribución de las universidades españolas al desarrollo económico y social de sus territorios, atendiendo a su caracterización como emprendedoras.

Referente a la aplicación de nuestra metodología para el FEyADE, proponemos una línea de investigación orientada a analizar con más profundidad estos procesos así como a detallar las relaciones existentes entre los diferentes agentes y sus aportaciones a cada una de las acciones concretas del modelo.

Por último consideramos interesante los siguientes ámbitos de investigación relacionados con el emprendimiento:

- Universidades Emprendedoras y su contribución al desarrollo económico y social en América Latina

- Emprendimiento Social y su contribución al desarrollo económico y social tanto de países desarrollados como en vías de desarrollo. 


\section{Bibliografía}

Acs, Z. J. (2010). Entrepreneurship and economic development: The valley of backwardness. Annals of Innovation y Entrepreneurship, 1(1)

Acs, Z. J. y Amorós, J. E. (2008). Entrepreneurship and competitiveness dynamics in latin america. Small Business Economics, 31(3), 305-322.

Acs, Z. J. y Armington, C. (2004). The impact of geographic differences in human capital on service firm formation rates. Journal of Urban Economics, 56(2), 244-278.

Acs, Z. J. y Audretsch, D. B. (2010). Introduction to the 2nd edition of the handbook of entrepreneurship research. Handbook of Entrepreneurship Research, 1-19.

Acs, Z. J. y Storey, D. (2004). Introduction: Entrepreneurship and economic development. Regional Studies, 38.8, 871-877. 
Acs, Z. J. y Szerb, L. (2010). The global entrepreneurship and development index (GEDI). Summer Conference, 16-18.

Acs, Z.J., Audretsch, D.B., Braunerhjelm, P. y Carlsson, B. (2004): The missing link: The knowledge filter and entrepreneurship in endogenous growth. CEPR Discussion paper $n^{\circ} 4783$, Center for Economic Policy Research, London.

Ahmad, N., y Hoffmann, A. (2008). A framework for addressing and measuring entrepreneurship. OECD Statistics Working Paper no.2,

Ahmad, N., y Seymour, R. G. (2008). Defining entrepreneurial activity: Definitions supporting frameworks for data collection. Paris: OECD.

Aidis, R., Mickiewicz, T., y Sauka, A. (2008). Why are optimistic entrepreneurs successful? an application of the regulatory focus theory.

Alchian, A. A. (1950). Uncertainty, evolution, and economic theory. The Journal of Political Economy, 211-221.

Alvarez, C., y Urbano, D. (2011). Environmental factors and entrepreneurial activity in latin america*. Academia Revista Latinoamericana De Administración, (48), 31-45.

Alvarez, C., Urbano, D., Coduras, A., y Ruiz-Navarro, J. (2011). Environmental conditions and entrepreneurial activity: A regional comparison in Spain. Journal of Small Business and Enterprise Development, 18(1), 120-140.

Anderson, A. R., y Smith, R. (2007). The moral space in entrepreneurship: an exploration of ethical imperatives and the moral legitimacy of being enterprising. Entrepreneurship and Regional Development, 19(6), 479-497.

Antoncic, B., y Hisrich, R. D. (2000). Intrapreneurship modeling in transition economies: A comparison of slovenia and the united states. Journal of Developmental Entrepreneurship, 5(1), 21-40.

Arancegui, M. N. (2001). Los sistemas nacionales de innovación: una revisión de la literatura. Instituto de Análisis Industrial y Financiero, Universidad Complutense de Madrid.

Arrow, K. (1962). Economic welfare and the allocation of resources for invention. In The rate and direction of inventive activity: Economic and social factors (pp. 609-626). Princeton University Press.

Arroyo Vázquez, M. y Jiménez-Sáez, F. (2008). La incorporación de la innovación y el emprededurismo en la Educación Superior: una formación de futuro. Actas del V Congreso Iberoamericano de Docencia Universitaria, Valencia 
Arroyo-Vazquez, M., y van der Sijde, P. (2008). Entrepreneurship encouragement and business development support at universities and science parks proposal for a new conceptualization. Industry and Higher Education, 22(1), 37-48.

Arroyo-Vázquez, M., van der Sijde, P., y Jiménez-Sáez, F. (2010). Entrepreneurialinnovative university services: A way to integrate in the university's third mission. New Technology-Based Firms in the New Millennium (New Technology-Based Firms in the New Millenium, Volume 8), Emerald Group Publishing Limited, 8, 25-33.

Atkins, D. (1932). The ciliary feeding mechanism of the entoproct Polyzoa, and a comparison with that of the ectoproct Polyzoa. Q. Jl microsc. Sci, 75, 393-423.

Audretsch, D. B., y Keilbach, M. (2004). Does entrepreneurship capital matter? Entrepreneurship Theory and Practice, 28(5), 419-429.

Autio, E. (1998). Evaluation of RTD in regional systems of innovation. European Planning Studies, 6(2), 131-140.

Azagra Caro, J. M. (2004). La contribución de las universidades a la innovación: efectos del fomento de la interacción universidad-empresa y las patentes universitarias. Universitat de València.

Baumol, W. J. (1968). Entrepreneurship in economic theory. The American Economic Review, 58(2), 64-71.

Baumol, W. J. (1990). Entrepreneurship: Productive, unproductive, and destructive. Journal of Political Economy, 893-921.

Begley, T. M. y Tan, W. L. (2001). The socio-cultural environment for entrepreneurship: A comparison between East Asian and Anglo-Saxon countries. Journal of international business studies, 537-553.

Birch, D. L. (1979). The job generation process. Cambridge, Mass.: M.I.T. Program on Neighborhood and Regional Change.

Birley, S. (2002): "Universities, Academics, and Spinout Companies," International Journal of

Entrepreneurship Education, April 2002.

Blanco, X. R., y Salgado, J. (2004). Amancio ortega, de cero a zara: El primer libro de investigación sobre el imperio inditex La Esfera de los Libros.

Boulding, K. E. (1974). Economics and General Systems. International Journal of General System, 1(1), 67-73. 
Bray, M. J. y Lee, J. N. (2000): "University Revenues from Technology Transfer: Licensing Fees vs Equity Positions", Journal of Business Venturing , n. 15(56), pp. 385-392.

Breschi, S., Malerba, F., y Edquist, C. (1997). Sectoral innovation systems: technological regimes. Schumpeterian Dynamics, and Spatial Boundaries. In Edquist, C. and McKelvey, M.(eds.),(2000), Systems of Innovation: Growth, Competitiveness and Employment, 1, 261-287.

Brinkman, R. (1995). Economic growth versus economic development: Toward a conceptual clarification. Journal of Economic Issues, 29(4), 1171-1188.

Brockhaus, R. H. (1980). Psychological and environmental factors which distinguish the successful from the unsuccessful entrepreneur: A longitudinal study. Academy of Management Proceedings, 11 368-372.

Busenitz, L. W., Gomez, C., y Spencer, J. W. (2000). Country institutional profiles: Unlocking entrepreneurial phenomena. Academy of Management journal, 43(5), 994-1003.

Braczyk, H. J., Cooke, P. N., y Heidenreich, M. (1998). Regional innovation systems: the role of governances in a globalized world. Psychology Press.

Bruton, G. D., Ahlstrom, D., y Li, H. L. (2010). Institutional theory and entrepreneurship: where are we now and where do we need to move in the future?. Entrepreneurship theory and practice, 34(3), 421-440.

Bull, I., y Willard, G. E. (1993). Towards a theory of entrepreneurship. Journal of business venturing, 8(3), 183-195.

Burgelman, R. A. (1983). Corporate entrepreneurship and strategic management: Insights from a process study. Management science, 29(12), 1349-1364.

Capelleras, J. L., Mole, K. F., Greene, F. J., y Storey, D. J. (2008). Do more heavily regulated economies have poorer performing new ventures? Evidence from Britain and Spain. Journal of international business studies, 39(4), 688-704.

Carayannis, E. G.; Rogers, E. M.; Kurihara, K. y Allbritton, M. M. (1998): "High Technology spin-offs From government RyD laboratories and research universities", Technovation , no. 18 (1), pp. 1-11.

Carland, J. W., Hoy, F., Boulton, W. R., y Carland, J. A. C. (1984). Differentiating entrepreneurs from small business owners: A conceptualization. Academy of Management Review, , 354-359.

Carland, J. W., Hoy, F., y Carland, J. A. C. (1988). Who is an entrepreneur? is a question worth asking. American Journal of Small Business, 12(4), 33-39. 
Carree, M. A., Van Stel, A., Thurik, R., y Wennekers, S. (2002). Economic development and business ownership: An analysis using data of 23 OECD countries in the period 1976-1996. Small Business Economics, 19(3), 271290.

Casson, M. (1982). The entrepreneur: An economic theory. Barnes y Noble Books. New Jersey, Great Britain

Castro-Martínez, E., Fernández de Lucio, I., Gutiérrez-Gracia, A., y Añón, M. J. (2001). La estrategia de dinamización en la cooperación investigaciónempresa: desarrollo conceptual y aplicaciones. Libro de actas del IX Seminario Latino-Iberoamericano de Gestión Tecnológica (ALTEC), San José (Costa Rica).

Chang, H. J. (1994). The political economy of industrial policy. Macmillan.

Child, J., y Tsai, T. (2005). The Dynamic Between Firms' Environmental Strategies and Institutional Constraints in Emerging Economies: Evidence from China and Taiwan*. Journal of Management Studies, 42(1), 95-125.

Clark, B. R. (1998). Creating entrepreneurial universities: Organisational pathways of transformation. Oxford: Pergamon Press.

Clark, B. R. (2004). Delineating the character of the entrepreneurial university. Higher Education Policy, 17(4), 355-370.

Cochran, T. C. (1949). Role and Sanction in American Entrepreneurial History, Change and the Entrepreneur. Postulates and Patterns in Entrepreneurial History, op. cit, 175.

Coduras, A., Guerrero, M., y Peña, I. (2011). Emprendimiento corporativo en España.

Comité Económico y Social Europeo (2003). Libro verde: el espíritu empresarial en Europa. Bruselas, Comisión de las Comunidades Europeas, http://eurlex. europa. eu/LexUriServ/site/es/com/2003/com2003_0027es01. pdf.

Comisión de las Comunidades Europeas (2003). Comunicación de la Comisión al Consejo, al Parlamento Europeo, al Comité Económico y Social Europeo y al Comité de las Regiones "Pensar primero a pequeña escala-Small Business Act para Europa: iniciativa en favor de las pequeñas empresas". Bruselas, 2.6.2003 $\operatorname{COM}(2003) 312$

Comisión Europea (2013) Comunicación de la Comisión al Consejo, al Parlamento Europeo, al Comité Económico y Social Europeo y al Comité de las Regiones. "Plan De Acción Sobre Emprendimiento 2020: Relanzar el espíritu emprendedor en Europa". Bruselas, 9.1.2013 COM(2012) 795 
Cooke, P. (1992). Regional innovation systems: competitive regulation in the new Europe. Geoforum, 23(3), 365-382.

Cooke, P., Uranga, M. G., y Etxebarria, G. (1997). Regional innovation systems: Institutional and organisational dimensions. Research policy, 26(4), 475-491.

Covin, J. G., y Miles, M. P. (2007). Strategic use of corporate venturing. Entrepreneurship Theory and Practice, 31(2), 183-207.

Daly, H. E. (1974). The economics of the steady state. The American Economic Review, 15-21.

Davis, T. C. (2006). Understanding entrepreneurship: Developing indicators for international comparisons and assessments: Report on the OECD's entrepreneurship indicators project and action plan.

Dalmau, J.I.; Alonso, J.L. y Colomer, J. (2003). Programa IDEAS. Un modelo de éxito para fomentar la creación de empresas desde las universidades. Valencia: Universidad Politécnica de Valencia.

Darwin, C. (1859). On the origins of species by means of natural selection. London: Murray, 247.

De Andrés Argente, T. (2002). Homo cybersapiens: La inteligencia artificial y la humana. EUNSA.

De la Mothe, J., y Paquet, G. (1998). Local and regional systems of innovation as learning socio-economies. In Local and regional systems of innovation (pp. 116). Springer US.

Dees, J. G. (1998). The meaning of social entrepreneurship. Comments and Suggestions Contributed from the Social Entrepreneurship Funders Working Group, 6pp,

Delors, J. (1996). Informe a la UNESCO de la comisión internacional sobre la educación para el siglo XXI: La educación encierra un tesoro. Madrid: Santillana, Ediciones UNESCO.

Díaz, J. C., Mogollón, R. H., y Pulido, D. U. (2005). Teoría económica institucional y creación de empresas. Investigaciones europeas de dirección y economía de la empresa, 11(3), 209-230.

Dimaggio, P. J. y Powell, W. W. (1983). The iron cage revisited: Institutional isomorphism and collective rationality in organizational fields. American Sociological Review, 48(2), 147-160 
DiMaggio, P. J. y Powell, W.W. (1991). The Iron Cage Revisited: Institutional Isomorphism and Collective Rationality in Organization Fields. En W. W. Powell and P. J. DiMaggio (eds.), The New Institutionalism in Organizational Analysis (63-82). Chicago, IL:University of Chicago Press

Dirección Delegada de Emprendimiento y Empleo (2014). Programa de Encuestas a Titulados Universitat Politècnica de València. Observatorio de Empleo UPV. Titulados del curso académico 2013/2014. Valencia.

Djankov, S., La Porta, R., Lopez-de-Silanes, F., y Shleifer, A. (2002). The regulation of entry. The Quarterly Journal of Economics, 117(1), 1-37.

Dosi, G., Freeman, C., Nelson, R., Silverberg, G. y Soete, L. (1988). Technological change and economic theory. Pinter, London.

Dosi, G. (1991). Una reconsideración de las condiciones y los modos del desarrollo: una perspectiva" evolucionista" de la innovación, el comercio y el crecimiento. Pensamiento iberoamericano, (20), 167-192.

Drucker, P.F. (1964). Managing for Results. New York: Harper and Row.

Drucker, P.F. (1985). Innovation and Entrepreneurship. New York: Harper y Row.

Druilhe, C., y Garnsey, E. (2004). Do academic spin-outs differ and does it matter?. The Journal of technology transfer, 29(3-4), 269-285.

Dugger, W. (1990). The new institutionalism: new but not institutionalist. Journal of Economic Issues, 423-431.

España, I. E. G. (2013). Global Entrepreneurship Monitor. Informe Ejecutivo GEM España. Available in: http://www. gem-spain. com.

España. Ley Orgánica 10/2002, de 23 de diciembre, de Calidad de la Educación. Boletín Oficial del Estado, 24 de diciembre de 2002, núm. 307, pp. 45188 a 45220

España. Ley Orgánica 2/2006, de 3 de mayo, de Educación. Boletín Oficial del Estado, , 4 de mayo de 2006, núm. 106, pp. 17158 a 17207

España. Ley Orgánica 5/2002, de 19 de junio, de las Cualificaciones y de la Formación Profesional. Boletín Oficial del Estado, 20 de junio de 2002, núm. 147 , pp. 22437 a 22442

España. Ley Orgánica 6/2001, de 21 de diciembre, de Universidades. Boletín Oficial del Estado. 24 de diciembre de 2001, núm. 307, pp. 49400 a 49425 
España. Ley Orgánica 4/2007, de 12 de abril, por la que se modifica la Ley Orgánica 6/2001, de 21 de diciembre, de Universidades. Boletín Oficial del Estado, 13 de abril de 2007, núm. 89, pp. 16241 a 16260

España. Ley 53/1984, de 26 de diciembre, de Incompatibilidades del Personal al Servicio de las Administraciones Públicas. Boletín Oficial del Estado, 4 de enero de 1985, núm. 4, pp. 165 a 168

España. Real Decreto Legislativo 2/2000, de 16 de junio, por el que se aprueba el texto refundido de la Ley de Contratos de las Administraciones Públicas. Boletín Oficial del Estado, 21 de junio de 2000, núm. 148, pp. 21775 a 21823

España. Real Decreto Legislativo 3/2011, de 14 de noviembre, por el que se aprueba el texto refundido de la Ley de Contratos del Sector Público. Boletín Oficial del Estado, 16 de noviembre de 2011, núm. 276, pp. 117729 a 117914

España. Real Decreto 898/1985, de 30 de abril, sobre régimen del profesorado universitario. Boletín Oficial del Estado, 19 de junio de 1985, núm. 146, pp. 18927 a 18930

España. Ley 11/1986, de 20 de marzo, de Patentes. Boletín Oficial del Estado, 26 de marzo de 1986, núm. 73, pp. 11188 a 11208

España. Real Decreto Legislativo 1/1996, de 12 de abril, por el que se aprueba el texto refundido de la Ley de Propiedad Intelectual, regularizando, aclarando y armonizando las disposiciones legales vigentes sobre la materia. Boletín Oficial del Estado, 22 de abril de 1996, núm. 97, pp. 14369 a 14396

España. Ley 14/2013, de 27 de septiembre de apoyo a los emprendedores y su internacionalización. Boletín Oficial del Estado, 28 de septiembre de 2013, núm. 233, pp. 78787 a 78882.

Etzkowitz, H. (1983). Entrepreneurial scientists and entrepreneurial universities in american academic science. Minerva, 21(2), 198-233.

Etzkowitz, H. (1998). The norms of entrepreneurial science: Cognitive effects of the new university-industry linkages. Research Policy, 27(8), 823-833.

Etzkowitz, H. (2004). The evolution of the entrepreneurial university. International Journal of Technology and Globalisation, 1(1), 64-77.

Etzkowitz, H y Leydesdorff, L. (1997). Universities and the global knowledge economy: a triple helix of university-industry-government relations. London: Pinter. 
Etzkowitz H, Leydesdorff L. (2000). The dynamics of innovation: from national systems and 'Mode 2' to a triple helix of university-industry-government relations. Research Policy. 2000;29(2):109-23.

Etzkowitz, H.; Webster, A.; Gebhardt, C. y Terra, B. (2000): "The Future of the Universityand the University of the Future: Evolution of Ivory Tower to Entrepreneurial Paradigm". Research Policy , nº 29 (2), pp. 313-330.

European Commission. (2004). Action plan: The european agenda for entrepreneurship. Communication from the Commission to the Council, the European Parliament, the European Economic and Social Committee and the Committee of the Regions, COM (04), 70

Evangelista, R., y Sirilli, G. (1995). Measuring innovation in services. Research Evaluation, 5(3), 207-215.

Fernández de Lucio, I., Castro Martínez, E., Conesa Cegarra, F., y Gutiérrez Gracia, A. (2000). Las relaciones universidad-empresa: entre la transferencia de resultados y el aprendizaje regional. Espacios, 21(2), 127-148.

Fernández De Lucio, I., Jiménez Sáez, F., Azagra Caro, J., Castro Martínez, E., \& Gutiérrez, A. (1999). Una primera aproximación de la contribución del programa nacional de tecnología de alimentos a la articulación del sistema alimentario español. Biblioteca Digital de la Asociación Latino-Iberoamericana de Gestión Tecnológica, 1(1).

Fernández de Lucio, I. y Castro, E. (1995). "La nueva política de articulación del sistema de innovación en España". VI Seminario Latinoiberoamericano de Gestión Tecnológica, ALTEC'95. Concepción.

Freeman, C. (1982). The Economics of Industrial Innovation. London: Frances Pinter.

Freeman, C. (1987). Technology policy and economic policy: Lessons from Japan. Frances Pinter, London.

Freeman, C., y Soete, L. (1997). The economics of industrial innovation. Psychology Press.

Freeman, C. (1998), "The economics of Technical Change", en: Archibugi, D. y J. Michie. (ed.), Trade, Growth and Technical Change, Cambridge: Cambridge University Press, 1998.

Friedman, J., y Silberman, J. (2003). University technology transfer: do incentives, management, and location matter?. The Journal of Technology Transfer, 28(1), 17-30. 
Fritsch, M., y Mueller, P. (2004). Effects of new business formation on regional development over time. Regional Studies, 38(8), 961-975.

Gallouj, F. (1998). Innovating in reverse: services and the reverse product cycle. European Journal of Innovation Management, 1(3), 123-138.

Gancia, G., y Zilibotti, F. (2005). Horizontal innovation in the theory of growth and development. Handbook of economic growth, 1, 111-170.

Gartner, W. B. (1985). A conceptual framework for describing the phenomenon of new venture creation. Academy of Management Review, , 696-706.

Gartner, W. B. (1988). Who is an entrepreneur? is the wrong question. American Journal of Small Business, 12(4), 11-32.

Gibb, A. (1999). Creating an entrepreneurial culture in support of SMEs. Small Enterprise Development, 10(4), 27-38.

Gnyawali, D. R., y Fogel, D. S. (1994). Environments for entrepreneurship development: key dimensions and research implications. Entrepreneurship Theory and Practice, 18, 43-43.

Goddard, J. (1998). The role of universities in regional development. Paper for CREColumbus), University of Newcastle upon Tyne,

Godin, K., Clemens, J., y Veldhuis, N. (2008). Measuring entrepreneurship: Conceptual frameworks and empirical indicators (studies in entrepreneurship and markets, 7). Studies in Entrepreneurship and Markets, (7)

Goel, R. K., y Ram, R. (1994). Research and development expenditures and economic growth: A cross-country study. Economic Development and Cultural Change, 403-411.

Goldstein, H. A. (2009). Theory and practice of technology-based economic development. Theories of Local Economic Development: Linking Theory to Practice,

Gong, G., y Keller, W. (2003). Convergence and polarization in global income levels: a review of recent results on the role of international technology diffusion. Research Policy, 32(6), 1055-1079.

Gray, S. R., y Cuevas, T. J. (2005). Regulatory, cognitive and normative factors affecting small business development in northern Mexico. International Journal of Entrepreneurship, 9, 91.

Growth, L. R. y Rebelo, S. (1991). Long-Run Policy Analysis and. The Journal of Political Economy, 99(3), 500-521. 
Gruchy, A. G. (1972). The Institutional School. International Encyclopedia of Social Sciences, 462-467.

Harbison, F. (1956). Entrepreneurial organization as a factor in economic development. The Quarterly Journal of Economics, 364-379.

Hayek, F. A. (1948). Individualism and economic order. University of Chicago Press.

Hayek, F. A. (1973). Law, legislation and liberty: a new statement of the liberal principles of justice and political economy. London: Routledge.

Hayek, F. A. (1988). The Fatal Conceit: The Errors of Socialism. In The Collected Works of FA Hayek, WW Bartley, ed. Chicago: University of Chicago.

Hébert, R. F., y Link, A. N. (1989). In search of the meaning of entrepreneurship. Small Business Economics, 1(1), 39-49.

Hindle, K. (2006). A measurement framework for international entrepreneurship policy research: From impossible index to malleable matrix. International Journal of Entrepreneurship and Small Business, 3(2), 139-182.

Hoffman, A. J. (1999). Institutional evolution and change: Environmentalism and the US chemical industry. Academy of management journal, 42(4), 351-371.

Homan, P. (1971). La escuela institucional. El pensamiento económico de Aristóteles a Marshall, 535-542.

Iglesias, P. (2010). Las Spin-Off Universitarias como mecanismo de transferencia de tecnología y su impacto económico en base a la actividad de I+ D+ i. Málaga: Universidad de Málaga. Tesis doctoral.

Ireland, R. D., Hitt, M. A., y Sirmon, D. G. (2003). A model of strategic entrepreneurship: The construct and its dimensions. Journal of Management, 29(6), 963-989.

Jelinek, M., y Litterer, J. A. (1995). Toward entrepreneurial organizations: Meeting ambiguity with engagement. Entrepreneurship Theory and Practice, 19, 137168.

Jensen, M. B., Johnson, B., Lorenz, E., y Lundvall, B. A. (2007). Forms of knowledge and modes of innovation. Research policy, 36(5), 680-693.

Jiménez Sáez, F. (2004). Una Evaluación del Programa Nacional de Tecnología de Alimentos: análisis de la articulación fomentada sobre el Sistema Alimentario de Innovación en España. 
Jovanovic, B. y Rob, R. (1989). The growth and diffusion of knowledge. The Review of Economic Studies, 56(4), 569-582.

Karadeniz, E. E. (2006). Entrepreneurship and economic development. Kocaeli Üniversitesi Sosyal Bilimler Enstitüsü Dergisi, 11(1), 85-99.

Kelley, D., Bosma, N., y Amorós, J. E. (2011). Global entrepreneurship monitor 2010 global report. Babson College and Universidad Del Desarrollo,

Kenney, M. (2000). Understanding Silicon Valley: The anatomy of an entrepreneurial region Stanford Business Books.

Kirzner, I. M. (1973). Competition and entrepreneurship. Chicago: University of Chicago Press.

Kraatz, M. S., y Moore, J. H. (2002). Executive migration and institutional change. Academy of Management Journal, 45(1), 120-143.

Kuratko, D., y Hodgetts, R. (2001). Entrepreneurship approach.

Lazear, E. (2005): Entrepreneurship, Journal of Labor Economics, 23(4): 649-680.

Leff, N. H. (1979). Entrepreneurship and economic development: The problem revisited. Journal of Economic Literature, 17(1), 46-64.

Lipsey. R. (1994). "Markets, technological change and economic growth". The Pakistan Development Review. Vol 33(4); pp. 327-352.

López, A. (1998). La reciente literatura sobre la economía del cambio tecnológico y la innovación: una guía temática. Revista de industria y desarrollo, 1(3), 105156.

López-Claros, A., Altinger, L., Blanke, J., Drzeniek, M., y Mia, I. (2006). Assessing latin american competitiveness: Challenges and opportunities. The Latin America Competitiveness Review, 1-36.

Lucas, R. E. (1988). On the mechanics of economic development. Journal of monetary economics, 22(1), 3-42.

Lumpkin, G. T., y Dess, G. G. (1996). Clarifying the entrepreneurial orientation construct and linking it to performance. Academy of management Review, 21(1), 135-172.

Lundvall, B. A. (1992). National innovation system: towards a theory of innovation and interactive learning. Pinter, London. 
Malerba, F. (Ed.). (2004). Sectoral systems of innovation: concepts, issues and analyses of six major sectors in Europe. Cambridge University Press.

Mallorquín, C. (2001). El institucionalismo norteamericano y el estructuralismo latinoamericano: ¿discursos compatibles? (North American Institutionalism and Latin American Structuralism: Compatible Types of Discourse). Revista mexicana de sociología, 71-108.

Manolova, T. S., Eunni, R. V., y Gyoshev, B. S. (2008). Institutional environments for entrepreneurship: Evidence from emerging economies in Eastern Europe. Entrepreneurship Theory and Practice, 32(1), 203-218.

Marshall, A. (1890). Principles of Political Economy. Maxmillan, New York.

McClelland, D. C. (1961). The achieving society. Princeton, NJ: D. Van Norstrand Company. Inc.

Metcalfe, J. S. (1994). Competition, Fisher's principle and increasing returns in the selection process. Journal of Evolutionary Economics, 4(4), 327-346.

Metcalfe, J.S. (1995). The economic foundations of technology policy: equilibrium and evolutionary perspectives. Handbook of the economics of innovation and technological change, 446.

Meyer, J. W., y Rowan, B. (1977). Institutionalized organizations: Formal structure as myth and ceremony. American journal of sociology, 340-363.

Michelacci, C. (2003). Low Returns in RyD Due to the Lack of Entrepreneurial Skills*. The Economic Journal, 113(484), 207-225.

Ministerio de Ciencia y Tecnología de España (1992): Manual para la Transferencia de Tecnología, Madrid, MICYT.

Miles, I. (1994). Innovation in Services. Part 2: Sectoral and Industrial Studies of Innovation en The Handbook of Industrial Innovation. M. Dodgson y R. Rothwell (editores), pp. 243-256. Edward Elgar, Gran Bretaña.

Miller, T., y Holmes, K. R. (2010). 2010 Index of Economic Freedom: The link between entrepreneurial opportunity and prosperity. The Heritage Foundation and the Wall Street Journal.

Millet Roig, J. y Talón Renuncio, J. (2014). Memoria Bianual de Actividades 2012/2013. Instituto IDEAS. Valencia, España.

Minniti, M. (2012). El emprendimiento y el crecimiento económico de las naciones. Economía industrial, 383, 23-30. 
Minniti, M. y Lévesque, M. (2008). Recent developments in the economics of entrepreneurship. Journal of Business venturing, 23(6), 603-612.

Minniti, M., y Lévesque, M. (2010). Entrepreneurial types and economic growth. Journal of Business Venturing, 25(3), 305-314.

Molas-Gallart, J., Salter, A., Patel, P., Scott, A., y Duran, X. (2002). Measuring third stream activities: Final report, the russell group in the russell group of universities. Brighton, SPRU, University of Sussex,

Moral, E. M., Sánchez, A. H., y Otero, J. V. (2010). Inmigración y desempleo en España: impacto de la crisis económica. Información Comercial Española, ICE: Revista de economía, (854), 37-48.

Morin, E. (2000). La mente bien ordenada: repensar la reforma, reformar el pensamiento. Seix Barral.

Motta, J. (2004). Patrones de Innovación en la Industria Autopartista Argentina. Tesis de Doctorado Universitat de Barcelona; 2004.

Napoleoni, C. (1968) El pensamiento económico en el siglo XX, Oikos-Tau Ediciones, Barcelona.

Nasution, H. N., Mavondo, F. T., Matanda, M. J., y Ndubisi, N. O. (2011). Entrepreneurship: Its relationship with market orientation and learning orientation and as antecedents to innovation and customer value. Industrial Marketing Management, 40(3), 336-345.

Naudé, W. (2010). Entrepreneurship, developing countries, and development economics: New approaches and insights. Small Business Economics, 34(1), $1-12$.

Naudé, W. A. (2013). Entrepreneurship and economic development: Theory, evidence and policy (No. 7507). IZA Discussion Paper.

Nelson, R. (1993). National innovation systems: a comparative analysis. Oxford university press.

Nelson, R. (1995). Recent evolutionary theorizing about economic change. Journal of economic literature, 48-90.

Nelson, R. y Nelson K. (2002). "Technology, institutions and innovation systems". Research Policy. Vol. 31; pp. 265-272.

Nelson, R. y Winter, S. G. (1982). The Schumpeterian tradeoff revisited. The American Economic Review, 114-132. 
Nikos (2004). "Nikos (2004) Progress Report 2001-2004. Nikos, University of Twente. The Netherlands.". The Nethederlands. Nikos, University of Twente.

North, D. C. (1990). Institutions, institutional change, and economic performance Cambridge Univ Pr.

North, D. C. (1993). Institutions and credible commitment. Journal of Institutional and Theoretical Economics (JITE)/Zeitschrift für die gesamte Staatswissenschaft, 11-23.

North, D. C. (2005). Institutions and the process of economic change. Management International, 9(3), 1-7.

OCDE (1998): Fostering entrepreneurship, París, OCED.

OCDE (2001): "Fostering high-tech spin-offs: a public strategy for innovation" [Special issue], STI Review, $\mathrm{n}^{\circ} .26$

O'Shea, R. P., Allen, T. J., Morse, K. P., O'Gorman, C., y Roche, F. (2007). Delineating the anatomy of an entrepreneurial university: The massachusetts institute of technology experience. R\&D Management, 37(1), 1-16.

Pérez Camarero, S. et alt. (2009): Emprendimiento económico y social en España. Guía de recursos para jóvenes emprendedores/as, Injuve, Ministerio de Igualdad, Madrid.

Porter, M. E., Sachs, J., y McArthur, J. (2001). Executive summary: Competitiveness and stages of economic development. The Global Competitiveness Report, , 16-25.

Pressman, S. (2013). Fifty major economists. Routledge.

Prigogine, I. (1988). El orden a partir del caos. Tan sólo una ilusión, 179.

Programa Nacional de Reformas de España (2005). http://www.mineco.gob.es/stfls/mineco/prensa/noticias/2014/Programa_Refor mas_2014.pdf

Raposo, M., Smallbone, D., y Karoly, B. (2011). Entrepreneurship, growth and economic development: Frontiers in european entrepreneurship research Edward Elgar Pub.

Rasmussen, E. y Borch, O.J. (2006). "The university and the spin-off process. A dynamic capability approach", en D. Urbano (Ed.). Diversity in entrepreneurship. $3^{\text {rd }}$ Inter-RENT Online Publication. Turku: European Council for Small Business and Entrepreneurship. 
Reynolds, P., Hay, M., Bygrave, W., Camp, M., y Autio, E. (2000). Global entrepreneurship monitor: 2000 executive report: Kauffman center for entrepreneurial leadership.

Roberts, E. B. y Malone, D. E. (1996): "Policies and structures for spinning off new companies from research and development organizations", R\&D Management, $n^{\circ}$. 26, pp. 17-48.

Robinson, D., van der Mescht, H., y Lancaster, J. (2003). Ethics beyond the code of conduct-understanding the ethical dilemmas of entrepreneurs. Meditari Accountancy Research, 11(1), 113-128.

Romer, P. M. (1986). Increasing returns and long-run growth. The journal of political economy, 1002-1037.

Romer, P. M. (1990). Endogenous technological change. Journal of political Economy, S71-S102.

Roscher, W. G. F. (1843). Grundriß zu Vorlesungen über die Staatswirthschaft. Nach geschichtlicher Methode.

Rostow, W. W. (1960). The process of economic growth. London and New York: Cambridge Univ. Press

Rothwell, R. (1986). The role of small firms in technological innovation. The survival of the small firm, 2, 114-139.

Rutherford, M. (2001). Institutional economics: then and now. Journal of Economic Perspectives, 173-194.

Sala-i-Martin, X., Blanke, J., Hanouz, M. D., Geiger, T., Mia, I., y Paua, F. (2007). The global competitiveness index: Measuring the productive potential of nations. In The global competitiveness report 2007-2008 (pp. 3-87) World Economic Forum.

Salimath, M. S., y Cullen, J. B. (2010). Formal and informal institutional effects on entrepreneurship: a synthesis of nation-level research. International Journal of Organizational Analysis, 18(3), 358-385.

Sarasvathy, S. D., y Venkataraman, S. (2011). Entrepreneurship as method: open questions for an entrepreneurial future. Entrepreneurship Theory and Practice, 35(1), 113-135.

Saxenian, A. L. (1996). Regional advantage: Culture and competition in silicon valley and route 128 Harvard Univ Pr. 
Say, J. (1803). Versión española (1807): Tratado de Economía Política ó del modo como se forman, distribuyen y consumen las riquezas. Ed. Gómez Fuentenebro y compañía. Madrid.

Say, J. B. (1821). Tratado de Economia Politica: ó exposición sencilla del modo con que se forman, se distribuyen y conservan las riquezas (Vol. 2). Imp. de Fermin Villalpando.

Schumpeter, J. A. (1911). The theory of economic development (english edition 1934), vol. XLVI of Harvard economic studies.

Schumpeter, J. A. (1939). Business cycles (Vol. 1, pp. 161-74). New York: McGrawHill.

Schumpeter, J. A. (1942). Socialism, capitalism and democracy. Harper and Brothers.

Shane, S., y Venkataraman, S. (2000). The promise of enterpreneurship as a field of research. Academy of Management Review, , 217-226.

Sharma, P., y Chrisman, J. J. (1999). Toward a reconciliation of the definitional issues in the field of corporate entrepreneurship. Entrepreneurship Theory and Practice, 23, 11-28.

Siegel, D. S.; Waldman, D.; Atwater, L. Y Link, A. N. (2003): "Commercial knowledge transfers from universities to firms: improving the effectiveness of universityindustry collaboration", Journal of High Technology Management Research , $\mathrm{n}^{\circ} .14$, pp. 111-133.

Sijgers, I., Hammer, M., Ter Horst, W., Nieuwenhuis, P., y Van Der Sijde, P. (2005). Supporting the contribution of Higher Education Institutes to regional development. Enschede: OECD.

Shane, S. (2002a): "Selling university technology: patterns from MIT", Management Science, $n^{\circ} .48(1)$, pp. 122-137.

Shane, S. (2002b): "University technology transfer to entrepreneurial companies", Journal of Business Venturing, n. 17, pp. 537-552.

Simón, E. K. (2003). La creación de empresas de base tecnológica: Una experiencia práctica. Proyecto para la promoción de empresas innovadoras de base tecnológica. España.

Solow, R. M. (1957). Technical change and the aggregate production function. The review of Economics and Statistics, 312-320.

Steffensen, M.; Rogers, E. M. y Speakman, K. (2000): "Spin-offs from Research 
Centers at aResearch University", Journal of Business Venturing , $n^{\circ} .15, \mathrm{pp}$. 93-111.

Sánchez Barrioluengo, M. (2012). Cómo afronta la universidad el cumplimiento de sus misiones: El caso de las universidades públicas españolas. Tesis Doctoral. Universidad Politécnica de Valencia

Sidrauski, M. (1967). Rational choice and patterns of growth in a monetary economy. The American Economic Review, 534-544.

Sidrauski, M. (1967). Inflation and economic growth. The Journal of Political Economy, 796-810.

Stephen, F. H., Urbano, D., y van Hemmen, S. (2005). The impact of institutions on entrepreneurial activity. Managerial and decision economics, 26(7), 413-419.

Stephen, F., Urbano, D., y van Hemmen, S. (2009). The responsiveness of entrepreneurs to working time regulations. Small Business Economics, 32(3), 259-276.

Strategy, O. J. (1998). Fostering entrepreneurship. Paris. OECD

Sundbo, J., y Gallouj, F. (1998). Innovation in services in seven European countries: the results of work packages 3-4 of the SI4S project (Doctoral dissertation, Université Lille 1, CLERSE; Roskilde University).

Teece, D. J. (1996). Firm organization, industrial structure, and technological innovation. Journal of Economic Behavior y Organization, 31(2), 193-224.

Thornton, P. H., Ribeiro-Soriano, D., y Urbano, D. (2011). Socio-cultural factors and entrepreneurial activity: An overview. International Small Business Journal, 29(2), 105-118.

Todt, O., Gutiérrez-Gracia, A., Fernández de Lucio, I., \& Castro-Martínez, E. (2007). The regional dimension of innovation and the globalization of science: the case of biotechnology in a peripheral region of the European Union. $R \& d$ Management, 37(1), 65-74.

Tolbert, P.S. y Zucker, L.G. (1983). Institutional sources of change in the formal structure of organizations: The diffusion of civil service reform, 1880-1935. Administrative Science Quarterly, 28, 22-39.

UNESCO (1998). Declaración Mundial sobre la Educación Superior en el siglo XXI: Visión y Acción. Conferencia Mundial sobre la Educación Superior, del 5 al 9 de octubre de 1998, 9 de Octubre de 1998. 
Universitat Politécnica de Valencia (2010). Estudio de Empleabilidad de Titulados de la Universitat Politècnica de València 2010

Universitat Politécnica de Valencia (2015). Presupuesto de la Universitat Politècnica de Valencia 2015

Urbano Pulido, D., Díaz, J. C. y Hernández Mogollón, R. (2007). La teoría económica institucional: el enfoque de North en el ámbito de la creación de empresas. In Decisiones basadas en el conocimiento y en el papel social de la empresa: $X X$ Congreso anual de AEDEM (p. 35). Asociación Española de Dirección y Economía de la Empresa (AEDEM).

Uzawa, H. (1965). Optimum technical change in an aggregative model of economic growth. International economic review, 6(1), 18-31.

Valdés, R. (1996). Apuntes sobre la Teoría Institucional. Documento no publicado. Departamento de antropología social y cultural. UAB

Van Twist, M., van der Steen, M., y van Wijk, A. (2013). Coordination practice Coordinating Innovation and Innovation Policy: the Innovation Platform in The Netherlands.

Veblen, T. (1899). The theory of the leisure class: An economic theory of institutions. New york, Macmillen.

Veblen, T. (1904). The Theory of Business Enterprise, Charles Scribner's Sons. New York.

Veblen, T. (1961). The Place of Science in Modern Civilization. 1919. Reprint, New York: Russell y Russell.

Veciana Vergés, J. M. (1999). Creación de empresas como programa de investigación científica. Revista Europea de Dirección y Economía de la empresa, 8(3), 11-36.

Veciana Vergés, J. M., y Urbano, D. (2008). The institutional approach to entrepreneurship research. introduction. International Entrepreneurship and Management Journal, 4(4), 365-379.

Vesper, K. (1990). Three faces of corporate entrepreneurship: A pilot study, unpublished manuscript. University of Washington, Seattle,

von Schmoller, G. F. (1908). Grundiss der allgemeinen Volkswirtschaftslehre (Vol. 1). Dunder y Humblot.

Wennekers, S., y Thurik, R. (1999). Linking entrepreneurship and economic growth. Small Business Economics, 13(1), 27-56. 
Wennekers, S., Van Wennekers, A., Thurik, R., y Reynolds, P. (2005). Nascent entrepreneurship and the level of economic development. Small Business Economics, 24(3), 293-309.

West III, G. P., Bamford, C. E., y Marsden, J. W. (2008). Contrasting entrepreneurial economic development in emerging latin american economies: Applications and extensions of Resource-Based theory. Entrepreneurship Theory and Practice, 32(1), 15-36.

Williamson, O. E. (1975). Markets and hierarchies. New York, 26-30.

Wilson, R. W. (1975). The sale of technology through licensing. publisher not identified.

Wong, P. K., Ho, Y. P., y Autio, E. (2005). Entrepreneurship, innovation and economic growth: Evidence from GEM data. Small Business Economics, 24(3), 335-350.

Yeoh, P. L., y Jeong, I. (1995). Contingency relationships between entrepreneurship, export channel structure and environment: A proposed conceptual model of export performance. European Journal of Marketing, 29(8), 95-115.

Yiu, D., y Makino, S. (2002). The choice between joint venture and wholly owned subsidiary: An institutional perspective. Organization science, 13(6), 667-683.

Zahra, S. A. (1993). A conceptual model of entrepreneurship as firm behavior: A critique and extension. Entrepreneurship theory and practice, Vol. 17, $\mathrm{N}^{\circ} 4$, pp. 5-21. 
